\title{
EFFECTS OF COUNTRY-OF-ORIGIN AND BENCHMARKING ON CREDIBILITY OF FOOD QUALITY ASSURANCE SCHEMES
}

\author{
Dissertation \\ to obtain the Ph.D. degree \\ in the Faculty of Agricultural Sciences, \\ Georg-August-University Göttingen, Germany
}

Presented by

Angelo Enrique Benjamin Lazo Galdos

Born in Lima, Peru

Gottingen, May 2011 
D7

1. First Referee: Prof. Dr. Achim Spiller

2. Co-Referee: Prof. Dr. Xiaohua Yu

3. Co-Referee: Prof. Dr. Ludwig Theuvsen

Date of Dissertation: 20 May 2011 
To my wife 


\section{Table of Contents}

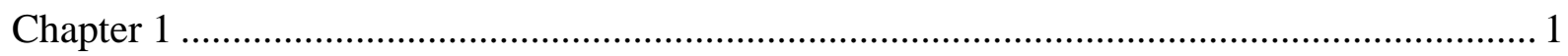

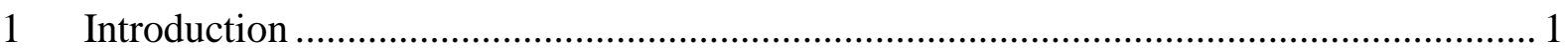

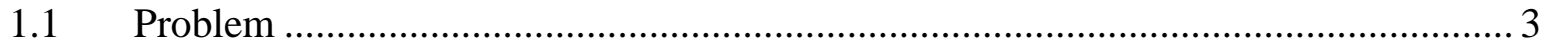

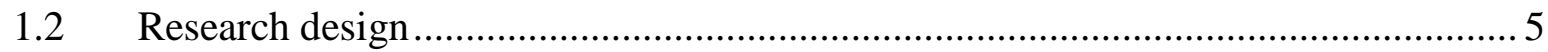

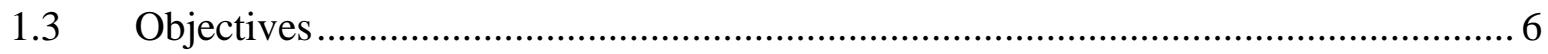

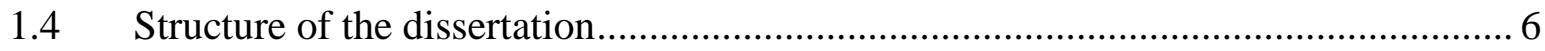

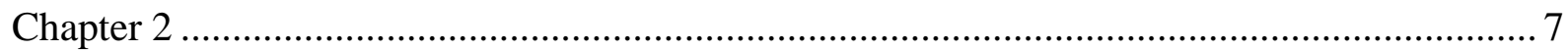

2 Economics of Food Quality Assurance Standards .......................................................... 7

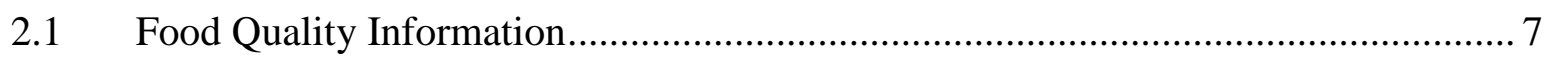

2.2 Driving Factors for Setting Food Standards .......................................................... 10

2.3 The Standardization of Food Products …………………..................................... 13

2.3.1 The Public Sector and Food Regulations …………………………………….... 13

2.3.2 The Reaction of the Food Industry: Private Standards and Assurance Schemes. 19

$2.4 \quad$ Characteristics of Private Food Standards ............................................................ 22

$2.5 \quad$ Harmonization of Food Standards ................................................................. 26

2.5.1 Harmonization Strategies and International Standardization ................................ 28

2.5.2 Private Harmonization Initiatives and Principles ................................................ 32

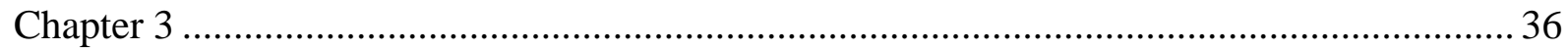

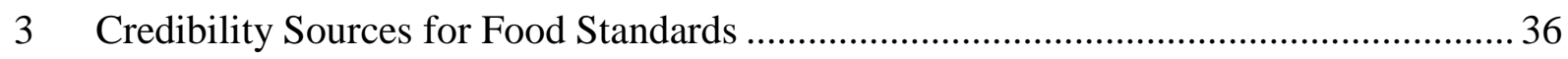

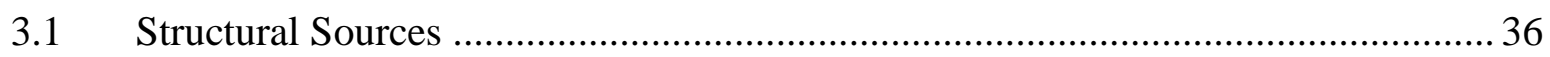

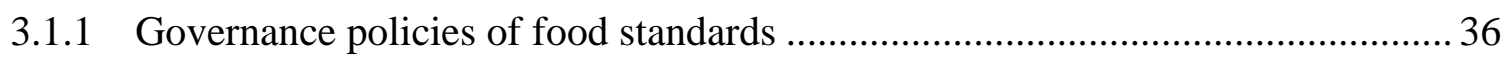

3.1.2 Standard Setting Process ………………………………………………….... 37

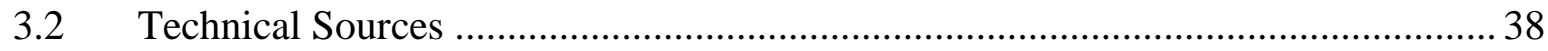

3.2.1 Conformity Assessment Structure _...................................................................... 38

3.2.2 Audit Performance ……………………………………………………… 40

3.2.3 Implementation Success .......................................................................... 41

3.2.4 Traceability and Information Completeness ………………………………..... 43

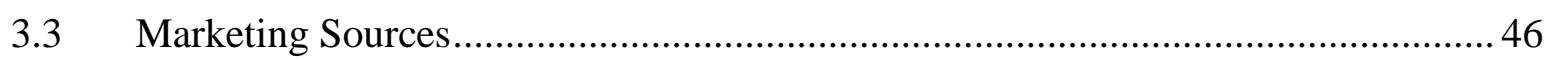

3.3.1 Marketing Efforts and Labelling Reliability ………………………………...... 46 


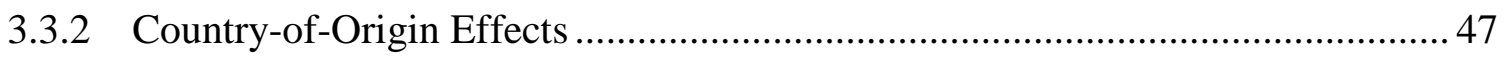

3.3.3 Adoption of Benchmarking Strategies ............................................................. 48

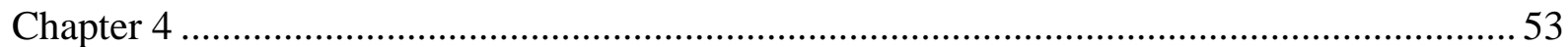

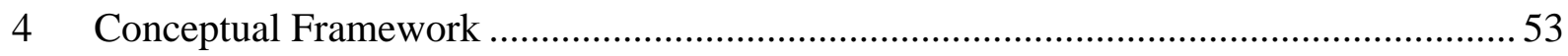

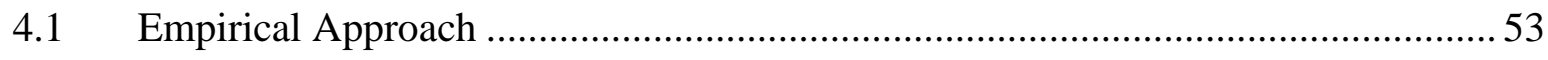

4.2 Proposed Model: Determinants of Food Standards' Credibility ............................ 55

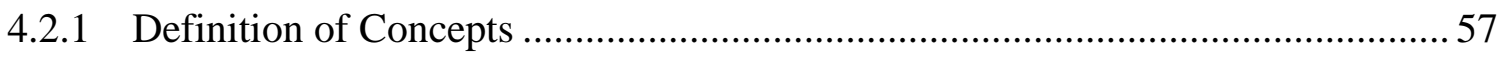

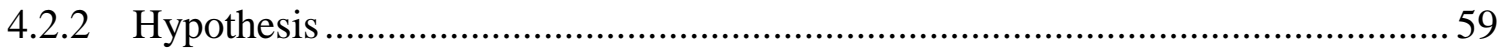

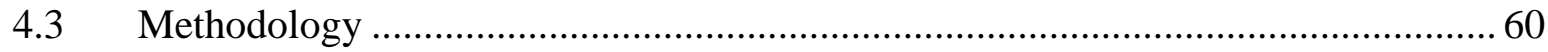

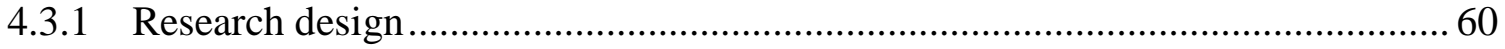

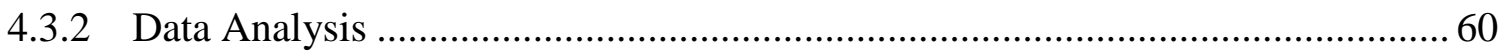

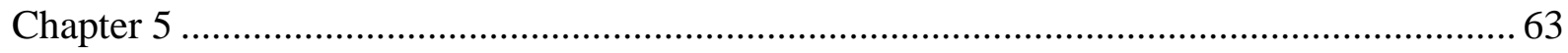

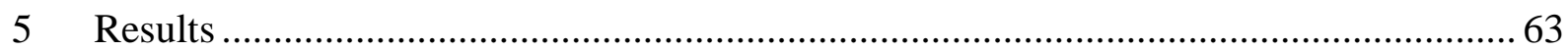

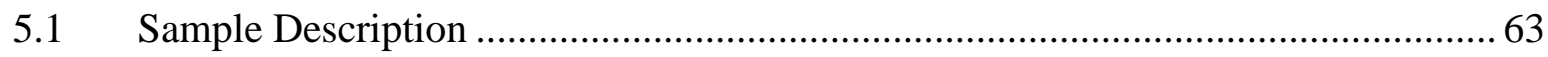

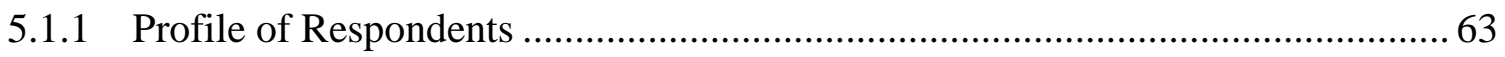

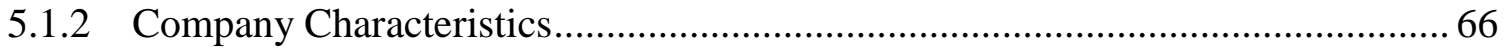

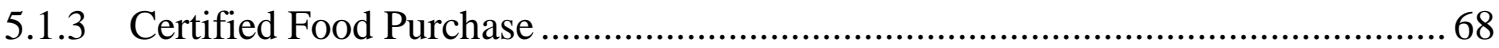

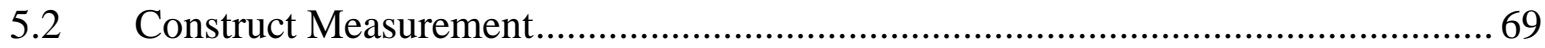

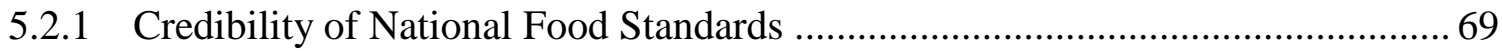

5.2.2 Credibility Improvement through Benchmarking Systems ................................ 71

5.2.3 Expectations about Credibility of Food Standards ............................................. 72

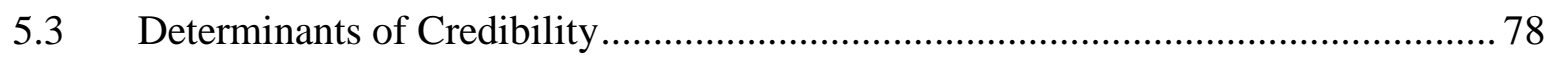

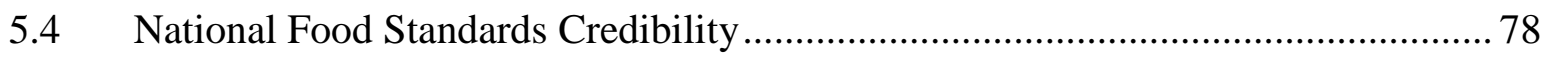

5.4.1 Indicators Associated with Food Standards Credibility ..................................... 79

5.4.2 Adoption of Benchmarking Signals by National Food Standards ....................... 83

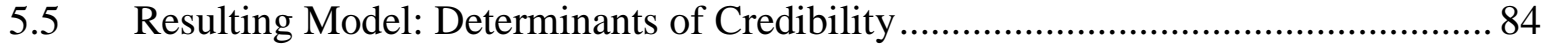

5.6 Sources of Credibility Influencing National Food Standards ................................ 86

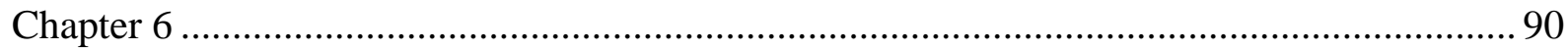

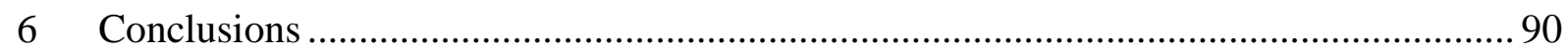

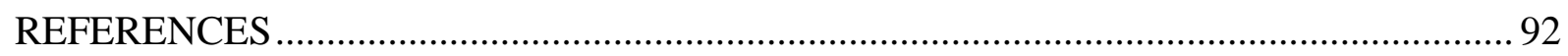

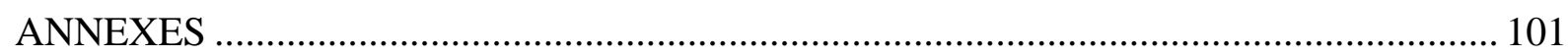




\section{List of Figures}

Figure 1: Typology of goods based on information economics.........................9

Figure 2: Historical development of private standards..............................23

Figure 3: Basic structure of conformity assessment...................................39

Figure 4: Certification information chain..........................................44

Figure 5: Empirical Model: determinants of food standard's credibility ..................................56

Figure 6: Country-of-birth distribution according to economic group..............................65

Figure 7: Country-of-birth distribution according to languages...........................................66

Figure 8: Demand by buyers of food standards.....................................................68

Figure 9: Resulting empirical model.....................................................85 


\section{List of tables}

Table 1: Demographic profile of respondents......................................64

Table 2: Companies' main features................................................67

Table 3: Credibility of national food standards.....................................69

Table 4: Reliability of national certification systems.................................70

Table 5: Confidence in national standard setting...................................71

Table 6: Likelihood of credibility improvement through benchmark systems...........72

Table 7: Results of the statements assessing the reliability of the food standards effectiveness..............................................................................73

Table 8: Results of the statements assessing the reliability of the audit rules..............73

Table 9: Results of the statements assessing the reliability of the audit information......74

Table 10: Results of the statements assessing the confidence in degree of economic development. .75

Table 11: Results of the statements assessing the reliability of the standard requirements.......................................................................76

Table 12: Results of the statements assessing confidence in governance structure........77

Table 13: Results of the statements assessing the influence of stakeholder trust . .78

Table 14: Results of the factor analysis for credibility of national food standards. .80

Table 15: Results of the factor analysis for food standard credibility indicators .82 
Table 16: Results of the factor analysis for adoption of benchmarking signals by

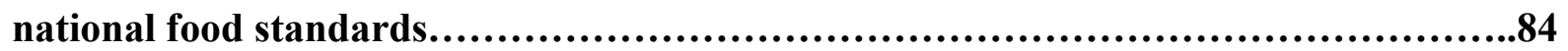

Table 17: Sources of credibility affecting food standards in developing countries

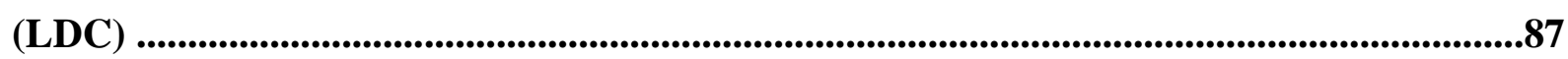

Table 18: Sources of credibility affecting food standards in developed countries

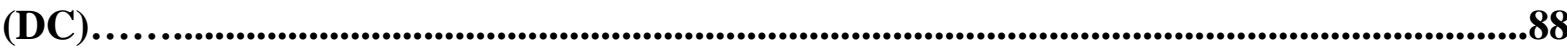


Abbreviations

\begin{tabular}{|l|l|}
\hline BRC & British Retail Consortium \\
\hline BSE & Bovine spongiform encephalopathy \\
\hline DC & Developed Countries \\
\hline EU & European Union \\
\hline EFSA & European Food Safety Authority \\
\hline FAO & Food and Agricultural Organization of the United Nations \\
\hline GLOBALG.A.P. & Global Good Agricultural Practices \\
\hline GFSI & Global Food Safety Initiative \\
\hline HACCP & Hazard Analysis and Critical Control Points \\
\hline IFOAM & International Federation of Organic Agriculture Movements \\
\hline IEC & International Electrotechnical Commission \\
\hline IFS & International Featured Standards \\
\hline ISEAL & International Social and Environmental Labelling Alliance \\
\hline ISO & International Standard Organization \\
\hline JRC & Joint Research Centre- European Commission \\
\hline LDC & Less Developed Countries \\
\hline NGOs & Non-Governmental Organizations \\
\hline QS & Qualität und Sicherheit \\
\hline SQF & Safety Quality Food Institute \\
\hline SPS & $\begin{array}{l}\text { WTO Agreement on the Application of Sanitary and Phytosanitary } \\
\text { Measures }\end{array}$ \\
\hline TBT & WTO International Agreement on Technical Barriers to Trade \\
\hline US & $\begin{array}{l}\text { United States of America } \\
\text { Service }\end{array}$ \\
\hline USDA & World Health Organization \\
\hline WHO & World Trade Organization \\
\hline
\end{tabular}




\section{Acknowledgements}

First of all, I would like to thank my family for giving me the incentive to carry out this research and for accompanying me during all these years. Secondly, I would like to thank the GLOBALG.A.P secretariat and make a special mention to Dr. Kristian Moeller for giving me the opportunity to do this thesis and at the same to become part of his team. I would also like to give special thanks to Prof. Dr. Achim Spiller, for his patience in providing me with the academic background needed for this research; also to Prof. Dr. Xiaohua Yu and Prof. Dr. Theuvesen for accepting to be the co-referees.

Last but not least, I would like to thank all the 700 respondents who participated in the survey as well as all the colleagues and friends I met during my stay at Food PLUS GmbH and at the University of Göttingen, who in one way or another enriched my knowledge and made my stay in Germany a pleasant moment in my life. 


\section{Chapter 1}

\section{Introduction}

The development and control of food standards is a role that has usually been taken on by national governments as part of their policies to protect consumers against market failures caused by information asymmetries (Akerlof, 1970; Nelson, 1970, Andersen, 1994). These standards were initially focused on controlling adulteration and misbranding (Gardner, 2003) through the definition of technical requirements for food products (Holleran et al, 1999). Later, the focus of food standards was expanded into food safety requirements and extrinsic information cues (Luning et al, 2002) and their enforcement regulations have also changed differently on regional and national levels (Hammoudi et al, 2009) and even the scheme governance for setting and controlling has been partially transferred to the private sector. The outbreak of food borne illness and food control scandals in the most important markets, like the BSE outbreak in Europe, the E.coli case in spinach in the USA or the detection of melamine in childrens' milk produced in China have been responsible for sparking these changes in food legislation worldwide. In addition, the power of the media and some charismatic organizations have raised concerns in public opinion regarding food production processes and their impact on social and environmental issues. It has been said that governments have the advantage of being more effective in enforcing food standards since they can prosecute violators of national food legislation (McCluskey, 2007), but at the same time, they apparently lack flexibility in adjusting these standards against the rapid changes in consumer preferences, technology and market structure (McCluskey, 2007). In the short term, the disadvantages of the public sector and the mistrust earned from past scandals have prompted the initiative to share more of the responsibility with the private sector, thus giving leverage to the food industry to develop their own standards and schemes. This has caused the proliferation of many private standards, which are becoming or have already become the dominant drivers in shaping the agri-food system (Henson and Hooker, 2001, Fulponi, 2006). 
As a matter of fact, there are several incentives for the private sector to set their own food standards and schemes. Firms have seen the adoption and implementation of food standards as an important strategy for acting with "due diligence" while reducing information asymmetries (Henson and Readon, 2005). This also to some extent secures their brand reputation (Fulponi, 2006) and either strengthens their market position or opens new opportunities for market access. In fact, the implementation of standard and quality assurance schemes have helped firms to avoid potential liability repercussions and to pre-empt mandatory public regulations (McCluskey and Winfree, 2009). Also in most cases it has helped them to maintain access to conventional and premium markets. These private assurance schemes have become an important element for building trust in business-tobusiness (B2B) relationships, especially in the first transaction stages between new trading partners (Fritz, 2006). Private food standards have been established under different governance structures and associations. The standard setting organizations may vary from single retailer programmes (e.g. Tesco Nature), to producer associations (e.g. Assured Food Standards - Red Tractor); from third party trustworthy organizations like NGOs (e.g. Rain Forest Alliance) to business oriented certification bodies (e.g. USGAP-Primus labs); from different label programmes (e.g. FairTrade/Transfair) to base platforms of stakeholders coalitions (e.g. GFSI, GLOBALG.A.P., IFOAM). The proliferation of numerous quality programmes has developed a new form of competition in the food industry, which actually has a narrow spectrum of differentiation in both standard content and control. In this scenario, credibility of schemes plays an important role; in this respect Tuncer (2001) suggested that credibility is needed to build a positive reputation of food standards and quality assurance schemes. He pointed out several "building blocks" that contributed to building up credibility for different food standards and that were used to add value and to allow them to differentiate from each other. In addition, some initial consensus about scheme credibility pillars has been established by stakeholder organizations like GFSI, GLOBALG.A.P IFOAM and ISEAL in both food safety and sustainability assurance. These organizations required the adoption of codes and/or benchmarking processes according to agreed principles between their stakeholders, being the most prominent requirements associated with standard setting process, third party certification rules, international accreditation codes and more stringent standard content. 
Despite this harmonization effort in the industry, until now only private standards operating at the global level have enrolled under these certification initiatives. This means that the general confusion generated by quality signals to local operators and consumers has still not been solved (Wood et al, 1998; Morris and Young, 2000) and a true consensus about credibility remains quite far from reality. On the other hand, this trend has been perceived to have a negative impact on international trade for developing countries and a risk of reducing access of small farmers to high value markets remains latent. The awareness that private standards may act as potential non-tariff barriers to trade has been signalled by several experts (Holleran et al, 1999; Martinez and Bañados, 2004; Jaffe and Henson, 2004; Anders and Caswell, 2007) and international organizations like the WTO SPS committee (UNCTAD, 2007a, b, UNCTAD 2008 a, b).

\subsection{Problem}

The impact of a non-tariff barrier to trade on developing countries will depend on how prepared each of these countries is (or how prepared they would be) to face stringent food regulations in the markets of destination and the proliferation of private certification scheme requirements by global customers. Also the impact on small farmers will depend on the amount of support given by local governments and private sectors to small-scale production systems. According Jaffe and Henson (2004), developing countries commonly lack adequate metrology and conformity assessment infrastructure. For example, local accreditation bodies are usually not authorized to deliver ISO/IEC 65 accreditation for third party product certification, which is an important credibility source for food safety assurance in many private schemes. This particular disadvantage makes developing countries dependant on the accreditation services existing in developed countries. In this way, accreditation of local certification providers may involve costly inputs and an influx of foreign providers becomes unavoidable. On the other hand, the reputation of the public sector of developing countries is not always positive among inhabitants of developed countries, since it is associated with weak law enforcement and opportunism of low production costs by private firms (Haucap et al., 1997). Unfortunately, food quality assurance is no exception to this type of inference that carries biases in the quality information of developing countries' products and prompt country-of -origin effects (Bilkey and Nes, 1982). 
Nevertheless, positive spillovers have occurred in developing countries due to the impact of new commercial requirements. Jaffe and Henson (2004) also argue about the catalystic effect of private standards, indicating “...some countries are using high quality standards to successfully reposition themselves in competitive global markets." .... "and may provide power incentive for modernizing export supply chains as well as domestic food safety and agricultural health can benefit local population and domestic producers...". Indeed, compliance to commercial requirements has strong repercussions on the public sector's role and has accelerated the regulation process concerning food safety, environmental protection and labour rights. In Peru, for example, the local government is due to approve a new food safety law, it recently created a Ministry of Environment, and the Labour Ministry has tightened up the inspections of private firms to assure compliance with labour regulations.

Overall, developing countries seem to have a long learning curve ahead of them in order to really improve their national food standards setting process and quality assurance systems. Policies will consider reputation improvement and credibility building. In this respect, some countries like Mexico, China, Chile, Kenya and Thailand have developed good agricultural practice (GAP) assurance programs as a way of demonstrating commitment to complying with international requirements through their local policies. Most of these GAP schemes have achieved the recognition of GLOBALG.A.P's stakeholders through the approval of its benchmarking process $^{1}$. This is case of MEXICOGAP, CHILEGAP, CHINAGAP, and THAIGAP, whose benchmark achievement is expected to signal an improvement in the credibility of their programmes. However, the effect of this harmonization strategy on the credibility of their standards cannot as yet be measured and as yet there is no clear confirmation of industrial success in any of these. If we assume that national food standards are considered industrial products and/or consumer quality cues, then we can also assume that the disclosure of the country names as a prefix in their brands and quality labels could disclose country-of-origin effects that could act against their credibility efforts. As a matter of fact, it is yet not clear if most schemes are aware of all the existing credibility sources and their strategy might not have calculated the influence of country-of-origin on both consumer and industrial purchasing decisions (Bilkey and Nes, 1982), but they expect at least that the benchmark against GLOBALG.A.P. standards and/ or against GFSI code can act as a credibility cue that helps to resist any bias generated from demographic effects.

\footnotetext{
${ }^{1}$ Currently there are 20 national GAP schemes recognized by GLOBALG.A.P (www.globalgap.org) Angelo Enrique Benjamin Lazo Galdos 
However, the risk of credibility failure cannot only be associated specifically to national food standards from developing countries since in general all quality assurance schemes are susceptible to opportunistic behaviour (Albersmeier et al., 2009). Therefore, it is important to identify and take into consideration credibility sources for food standards that may be used as marketing cues for increasing the reputation and acceptance of all quality programs, especially those national food standards that may be susceptible to origin effects.

Despite this, the structural, technical and marketing sources of credibility cues associated with food standards are still at an early stage and deserve analysis and evaluation of their effects on the acceptance of national and international food quality assurance and standards.

\subsection{Research design}

In this study we attempt to prove if national food standards are susceptible to country-of origin effects and at the same time explore how credibility cues may influence stakeholder perceptions. From the literature review we classified three types of credibility sources: structural, technical and marketing sources, that together might have an effect on the credibility of food standards. In this study we consider structural sources to be those related to the type of standard governance policies, standard setting procedures (Tuncer, 2001). Technical sources are instead associated with the effectiveness of conformity assessment rules, i.e. their reliability in assuring quality and safety (Albersmeier et al., 2009); these are associated to audit performance (Jahn et. al, 2005; Anders et al., 2010), implementation success (Jahn and Spiller, 2005) as well as traceability and information completeness (Theuvsen, 2005). Finally, marketing sources are those cues that in one way or another are considered to affect the acceptance from producers and consumers' perceptions towards food standards (Fearne et.al, 2001); sources in this group include marketing efforts (Nilsson et al., 2004) and labelling reliability (Giannaka, 2002, Amstel et al., 2007), country-of-origin (Bilkey and Nes, 1982) and adoption of benchmarking strategies (Mazé et al.,2007) like those offered by GFSI and GLOBALG.A.P.

Since research on this topic is relatively scarce, I developed an experiment based on explorative factor analysis. With this methodology I test whether food standards are susceptible to country-of-origin effects. At the same time, based on marketing credibility source theory, I develop statements that are related to food standard credibility perceptions. 
From the factor analysis, I expect to identify factors that may explain the perceptions of stakeholders towards national food standards. Finally, a linear regression analysis is applied to measure the effect of the different factors on the overall credibility of national food standards. For data collection, an online survey with 20 questions was prepared and distributed by mail to more than ten thousand contacts of FoodPLUS GmbH over a period of two weeks. Only those questionnaires that were fully completed were considered for the analyses. The data collected was subject to univariate, bivariate and multivariate analysis. The results are presented using tables and diagrams.

\section{$1.3 \quad$ Objectives}

The first objective of this experiment is to test the main hypothesis that "benchmarking signals have a positive influence on the credibility of national food standards in the presence of country-of-origin effects." The second objective is to attempt to design a structural model that identifies credibility sources associated with food standards and tests the effects of each of these against the overall credibility of different national standards. Finally, this research attempts to provide suggestions for standard owners by considering some aspects of credibility that may work in favour of improving their administration and acceptance in international food markets.

\section{$1.4 \quad$ Structure of the dissertation}

The structure of this thesis is as follows: Chapter 2 covers the economics of food quality assurance standards by summarising the definition of food quality and the driving factors influencing the setting of food standards. In addition, this chapter describes the public sector policies used to tackle information asymmetries and how these influence the private sector in developing their own food standards and quality assurance schemes. Also in this section the discussion about standard harmonization is highlighted and linked to some strategies operating in the private sector. Chapter 3 describes what we consider to be the current sources of credibility for food standards, including structural, technical and marketing sources. Chapter 4 develops the research design for testing the main hypothesis. Chapter 5 presents the results of the online questionnaire and the different levels of data analysis i.e. univariate, bivariate and multivariate analyses. Chapter 6 discusses the outcomes and presents the conclusions of this investigation. 


\section{Chapter 2}

Economics of Food Quality Assurance Standards

\subsection{Food Quality Information}

In the literature, there are several definitions which refer to the quality of products: "fitness of use" (Juran, 1990 mentioned by Luning et al., 2002), "the totality of features and characteristics of a product or service that bears on its ability to satisfy stated or implied needs" (American Society for Quality Control, mentioned by Kotler, 1997) or "achieving customer satisfaction by improving efficiency and effectiveness of the company" (ISO, 1998). Although these definitions could be considered ambiguous, they illustrate that quality has different dimensions that are definitively related to consumers' perceptions and expectations about a particular product. As a matter of fact, the food quality techno-managerial approach explains that these dimensions are indeed the combination of different product attributes, related to technical aspects and factors that contribute to a "quality performance" defined by the consumer itself. Following this concept, the techno-managerial approach classifies food product attributes into two main groups: intrinsic attributes and extrinsic attributes (Luning et.al, 2002). Intrinsic attributes are directly related to physical and sensory properties like taste, flavour, texture and appearance (i.e. size, colour, weight, etc.), or health aspects such as nutritional value and safety. On the other hand, extrinsic attributes are associated to food production process characteristics like hygiene conditions, use of pesticides and antibiotics, organic systems; as well as to marketing values like price, brand name, packaging, labelling, shelf life etc. In addition, it would appear that quality dimensions become more complex over time since new factors appear and change consumer perceptions concerning food quality. To give a recent example, extent of public ethical awareness on environment impacts; social responsibility and climate change are influencing consumers purchasing decisions. These, of course, are also expanding the spectrum of food quality definition. The existence of so many combinations of attributes may imply that consumers require information about the products' quality prior to purchase, but the complete account of attributes is generally not always available in the first instance. 
In the ideal market of perfect competition, welfare is obtained based on a price that has been reached through the balancing of supply and demand. This balance is achieved through various assumptions including perfect information and homogenous products. Nevertheless, these two conditions are not always present in reality (Centeno, 2008). In fresh food markets for example, it is almost impossible to maintain supplies of homogeneous quality products in general or within the same season. On the other hand, complete information about quality attributes cannot be always be disclosed completely. The presence of imperfect information about products appears in markets where information asymmetries exist (Akerlof, 1970). This concept implies markets where suppliers have more knowledge about the attributes of a product than buyers, giving them an advantage in the transaction of the products. This could cause those high quality products to be removed from the market by products of lesser quality. The risk of this displacement may also be associated with the type of product existing in the market: search goods, experience goods and credence goods (Nelson, 1970). Search goods are those products for which customers have most information about their quality before purchasing it. In the case of experience goods, customers can only judge product quality after purchasing the good. Credence goods are those products whose qualities are difficult to detect but buyers have great concern about while purchasing (Andersen, 1994). Food products have developed a large number of attributes (intrinsic or extrinsic) due to their longer life cycle (Andersen, 1994), which are related to the levels at which consumers could obtain information about them (Jahn et al., 2005). Freshness and appearance, for example, may be easily identified on searchable products; while taste and shelf life can only be appreciated on experience products after purchase. To obtain information about nutrition and hygiene, however, would be highly costly for the consumer since it would require a thirdparty judgment from an expert or similar source. In such cases, a third party judgement would be necessary to deliver the information, through certification and/or information on the label. Furthermore, Potemkin products are those where attributes that involve processed oriented practices are hidden to both third parties and customers e.g. animal welfare, fair trade, etc. (Tietzel and Weber, 1991 mentioned by Jahn, 2005). This type of product may contain higher information asymmetries than other credence goods and makes them even more costly to deliver the quality attributes. This causes these products to have a higher market value when attributes are communicated through reputation mechanisms like labelling or branding (Andersen, 1994) (see Figure 1). 
In the case of food products, some quality information such as food safety may not only be imperfect but also symmetric (Antle, 1995). This means that not only buyers may lack information about food safety of the end product but food producers could also lack information to some extent. For example a producer might know about the pesticide used in the production process but not know if there is contamination of pesticide residue that will remain after selling the product to the buyer. Even if the producer has this information it is costly for this information to be carried with the product throughout the supply chain from processing to distribution and retail marketing. Moreover, reputation has an important role in

\begin{tabular}{|c|c|c|c|}
\hline $\begin{array}{c}\text { Search } \\
\text { attribute }\end{array}$ & $\begin{array}{c}\text { Experience } \\
\text { attribute }\end{array}$ & $\begin{array}{c}\text { Credence } \\
\text { attribute }\end{array}$ & $\begin{array}{c}\text { Potemkin } \\
\text { attribute }\end{array}$ \\
\hline $\begin{array}{c}\text { Qualities, which are } \\
\text { known before purchase }\end{array}$ & $\begin{array}{c}\text { Qualities, which are } \\
\text { known only after } \\
\text { consumption }\end{array}$ & $\begin{array}{c}\text { Qualities, which can be } \\
\text { observed by the customers } \\
\text { only to prohibitive costs, } \\
\text { but buyers can rely on } \\
\text { third-party judgements }\end{array}$ & $\begin{array}{c}\text { Process-oriented qualities, } \\
\text { which are hidden for third } \\
\text { parties as well as to } \\
\text { customers at the end of the } \\
\text { product level }\end{array}$ \\
\hline Freshness, appearence & Taste, shelflife & Nutrition, contamination & Animal welfare, fair trade \\
\hline
\end{tabular}

Figure 1: Typology of goods based on information economics (Jahn et al. 2005)

determining the property of market equilibrium (Antle, 2001). Foods could turn into experience goods when consumers can identify certain toxic residues or microbiological pathogens that cause them an acute illness after eating the food. In this case, firms can differentiate and provide a higher quality product and could charge higher prices. When consumers are not able to associate illnesses with food intake (e.g. as in the case of cancer), they cannot differentiate low from high quality products and reputation mechanisms are not effective in revealing product safety. In this case there is a market failure in providing consumers with the opportunity to buy low safety risk products (Antle, 2001).

As a consequence, the distinction between symmetric and asymmetric imperfect information has important implications for market equilibrium. Therefore the disclosure of quality information plays an important role in reducing costs of preventing dishonest trading in market (Antle, 2001). Food standards thus play an important role in securing product definition, to assure that hidden attributes are being covered, and to make products acceptable for the customers, especially those that could present high risks to public health. Beside these explanations, there are other substantial factors that drive the development and evolution of 
food standards. The next section describes the main drivers that have influenced the establishment of public and private standards.

\subsection{Driving Factors for Setting Food Standards}

It has been little over a decade since several food scandals in Europe and the United States, have marked important episodes in the history of the international food industry. During the late 1990's in Europe, the outbreak of the "Mad Cow" disease (BSE) in the United Kingdom and the dioxin scandal in Belgium caused by contaminated animal feed were the first food scares that impacted the region, causing the loss of several million Euros in the meat industry (The Economist, 1998 mentioned by Lindgreen, 2003; Larsson et al, 2005). In the United States, the most serious food borne illness crisis was caused by Escherichia coli O157:H7 in fresh spinach, which appeared in 2006 when more than 250 infected people were registered (Grant et. al, 2008). Years later, two Salmonella crises occured in this country, one outbreak coming from jalapeno peppers which spread to more than 43 states and another more severe outbreak from alfalfa sprouts affecting more than 250 people in 14 states $^{2}$. Also Asian countries had their own milestones of food safety crises that obliged governments to develop tighter regulations. In September 2001, BSE hit Japan and the scandal was followed by a series of labelling scandals when local companies labelled imported meat as locally produced in order to obtain government compensation during the BSE crisis (Clemens, 2003). In 2008 a new food crisis struck the Chinese diary industry when melamine was found in milk powder, affecting around 53,0000 babies (Byrne, 2008). This crisis appeared just a year after the Chinese government decided to take stricter measures on their food and drug safety regulation ${ }^{3}$. These food safety scandals had a huge negative impact on governments by challenging the credibility of their food control policies. At the same time, it affected consumers' behaviour and trust not only in the crops that originated the food scares, but also in food products in general. In addition, there is an increasing awareness from the media and Non Governmental Organizations (NGOs) to consumers not only about food hazards but also on the social and environment impact generated from food production and manufacturing.

\footnotetext{
${ }^{2}$ Department of Health and Human Services. Centers for Disease and Control Prevention. (www.cdc.gov/salmonella/saintpaul/).

${ }^{3}$ The Chinese government's measures included the introduction of nationwide inspections and seting up a food recall system as a reaction to international pressure due to embarrassing episodes involving the exportation of contaminated pet food ingredients and toothpaste (source: The International Herald Tribune, 2007). 
Especially in developed countries, NGOs have a strong influence in public opinion and their actions are also have a significantly influence on consumer food preferences. Since the outbreak of the food scandals, these organizations have increased their pressure both on the government and industry corporations to guarantee public health aspects related to food consumption. For example, the organization "Green Peace" has a strong local and international reputation and their campaigns associated to food consist of protesting against the impact of agriculture using Genetically Modified Organisms (GMOs) on biodiversity, and against pesticide residues in food. Their activities include monitoring chemical residues in fresh fruit and vegetables that are for sale in major supermarket chains. All evidence of exceedance or proof of illegal chemical use (e.g. DDT, Lidane, Metamidophos, etc.) in these products are publicly exposed, challenging the reputation of retailers. Another well-known and influential organization is the "World Wildlife Fund for Nature" (WWF) ${ }^{5}$. The campaigns of this NGO associated to food are focused on the impact of food production on the environment. They encourage food producers and manufacturers to implement better management practices in order to reduce ecological and social impact in both agriculture and aquaculture sectors. Their major concerns are related to chemical pollution, habitat loss, and degradation of conservation areas, climate change, water consumption and the poverty cycle. The way they intend to address these issues is by establishing round tables where open discussions can be held between experts, industry representatives and politicians. In this way, they attempt to influence the development of healthier agricultural systems by creating financial incentives that promote the use of more environmental services. The third important NGO that could be considered to have a significant impact on public perceptions is "Oxford Committee for Famine Relief (OXFAM)" ". This organization focuses it's campaigns on poverty alleviation, and their campaigns related to the food sector center on awareness of policies that might impact negatively the market access for small farmers. In this respect, they support awareness about the impact of food standards on the discrimination of small farmers selling their products in high valued markets.

Together with NGOs, the media also has an important influence on changes in consumer attitudes against food by increasing the awareness of food borne illness and knowledge about the nature, quality and associated hazards. Articles about food nutritional attributes, safety and food crisis have flourished in popular magazines, tabloid press and radio, resulting in an increase in public consciousness about food production as well as in the apprehension

\footnotetext{
${ }^{4}$ http://www.greenpeace.org

${ }^{5} \mathrm{http}: / / \mathrm{www}$.panda.org

${ }^{6} \mathrm{http}: / / \mathrm{www} .0 x$ fam.org 
concerning food quality. This could have changed consumers' purchasing preferences, in fact, these have been extended from sensorial (e.g. taste, flavour, texture and appearance) and reliability preferences (e.g. weight contents, size variations, right composition) to search for health aspects (safety and nutritional value) and food production impacts on environmental and social aspects.

Beside the awareness and information for consumers about food quality, other important drivers for the setting of food standards have been the introduction of new products into the market and the technological innovation in food production, processing and packing (WTO, 2005). These usually push governments to set new standards and specifications to avoid fraud, contamination and risk to public health. For example, the release of new food additives that are offered in manufactured products or the introduction of nanotechnology in food packaging might raise concerns about their security in public health and set implementation parameters. Next to food technology innovation and progress, chemical analysis has become important for determining the purity of food products and distinguishing safe from unsafe ones (WTO, 2005). The development of more efficient analytical tools and focused media information have increased the awareness of food safety among governments, industry and consumers. The development of scientific research has reduced levels of preservatives in products and prohibited substances in food, in this way supporting the compliance to standards. Last but not least, the globalization of commerce together with the consolidation of international distribution sectors and the integration of the food supply chains has also influenced the development of standards, particularly in the private sector (WTO 2005). Opening up to international trade extends the option of supplying a larger variety of products from new regions to the local market. Therefore, public and private sectors are looking to these foreign products to comply with the quality level demanded in local markets in order to assure consumer trust in imported goods. As a consequence, government negotiations about food standards are carried out on the international platforms of the WTO. Where there is a need for fast and flexible implementation, the private sector has to fill in the gap left by governments in order to assure not only compliance with public food standards but also to set their own standards to keep customer or consumer loyalty to their brands, companies and stores.

The next section will explain the role of governments in establishing food standards to avoid market failures associated with imperfect information on food quality. It also describes the 
interactions that caused the increase in private food standards and assurance schemes as a response to some of the driving factors already discussed.

\subsection{The Standardization of Food Products}

\subsubsection{The Public Sector and Food Regulations}

Traditionally, national governments have been responsible for establishing food standards as part of their policies to protect consumers against dishonest trade practices of adulterated food, misbranding, low quality and safety of products (Mc Cluskey, 2007). These standards become mandatory or voluntary norms within the framework of national "Food Laws". These norms or regulations were the earliest forms of government regulations for entrepreneur transactions, and their development has run in parallel with the growth of industrialization, urban population and public health problems. Nevertheless, standardization seemed to have started spontaneously well before government regulations were created. If we look into the human history, standardization appeared naturally due to the need for communication and evolved into a conscious need for uniformity when ancient cultures established measurements for length and in the middle ages weight and quantity became important measures for transactions. But only in modern times has the adulteration of food and the development of chemical research sparked the first food laws, and between the end of the nineteenth century and beginning of the twentieth century the public sector included food standards and food controls as part of their policies (Lasztity et. al, 2009). This was true primarily in industrialized countries where most national standard organizations were established in Europe during the 1920's and when the U.S. enforced their famous Food, Drug and Cosmetic Act in 1938 (FDA, 2009a and 2009b). Later on, the rapid expansion of international trade after World War II motivated the establishment of international organizations like the International Standard Organization (ISO) in 1947 and with respect to food the Codex Alimentarius Commission (CAC) was created in 1958 by the Food Standards Programme of the Food and Agriculture Organization (FAO) and the World Health Organization (WHO) (Lasztity et. al, 2009). The CAC objective was to develop first international food standards with the aim of improving public health and food control as well as to harmonize food standards and facilitate trade worldwide (FAO/WHO, 2010). This code of standards is well known as the "Codex Alimentarius". 
The Codex Alimentarius has become the global reference code for consumers, food producers and processors, national food control agencies and for the international food trade. Codex guidelines cover phytosanitary plant and animal protection, food safety, food labelling and to some extent marketing of food products. These guidelines have been recommended as a reference for harmonization for national food regulations and standards by the two main World Trade Organization (WTO) agreements, the Sanitary and Phytosanitary agreement (SPS) as well by Technical Barriers to Trade (TBT) agreements (FAO/WHO, 2010). The influence of the Codex Alimentarius on governments decisions for national food policies is very significant due to the fact that under the WTO platform, this international set of standards is based on both scientific and economic criteria (Henson and Caswell, 1999). The scientific criteria of Codex falls under the framework of risk analysis and its three-stage process that have been set by FAO and the WHO: risk assessment, risk management and risk communication. On the other hand, the economic criteria are related to the impact assessment of food regulations on the equilibrium between marginal costs and marginal benefits (Henson and Traill, 1993; Antle, 1999). Together both types of criteria shape the different forms and approaches that national food standards can take.

We have already mentioned that public food standards (or norms) could be either mandatory or voluntarily enforced (WTO, 2005). Mandatory national food standards only allow products that are compliant to the standards onto the market, and in most cases restrict the supply to few product varieties; whereas voluntary standards let products not meeting the standards to also be supplied on the market, making it difficult to distinguish them from those meeting the standards. In the case of implementing voluntary standards, governments may have to make the additional decisions to complement the policy with either negative or positive labelling to support the identification of products by final consumers (WTO, 2005). Furthermore, national food standards could take the form of "ex post" regulations such as "Target Standards" which impose criminal liability to suppliers when selling pre-specified harmful products; or "ex ante" regulations like "Performance Standards" which require, for example, that products achieve a certain level of safety and suppliers are free to choose the methods to meet these conditions; and could also take the form of "Specification Standards" that include both product standards (e.g. percentage of fruits in marmalade) and process standards (e.g. pasteurization of milk) (Henson and Caswell, 1999). This variety of standard forms and approaches generates a multi-layered framework that often creates an increase in costs associated with compliance, restricts suppliers operations and hampers their efficiency and 
innovation (WTO, 2005). As a matter of fact, the organizational infrastructure of the standardization system plays an important role in improving or decreasing the effectiveness and efficiency of standard compliance.

Organizational infrastructure of the standardization systems refers to the way governments administrate the standard setting process and their respective compliance assurance. These are managed by distributing responsibilities among public institutions that are related to the policy intendment to cover. The organization of the standardization system usually differs among countries and in most cases they experience several reforms and adjustments. To illustrate this better we share an interesting report presented by the United States Government Accountability office (GAO) to the congress of that country in 2005 (GAO, 2005). The aim of this document was to make a comparison of the United States' food safety system against the consolidation initiatives and process that have been held in several other developed countries. The United States standardization system appears to have multiple responsibility institutions that are ruled by the Food Drug and Cosmetic Act of 1938 and it defines both the organizational structure and the responsibilities associated to their national food standard. This law empowers the main responsibility to two main organizations: the Food and Drug Administration (FDA) and the Department of Agriculture's Food Safety and Inspection Service (USDA). While the USDA is responsible for the safety and labelling of traditional food such as meats and poultry, the FDA is responsible for the safety and labelling of all other foods products and food additives including livestock feeds, veterinary drugs etc. Nevertheless, not all food standardization and control activities are the responsibility of these two institutions since the national food law also empowers another 15 agencies with specific responsibilities regarding food safety standards and control. For example, the Environmental Protection Agency (EPA) shares the responsibility for regulating pesticides and determines the safety and effectiveness of chemicals that can be used as well, establishes the tolerance levels for residues on feed crops, for raw and processed foods. Another example can be found in the fishery sector, where the National Marine Fisheries Service within the Department of Commerce is responsible of carrying out inspections to ensure the safety and quality of commercial seafood. Similarly, the Agricultural Marketing Service (AMS) performs food quality assurance inspections that include food safety elements. Furthermore, the previous organizations coexist with principal federal agencies with independent food safety responsibilities and who operate under numerous federal statutes to ensure the safety and quality of the food supply in the United States. These laws give the agencies different 
regulatory and enforcement authority, and about 70 interagency agreements aim to coordinate the combined food safety oversight responsibilities of the various agencies. The federal system is supplemented by each one of the states, which have their own statutes, regulations, and agencies for regulating and inspecting the safety and quality of food products (GAO, 2005).

However, although the GAO report (GAO, 2005) recognized that other developed countries used to have similar arrangements to the U.S. for managing and enforcing food standards, most of these countries have changed their organizational frameworks by consolidating the responsibilities into one single agency. For example, in Germany before the consolidation the Federal Ministry of Food, Agriculture and Forestry and the Federal Ministry of Health shared the management of the food safety system. In addition, the sixteen federal states shared the implementation of the food legislation while other governmental agencies performed inspections. Nowadays, the responsibility of the food safety management relies on the Federal Office of Consumer Protection and Food Safety, which is an agency branch of the Federal Ministry of Consumer Protection, Food and Agriculture. Its main responsibilities are to coordinate food safety surveillance at national level and formulate administrative rules to guide the implementation of national food legislation by the German Federal states, who remain responsible of the implementation of the food law and oversee the inspections performed by local governments. In addition, the Federal Office of Consumer Protection and Food Safety is the direct contact organization to the European Food Safety Authority (EFSA) and serves as a coordinator of the food and veterinary office audits for compliance with the European Union (EU) Food legislation $N^{\circ} 178 / 2002$ and for implementing in Germany the European Food Safety rapid alert system for consumer health protection and food safety (GAO, 2005). Similar consolidation reforms have been followed not only by the United Kingdom, Ireland and most EU member states, but also by non-European countries such as Canada and New Zealand. These reforms are expected to bring several benefits, which will likely exceed the costs by bringing qualititative improvement in the effectiveness andefficiency of the food safety system such as less overlaps of inspections, more clarity of the responsibilities and more consistent enforcement of food regulations (GAO, 2005). Nevertheless, the USDA argued against the GAO report because it was based on qualitative analysis, and could not quantify the effectiveness between both models. For sure the need for a quantitative comparison between the old and new food safety management system could be assured if the expected benefits of food safety improvements due to consolidation reforms 
could now be quantified and become a benchmark for improvement.

Along with the above institutional adjustments, food standards have also changed and most authors agree that these have become stronger and have been enforced more rapidly in developed countries than in developing countries. This is especially true in the area of food safety, where in response to public concerns, modern laws have become more precise in their application, more specific and complete in their content and are also taking into account situations that are beyond national borders (Lasztity et. al, 2009). In European countries for example, there have been notorious regulatory reforms as a consequence of food scares and the integration policies of the European Union (EU). The EU food legislation framework is stipulated in the Council Regulation No178/2002, whose general principle is the so-called "farm to fork" approach. This regulation covers rules to ensure the protection of human life and health, and establishes strong responsibilities to food operators on food safety requirements and traceability and exercises harmonization of existing national requirements in order to ensure free movement of food and feed within the region. In addition to the EU Food Law $\mathrm{N}^{\circ} 178 / 2002$ a complementary package of comprehensive food safety legislation exists that has been adopted in the region, including regulation (EC) No. 852/2004 on the hygiene of foodstuffs; Regulation (EC) No. 882/2004 on official controls performed to ensure the verification of compliance with feed and food law and animal health and animal welfare rules; among others $^{7}$ that became effective, largely on January 1, 2006 (Europa, 2010).

Meanwhile, in the United States there have also been several amendments (around 26) to the national food law of 1938 since it was first established. At the same time, several other regulations have been established to complement the primary framework of the Act of 1938 . The most curious ones are related to the new concept of "food defence", where new laws have been established to combat new threats to public health. This is represented by the Public Health Security and Bioterrorism Preparedness and Response Act of 2002 which aims to prevent contaminated food from being introduced into the country and authorizes, among other provisions, the registration of food processes and inspection of their records, detaining of adulterated food and the taking of a number of steps to ensure safety of imported foods

\footnotetext{
${ }^{7}$ The EU legislative package also include Regulation (EC) No. 853/2004 on specific hygiene rules for food of animal origin; Regulation (EC) No. 854/2004 on specific rules for the organization of official controls on products of animal origin intended for human consumption; and Directive 2004/41/EC repealing certain directives concerning food hygiene and health conditions for the production and placing on the market of certain products of animal origin intended for human consumption and amending Council Directives 89/662/EEC and 92/118/EEC and Council Decision 95/408/EC.
} 
(FDA, 2009c). On the other hand, it is not easy to gather information about progress in food regulations and standards in developing countries. We can assume that they are quite well backed by the EU and U.S. regulations but at the same time, we can also assume that they are being reviewed and improved to adapt them to current international scenarios. Some indications of this can be obtained from the media, when for example China announced strong reforms on their internal food control system after the Melanin scandal in child milk powder. Also from personal experience in Peru, in 2008, the government launched the supreme decree about the rules for food safety law and currently there is a project for the revision of the new national food safety legislation. ${ }^{8}$

These trends towards more stringent regulations set for a wider range of risks and quality attributes, as well as the rise in independent establishments of laws and standards in developed countries, have been taken by most developing countries as potential barriers for international trade in the export of food products (Unnevehr and Roberts, 2003). Despite countries making individual progress, we have recognized that some developing countries have followed similar courses in food standard development and structural organization to the developed world. However, other countries have demonstrated unsatisfactory food laws or laws that are barely applied. There is thus a wide variation in regulatory, technical and administrative capacities related to procedures of national food control systems involving monitoring and sampling, detection and analytical methods, and applications of standards and food safety requirements (Lasztity et. al, 2009). At the same time, the importance of conformity assessment systems that require testing and certification of both food management and products is increasing and the absence of accredited laboratories and/or internationally recognized systems for certification may also affect confidence in importing countries (Jeffe and Henson, 2004). In fact, there is the perception that within international trade, there is a lack of provision of acceptable confidence to stakeholders in terms of monitoring and enforcement of food assurance.

Overall, although we can recognize that public food regulations have advantages in setting mandatory standards with certainty and prosecuting violators under criminal laws, most of the time they are restricted to the given available scientific evidence and the prevailing level of acceptable risk (McCluskey 2007), which consequently makes them "lack flexibility and to

\footnotetext{
${ }^{8}$ Carlos Caballero, SENASA director. Presentation held at the 5th International Asparagus Congress. 10-12 November 2010. Lima-Peru 
quickly adapt to changes of dynamic consumer preferences which are not guided by science but by their own expectations and fears" ${ }^{\prime}$. In this respect, private quality assurance standards are playing an important role providing flexibility and adoption of consumers' demands, and filling the gaps where food laws are not enough to improve confidence among business agents. The private standards approach has made them become a decisive practice within the food supply chain and have even become a "de facto" requirement for international food trade (Fulponi, 2006; Henson and Readon, 2005). The next section will describe the nature of private standards and how they have turned into a key element for the food industry.

\subsubsection{The Reaction of the Food Industry: Private Standards and Assurance Schemes}

Along with the changes in public food regulations, the private sector has quickly taken the role of addressing the concerns of consumers, resulting in the proliferation of private standards and other forms of supply chain governance (Jafee and Henson, 2004). Private standards take over the public regulations and private requirements and codes of compliance that are controlled either through second or third party audits. Private organizations such as retailers, certification bodies, NGO groups etc. are responsible for setting and administrating these standards and assurance systems. There are several incentives that influence food companies to establish and adopt private standards. Firstly, as mentioned before, companies have an interest in immediately attending variations of consumers' perceptions and concerns about quality and food safety (Fearne et al., 2001), especially when these interests correspond to their own interests (WTO, 2005). At the retail level for example, there is higher pressure to fulfil their consumers' and shareholders' expectations, similar to multinationals that are present in international financial markets and are thus more susceptible in terms of reputation and the delivery of quarterly returns (Fulponi, 2006). However, reputation is not only a concern for retailers. This is also true for food producers, manufacturers and any agent of the supply chain who has an interest in keeping their customers and maintaining their position in high value markets. Private standards have been considered to help maintain costs under control and to accomplish a good reputation for many suppliers (Asfaw et al., 2009) although these may be beyond food technical qualities such as labour and/or environmental ethics. These achievements are assured through certifications that are communicated in a business-tobusiness manner, and in some cases certified products are identified with quality labels which

\footnotetext{
${ }^{9}$ Dick Boer, CEO Albert Heijn speach during the CIES conference held in Amsterdam in February 2008
} 
act as a marketing tools for product differentiation purposes (Golan et. Al 2001, Jahn et al, 2005).

Secondly, operators have incentives for setting food standards in the supply as either a mechanism to increase market share by delivering higher or more dependable quality or as a mechanism to protect current market share from competitors (Salop and Scheffman, 1983). Firms can benefit strategically from food standards in situations where costs of compliance differ according to efficiency in compliance, which in turn relates to factors such as firm size, existing standards of operation, and cost structure. This creates opportunities to obtain first mover advantage, to enhance competitiveness in the market or build barriers to entry or mobility (Anders and Caswell, 2007). On the other hand, liability measures in some countries have pushed food operators to take precautions like the adoption of private standards to reduce the risk of legal prosecution for being found responsible for negative market impacts associated with outbreaks of food borne illness. In the UK for example, bankruptcy risks are higher for small companies. For large operators who supply own branded products, being accused of product failure would generate great losses in their incomes. In the US, the costs of liability settlements are typically large but may be offset by insurance coverage. The impacts of loss of reputation and market sales are stronger in countries like the UK rather than in the US where these have an additional cost rather than a central effect (Henson and Caswell, 1999).

We have seen that the flexibility to adapt to consumers' expectations and the direct impact in enhancing reputation and competitive advantages increases the establishment and implementation of private standards by firms. Nevertheless, private standards (as do public standards) affect the organization and strategy of firms as well as the organization and governance of the food supply chain (Fulponi, 2006, Hammoudi et al., 2009). In particular private standards have reinforced vertical integration by centralizing quality in the operations of the food supply chain (Morris and Young, 2000). Although this might be seen as a positive cooperative action, it has also resulted in conflicts between food supply agents over who controls the definition of quality for food (Morris and Young, 2000). This has generated competition among agents seeking economic advantages and at times has even confronted buyers with suppliers. In Europe for example, retailers use their buying power to manage vertical relationships with their suppliers, imposing upon them specific compliance with process standards, which are sometimes higher than those required by law (Henson and 
Readon 2005; Fulponi, 2006). These requirements are assured either through their own controls or by demanding different third party certifications of those standards that have reached credibility in their markets and/or supply chain.

In response to this force, and in order not to lose market access, suppliers have satisfied these demands by building and/or adjusting their quality management systems to the specifications of their customers. However, the introduction and implementation of new standards carries additional costs. Most private standards generate costs of compliance to conformity assessment services, usually offered by third party certification bodies, that are perceived to involve high costly processes (Garcia-Martinez et al., 2004). For example, standards will require self-assessments prior to the certification body audit. Both internal and external controls include, in most cases, a high degree of bureaucracy preparation and assessment of records (Theuvsen, 2003). Furthermore, all indicate that food suppliers could also be subject to multiple audits from different private assurance schemes. In pre and post farm gate scenarios, they are subject not only to third controls and/or second party evaluations by their customers, but also official controls from the public sector to assure the compliance of regulations. This is even more problematic for farmers who operate integrated production systems with multiple crops and /or livestock, and with different customers demanding different certifications (Mazé, A. 2007). Production costs may also be affected when running different lines of products at the same time (e.g. both certified and not certified products). Variable costs may change, for instance when it would be significantly more expensive to produce certified products than non-certified products and may increase fixed costs when producers need to make additional investments in infrastructure and re-organization (WTO, 2005).

Like with public standards, the proliferation and stringency of private food standards have raised concerns in local and international markets where in some cases private standard certifications have become a "de facto" requirement for accessing high value markets (Fulponi, 2006). As a matter of fact, these standards could be perceived as potential barriers to trade for small producers, especially those in developing countries (UNCTAD, 2007a, 2007b, 2008a and 2008b) because most of the time they present disadvantages related to the lack of technical and administrative structures required for compliance and guarantee the safety of food exports (Unnevehr, 2000; Jaffee and Henson, 2004). Furthermore, differences in standards and certification systems may also contribute to their acting as major non-tariff 
barriers to trade (Martinez and Bañados, 2004) but could also generate additional competitive disadvantages if costs of compliance associated with private standards have a negative impact on food companies and producers (Henson and Caswell, 1999); for example, if the expenditure of production does not change considerably when implementing private standards (Asfaw et al. 2009) or when there is no price differentiation of a product regardless of whether it is certified or not. However, the standards-as-catalystic perspective (Jaffee and Henson, 2004) indicates that some countries use these standards to reposition themselves in the food markets through the modernization of their local supply chains and providing a more sustainable basis and profitable trade in the long term. In addition, domestic markets may benefit from positive spillovers for phytosanitary and safety aspects. Still, this dichotomy perception about food standards does not consider the influence of the credibility of compliance (when considering the advantages and disadvantages of private standards, it is good to know their nature and purpose ).

\subsection{Characteristics of Private Food Standards}

According to the WTO (2005), the International Organization for standardization (ISO) has published around 14,900 standards and Perinorm (a consortium of European standard organizations) have a database of around 650,000 standards in 21 countries, many of which have been set by the private sector. Furthermore, the Joint Research Centre of the European Commission (JRC) made an inventory in 2006, recording 386 private food standards in existance within the EU25. These private food standards have different information dimensions that have been grouped by the JRC in two main criteria: "qualitative" and "technical" information (JRC, 2005). While the qualitative information gathers the dimensions associated to the scope and governance of the private standards, i.e. geographical, communication target, supply chain level and proposer typology, the technical information collects specific objectives or requirements that are typical for each private food standard that includes dimensions like standard objective, market objective, assessment objective and certification objective. The territorial scale of the enforcement defines the geographical dimension of private food standards, which could be regional, national or international. From the perspective of the communication targets, private food standards labels or trademarks could either focus on Business-to-Business communication (B2B) among food supply operators, or reach the point of sale through Business-to-Consumer communication (B2C). The proposer typology dimension refers to the type of standard setting organization i.e. could 
be either public institutions, producer/processor organizations, retailers, certification bodies, NGOs or multi-stakeholder organizations, also considered as "supply chain partnership organizations" (Moeller, 2007). The supply chain level aspect of private standards is focused on the extension of their implementation within the food supply chain. In that sense, private food standards could cover the pre-farm gate stage (primary the production sector), post-farm gate stage (industry sector), transportation, trade and distribution (retail or food service). There are cases where private food standards could cover more than one stage of the supply chain like German $\mathrm{QS}^{10}$ system or the American $\mathrm{SQF}^{11}$ system. On the other hand, the technical dimension associated to the standard objective describe the type of requirements or quality attributes which are covered by the private food standard (JRC, 2005) e.g. safety, environmental protection, corporate quality and animal welfare. In addition, the market objective dimension refers to the type of market that the private food standards are setting their requirements for, these markets could be conventional food markets, organic markets or fair trade markets. Concerning the assessment objective, these refer to the ex post and ex ante control dimensions, e.g. performance standards or process standards (Antle, 1995). In relation to the certification objective, private food standards could either focus on product certification, process certification or service certification (ISO/IEC, 1996).

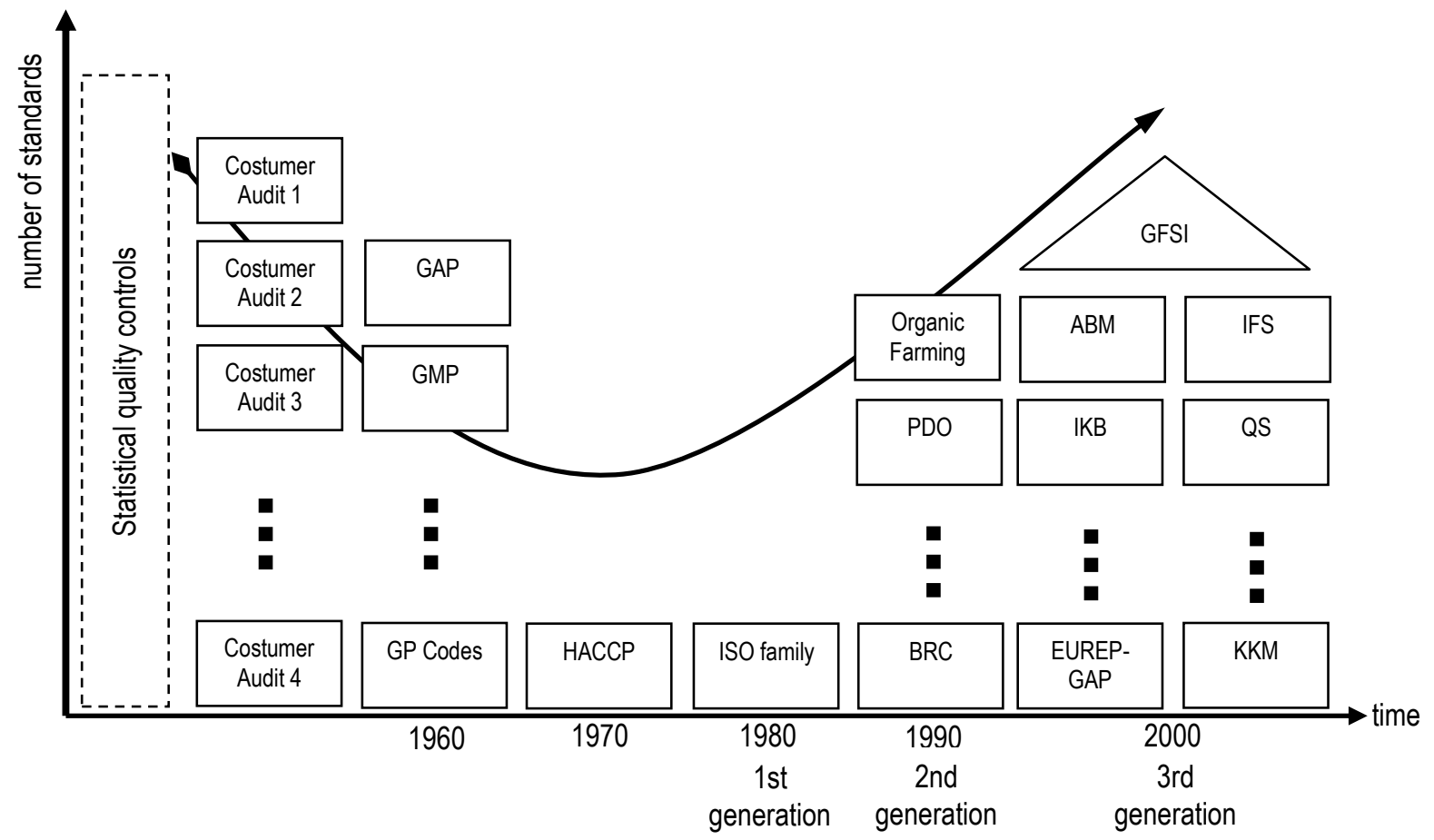

Figure 2: Historical development of private standards (Jahn et al., 2004 modified)

Moreover, another criteria type (also mentioned in the literature) is what Caswell et al. (1998) called "meta-systems". Meta-systems are strategies that affect a broad range of product

\footnotetext{
${ }^{10}$ Qualität und Sicherheit. http://www.q-s.de

11 Safe Quality Food. http://www.sqfi.com/ 
attributes and due to their general nature are often applied in many different industries many different firms within the supply chain. These could be mandatory, voluntary or quasivoluntary standards and at the same time could have a public or private nature. The most representative private standards are the ISO/IEC standards ${ }^{12}$, in particular ISO 9000 series. This introduced the concept of third party certification in the 1990s, which mostly have voluntary adoption and have spread widely in many industries, also as a means to achieve business benefits. However, the ISO 9000 series failed to meet the requirements of all industries, especially in the food sector. Here, the differentiation and specifications of new private standards and audit systems expanded rapidly (See Figure 2). The level of differentiation not only consists of a variation of voluntary systems but also the establishment of quasi-voluntary meta-systems (Caswell et al., 1998). These type of meta-systems have reached a privileged position where they are required by a large proportion of the market actors and become a 'de facto' (Fulponi, 2006) required standard for food operations and procedures. Perhaps, GLOBALG.A.P ${ }^{13}$, BRC Global Standards ${ }^{14}$ and the International Featured Standards (IFS) ${ }^{15}$ could be considered as examples of this group of private standards.

In general, private standards are identified by their most distinguished dimension, which in many cases is the standard setting organization (also known as "the standard owner"), whose responsibility is to administrate the development and implementation of the quality requirements and the assurance control procedures. Still, there are cases where there is a combined participation between public and private sectors. For example, organic standards and protected designation of origin standards (PDO) have been established by national governments, but these have delegated the inspections to private certification bodies (WTO, 2005). Another example could be the case of "Mexico Calidad Suprema", a national quality and safety standard whose governance and administration responsibilities are distributed between public and private institutions ${ }^{16}$. Purely private standards are mainly found in the retail and supply sectors. Especially in Europe, retailers are competing to differentiate themselves by promoting their own private standard and assurance scheme. This is the case of “Tesco Nurture” (previously known as Tesco Nature's Choice), Marks \& Spencer's "Field to Fork", Carrefour' "Filière Qualité", etc. On the other hand, there are private organizations that develop food quality schemes for national producer associations. These are usually

\footnotetext{
$12 \mathrm{http}: / /$ www.iso.org

$13 \mathrm{http}: / /$ www.globalgap.org

$14 \mathrm{http}: / / \mathrm{www}$. brcglobalstandards.com

$15 \mathrm{http}: / / \mathrm{www}$. ifs-certification.com

$16 \mathrm{http}: / / \mathrm{www} . \mathrm{mexicocalidadsuprema.com} . \mathrm{mx} /$

Angelo Enrique Benjamin Lazo Galdos
} 
promoted through a $\mathrm{B} 2 \mathrm{C}$ label to differentiate their local quality of products from products of other origins. Examples of this type of programmes are: the Assured Produce ${ }^{17}$ scheme of the UK, the QS system of Germany, Agri Confiance ${ }^{18}$ of France, the IKB $^{19}$ Standard of The Netherlands, etc. All these private standards mainly belong to agriculture and livestock sectors. In the fishery sector the most representative private standard is the Marine Stewardship Council (MSC), which is an ecolabel that assures responsible fishing and conservation of open sea fish species. In recent years, the increased importance of the aquaculture alternative has also attracted private standards to get involved in the assurance of safety, environment and the social aspect. In this sector standards such as GLOBALG.A.P. , $\mathrm{BAP}^{20}$ and AquaGAP ${ }^{21}$ are expanding and competing for stakeholders' acceptance. .

Even though the literature indicates that there is a consistent growth in the number of private food standard bodies, there is unfortunately no concrete data that can demonstrate their growth in terms of the numbers of certified firms for each private food standard. Most related information can be obtained from annual publications or flyers, and other marketing tools that private standards have used to promote their progress over the years. For example GLOBALG.A.P indicate that they have reached 102,300 certified producers for the fruit and vegetable market in more than 100 countries $^{22}$, BRC claim that they have around 10,000 sites certified in 60 different countries ${ }^{23}$, IFS claims 12,000 suppliers certified in 80 countries $^{24}$ and similarly, FLO says that they have 865 producer organizations certified in 60 countries which includes approximately 1 million beneficiaries ${ }^{25}$. Both the increase and the expansion of private standards brought some concerns because of the lack of current specific legislation that addresses rules or requirements for these organizations. In fact, this could have led in some cases to non-transparent and complex structures of compliance and control (Jahn et al., 2004), and if we add to this the eminent duplication and overlapping of requirements among private standards and between private and public controls, then the situation become even more catastrophic. Nevertheless, harmonization of standards has been discussed for many years within the public sector and it is now being considered how to introduce this into private standards as well.

\footnotetext{
$17 \mathrm{http}: / / \mathrm{www}$.assuredproduce.co.uk

$18 \mathrm{http}: / / \mathrm{www}$.agriconfiance.coop/agriconfiance/accueil.htm

$19 \mathrm{http}: / /$ www.pve.nl

${ }^{20}$ http://www.gaalliance.org/bap/standards.php

${ }^{21}$ http://www.aquagap.net

22 GLOBALG.A.P. Facts \& Figures October 2010

${ }^{23} \mathrm{http}: / / \mathrm{www}$.brcglobalstandards.com

${ }^{24} \mathrm{http} / / / \mathrm{www}$.ifs-certification.com

25 FLO Annual Report 2009-2010
} 
Despite of the attributes associated with food standards in reducing information asymmetries, preventing negative externalities (e.g. environmental impacts) and market failures (WTO, 2005), the rapid increase of stricter requirements, the difference of assurance controls and production technologies, the proliferation of private standards and their related implementation costs are all seen as significant threats that could inhibit national and international trade and have a negative impact on small-scale producers (Sawyer et al., 2008; UNCTAD, 2007).

As a matter of fact, there is the perception among exporting countries that behind the interests of governments in importing countries to minimize food safety risks and to protect animal and plant health as well as environment, there is the interest in these governments to use them as protective measures for their local production (Roberts, 1999). Currently, mandatory safety and environmental product standards have an ambiguous effects on the size of trade flows, but are likely to decrease trade if they create cost disadvantages for producers exporting to countries imposing the standard (WTO, 2005). The impact of mandatory process standards related to the environment depends on whether they are applied to foreign producers or not. If they are applied to foreign producers, trade flows may decrease. Yet such standards raise important questions concerning control and enforcement, given that production takes place abroad. Standards will affect trade flow if they have a different effect on the demand for and supply of varieties produced abroad and varieties produced domestically. This may, for instance, be the case if foreign and domestic producers supply different varieties of the relevant product, or if standards affect their production costs differently (WTO, 2005). In addition to this, public food standards, which are usually taken into account as part of the private scheme requirements, are also not harmonized. In the fresh produce sector for example, there was a lack of harmonization in the EU about technical definitions and treatment, like the case of the maximum residue levels (MRLs) and the number of active ingredients allowed for crop produce (UNCTAD, 2007). Nevertheless, these cases have been on the authorities' agenda and there has been positive progress so far.

Moreover, the reason that a large number of private food standards exist is due to their private and spontaneous nature and the lack of uniform legislation framework controlling them (Fulponi, 2006). This might consequently create some differences among them in terms of 
their origin and institutional objectives. Private standards cannot always have a common compliance criteria for different production systems and local conditions. For example, different technologies used in production may result in the identification of different risk levels (e.g. mechanical harvesting vs. manual harvesting) or legal conditions of compliance for specific standards may differ or even be absent (e.g. pesticide use, labour, environment protection, etc.). Moreover, the certification systems may differ in audit rules and conditions for granting certificates (e.g. conformity requirements, compliance coding, auditing rules, auditor competency, etc.), and usually these could lead to inconsistent interpretations by both certification bodies and producers. On the other hand, the existence of a large number of certification programs may have an impact on buyers' procurement decisions since they may face additional transaction costs when searching for certified products that match their commercial specifications. This investigation costs them time and money, and if it is too expensive, they may look for domestic substitutes (even non-certified products) and/or offer lower prices to suppliers. In this way, some of the transaction costs will be absorbed by suppliers as well, therefore a reduction in these costs should prove beneficial to both buyers and sellers (Sawyer et al., 2008).

In response to the above situation, it is thought that harmonization could reduce potential trade barriers linked to food standards and allow the flow of food from other countries without jeopardizing the health of consumers (Roberts, 1999; JRC, 2005). Also it is suggested that harmonization could be used as a means of correcting externalities, transaction costs and interdependencies between countries while gaining efficiency from economies of scale (Fox, 1991/1992; Leebron, 1996). However, achieving harmonization is a complex process since it does not assure maximization of welfare and not all parties will necessarily benefit economically from it. Harmonization of standards is not always sufficient due to the fact that it is not easy to bundle together all product characteristics, different risk conditions and consumer preferences in one optimal set of standards (Sawyer et al., 2008). Harmonization of standards is also been seen to struggle with countries' sovereignty on domestic industry when they face the decision to take international standards over existing national standards (Jackson, 2000). Therefore the perceived benefits of harmonization must be large enough to compensate a perceived loss. Furthermore, difference among consumer trust in different local markets is considered to be another factor that makes harmonization difficult. Consumer perceptions are a key element of harmonization success, since it has a significant influence in the development of food standards and acceptance of equivalence 
(Sawyer et al., 2008). Standards may affect the willingness of consumers to pay for product varieties meeting the standard, because they change consumers' perception or appreciation of these varieties. Overall, the introduction of a standard is likely to affect the prices that consumers are willing to pay for certain product varieties and the prices at which producers are willing to supply those varieties (WTO, 2005). The impression that goods coming from third countries are commonly of lower quality and safety guarantees creates a barrier in accepting equivalence among standards and thus maximizes welfare. Thus, harmonization could generate a false sense of security for producers as it may lead to the reduction of transactional costs but may not lead to increased sales due to consumer rejection (Lohr and Krissoff, 2002). One last argument against harmonization is that setting one single minimum standard will not necessarily contribute to the distribution of economic benefits in an equitable manner and it may lead to the exclusion of some producers and at the same time create more market power for some other suppliers (Marchant and Bellenger, 1994). In the same line of thinking, Casella (1996) found that there is no correlation between uniformity of standards with trade gain since the difference in productivity levels resulting from trade will mainly favour developed countries and suggested that only the convergence of national income from trading will cause standards to harmonize. This has an important relationship with the fact that developing countries are less prepared for harmonization due to the fact that they present lower conformity assessment infrastructures, technical capacity and financial resources (World Bank, 2004). However, there is still no consensus on which should be the best harmonization approach for the food industry and several strategies have been proposed within the public and private sector.

\subsubsection{Harmonization Strategies and International Standardization}

According to the economics of harmonization, "mutual recognition" and "unilateral recognition" strategies are the main measures used in the public sector as a means to enhance product trade flow and to correct market failures such as network externalities (e.g. product compatibility), information asymmetries (e.g. product quality) and environmental externalities (e.g. pollution) (WTO, 2005). Harmonization strategies have been focused primarily on standardisation through setting "de facto " and "de jure" standards (David and Greenstein, 1990), which implies that both country policy objectives and technical provisions are commonly defined and that standards are then adopted widely by a specific industry. Multilateral recognition implies that countries accept each other's standards and will mainly 
occur in situations where countries present equivalent policy objectives and presupposes a fair amount of trust among trading partners. Unilateral recognition implies that one country recognizes the standards of another country if the latter, regardless of its policy objectives, adopts the same technical provisions as defined by the former, e.g. when the exporting country adopts the standards of the importing country to achieve market access.

According to the analysis of the WTO (2005), harmonization has been shown to be more desirable in the context of compatibility standards, where the development of the markets of mobiles phones, computers and media equipment have benefitted from the reduction of the oversupply of input varieties. In the case of standards designed to correct information asymmetries, however, consensus for harmonization has been weaker within the public sector since there is no clear cut way to identify the improvement of national welfare against the gains obtained from trade. Countries may differ to an extent that it would be preferable to have separate policy instruments for each country rather than opting for a single one. It would also imply higher compliance costs to firms in one country rather than various countries. Likewise it could hamper trade in markets where a large variety of products is desired. On the other hand, mutual recognition allows any firm to select a standard to sell into a regional market, and unless consumers are biased toward domestic specifications, a firm can access a market without the additional costs of complying with a specific harmonization standard (Baldwin 2000).

It is currently not possible to draw clear conclusions on the benefits of harmonization or mutual recognition of standards to facilitate trade, but there is some evidence that indicates that mutual recognition has more significant effects in enhancing trade than harmonization when it is applied for bilateral recognition of conformity assessment systems. Arrangements concerning conformity assessment can result in key implications in favour of competitiveness and market access (WTO, 2005). Although mutual recognition of conformity assessment provides the flexibility for suppliers to select activities, procedures and service providers, availability and international confidence of another country's system is even more relevant for reducing transaction costs to foreign suppliers and thus any impact that would hamper trade. Improved national technical infrastructures would not necessarily lead to a one-stop control system recognized everywhere if confidence in conformity assessment bodies has not been established among countries. Currently, confidence in conformity assessment systems is facilitated through multilateral cooperation obtained in international organization forums 
linked to setting harmonization standards and practices of conformity assessment, e.g. $\mathrm{CASCO}^{26}, \mathrm{ILAC}^{27}, \mathrm{IAF}^{28}$. Their main objective is to assist mutual recognition agreements between its members in order to reduce duplication of assessments in different countries.

In the same manner, cooperation for the harmonization of national standards has been facilitated through the framework of the WTO agreements. Countries should apply policies, which are consistent with both SPS and TBT agreements, which at the same time encourage the creation, use and harmonization of international food standards. The SPS agreement for example encourages the harmonization of sanitary and phytosanitary measures and prevents that standards are used for arbitrary discrimination or as a hidden restriction on international trade. Furthermore, international standards chosen as reference will be based "on scientific principles and must not be maintained without scientific evidence "( SPS Article 2.2). In the case of food safety the FAO/WHO Codex Alimentarius standard guidelines and recommendations have been chosen as the international standard of reference and have become an integral part of the legal framework within which international trade is being facilitated through harmonization. The Codex standards include specific requirements for pesticide residues, food additives, veterinary drugs, contaminants and methods of analysis and sampling. These standards are being used as the benchmark in international trade disputes and it is expected that they will be used increasingly in this way (Codex Alimentarius, 2007). The main function is "to protect the health of consumers, to promote coordination of all food standards work undertaken by international governmental and non-governmental organizations, and to ensure fair trade practices in food trade. "29 However, in practice it is difficult for many countries to accept Codex standards in the statutory sense. Reserachers have found that SPS measures could sometimes involve loss of welfare in importing countries (Calvin and Krissoff, 1998; James and Anderson, 1998; and Paarlberg and Lee, 1998; Henson, et al., 1999; Wilson and Otsuki, 2004; all mentioned in WTO, 2005) and at the same time could imply high costs in losses of sale for developing countries when they have been denied market access because of sanitary or phytosanitary issues, and in combination with institutional weakness and rise of compliance costs it may contribute to marginalizing weaker economic players (Dolan and Humphrey, 2000 mentioned by Fulponi, 2006). In

\footnotetext{
${ }^{26}$ ISO's Committee for Conformity Assessment,

${ }^{27}$ International Laboratory Accreditation Cooperation

${ }^{28}$ International Accreditation Forum

${ }^{29}$ Codex Alimentarius Comission website

Angelo Enrique Benjamin Lazo Galdos
} 
contrast, countries are also able to find important niches and improve their position in global markets when their producers are adopting higher quality and safety standards (WTO, 2005).

Despite the fact that standardization activities at the international level are clearly defined by the WTO agreements, at regional and national levels such activities are generally more complex. In most developed countries, their standardization infrastructures are integrated into the network of international standardization. In the EU for example the adoption of EU directives are mandatory for its members and European standard organizations transpose international standards into their regional standards. Likewise, most East Asian countries have aligned with international standards and new developments are increasingly based on international criteria. According to the WTO (2005) The World Standards Services Network provides comprehensive lists of international and regional standardizing bodies among which ISO and the IEC are found to the be the most important and largest developers of standards. The expansion of membership in both organization as well as its influencial role in setting international standards reflects the increasing importance of such organizations. Even though ISO and IEC are non-governmental bodies, they occupy a position between the public and the private sector. On the one hand, many ISO members are part of the governmental structure or mandated by their individual country's governments and on the other hand, ISO liaise with several other regional organizations that are mainly producers associations like for example COELAP representation in the food sector.

Nevertheless, a considerable number of developing countries are not yet following this trend, since their national institutions are not part of the international network. As a matter of fact, constraints in resources restrict these countries to integrate into the international standardization system (WTO, 2005). Improving participation of developing countries in international standardization has been recognized as crucial for several decades. However, recent evidence implies that these initiatives have not improved as yet. For example ISO only has 3 members from developing countries and the majority do not have a formal contact with this organization. Also the progress in this aspect will still be difficult for developing countries due to the lack of expertise at the technical level on the formulation of standards as well as the limited support from their private sectors (WTO, 2005).

The scope of the ISO standards extends to all fields and industry sectors except the electronic sector, which is responsibility of IEC. Although all standards set by ISO are known as 
voluntary standards, some of them are referred into technical regulations and in some cases have become "de facto" mandatory requirements of the regulatory framework in some countries (e.g. ISO 14000 for environment management). Moreover, some of the ISO standards have become market requirements, such as ISO 9000 quality management systems, which was intented to be established as a general open certification system for all economic sectors (WTO, 2005). Unfortunately, this was proved not to be possible in the food sector, where the concept of quality evolves into something more complex and industry specific requirements and new schemes have rapidly evolved to cover the gap left by ISO standards (Jahn et al., 2005).

The process of establishing international consensus on voluntary standards is regulated by the WTO and ISO codes of good practice. Although the process is open and transparent, producers usually take the leading role since they are better organized and have clearer priorities than consumers. There is in fact the risk that producer and consumer interest will diverge in some cases. Producers will set standards in order to maximize their profit by only taking into account consumer interest to the extent that these preferences are reflected in prices or as a way to achieve artificial competitive advantage over other suppliers (Henson and Caswell, 1995). In this case, government intervention would be necessary to ensure that consumer interests are taken into the account and that harmonization procedures are not hampered by protectionist devices of lobbying groups (WTO, 2005). On the other hand, industrial organizations are concerned that the formal standardization process carried out by international standard setting organizations may be too slow. The general trend of leaving the standardization activities to the private sector and regulatory activities to the public sector is getting stronger (Fulponi, 2006), however, there is still not a clear cut separation between public and private standard setting as well as of the role that private stakeholder coalitions should take for the harmonization of voluntary standards.

\subsubsection{Private Harmonization Initiatives and Principles}

As mentioned above, both mandatory and voluntary standards can differ across countries, and could potentially be raising barriers to trade. Such barriers can be removed through harmonization or mutual recognition, and these strategies have been widely applied for solving the negative impact of mandatory standards and have been mainly and actively carried out between governments. In the area of international harmonization of voluntary 
standards, however, it has been suggested that it could either take place through intergovernmental treaties or be left to the market (WTO, 2005). Nevertheless, there are arguments that propose that the harmonization of standards should not be a principal concern of governments at all. Casella (2001) built a model demonstrating that when economies open up to international competition, coalitions of firms will reorganize standards internationally and will exploit economies of scale at a more disaggregated level of economic activity. There will be more harmonization initiated by private industry groups ("from the bottom to top"), in order to avoid duplication of national standards and a larger number of specialized international standard groups.

Consequently if this would be an optimal path, current harmonization strategies of private food standards should also take into account efficiency considerations through economising on costs of transaction (Williamson, 1996), and the main economic issue to consider at this level would be the reduction of coordination and auditing costs (Maze, 2007). In addition, Fulponi (2005) mentioned that reduce transaction costs, most retailers of the EU would prefer to have one global standard for food safety and harmonize minimum understanding product attributes related to labour, environmental protection and animal welfare. She commented that this would on the one hand allow retailers to benefit through more efficient global sourcing, while suppliers would benefit with lower total certification costs. Furthermore, harmonization of private food standards could contribute to facilitate and accelerate agreements on requirements which have not yet reached scientific consensus but that are highly valued by consumers. Moreover, she foresaw that retailers' requirements would become even more stringent and precise and harmonization could also help to achieve quick consensus across private standard organizations.

All these indicate that the industry could take a global approach to managing the food system and governing the standard setting arena. It also represents a basis of harmonization efforts to promote competitive advantages between member firms, while continuing to compete over quality, price, service and variety, and at the same time pursuing common objectives in a non competitive manner such as food safety and good agricultural practices (e.g. GFSI, GLOBALG.A.P.). On the other hand, producer associations which set technical and compatibility standards have long existed, they are corporate led with the power to impose decisions on players at different points in the system, which might raise a number of issues concerning competition particularly when undertaken by firms who dominate the markets 
(Fulponi 2005). Therefore, in that case there would still be a need for policy intervention. Yet the role of the government would not be that of establishing harmonization through intergovernmental treaties, but rather setting up the appropriate regulatory framework to prevent anti-competitive outcomes (WTO, 2005).

As previously discussed, the standardization activities have been mainly oriented in the establishment of a "de facto" or "de jure" standard (David and Greenstein, 1990). Foray (1995) explains that while " de facto" standards are established and adopted through market competition, "de jure" standards are established by formal institutions through mandatory regulations or by international standard setting organizations. According to Mazé (2007), so far private harmonization initiatives in the food sector have followed "hybrid arrangements" which fall between these two conventional situations, and rather than fully standardizing standards, they are trying to harmonize the requirements that are demanded to producers. The harmonization strategies include:

1. Mutual Recognition or "equivalence principle": Where guidelines and standard protocols are recognized arbitrarily as equivalent by the demanding party despite the existence or not of differences between schemes. This principle predominantly aims for quality product sourcing guarantees rather than focusing on specific technical assessment of individual requirements. For example, in Europe distributors and manufactures implement this principle to facilitate their procurement policies as well as to create incentive mechanisms for farmers (e.g. global sourcing of different certified organic coffee for a manufacturer brand, retailers sourcing conventional certified products under different GAP schemes to cover due diligence requirements). Although, this harmonization principle is limited to single large firms and does not completely solve the coordination problems, it allows more flexibility in acceptance, and thus to some extent does not discriminate producers arbitrarily.

2. The common base principle consists of the inclusion of an existing certification scheme as a reference for other private quality systems. This principle was implemented for example after the BSE crises by the French beef sector where there was a general adoption of the Laboul Rouge CCP requirements as a means to facilitate the access of a large number of breeders to higher standards regarding traceability and quality certifications of beef products. 
3. Bilateral Recognition or Negotiation where parties try to improve the "articulation" of coordination of auditing activities, including external audits, internal audits, planning, statutes of auditors, formalisation of the audit report and its use as a reference for other audits etc.

4. Benchmarking or one-way recognition principle consists of a formal acknowledgment of schemes by a stakeholder coalition. (e.g. GFSI, GLOBALG.A.P., ISEAL, IFOAM, etc). This includes a comparitive assessment of the scheme's technical content against a set of minimum requirements. It includes the common base principle and is linked to meta-system management and aims to improve coordination problems at both the implementation and the procurement level.

As a final remark of this chapter, the proliferation and concentration of a large number of food standards generates confusion in the market (jungle of standards) making procurement decisions and assurance of fairness of implementation difficult. One way to support decisions for food agents is to identify the credible food standards from those that are not. As a matter of fact, credibility will become a strong marketing tool for the acceptance of standards. The work of Tuncer (2001) suggested that credibility is needed to build a positive reputation on food standards and quality assurance schemes. He pointed out several "building blocks" that contributed to the building up of credibility for different food standards and that were used to add value and to lead them to stand out from each other. Nevertheless, the sources of credibility associated to food standards remain unclear for most stakeholders and deserve an analysis and evaluation of their effects in the acceptance of food standards. 


\section{Chapter 3}

From the literature review we can classify several structural, technical and marketing sources that altogether might have an effect on the credibility of food standards. In this study we consider structural sources to be those related to the type of standard governance policies, standard setting procedures (Tuncer, 2001). Technical sources instead are focused on the effectiveness of conformity assessment rules, i.e. their reliability in assuring quality and safety (Albersmeier et al., 2009); these are associated to audit performance (Jahn et. al, 2005; Anders et al., 2010), implementation success (Jahn and Spiller, 2005) as well as traceability and information completeness (Theuvsen, 2005). Furthermore, marketing sources have been considered to affect the acceptance and consumer perceptions of food standards (Fearne et.al, 2001); we associate these with marketing efforts (Nilsson et al., 2004) and labelling reliability (Giannaka, 2002, Amstel et al., 2007), country-of-origin effects (Bilkey and Nes, 1982) and adoption of benchmarking strategies (Mazé et al.,2007) like those offered by GFSI and GLOBALG.A.P.. The following sections will describe these credibility sources and explain how they may influence food standards and quality assurance schemes.

\subsection{Structural Sources}

\subsubsection{Governance policies of food standards}

Governance of food standards is related to the ownership and administration structure of a standard setting organization. Stakeholders behind the organization endorse their credibility to the food standard organization just as a celebrity would with a particular perfume or any other product (Tripp et al., 1994). Stakeholders behind the establishment and management of food standards become the face of the reputation of the organization and would spark different attitudes and perceptions in the industry about the credibility of the food standard. In the previous chapter we explained that the ownership could have a public or private nature and that it may involve different institutions. Credibility is a key issue in the establishment of market-based non-state governance since it will drive an active approval of a broad group of stakeholders (Boström, 2006). In fact, the credibility of the governance of a food standard would depend on perceptions about their expertise in setting standards and the trustworthiness of their controls. The reputation of the standard setting organization is influenced by the 
reputation of the institutions supporting food standards. Certainly here the media plays an important role as well, since the institutional reputation could decrease if they were associated to any food scandal, like for example, when the UK government lost credibility after the BSE outbreak. The expertise of the stakeholders supporting food standards is usually promoted (most of the time unintentionally) through open dialogues, round table discussion, conferences etc. In these events one can identify leaders of opinions and learn from companies' experiences about setting and implementing food standards. Concerning the trustworthiness of controls, words like transparency, openness and independence are always in the stakeholder's discourse. In this case credibility is judged on the degree in which the standard organization implement or promote the implementation of their values in their assurance management. Most of the time independency is said to be gained through third party certification. Nevertheless, if a certification body owns a food standard, some buyers may perceive it as a lack of independence in the assessment process. Furthermore, the openness of muti-stakeholder organizations in their consultation process might be perceived as better practice than a retailer setting its own protocols. In fact, the standard setting process might be considered as another source of credibility for food standards too.

\subsubsection{Standard Setting Process}

We have also seen before that the scope of the standards, content varies according to the scheme objective (e.g. process or performance, primary or post farm, type of products, etc). According to the codex alimentarius, standards must justify that they will protect human, plant and animal health and that the regulations must be scientifically supported, international agreements, which do not restrict trade. Government delegates participate in the setting of codex standards and guidelines. Governments under their own legislation then adopt these voluntarily in order to avoid trading disputes. Currently, there are several codes of good standard setting processes that are recommended for standard setting organizations (governmental and not-governmental) to follow. These codes are the Annex 3 code of the TBT agreement "code of good practice for the preparation, adoption and application of standards"; the ISO/IEC Guide 59 "Code of good practice for standardization" and the ISEAL ${ }^{30}$ "code of practice for setting social and environmental standards". These codes make recommendations on procedures for developing standards, targeting effectiveness, application relevance, international harmonization and participation in standard setting process.

\footnotetext{
${ }^{30}$ The International Social and Environmental Accreditation and Labelling Alliance 
According to the ISEAL code, the process of standardization must take into account relevant regulatory and market needs as well as scientific and technological developments; they must avoid interpretational ambiguities in language and structure. Nevertheless, taking into account the differences of compliance in local conditions must be considered when setting standards, otherwise there would be a risk of raising unnecessary competitive advantages, even if this is not the main objective of the standard, like favouring any type of production of interested groups (ISEAL, 2010). Also the capacities of achieving compliance by food producers or manufacturing firms is important for the acceptance of the standards (Albersmeier et al. 2009a) and for reaching the amount of products required by the food supply chain (Henson and Readon, 2005). In addition, it is recommended that standards should include objective and variable criteria indicators and benchmarks (ISEAL, 2010). These indicators should reflect how the criteria are measured and the benchmarks should show what is in practice acceptable or not. How the "acceptability" is defined is not yet clear among the codes, nevertheless in practice there are private benchmarking initiatives of multistakeholders organizations which are setting acceptance processes that aim to improve the credibility of food standards. Still, the absence of robust conformity assessment rules will develop schemes without substance (Adams et al., 2004).

\subsection{Technical Sources}

\subsubsection{Conformity Assessment Structure}

While public controls could take the form of standards, inspections, performance tests (ex ante regulations) or the mode of product liability (ex post regulations), private standards systems include either a self-regulation approach by the individual or trade organizations or could also involve the setting of product quality standards and their certification by external parties (Henson and Caswell, 1999). In addition, trust relations in business have influenced the changes of the different control approaches, private control systems adopted by buyers have evolved over the years from individual self-assessments, to vertical integrated controls (or second party), to third party audits. Nowadays, most certification schemes are privately organized. Certification procedures tend to be significantly different depending on whether the certification is to be used for consumer marketing purposes or should meet the demands of institutional buyers (Jahn et. al, 2005). 


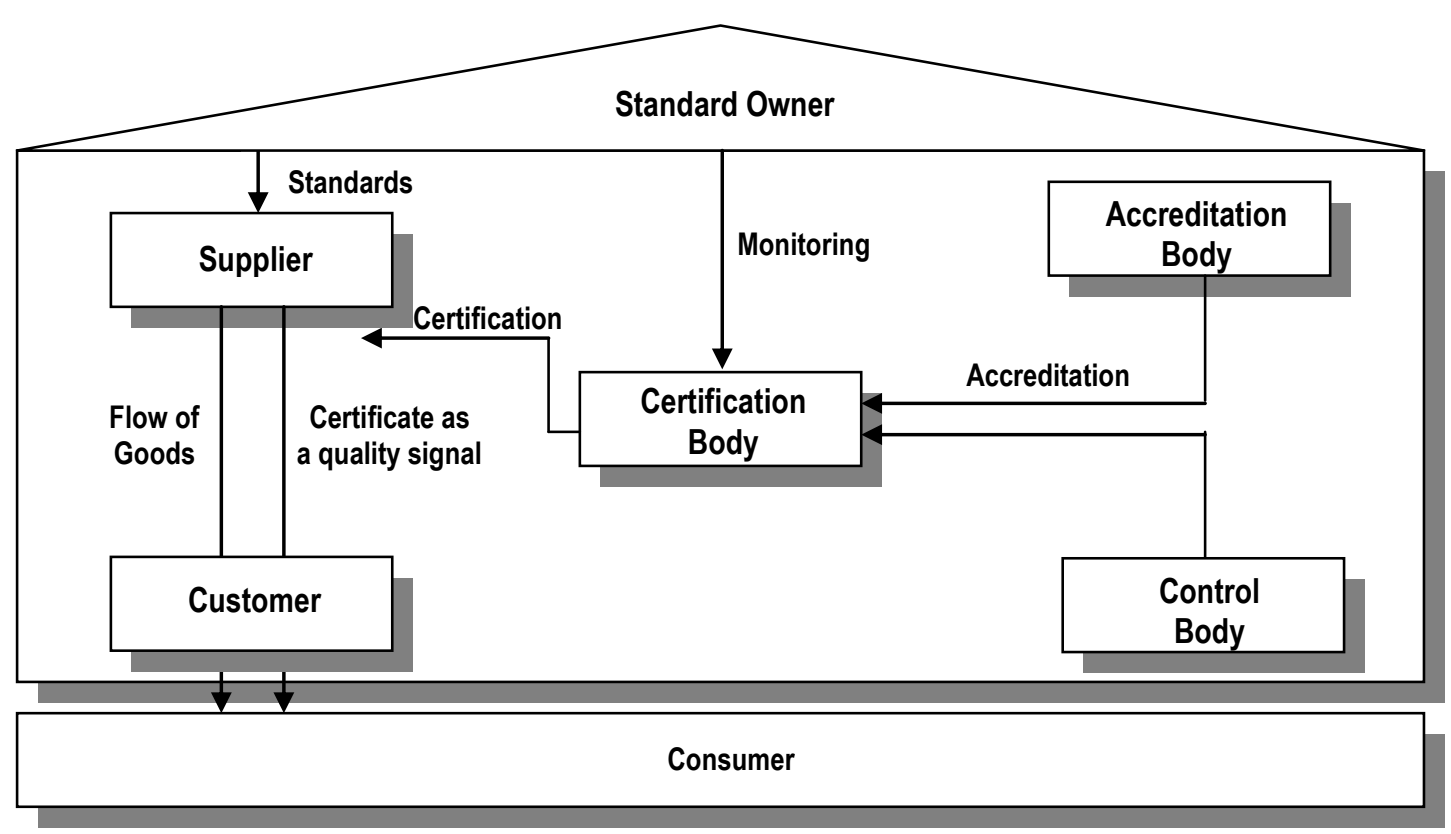

Figure 3: Basic structure of conformity assessment (Jahn et al., 2005)

Most of the existing private assurance systems present a similar basic operational structure (Figure 3), where according to Jahn et. al (2005), the starting point is the flow of goods between the suppliers and the customer and the existing demand of certified products. Producers or manufacturers are required to provide evidence of compliance with the standards and rules set by the standard owner organization. Such evidence could be by means of a certificate that can be validated in a central registry (e.g. database). Certificates are commonly issued by a neutral third party organization, which could be a certification body or any other similar organization approved by the standard owner organization. Participants of the scheme are able to extend their certification status during or after the expiration of the certificate validity. The frequency of audits may vary according to the food standard rules, usually between 1 to 3 years. In the case of food safety audits, high frequency is preferred, some assurance schemes have even introduced unannounced audits. In addition to this, third party certification bodies are required to become accredited by an international standard for conformity assessment body (usually ISO 65 or ISO 62), an Accreditation Body, which is part of the International Accreditation Forum. In some cases (e.g. organic certification), certifiers are monitored by public authorities or are even accredited by the same standard owner (e.g. Sustainable Labels). Here credibility is recognized by the quality of the audit, which means the way certification bodies deliver their service by following the scheme rules and keeping their independence. All in all, it is important to note that private food standards requirements rely on public systems to ensure credibility and allow for rigorous liability 
defence (Henson, 2006). Nevertheless, market pressure originated by highly competitive environments could lead to dependency of certification bodies and auditors on their clients and increase the risk of opportunistic behaviour (Jahn et.al 2005, Anders et.al 2007).

\subsubsection{Audit Performance}

Certification bodies play an important role in providing independent and credible signals on quality differentiation claims (Hatanaka et al., 2008; Anders et al., 2010). Nevertheless, much verification and assurance practices has to date been of questionable reliability and consistency (Dando and Swift, 2003). Jahn et.al 2005 pointed out that opportunistic behaviour of auditors and inspection bodies could be jeopardizing audit quality in third party private schemes. She referred to the phenomenon of "Low balling", which has been identified in finance auditing (DeAngelo, 1981), and could also be occurring in agribusiness audits. Inspectors appear to be agents of certification bodies and at the same time agents of scheme owners. It cannot be assumed that inspectors pursue the same objective as the certification company, neither that the latter pursues the same objectives as the scheme organization. In fact all agents are maximizing their own profit. The "low balling" factor generates strong dependency of the certification bodies on the clients due to quasi rents that they obtain from initial inspection costs and from their reliance on customer loyalty. This opportunistic behaviour effect could be even exponentially increased in third party certification markets where competition among food standards increases and many certification bodies exist (Anders et al., 2010). Still, as business oriented organizations certification bodies have to balance between being competent for their customers and not losing customers by being too strict or expensive and losing accreditation or credibility by being too lenient (Havinga, 2006).

Financing theory has proposed several technical practices for enhancing audit quality, including intensification of auditor liability (Becker, 1968) increased reputation effects (Bauwhede and Wilkens, 2004) or increased independence of auditors (Lennox, 2000). These measures could also be implemented for certification quality in agribusiness and could be complemented in addition to the rotation of certifiers by improving inspection technology. This could have a direct effect in reducing certification costs as well as including mainly vocational training and technical support, improvement of data information exchange among regulation bodies and risk oriented audits (Jahn et. al 2005). The latter have been well 
implemented in finance auditing and have been proposed as an alternative practice against the use of standardized checklists in private schemes. An empirical analysis on audit results of the German QS system revealed that standardized checklists might not be an efficient control system approach and could not guarantee the validity and reliability of audits (Schulze et al, 2006) Risk-oriented audits are theoretically considered to be an "efficient and effective" approach in contrast to the fairness of standardized checklists (Albersmeier et al., 2009a). Still, the improvement of audit quality due to risk-oriented audits has not been proven. In addition, Adams and Evans (2004) mentioned the importance of accountability in social and environment reports which links to concerns about audit expectation gaps prompted by the lack of completion and credibility in reports. They suggest the involvement of multidisciplinary teams in the certification process, and this should be robust and independent (Dando and Swift, 2003) in order to add credibility cues to reduce this gap.

\subsubsection{Implementation Success}

Due to the high concentration of global retailers in major international food markets and their "de facto" demand for private scheme certifications for supplying food in their stores (Fulponi, 2005), suppliers to these are under strong economic pressure to become certified (Jahn et al. 2005). Several studies have analyzed the implementation of private schemes and have provided different arguments about the benefits and problems in adopting these systems. These reveal a motivational gap (Jahn and Spiller, 2005) that may vary according to market access and geographical position. On the one hand, it has been said that private schemes are having an important effect on competitiveness (Caswell et al., 1998) since food standards require improvement in internal organization and market linkages between firms. However, the competitive advantage is more expected among small-scale producers than larger producers who mainly expect effective cost savings (Caswell et al., 1998). In addition, compliance with private standards has the potential to enhance product quality, demonstrate compliance with regulations and improve responsiveness to customer s given that they could serve as a communication mechanism to reduce transaction costs and increase trust in the products supplied (Holleran et al., 1999).

Contrary to these expectations, private schemes are often perceived as an unpopular burden for suppliers. Management surveys demonstrate that most participating companies are not convinced of the economic benefits of third party audits (Jahn and Spiller, 2007) and that 
external market pressures (i.e. customer or authority demands) holds strong weight in driving suppliers to implement quality standards. In addition, there are fears that certification also brings bureaucratic burden (Theuvesen and Spiller, 2007) due to record keeping practices and direct cost increases associated with staff training, the monitoring process (Fouayzi et al., 2006 mentioned by Albersmeier, 2000 b.), and infrastructural elements like storage or produce handling facilities (Martinez and Banados, 2004) and economic burdens that may represent compliance blocks (Barret et al., 2002; Getz and Schreck, 2006) They may also generate higher transaction costs for small-farmers when they try to access the right information and knowledge (Kleinwechter and Grethe, 2006). Moreover, Jahn et al. (2003) pointed out that only $50 \%$ of German farmers who have already been certified in the QS system claimed that they mentioned extrinsic motives like pressure from customers or price reductions (Jahn et al., 2003). However, Walgenbach (2007), argued from a neo-insitutional perspective that besides the external pressure, the adoption of the ISO 9000 standards by suppliers may also be motivated by a voluntarily interest in enhancing the effectiveness of their quality system. Although voluntary motivation seems to be lower in countries like Germany where according to Jahn et al. (2003) only $7.7 \%$ of certified farmers claimed to participate in the system to enhance the overall quality, in market-oriented export sectors like in Peru, farmers were less concerned about bureaucratic burden and imperative requirement. Instead they considered the relationship towards customers and the relevance of certification systems like EUREPGAP of major importance for entering into new markets (Lazo et al, 2007). Likewise Albersmeier et al., (2009) found that the acceptance of organic schemes is higher and less controversial in Latin America than in Europe and stressed that farmer conviction is necessary in ensuring farmer diligence.

From the above we can speculate that where there is a higher motivational gap, suppliers will have an incentive to reduce costs as much a possible by hiring the services of the "easiest" auditor or certification body with knowledge about low inspection standards (Pie Pierce \& Sweeney, 2004). On the other hand, if suppliers have higher voluntary incentives to improve quality control, they will search for higher external audit quality services. In that sense, the credibility of food standards will be jeopardized due to lack of producer motivation and opportunist behaviour, especially if these "lemon growers" or even non-certified farmers are not discriminated against regarding market access. To avoid this, food standards might need to strengthen traceability requirements and the completeness of this information. 


\subsubsection{Traceability and Information Completeness}

Traceability is the system used to describe the production history of the product and any further processes that the food may undergo along the way from the primary producer to the consumer (Tuncer, 2001). The aim is to transfer complete and reliable information to the supply chain agents who should have the possibility to verify and trace product information related to the origin and characteristics of the production process (Theuvesen, 2005). Despite traceability implemented through modern technology (software and IT systems), the risk of coordination problems and principle agent dilemma (Arrow, 1985) in highly interdependent supply chains may instigate opportunistic behaviour that motivates actors to reduce their effort in sharing accurate information, jeopardizing the identification of assured produce from those which are not assured. If we make the assumption that third-party certification systems are structured along an information chain (see Figure 4), we could likewise assume that information regarding certification flows is distributed through different actors of this chain. Each one of these actors has the responsibility to transfer and communicate the certification information as adequately and transparently as possible. Failure to do so denotes the reduction of both efficiency and effectiveness in the whole certification system.

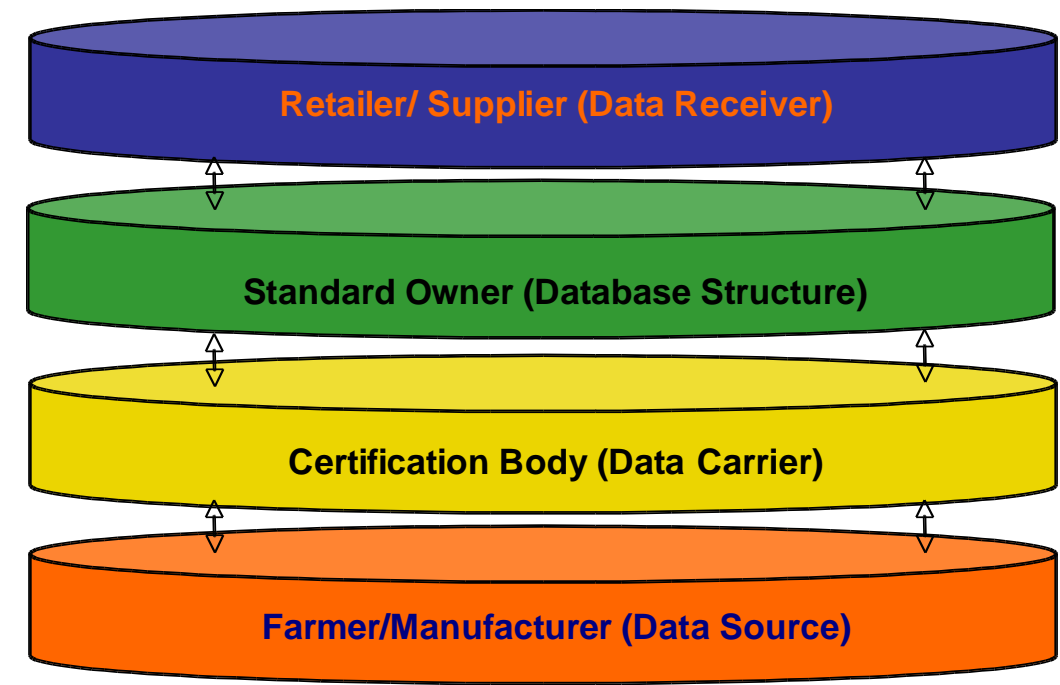

Figure 4: Certification information chain (modified from FoodPLUS GmbH, 2007)

Certification information consists in a series of elements, which together build the scope of certification that has been defined by the scheme rules. The scope of certification varies 
according to the objectives and structure of each one of the private schemes. In agribusiness, food certification is divided into two main areas: pre-farm gate and post farm gate. The former gathers the certification of farms and activities related to primary production and certification can cover product certification (e.g. product tests), process certification (e.g. organic farming) or both (e.g. good agricultural practices). In addition pre-farm gate certification could be specific for inputs (e.g. feed, propagation material, etc.) as well as for services (e.g. application of pesticides, harvesting etc.). On the other hand, post-farm gate certification gathers certification of manufacturers (e.g. packing or processing) transport (e.g. ground or marine) or distribution, it includes controls for good manufacturing practices, HACCP or process quality (e.g. ISO 9000 series). Certification scope can also be granted for one single product (e.g. tomato, tomato juice) or a group of products (e.g. fruit and vegetables, fruit juice, etc.). In addition to this, the scope could cover the certification of individual companies or to be granted to a group of companies.

From the above you can expect a quite detailed collection of data, which will reflect the information that is behind a scheme certificate and brand. For this reason it is important that the data is accurate enough to guarantee that products linked to the certification are really coming from sites that have been inspected and have certified compliance with the private scheme rules and standards. In addition to this, the relevant information gathered at the audit must be transparently transferred through the certification chain and to the food supply chain. Some private schemes whose scope covers food safety elements are requiring companies to implement basic traceability systems (one step forward - one step backwards) for tracking and tracing their certified products. Traceability is meant not only to trace the origin of products and identify the certified company but also to transfer complete and reliable information about the product and process characteristics throughout the value chain. Furthermore, certification bodies are required to collect company data in a centralized database from where the scheme owner can validate the certificate content and communicate into the food supply chain.

Theuvsen (2005) highlighted the fact that although there is currently modern information technology for collecting and transferring certification data, due to coordination and motivational problems the correctness and completeness information can still not be granted. Most food supply chains present interdependencies between different actors (Thompson 1967), and coordination problems in completing and transferring reliable information through 
the chain raise when the number of these interdependencies increases. On the other hand information asymmetries between principles and agents (Eisenhardt, 1989) could potentially occur along with opportunistic behaviour by agents known as hidden actions (Arrow, 1985). When agents reduce effort and thereby jeopardize the completeness of the information or try to disguise actions which are not in the best interest of the principles, the question of correctness and the credibility of the information is raised. Likewise within the certification chain there are input-output relationships and therefore interdependencies between the actors, so it could be assumed that coordination problems and principle-agent dilemmas are also present and affect the credibility of the certification information.

In order to improve transparency and traceability, it is suggested that the food industry should strengthen the cultural value of storing and transferring correct and complete information, but this would be very difficult without an economic incentive. Theuvsen (2005) also emphasizes that to overcome the motivational barriers related to track and tracing, it is important that changes in the organization of food production is oriented towards reducing transactions either by vertical integration strategies within a food sector, or by strengthening the industry culture towards improving transparency and the transfer of information. In addition to screening good actors from bad actors through third party certification or by improving monitoring systems, there should be investments in signalling devices (e.g. branding), to generate responsibilities and trust in the value chain. However, branding strategies do not always ensure adequate information provision and could even be insufficient to alleviate market failures.

The high number and great variety of existing schemes could imply a lower level of transparency and the possibility of confusion for consumers, with a consequent possible loss of faith in the system itself (JRC, 2005). Under these conditions, the system could "fail" in the objective of communicating quality and valorising products and/or firms (JRC, 2005). For example, some studies reveals that eco-labels like "environmental friendly" and "organic" fail to communicate adequately, thus could not efficiently diminish information asymmetries (Amstel et al., 2007). According to Giannakas (2002), with the introduction of certification activities, there are clear incentives for mislabelling and fraudulent behaviour, especially when consumers are not able to identify the certified characteristics even after purchase experience and use of the products. Incentives of mislabelling will be stronger in markets where the certified products are more profitable or generate other attractive commercial 
benefits to suppliers. Cases of mislabelling have been reported in organic product markets where conventional food counted between $15 \%$ and $40 \%$ of organic labelling produce. Consumer deception due to mislabelling affects consumer trust in the labelling process and can have detrimental consequences for market acceptance of certified products. When extensive mislabelling occurs, the value of labelling is undermined and the certified food market fails.

\subsection{Marketing Sources}

\subsubsection{Marketing Efforts and Labelling Reliability}

Marketing efforts refer to the target markets addressed by the schemes and the promotion efforts performed by the food standard owners in order to enhance their acceptance (Nilsson et al., 2004). The target markets could be the private consumer market and potential participants in the food standard (Tuncer, 2001). When a food standard initiative is seen as a product it will be promoted for adoption and implementation by agents along the food supply chain (Tuncer, 2001). These promotional efforts are generally carried out through advertising, or through formal means of communication (such as the media) or by the creation of publicity at an individual level (such as word-of-mouth). On the other hand, private consumer/customer markets could be segments with environmental concerns, buyers and manufactures searching for certified companies or the society at large. The most useful way to reach these markets is through labelling, which is considered a stakeholder communication tool rather than a promotional instrument.

Indeed, the construction of trust and reputation around a visible symbol of a brand arguably acts to enhance the credibility of private standards among consumers. (Henson and Northen, 1998) The reliability of the information behind the labels is a key element to build credible cues; unfortunately there is much evidence that some labels fail to communicate adequately and do not diminish the information gap between buyers and sellers (Amstel et al., 2007). Although food standards have the potential to reduce both perceived product category risk (e.g. in meat) and specific product risks (e.g. associated to scheme label, retailer label etc), it still remains to improve the communication of their objectives as most of the cases have been poorly understood by stakeholders and consumers (Fearne et al., 2001). The high number and great variety of existing schemes could imply a lower level of transparency and the possibility of confusion for consumers, with a consequent possible loss of faith in the system itself (JRC, 
2005). Consumer deception due to mislabelling affects consumer trust in the labelling process and could have detrimental consequences for the market acceptance of certified products. When extensive mislabelling occurs, the value of labelling is undermined and the certified food market fails (Giannakas, 2002)

\subsubsection{Country-of-Origin Effects}

Country-of-origin has been considered as a product extrinsic cue which has been broadly discussed in studies related to consumer purchasing decisions (Bruning, 1997 and Grooves, 2000) At the same time, it has also been recognized to have effects on buyers perceptions of products and consequently in industrial purchasing decisions (Bilkey and Nes, 1982, Verlegh and Steenkamp, 1999). It is agreed that the location of production has considerable effects on consumers' beliefs about product quality in the sense that high country specific production costs signal high product quality (Haucap and Barmdold, 1997). Lobb and Mazzochi (2006) mentioned that consumer perceptions commonly classify country-of-origin in two behavioural components. The first one includes country-of-origin as an indicator of the safety or quality of the product and the second one is related to the group identity or national pride (Bruning, 1997). In addition, they state that there are cognitive, affective and normative variables influencing country-of-origin effects and perceived risks associated to products. On the one hand, socio-psychological variables like political and ethical motives or cultural values explain attitudes towards the country image and ethnocentric behaviour includes normative concepts that influence purchasing behaviour under the assumption that it is a proper action in favour of the home country and its people (Grooves, 2000). Moreover, socio-demographic variables such as age, education, gender and income work in conjunction with these sociopsychological influences on food purchasing behaviour (Bilkey and Nes, 1982; Lobb and Mazzochi, 2006).

The motive behind the adoption of quality assurance schemes by agribusiness organizations is to reduce consumers perceived risks associated with food purchase which involves reducing both product category and product specific risks (Fearne et al. 2001). However, attitudes toward products from a country vary by product and there are significant differences between general country attitudes and specific product attitudes by country of source. In fact there is a hierarchy of biases between developed countries and developing ones, including degree of economic development, cultural and political climate and similarity with the country's belief 
system (Berkley and Nes, 1982). Information imperfection may cause consumers to practice "statistical discrimination" against imports from developing countries (Chiang and Mansson, 1988) since there is a particular salient norm to buy domestic (Verlegh and Steenkamp, 1999). Actually, Verbeke and Roosen (2009) argues that origin labels have the marketing potential to mainly disclose product's healthiness appeal and if consumers are on average correct about their perception then a "lemons" effects may emerge (Chiang and Mansson, 1988). The study carried out by Hampton (1997) suggested that products sourced in Less Developed Countries (LDC) are perceived to be more risky due to price stability, uncertainty regarding delivering time, quality etc. In addition, Verlegh and Steenkamp (1999) indicate that beside the perception that products from LDCs have a lower quality, these are also associated with high risk of bad performance and dissatisfaction. In this regard risk safeguards might include third party assurance schemes, laboratory tests and warehousing within importing countries (Bilkey and Nes, 1982). Therefore, when national food standards and quality assurance schemes try to differentiate through country identification labels and trademarks (e.g. CanadaGAP, ChinaGAP, MexicoGAP, etc.), this may be exposing country-of-origin effects to buyers and may have some negative effects on credibility perceptions about the national standards. This study aims to analyze the effects of country of origin and benchmarking strategies on credibility of food standards. We assume that negative country of origin effects on food standard credibility should significantly diminish when the quality assurance schemes owner decides to take a benchmark strategy. The following section describes the theoretical framework of this research.

\subsubsection{Adoption of Benchmarking Strategies}

The economic definition of Benchmarking is "the process of comparing one's business processes and performance metrics to industry bests and/or best practices from other industries. Dimensions typically measured are quality, time and cost. Improvements from learning mean doing things better, faster, and cheaper" (Boxwell, 1994). In the food industry so far benchmarking has been taken as a process of equivalence assessment for food standards, whose main objective is to improve standards effectiveness and efficiencies by reducing redundancy and overlaps in the application fields and in the markets. In the previous chapter, we mentioned that benchmarking procedures in food standards is also one of the harmonization strategies existing in the private sector, which as in all other strategies is seen to have the potential to mitigate trade barriers and allow the flow of food from other countries 
without jeopardizing the health of consumers (Roberts, 1999; JRC, 2005).

Benchmarking principles consist of a formal acknowledgment of food standards by a stakeholder coalition. This includes a comparison assessment of the schemes technical content against a set of minimum requirements. The most prominent benchmark procedures are those offered by GFSI ${ }^{31}$ and GLOBALG.A.P. National food standards apply to an independent assessment for obtaining formal recognition of equivalence against the GFSI or GLOBALG.A.P requirements which are widely accepted by food stakeholders, such as major international retailers. The objective of the benchmark is to reduce multiple certification costs to producers by recognizing one single audit at the pre and post farm levels. The differences between both alternatives consist of the scope of acceptance for food standards. While the GFSI benchmarking process is focused only in the harmonization of food safety key elements, GLOBALG.A.P offers, in addition to these food safety elements, benchmarks against sustainable production requirements linked to environment protection, occupational health and safety and animal welfare. In addition, GLOBALG.A.P provides a close follow up of certification bodies performance through an integrity programme as well as certificate validation through a database. Also within the processes of equivalence assessment, GLOBALG.A.P delivers the service to a third party accreditation body who will evaluate the normative documents and carry out a witness audit to verify in practice the compatibility of national standards. In GFSI, this role is delivered by an internal technical committee. Recently, both organizations have started cooperating to align their benchmark procedures and offer a wider scope of harmonization and credibility of national food standards. The strongest incompatibility between both organizations still seems to be their different governance structure and decision making policies

\subsubsection{Global Food Safety Initiative (GFSI) Governance}

GFSI is the food safety programme of the International Committee of Food Retail Chains $\left(\mathrm{CIES}^{32}\right)$. CIES was founded in 1953 in Belgium with the objective of creating a body to represent food retail chains. Although membership was initially restricted to retail chains, with the evolution of food distribution in larger companies, the dialogue was extended to include suppliers and cooperatives during the mid 1960's. Today the organization is called CIES- The Food Business Forum, and has gathered 400 members from the retail and

\footnotetext{
${ }^{31}$ Global Food Safety Initiatiative

${ }^{32}$ French Abbreviation: Comité International d'Entreprises à Succursales 
manufacturing sector from 150 countries and offices have expanded in key regions like North America, Asia/Pacific, China and Japan. Its mission is to provide a platform for leadership, debate and networking between retailers and their partners. The main services or programs consist of leadership events (Summits) for senior executives for taking new strategic perspectives by providing practical information, debate and reflection on the latest trends and developments in the social, political and economic context of the global food and retail business.

In May 2000, a group of international retailer CEOs identified the need to enhance food safety, ensure consumer protection and strengthen consumer confidence. They proposed a programme, which would set requirements for food safety schemes and improve cost efficiency throughout the food supply chain. Following their lead, CIES - The Food Business Forum established the GFSI programme as an instrument of continuous improvement in food safety management systems for ensuring confidence in the delivery of safe food to consumers: GFSI's objective is the convergence of food safety standards through maintaining a benchmarking process for food safety management schemes, improved cost efficiency solutions throughout the food supply chain by way of the common acceptance of GFSI recognized standards by retailers around the world and to provide an international stakeholder platform for networking, knowledge exchange regarding food safety practices and information.

The governance structure of GFSI is coordinated by CIES and it mainly consists of the GFSI Foundation Board, a retailer-driven group, with manufacturer advisory members, providing strategic direction and overseeing daily management. Membership of the Board is by invitation only. The GFSI Technical Committee was formed in September 2006 and is composed of retailers, manufacturers, standard owners, certification bodies, accreditation bodies, industry association and other technical experts. It provides technical expertise and advice for the GFSI Board. Membership of the Technical Committee is by invitation only. Industry stakeholders are also invited to participate in the decision-making process of GFSI through annual meetings and regular exchange of information.

The GFSI benchmarking process consists of a documentary comparison assessment of existing food safety standards against the GFSI Guidance Document (currently in its $5^{\text {th }}$ version). This reference document contains commonly agreed criteria for food safety 
standards (key elements) and management schemes, against which any food or farm assurance standard can be benchmarked. The technical assessment is carried out by a benchmarking committee pointed out by GFSI, who within three months would make a recommendation report to the GFSI Board for accepting the compliance and recognition of applicant scheme. Once the food safety scheme is approved, it will be commonly accepted by 7 major retailers (Carrefour, Tesco, Metro, Migros, Ahold, Wal-Mart and Delhaize) who will accept certificates based on the benchmarked standards in order to be able to make an assessment of their suppliers of private-label products and fresh products and meat, to ensure that production is carried out in a safe manner.

GFSI approval include both pre and post farm gate stages, currently there are 11 private food standards recognized, including BRC, IFS, Dutch HACCP, SQF, CanadaGAP, GLOBALG.A.P etc. Furthermore GFSI has announced that the technical committee has completed a detailed comparison of the ISO 22000 as part of their harmonization activities to reduce duplication in the manufacturer sector.

\subsubsection{GLOBALG.A.P. Governance}

GLOBALG.A.P. (formerly known as EUREPGAP) is a private voluntary scheme for good agricultural practices which was founded in 1997 by the Euro Retailer Produce Working Group. It was primarily designed to reassure consumers about how food is produced on the farm by minimising detrimental environmental impacts of farming operations, reducing the use of chemical inputs and ensuring a responsible approach to worker health and safety as well as animal welfare. The EUREPGAP certification scheme and standard was first launched in 2001 for the fruit and vegetable sector and since then acceptance of the standard has been growing. In 2007 the programme changed it's name to become GLOBALG.A.P., in order to represent the achievements reached leading up to that date. These included more than 90,000 participants in 80 different countries, with a certification capacity of 130 Certification Bodies operating worldwide. Its certification activities have also since expanded to other product lines such as flowers and ornamentals, combinable crops etc, as well as introducing other prefarm sectors such as livestock and aquaculture.

The governance structure of GLOBALG.A.P. is coordinated by the GLOBALG.A.P. secretariat and involves voluntary membership participation of different stakeholders within the food industry. This organization is known for its strong representation of retailers and 
suppliers in the GLOBALG.A.P.'s Board and the Sector Committees. While the former decide on policies and strategies, the latter establishes and designs the standard content and compliance criteria. This work is supported by National Technical Working groups where regional stakeholders have their local voice and provide input to the standard setting process. Likewise, agricultural service companies are associated members who participate in a consultancy role.

In addition, GLOBALG.A.P. as a non-profit organization is also involved in providing harmonization solutions to the industry by reducing duplication costs to producers. Harmonization takes place not only vertically by the consolidation of several retailers' requirements in one set of normative documents recognized worldwide, but also horizontally by the recognition of national schemes, through a process of benchmarking. This process consists of the technical comparison of the normative documents of the applicant schemes against the GLOBALG.A.P. documents, i.e. the applicant scheme's Certification System Rules will be compared against the GLOBALG.A.P. General Regulations and the applicant scheme's standard will be compared against the GLOBALG.A.P. Control Points and Compliance Criteria. This technical assessment is carried out by either one of the two independent organizations approved by GLOBALG.A.P., the Joint Accreditation System for Australia and New Zealand (JAS ANZ) or the Deutsches Akkreditieriungssystem Prüfwesen (DAP). The process also contemplates the involvement of industry stakeholders through a Peer Review process of GLOBALG.A.P. members, as well as a Witnessed Assessment to audit the implementation and interpretation of the applicant scheme in practice. Finally, the Independent Organization will send a recommendation report to the GLOBALG.A.P. Secretariat for approval or rejection of the recognition. After this period, certification bodies seeking to participate in benchmark audits must achieve ISO 65 accreditation to the scope of the benchmark scheme.

Currently there are 20 different GLOBALG.A.P. benchmarked foods. These represent countries like Austria, Colombia, Chile, China, Germany, Kenya, Mexico, Japan, New Zealand, Spain, Sweden, Switzerland, Thailand, The Netherlands, Uruguay and the UK. Not all of these schemes represent the fruit and vegetable sectors but include those of flower and ornamentals as well as cattle and sheep meat products. 


\section{Chapter 4}

\section{4}

Conceptual Framework

In this research I attempt to prove if national food standards' credibility is susceptible to country-of origin effects and at the same time explore which credibility sources may have an influence on stakeholders' perceptions. We base our investigation on the literature review, making the associating quality assurance theory, the trust theory and marketing research concerning credibility sources.

\subsection{Empirical Approach}

As mentioned previously, the focus of food standards has adapted over time to changes in consumers' perceptions about the risks associated with food consumption originating from quality inconsistencies and information asymmetries that appeared along the supply chain (Akerlof, 1970, Nelson 1970, Fearne et al., 2001). To solve these problems, food standards have not only remained to standardize product specifications but also to standardize production and distribution practices. While official control systems have been strong, the food supply chains have been governed by private assurance schemes that have centralized quality in all operations (Morris and Young, 2000). At the same time, these have shaped supply chains into food networks that are characterized by strategic vertical linkages between the different agents (Hanf and Pieniadz, 2006). These networks are normally driven by "focal companies" such as retailers or manufacturers, who use their buying power to manage vertical relationships with their suppliers by imposing upon them specific compliance with food standards that have been designed either by industry coalitions (Fulponi, 2005) or by their own quality department.

From an economic point of view, Fritz (2006) argued that any variations of the supply and demand of food could easily force food network agents to look for new buyers and suppliers outside their existing supply chain. This decision coould make agents experience new uncertainties and risks caused again by information asymmetries that exist with the first transaction with a new trading partner. As a matter of fact, as in the case of consumers, buyers' perceptions of potential risks in a given transaction are socially constructed and psychological elements, available information influences individual perceptions, decisions and behaviour (Bauer, 1967; Lobb, 2005). As a consequence, the individual perception of 
information communicating trust signals and control mechanisms is the key to the transaction decision. To influence decisions and transaction behaviour, the existence and communication of trust and control is necessary (Hunt \& Frewer, 2001). Therefore, quality assurance schemes again turn into a safeguard mechanism as a communication device for the information required to diminish the pre-purchase risk perception and consequently establish the desirable trust to initiate business-to-business relationships (Fearne et.al, 2001).

Coincidentally, it is quite interesting to note that "Trust" has been revealed as the most important and frequent dimension used in empirical models to measure business-to-business relationships (Wilson and Moller, 1991 mentioned by Fynes et. al, 2001). Anderson and Narus (1990), defined trust as "the firm's belief that another company will perform actions that will result in positive actions for the firm, as well as not taking unexpected actions that would result in negative outcomes for the firm". Trust in transactions is often considered to be an economic asset creating value (Fritz, 2006) by reducing transaction costs, enhancing commitment and cooperative behaviour and establishing a safe environment for critical transfers of information, performances, goods and resources (Doney and Canon, 1997; Galizzi and Venturini, 1999; Büssing, 2000 and Pelzmannm 2005 mentioned by Bahlmann et al, 2007). According to Heffernan (2004) trust emerged as a critical component of successful cross-cultural business-to-business relationships developing in different forms in the different lifecycle of the relationship. In the pre-relationship stage, trust was primarily generated by the reputation of the partner. In the early interaction stage total trust was produced by the trust generated in the pre-relationship stage, the level of contractual trust and the level of competency trust. In the relationship growth stage, total trust was developed from the transfer of trust developed in the early interaction stage, coupled with levels of goodwill and trust in competency.

At the same time, credibility has been identified as an important component of trust. Doney and Cannon (1997) defined trust as: "the perceived credibility and benevolence of a target of trust, where credibility is the expectancy that the partner's word or written statement can be relied on (Lindskold, 1978), and whether the partner has the capability and expertise to undertake the purpose of the partnership (Ganesan, 1994). On the other hand, benevolence is the extent to which one partner is genuinely interested in the other partner's welfare and motivated to seek joint gain. And whether the partner will be accommodating and act with equity when new conditions relating to the relationship arise (Ganesan, 1994)." Furthermore, 
Scott (2000) considered that trust can be classified as a rational cognition perspective by gathering credibility with other elements such as integrity, reliability, competence etc. Furthermore, Hunt \& Frewer, (2001) holds the theory that the credibility of a piece of information source is determined by two types of expectations about possible biases in its information. The first is a "reporting bias", which refers to the degree to which the information source can be expected to be truthful about a particular issue. The second is a "knowledge bias" (hereafter "degree of knowledge"), which refers to the degree of expertise or knowledge a source is assumed to have about a particular issue. These expectations are also determinants of the degree of trust associated with an information source, and both feature as important constituent elements in several distinct accounts of trust.

Taking into account the above theoretical background, we could assume then that credibility of information sources of food standards are related with the trust building process in business-to-business relationships. As matter of fact, food standards have been recognized as a de facto condition for local and international trade (Fulponi, 2005) and it would make sense to explore which determinants might be affecting the credibility of these food standards. In that sense, this research uses cognitive methods to capture the attitudes of stakeholders towards the credibility of food standards and identify which sources of credibility might have a major influence.

The first objective of this experiment is to test the main hypothesis that benchmarking strategies have a positive influence on the credibility of national food standards in the presence of country-of-origin effects. The second objective is to attempt to design a structural model that identifies credibility sources associated with food standards and tests the effects of each one of these against the overall credibility of different national standards. Finally, this research provides suggestions for standard owners considering some aspects of credibility that may work in their favour to improve their administration and acceptance in international food markets.

\subsection{Proposed Model: Determinants of Food Standards' Credibility}

The following empirical model is proposed for the analysis of credibility of national food standards. As this is a primary stage of an empirical investigation about food standards credibility, most of the items and variables of the model have been selected based on the 
technical requirements of GFSI and GLOBALG.A.P. benchmarking processes and the ISEAL code for setting sustainable standards, since these guidance are considered an important industry reference for credibility.

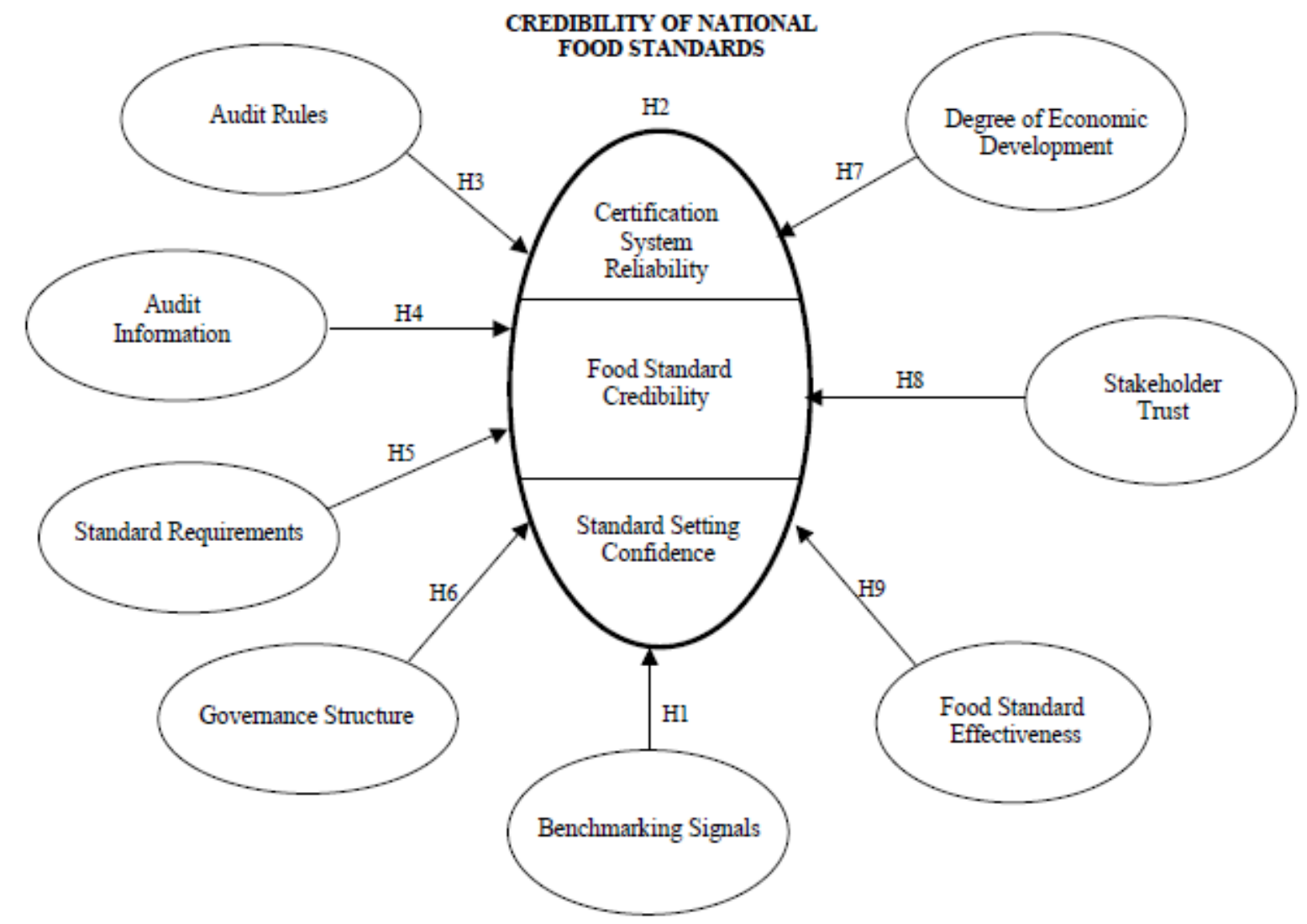

Source: Author's elaboration

Figure 5: Empirical Model: determinants of food standard's credibility

With this model I try to capture the overall credibility of a food standard by measuring certification system reliability and confidence on the standard setting process since both components are the main elements to develop within any quality assurance system. Also we use two variables to detect the origin effects (Bilckey and Nes, 1982), one based on the economic aspects and trust on the auditing process. The effectiveness of standards is added since this item has always been mentioned and discussed in stakeholders dialogues. Finally we include marketing efforts as a concept brought by Tuncer's study (2001). 


\subsubsection{Definition of Concepts}

\section{Credibility of National Food Standards}

The term "food standards" denotes the colloquial term used in the food industry to refer to a quality assurance scheme or programme. This consists of developments and management of a conformity assessment system and standards or requirements that the product has complied with. This construct is designed to capture the general perception about the credibility of national food standards for different countries. The countries selected were 4 developed countries (Australia, Italy, the United Kingdom and the United States of America) and 4 developing countries (China, Ghana, India and Mexico).

\section{Certification System Reliability}

"Certification Systems" are rules, procedures and management systems for carrying out certification (ISO 17000:2005). This construct is designed in such a way as to capture the perception about the reliability of national certification systems for different countries. The countries selected were 4 developed countries (Australia, Italy, the United Kingdom and the United States of America) and 4 developing countries (China, Ghana, India and Mexico).

\section{Standard Setting Confidence}

This construct refers to the process for developing a "standard", "which is a document that provides for common and repeated use, rules, guidelines or characterises for products or related processes and production methods, with which compliance is not mandatory" (ISEAL, 2010). This construct is designed to capture the perception about the confidence on the standard setting process held in different countries. The countries selected were 4 developed countries (Australia, Italy, the United Kingdom and the United States of America) and 4 developing countries (China, Ghana, India and Mexico).

\section{Audit Rules}

An "audit" is a systematic and functionally independent examination of a production site to determine whether activities and results comply with planned procedures established in a certification system and whether these procedures are implemented effectively (ISO 19011, GFSI Guidance Document and GlobalG.A.P. General Regulations v3.1 Annex 1). For this construct we explore the perception about the confidence and reliability of the certification systems based on their audit rules such as the audit frequency requirements, (annual vs. every 3 years); certification options (individual or group certification) and if the audit rules 
contemplate or not unannounced visits to the production facilities.

\section{Audit Information}

This construct intends to identify the opinion about the confidence or reliability of the information provided by food standards concerning audit results such as: certification status, production site information (e.g. area of the farm), and traceability.

\section{Standard Requirements}

This construct evaluates the confidence and reliability of the content of a food standard. This includes items like scope of standards concerning stage of the supply chain at which the criteria are set to cover (e.g. pre-farm or post-farm vs. pre-farm and post-farm); integration of principles (food safety or/and social and/or environmental).

\section{Governance Structure}

This construct assesses the confidence and reliability towards the organizations who develop and manage the food standards, these organizations take different types or forms like producer associations, certification bodies, NGOs, international organizations like ISO, FAO/WHO, governments or multi-stakeholder organizations, etc.

\section{Food Standards Effectiveness}

This construct measures the reliability on the food standards' success in reaching their objectives in assuring the control or prevention of risks associated to food production, such as food safety risks or environmental impact risks.

\section{Benchmarking Signals}

This construct intends to capture the effect of benchmarking signals (i.e. the adoption of GFSI and GLOBALG.A.P benchmarking process ) on the improvement of national food standards credibility.

\section{Marketing Efforts}

This construct intends to identify the influence of the promotion of food standards and preferences of stakeholders based on what they would recommend others to select as components of credible of food standards 


\section{Degree of Economic Development.}

This variable associates the effects of the country consideration of the respondence regarding food standards and the degree of economic development (Barkley and Nes, 1982): more developed countries (Major Advanced and Advanced Economies) and less developed countries (Developing Countries).

\subsubsection{Hypothesis}

As mentioned previously, the main hypothesis of this research is:

H1: Benchmarking signals have a positive influence on the credibility of national food standards in the presence of country-of-origin effects

In addition, based on the proposed empirical model, we will test the following secondary hypotheses:

H2: The national food standard's credibility is highly correlated to their certification system reliability and the confidence on their standard setting process.

H3: The higher the confidence in the audit rules, the higher the credibility of the national food standard.

H4: The higher the audit information reliability, the higher the credibility of the national food standard.

H5: The higher the confidence in the standard requirements, the higher the credibility of the national standard.

H6: The higher the confidence in the governance structure, the higher the credibility of the national standard.

H7: The lower the degree of economic development, the lower the credibility of national standards.

H8: The stronger the impact of the standards' marketing efforts on stakeholders, the higher the credibility of national standards.

H9: The higher the reliability of the effectiveness of food standards, the higher the credibility of national standards.

H0: There is no significant relationship between credibility sources and the overall credibility of national food standards (applies for all exogenous variables). 


\subsubsection{Research design}

A structured survey was designed for the collection of the data required for this research. To assess stakeholders' perception about the credibility of food standards, I constructed a set of statements using adjectives (e.g. reliability, confidence, trustworthiness) and dimensions (e.g. trustworthiness, expertise, attractiveness) that have been proposed in source credibility theory, (Hoveland and Kelley, 1953; Berlo, Lemert and Mertz, 1960/70; Withehead, 1968; Harmon and Corney, 1982; Roobina, 1990.) These statements are shown in Annex 1, and were evaluated using a 5 point Likert-scale (from I strongly agree to I strongly disagree). For each respondent, business and socio-demographic information was also recorded. The instrument was designed in the English language. Statements used in the questionnaire were formulated based on the experience of the author who worked for 5 years in a standard setting organization, combined with samples of credibility and country of origin statements used for other types of research. Also additional suggestions to the statements were obtained from a pilot test carried out with 13 respondents during the Fruit Logistica fair in Berlin held between the 3rd and 5th of February 2010. Some other outcomes of the pilot helped to improve the questions to make them more understandable and specific when required. One of the major changes made was to include specific country names when referring to "developed" or "developing countries". Another important improvement was to separate the perceptions towards national certification systems and national standards setting process besides asking about the credibility of food standards to avoid generalities and capture specific beliefs about the two components. Also new questions were incorporated in the survey to reflect the other interests of stakeholders in credibility. The amendments and improvements which resulted from the pilot were incorporated into the final instrument which was formatted so as to launch it as an online survey. The online survey was created using the GlobalPark software Enterprise Feedback Suite 7.0 (EFS Survey). An email inviting recipients to participate in the survey was sent out randomly to the info-mail contacts of GLOBALG.A.P on 26th March 2009.

\subsubsection{Data Analysis}

The data analysis was divided in different stages. The first phase corresponds to the preparation of the database to proceed with the analysis. The second phase involved a 
univariate analysis to obtain a statistical description of the sample. The third phase consists of a bivariate analysis for corroborating correlations between the different statements. In the fourth stage, a factor analysis was run to test and build up the different constructs included in the model. Finally a regression analysis was carried out to test the different hypotheses. All computations were performed using SPSS statistical software.

The data was collected into a SPSS file obtained from the EFS survey. Filters available in the EFS software were used to capture the data from only those responses where the whole survey was completed. In addition, consistency checks and extreme case checks were carried out to further clean the data. Afterwards, the descriptive statistics, frequencies and percentages were extracted for the demographic and business questions and additionally parameters such as mean $(\mu)$ and standard deviation $(\sigma)$ were calculated for the statements of the model.

Based on information from these preliminary results, a principal component factor analysis was carried out in order to obtain a success factor, which included both qualitative and quantitative statements. This factor was then split into three different success groups. Next, the distribution of the active and descriptive variables among the groups was analyzed. Afterwards, the author compared the variance distribution of success factors quoted by the respondents with the passive success factors extrapolated during the investigation. For each construct of the above-mentioned framework, the variables with the highest variance among the groups were then used as independent variables in a regression analysis towards the success groups (dependent variable).

Using the items assessed on the Likert scales, the underlying variables of the research model were captured. The relationships between the items were first tested through bivariate analysis as Pearson correlations and F-test mean comparisons. Then an explorative factor analysis using the principal component algorithm was carried out to test the level of fit and reliability of these statements. Varimax rotation was implemented to assure the independence of factors. Those items with double loading, those with loading below 0.5 , and items loading on improper factors were excluded from the final analysis. Bartlett's test of sphericity and KaiserMeyer-Olkin (KMO) as a Measure of Sampling Adequacy (MSA) were used to determine the matrix suitability for factor analysis. The internal consistency or reliability of the statements composing a construct was achieved with the Cronbach's Alpha test (Cronbach 1951). The chosen standardized factors were saved for subsequent analysis according to the Bartlett's method. 
Finally, a linear regression analysis with the method stepwise was carried out to measure the impact of the identified factors and individual statements on the attitudes of the producers towards the reliability of the organic standard. The goodness of fit was checked with the $\mathrm{R}^{2}$, and through the analysis of residuals and hypothesis testing. Statistical significance was checked by an F-test of the overall fit, followed by t-tests of the individual parameters. Additionally, an item-to-item correlation analysis was calculated for excluding any problem of multicollinearity, and the Durbin Watson test was calculated to check the absence of autocorrelation in the residuals. Finally, the proposed original model was modified to reflect the obtained results. 


\section{Chapter 5}

Results

The online questionnaire reached a sample of 835 contacts, there was a net response rate of $85.15 \%$ and a completion rate of $44.11 \%$ of respondents. The highest participation was observed during week 12 and 13 of 2010. During the whole period when the questionnaire was available online, there was an average participation of 24 respondents per day and 119 respondents per week. The questionnaire was completed in an average of 19 minutes. After checking each completed questionnaire and verifying consistency matters, there were 310 questionnaires considered as valid and useful for the analysis.

\section{$5.1 \quad$ Sample Description}

\subsubsection{Profile of Respondents}

Table 1 shows some characteristics about the sample as well as the demographic distribution of the respondents. From this table we can observe that over half of the respondents were male $(74 \%)$ and approximately a quarter were female. Both of these groups ranged between 25 years and 65 years of age, the largest concentration of participants being between the ages of 36 to 55 years old. Most of the respondents had a managerial position in their company (approx. 32\%) but there was also a significant participation of executives (15.8\%), technical personnel $(25.2 \%)$ and auditors (18.1\%). The majority (approx. 60\%) of the sample had 11 years or more experience in the food sector. In addition, almost one third of the respondents stated that they were quite involved with food standards. Altogether these general statistics show that the respondents are considered to be a good source of information for this research.

Concerning the origin of the respondents, the survey captured respondents who were born in 60 different countries. Almost half of them indicated that they were from a European country (51\%), $14.8 \%$ were born in a Latin American country and $10 \%$ in an African country. The other $8.7 \%$ respondents stated their birth origin to be North America ${ }^{33}$ and another $8.1 \%$ from Asia. Detailed information about country of birth is shown in Annex 2; here the frequency response highlights that the largest concentration of respondents came from countries such as Germany, the United Kingdom, the Netherlands, the United States of America and Australia.

\footnotetext{
${ }^{33}$ Canada and the United States 
Table 1: Demographic profile of respondents

\begin{tabular}{|c|c|c|c|}
\hline Variable & Category & Frequency & $\%$ \\
\hline \multirow[t]{3}{*}{ Gender } & Female & 76 & 24.52 \\
\hline & Male & 229 & 73.87 \\
\hline & No response & 5 & 1.61 \\
\hline \multirow[t]{6}{*}{ Age } & $25-35$ & 61 & 19.68 \\
\hline & $36-45$ & 89 & 28.71 \\
\hline & $46-55$ & 89 & 28.71 \\
\hline & $56-65$ & 47 & 15.16 \\
\hline & more than 65 & 12 & 3.87 \\
\hline & No response & 12 & 3.87 \\
\hline \multirow[t]{6}{*}{ Position in the Company } & Executive Director & 49 & 15.81 \\
\hline & Manager & 98 & 31.61 \\
\hline & Technical & 78 & 25.16 \\
\hline & Auditor & 56 & 18.06 \\
\hline & Other & 17 & 5.48 \\
\hline & No response & 12 & 3.87 \\
\hline \multirow[t]{5}{*}{ Years in the Food Industry } & 10 or fewer & 130 & 41.94 \\
\hline & $11-20$ & 69 & 22.26 \\
\hline & $21-30$ & 58 & 18.71 \\
\hline & more than 30 & 26 & 8.39 \\
\hline & No response & 27 & 8.71 \\
\hline \multirow[t]{6}{*}{ Involvement with Food Standards } & Very involved & 175 & 56.45 \\
\hline & Involved & 86 & 27.74 \\
\hline & Partially Involved & 36 & 11.61 \\
\hline & Little involved & 8 & 2.58 \\
\hline & Not involved & 5 & 1.61 \\
\hline & No response & 0 & 0 \\
\hline \multirow[t]{7}{*}{ Country of Birth (by Region) } & Africa & 31 & 10.00 \\
\hline & Asia & 26 & 8.39 \\
\hline & Australasia & 13 & 4.19 \\
\hline & Central and South America & 46 & 14.84 \\
\hline & Europe & 158 & 50.97 \\
\hline & North America & 27 & 8.71 \\
\hline & No response & 9 & 2.90 \\
\hline
\end{tabular}

Source: Author's elaboration

In order to have an economic and cultural perspective of the country of birth distribution, the different countries obtained from the survey were grouped according to the classification given by the International Monetary Funds World Economic Outlook Report, October $2009^{34}$ which divides countries by their economic situation and another categorization was built up based on the languages spoken in each of the countries.

\footnotetext{
${ }^{34}$ http://www.imf.org/external/pubs/ft/weo/2009/02/weodata/groups.htm\#oem Angelo Enrique Benjamin Lazo Galdos 


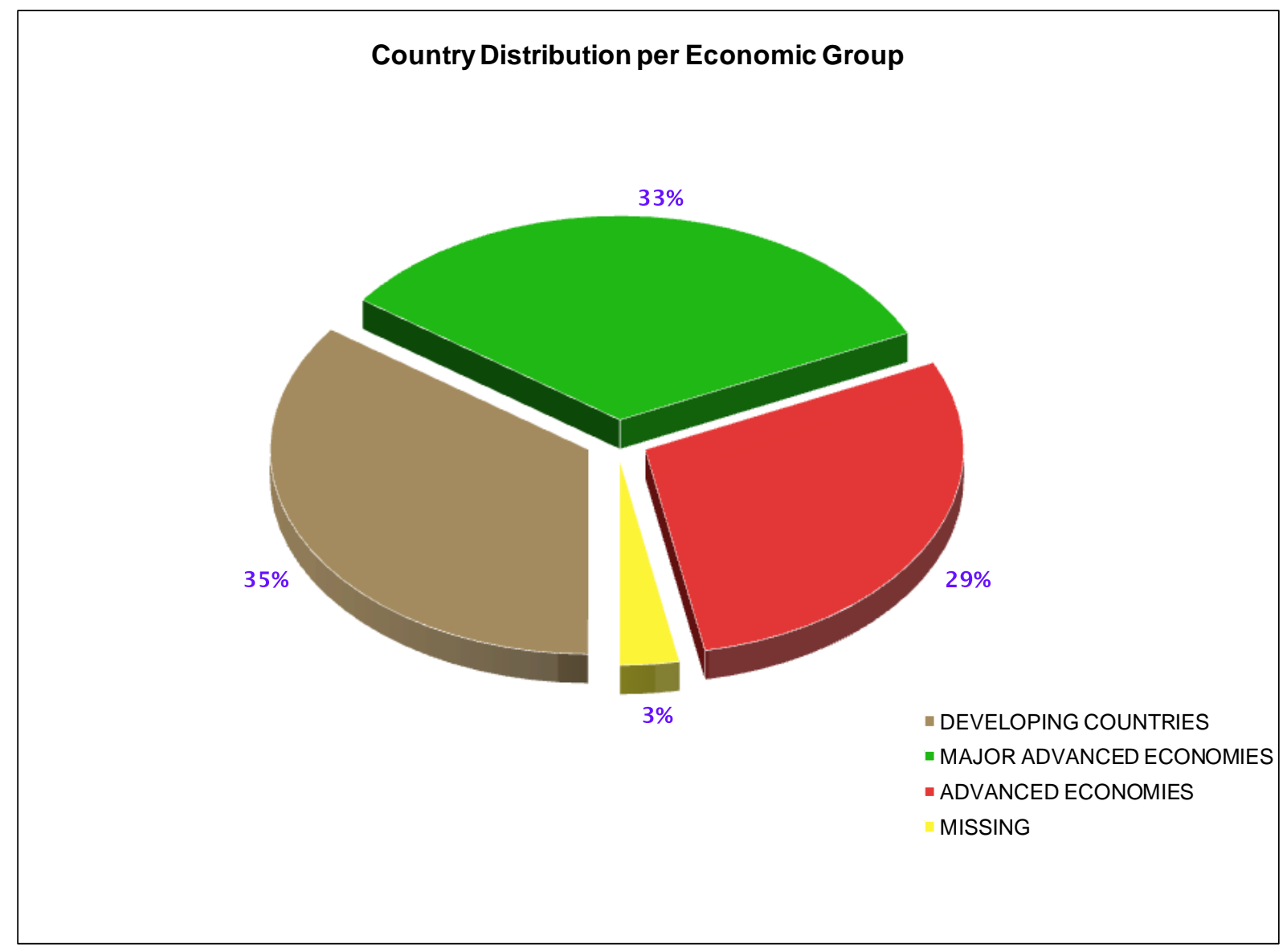

Source: Author's Elaboration

Figure 6: Country-of-birth distribution according to economic group

The first pie diagramme above (Figure 6) shows the country-of-birth distribution according to the economic groups. Here we can observe that countries are almost evenly distributed among the different groups. Nevertheless, $29 \%$ of respondents belonging to the group of advanced economies are distributed only in 6 countries including Canada, France, Germany, Italy, the United Kingdom and the United States of America. The group of major advanced economies contains $33 \%$ of the net sample and includes 22 countries such as the Netherlands, Australia, Spain as well as new growing economies like Taiwan, Singapore or the Czech Republic. 32 developing countries were the country of birth of $35 \%$ of the respondents, of which Egypt and Brazil had the highest number of respondents. (For more information see Annex 2).

The second pie diagramme below (Figure 7) shows the country of birth distribution according to language groups. 30\% of the respondents were born in an English-speaking countries, 28\% of the respondent's mother tongue is of Latin origin (Spanish, French, Portuguese and Italian), $22 \%$ are from countries with Germanic languages (including about 8 different European 
languages), 7\% speak an Asian language and 6\% speak Arabic. 4\% speak other languages including Greek, Turkish, Russian, etc. (for more information see Annex 4).

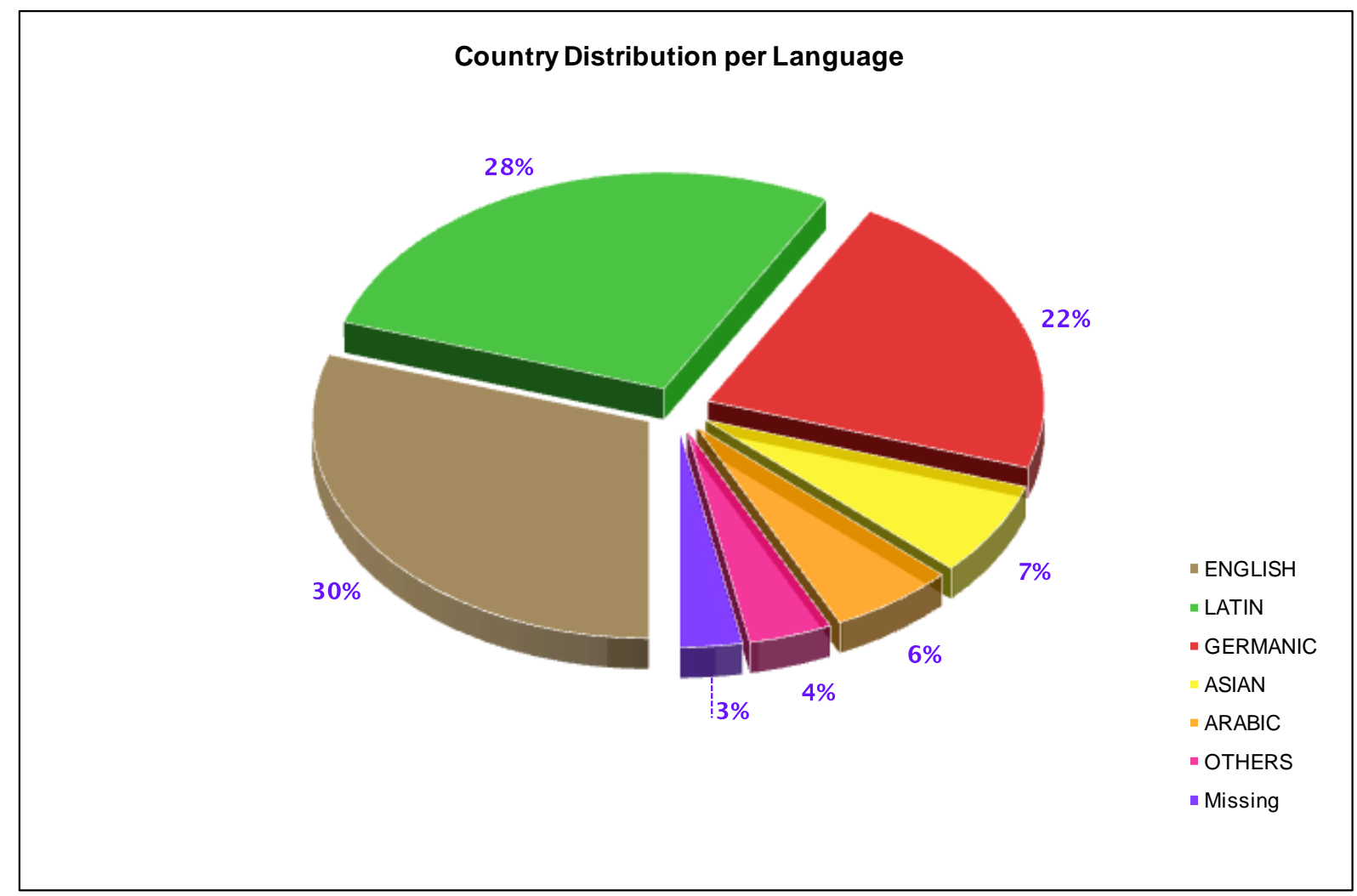

Source: Author's Elaboration

Figure 7: Country of birth distribution according to language

\subsubsection{Company Characteristics}

Table 2 illustrates the professional backgrounds of the respondents from different sorts of companies, with different business types, covering not only activities at different stages of the food supply chain (from supplying to retailing) but also includes various service providers, developing agencies (private and public), input suppliers, researchers etc. The largest group of respondents work in service supplier companies (46.1\%) that offer services like certification, laboratory analysis, food safety consultancy, accreditation, etc. A second group of respondents (42.9\%) represent food supply chain agents and are distributed as follows: Retailer/food Service (8.7\%), Manufacturer/Packer (9.7\%), Trader (11.9\%) and Food Supplier $(12.6 \%)$. A third group of respondents (9\%) work in companies dedicated to other activities in relation to the food industry, here the most representative are public/private development agencies (3.2\%), input supplying companies (2.6\%) and research organizations (1.9\%). 
In terms of annual sales, almost $70 \%$ of respondents indicated that they work in medium or small companies with an annual turnover that ranges between less than 1 million Euros up to less than 500 million Euros. Around $25 \%$ of the sample work in large companies where annual sales range between 500 million Euros to more than 1 billion Euros. Concerning the location of the companies' headquarters, Table 2 also shows the distribution of the countries grouping the companies according to their geographical regions. Here more than half of the sample indicated that their headquarter location is a European country, meanwhile $12 \%$ of the respondents answered that they were located in a country in Central/ South America and 10\% in North America. The rest of respondents (22\%) said that the location of their headquarter office is either in Asia (9\%), Australasia (6.8\%) or Africa (6.5\%).

Table 2: Companies' main features

\begin{tabular}{llrr}
\hline Variable & Category & Frequency & \% \\
\hline Business Type & Retailer/Food Service & 27 & 8.7 \\
& Manufacturer/Packer & 30 & 9.7 \\
& Trader & 37 & 11.9 \\
& Food Supplier & 39 & 12.6 \\
& Service Provider & 143 & 46.1 \\
& Input Supplier & 8 & 2.6 \\
& Public/Private Agencies & 10 & 3.2 \\
& Research Organization & 6 & 1.9 \\
& Other & 4 & 1.3 \\
\hline Annual Sales (EUR) & Less than 1 million & 75 & 24.2 \\
& 1 million to less 50 million & 99 & 31.9 \\
& 50 million to less 100 million & 39 & 12.6 \\
& 100 million to less 500 million & 19 & 6.1 \\
& 500 million to less 1 billion & 14 & 4.5 \\
& 1 billion or more & 37 & 11.9 \\
\hline Headquarters Location (Region) & Africa & 20 & 6.5 \\
& Asia & 28 & 9.0 \\
& Australasia & 21 & 6.8 \\
& Central and South America & 38 & 12.3 \\
& Europe & 163 & 52.6 \\
& North America & 32 & 10.3 \\
\hline
\end{tabular}

Source: Author's elaboration

It should be noted that there is a strong correlation between the location of the company headquarters and the country of birth of the respondents (Pearson $0.575^{* *}$ at 0.001 significance). Therefore we can assume that perceptions of respondents about food standards might not differ even though some of the respondents work outside their country of birth. 


\subsubsection{Certified Food Purchase}

Figure 8 illustrates the buyer's demand of different food standards. In this figure the $\mathrm{x}$ axis shows the food standards demanded by the buyers while the y axis shows both the number of buyers demanding each one of the food standards (light blue bar) and the average percentage of the certified product purchased (red bars). For this question the survey has identified a total of 110 buyers, of which most demand several standard certifications at the same time. Out of these 110 buyers, 85 demand GLOBALG.A.P. in an average of 52\% of their total product purchased. Likewise, 63 out of the 110 buyers demand ORGANIC products in an average of $45 \%$ of their total purchase, and 42 buyers purchase FAIR TRADE products in an average of $35 \%$ of total products purchase. RAIN FOREST ALLIANCE labelled food is demanded by 33 buyers in an average of $36 \%$ of their total purchase. 51 buyers also demand BRC certified food, representing an average of $44 \%$ of their total product purchase. Meanwhile, 37 buyers also demand ISO 22000 certification for an average of $42 \%$ of their total food purchased and 47 request IFS certifications representing in 38\% of their total product purchase. SQF 2000 standards is demanded by 30 buyers who on average represented $34 \%$ of the total purchase. Moreover, other standards like TESCO NATURE, FIELD TO FORK, HACCP etc, were also mentioned as being demanded by a smaller group of buyers.

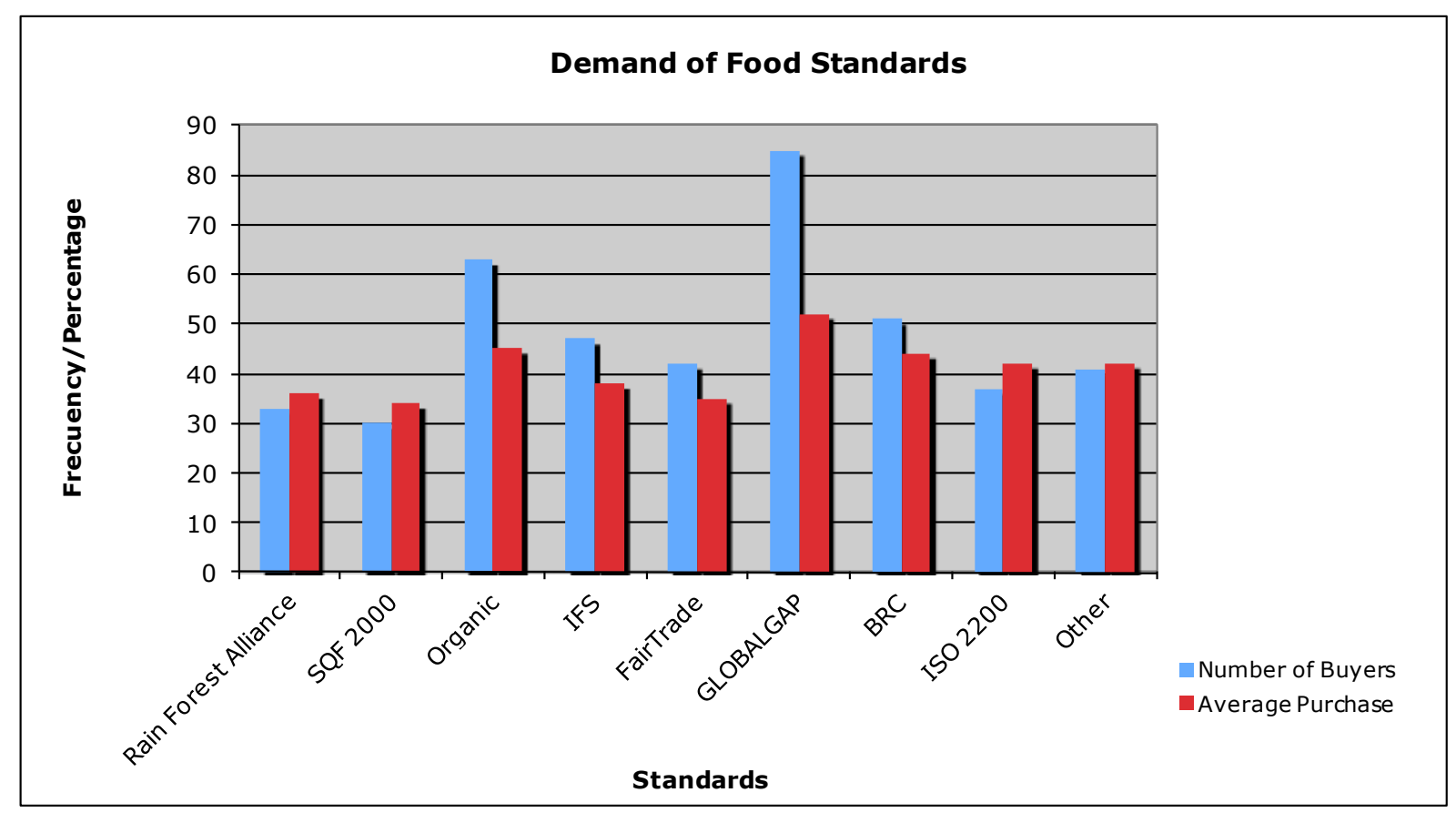

Source: Author's elaboration

Figure 8: Demand by buyers of food standards 
When buyers were asked about the reason why they require food standards from their suppliers, they give priority to satisfying customer demand and maintaining market access, followed by the ensuring due diligence and maintaining the company reputation.

\subsection{Construct Measurement}

In total, twelve variables were proposed in the theoretical model and presented to the respondents. The following section presents the results of the assessment of these constructs. To that end, mean $(\mu)$ and standard deviation $(\sigma)$ are mixed with answers to open-ended questions (Annex 1), as well as further comments of the farmers, and information from the additional interviews, all in order to provide a valid explanation for the obtained results.

\subsubsection{Credibility of National Food Standards}

The credibility of national food standards was evaluated for eight different countries. The results show mean values ranging between 1.60 and 3.40 and standard deviation levels between 0.85 and 1.55 indicating a high variance of responses about the credibility of food standards in the different countries (Table 3). Overall we observe that food standards from developed countries have higher credibility than those from developing countries.

Table 3: Credibility of national food standards

\begin{tabular}{|c|c|c|c|c|c|c|c|}
\hline & & & $\begin{array}{c}\text { Very } \\
\text { Credible } \\
\end{array}$ & Credible & $\begin{array}{c}\text { Neither } \\
\text { /nor }\end{array}$ & $\begin{array}{l}\text { Slightly } \\
\text { Credible }\end{array}$ & $\begin{array}{c}\text { Not } \\
\text { Credible }\end{array}$ \\
\hline & & & 1 & 2 & 3 & 4 & 5 \\
\hline Country & $\mu$ & $\sigma$ & \multicolumn{5}{|c|}{ Frequency (\%) } \\
\hline Australia & 1.77 & 0.91 & 23.9 & 51.0 & 12.6 & 2.9 & 0.3 \\
\hline China & 3.36 & 1.50 & 1.9 & 11.6 & 24.2 & 25.8 & 27.1 \\
\hline Ghana & 3.20 & 1.54 & 1.3 & 9.4 & 29.0 & 26.1 & 21.6 \\
\hline India & 3.01 & 1.46 & 2.3 & 12.3 & 32.9 & 26.5 & 13.9 \\
\hline Italy & 2.35 & 1.16 & 9.0 & 39.7 & 27.7 & 11.9 & 3.2 \\
\hline Mexico & 2.73 & 1.34 & 2.9 & 20.0 & 37.4 & 21.0 & 6.8 \\
\hline United Kingdom & 1.63 & 0.84 & 43.5 & 42.6 & 5.8 & 3.9 & 0.3 \\
\hline United States & 1.99 & 1.07 & 22.9 & 43.9 & 16.5 & 7.7 & 1.6 \\
\hline
\end{tabular}

The food standards in the United Kingdom appear to have the highest credibility $(\mu=1.63)$ where $43.5 \%$ of the respondents consider them very credible, followed by those from Australia $(\mu=1.77)$ and the United States $(\mu=1.99)$ and Italy $(\mu=2.35)$. Those food standards 
from China were considered to be the less credible $(\mu=3.63)$; here the largest group of respondents $(27.1 \%)$ considered that these standards are not credible. On the other hand, countries like Mexico $(\mu=2.73)$, India $(\mu=3.01)$ and Ghana $(\mu=3.20)$ fall in an intermediate level of credibility.

Table 4: Reliability of national certification systems

\begin{tabular}{|c|c|c|c|c|c|c|c|}
\hline & & & Reliable & $\begin{array}{l}\text { Slightly } \\
\text { reliable }\end{array}$ & $\begin{array}{l}\text { Neither } \\
\text { /nor }\end{array}$ & $\begin{array}{l}\text { Slightly } \\
\text { unreliable }\end{array}$ & Unreliable \\
\hline & & & 1 & 2 & 3 & 4 & 5 \\
\hline Country & $\mu$ & $\sigma$ & \multicolumn{5}{|c|}{ Frequency (\%) } \\
\hline Australia & 1.44 & 0.93 & 49.7 & 25.5 & 11.6 & 1.3 & 0.6 \\
\hline China & 3.11 & 1.64 & 3.9 & 13.2 & 22.9 & 22.3 & 24.5 \\
\hline Ghana & 3.00 & 1.54 & 3.5 & 11.0 & 32.3 & 22.6 & 17.4 \\
\hline India & 2.83 & 1.49 & 4.2 & 16.5 & 31.3 & 22.6 & 12.3 \\
\hline Italy & 2.02 & 1.24 & 22.6 & 31.0 & 24.2 & 6.8 & 3.5 \\
\hline Mexico & 2.53 & 1.45 & 6.1 & 20.6 & 32.9 & 17.7 & 7.1 \\
\hline United Kingdom & 1.31 & 0.80 & 63.5 & 20.0 & 6.5 & 1.6 & 0.3 \\
\hline United States & 1.63 & 1.13 & 43.5 & 24.5 & 14.2 & 4.2 & 2.3 \\
\hline
\end{tabular}

Moreover, the reliability of national certification systems in the eight countries was also evaluated. The results show mean values ranging between 1.30 and 3.10 and standard deviation levels between 0.80 and 1.65 , indicating a high variance of responses about the reliability of certification systems in the different countries (Table 4). Overall, we observe that certification systems from developed countries have higher reliability than those from developing countries. The certification systems of the United Kingdom appear to have the highest reliability $(\mu=1.31)$ where $63.5 \%$ of the respondents consider them very reliable, followed by those from Australia $(\mu=1.44)$, the United States $(\mu=1.63)$ and Italy $(\mu=2.02)$. Those certification systems from China were considered to be the least reliable $(\mu=3.11)$; here the largest group of respondents, $24.5 \%$, considered that these standards are unreliable. On the other hand, countries like Mexico $(\mu=2.53)$, India $(\mu=2.83)$ and Ghana $(\mu=3.00)$ were most frequently ranked intermediate (neither/nor).

Furthermore, the confidence in national standard setting of the eight countries was evaluated. The results show mean values ranging between 1.40 and 3.05 and standard deviation levels between 0.85 and 1.60 indicating a high variance of responses about the confidence in the standard setting process in the different countries (Table 5). Overall we observe that there 
Table 5: Confidence in national standard setting

\begin{tabular}{|c|c|c|c|c|c|c|c|}
\hline & & & $\begin{array}{c}\text { I have } \\
\text { confidence }\end{array}$ & $\begin{array}{c}\text { I have } \\
\text { slight } \\
\text { confidence }\end{array}$ & $\begin{array}{c}\text { Neither } \\
\text { /nor }\end{array}$ & $\begin{array}{l}\text { I have slight } \\
\text { no } \\
\text { confidence }\end{array}$ & $\begin{array}{l}\text { I have no } \\
\text { confidence }\end{array}$ \\
\hline & & & 1 & 2 & 3 & 4 & 5 \\
\hline Country & $\mu$ & $\sigma$ & \multicolumn{5}{|c|}{ Frequency (\%) } \\
\hline Australia & 1.48 & .95 & 50.3 & 22.6 & 14.5 & 1.9 & .3 \\
\hline China & 3.04 & 1.58 & 4.5 & 19.4 & 19.7 & 23.9 & 21.3 \\
\hline Ghana & 2.93 & 1.51 & 5.5 & 16.1 & 30.3 & 20.0 & 16.8 \\
\hline India & 2.75 & 1.41 & 5.5 & 23.5 & 29.7 & 20.0 & 10.6 \\
\hline Italy & 2.04 & 1.18 & 21.9 & 34.5 & 23.2 & 8.1 & 2.3 \\
\hline Mexico & 2.49 & 1.37 & 8.4 & 25.5 & 29.7 & 18.7 & 5.2 \\
\hline United Kingdom & 1.38 & .86 & 60.6 & 20.6 & 8.4 & 2.3 & .3 \\
\hline United States & 1.69 & 1.08 & 40.6 & 30.0 & 12.9 & 5.8 & 1.3 \\
\hline
\end{tabular}

is more confidence in the standard setting processes held in developed countries than those held in developing countries. The standard setting held in the United Kingdom appear to have the highest confidence $(\mu=1.38)$ where $60.6 \%$ of the respondents have confidence, followed by those held in Australia $(\mu=1.48)$, the United States $(\mu=1.69)$ and Italy $(\mu=2.04)$. The largest group of respondents (23.9\%) also had slight /no confidence on the standard setting process in China $(\mu=3.11)$. On the other hand, respondents considered having intermediate confidence in the standard setting process held in countries like Mexico $(\mu=2.49)$, India $(\mu=2.75)$ and Ghana $(\mu=2.93)$.

\subsubsection{Credibility Improvement through Benchmarking Systems}

Respondents' opinions were evaluated on how likely it would be that the credibility of the food standards of the eight countries could be improved if they would become benchmarked under the benchmark systems offered by GFSI and GLOBALG.A.P. The results show mean values ranging between 1.90 and 2.15 and standard deviation levels between 1.14 and 1.40, indicating a high variance of responses about this specific issue (Table 5). Overall, it seems that adopting a benchmark system would be likely to improve the credibility of the national food standards. In fact, Italy $(\mu=1.90)$ was noted to have greater benefit from the benchmark outcome where $45 \%$ of the respondents expected that an improvement in credibility would be likely. On other hand, China appears to be slightly less likely to improve credibility of their food standards $(\mu=1.38)$ than the rest of the countries whose credibility is shown to improve in a more even tendency. 
Table 6: Likelihood of credibility improvement through benchmark systems

\begin{tabular}{|l|cc|ccccc|}
\hline \multicolumn{2}{|c}{} & & $\begin{array}{c}\text { Extremely } \\
\text { likely }\end{array}$ & \multicolumn{2}{c}{$\begin{array}{c}\text { Neither } \\
\text { lnor }\end{array}$} & $\begin{array}{c}\text { Extremely } \\
\text { unlikely }\end{array}$ \\
\cline { 4 - 8 } & & & 1 & 2 & 3 & 4 & 5 \\
\hline Country & $\mu$ & $\sigma$ & & & Frequency (\%) & & \\
\hline Australia & 1.97 & 1.21 & 23.5 & $\mathbf{3 4 . 8}$ & 18.4 & 9.4 & 2.3 \\
China & 2.15 & 1.39 & 23.5 & $\mathbf{2 9 . 0}$ & 15.5 & 14.8 & 5.5 \\
Ghana & 2.04 & 1.32 & 24.5 & $\mathbf{3 0 . 6}$ & 15.8 & 13.5 & 3.2 \\
India & 2.07 & 1.27 & 22.6 & $\mathbf{3 5 . 5}$ & 15.5 & 12.3 & 3.5 \\
Italy & 1.90 & 1.14 & 21.0 & $\mathbf{4 5 . 2}$ & 12.3 & 7.7 & 2.3 \\
Mexico & 1.96 & 1.23 & 23.9 & $\mathbf{3 4 . 2}$ & 18.7 & 8.4 & 2.9 \\
United Kingdom & 1.98 & 1.22 & 26.5 & $\mathbf{3 2 . 9}$ & 17.4 & 10.6 & 2.3 \\
United States & 1.98 & 1.18 & 23.2 & $\mathbf{3 6 . 8}$ & 18.1 & 9.4 & 1.9 \\
\hline
\end{tabular}

Source: Online survey 2010

\subsubsection{Expectations about Credibility of Food Standards}

The expectations about credibility of food standards was evaluated using the concepts of reliability, confidence, and trustworthiness towards different credibility sources such as food standards effectiveness; audit rules, information and economic development; standard requirements, governance structure and stakeholder trust.

The food standards effectiveness was measured with statements concerning the expectation of the general reliability among food standards to more specific aspects such as the effectiveness of food standards in minimizing food safety risks and environmental impact. The results show mean values ranging between 2.02 and 3.37 with high levels of standard deviation ranging from 0.83 to 1.19 , indicating high variance of opinions about the expectations on the effectiveness of food standards (Table 7). While $37.1 \%$ of the respondents disagree that most food standards have the same level of reliability, 25.2\% agreed with this statement. Around half of the respondents believed in the effectiveness of food standards. $60 \%$ of the respondents agreed that food standards are reliable in minimizing food safety risks and 50\% thought that food standards can help to minimize environmental impacts.

In the case of the reliability of the audit rules, means varied from 1.90 and 3.60. The levels of standard deviation are high, indicating that contrasting opinions are held on this topic (Table 8). In the first place, it seems that the type of certification implemented in the food standard 
Table 7: Results of the statements assessing the reliability of the food standards effectiveness

\begin{tabular}{|c|c|c|c|c|c|c|c|}
\hline & $\begin{array}{c}\text { I } \\
\text { strongly } \\
\text { agree }\end{array}$ & I agree & $\begin{array}{c}\text { Neither / } \\
\text { nor }\end{array}$ & I disagree & $\begin{array}{l}\text { I strongly } \\
\text { disagree }\end{array}$ \\
\hline & & & 1 & 2 & 3 & 4 & 5 \\
\hline Statements & $\mu$ & $\sigma$ & \multicolumn{5}{|c|}{ Frequency (\%) } \\
\hline $\begin{array}{l}\text { Most food standards have the same } \\
\text { level of reliability }\end{array}$ & 3.25 & 1.19 & 4.5 & 25.2 & 18.4 & 37.1 & 13.2 \\
\hline $\begin{array}{l}\text { Food standards are reliable in } \\
\text { minimizing food safety risks }\end{array}$ & 2.02 & 0.83 & 21.9 & 59.4 & 11.0 & 5.8 & 1.0 \\
\hline $\begin{array}{l}\text { Food standards cannot help to } \\
\text { minimize environmental impacts }\end{array}$ & 3.37 & 1.12 & 6.1 & 17.1 & 16.1 & 50.0 & 9.7 \\
\hline
\end{tabular}

Source: Online survey 2010

would not make it more or less reliable, but looking closely at the data it seems that individual certification is preferred over group certification. While clearly more than half of the respondents considered that individual certification requirements make food standards more credible, they are divided in 30\% agreement and disagreement when asked if group certification makes food standards less reliable. Secondly, the data shows that food standard audits are considered to be more reliable when they are required in a higher frequency. On the one hand, more than half of the respondents agreed with the statement that food standards are more reliable when they require annual inspections of producers.

Table 8: Results of the statements assessing the reliability of audit rules

\begin{tabular}{|c|c|c|c|c|c|c|c|}
\hline & $\begin{array}{c}\text { I } \\
\text { strongly } \\
\text { agree }\end{array}$ & I agree & $\begin{array}{c}\text { Neither / } \\
\text { nor }\end{array}$ & I disagree & $\begin{array}{l}\text { I strongly } \\
\text { disagree }\end{array}$ \\
\hline & & & 1 & 2 & 3 & 4 & 5 \\
\hline Statements & $\mu$ & $\Sigma$ & \multicolumn{5}{|c|}{ Frequency (\%) } \\
\hline $\begin{array}{l}\text { Food standards are more credible } \\
\text { when they require an audit of each } \\
\text { individual producer }\end{array}$ & 2.16 & 1.13 & 30.6 & 41.6 & 8.4 & 16.1 & 2.6 \\
\hline $\begin{array}{l}\text { Certification of producers groups } \\
\text { makes food standards less reliable }\end{array}$ & 3.03 & 1.20 & 10.0 & 29.0 & 18.1 & 32.6 & 10.0 \\
\hline $\begin{array}{l}\text { A food standard is more reliable } \\
\text { when it requires producers to be } \\
\text { inspected every year. }\end{array}$ & 1.93 & 1.04 & 37.1 & 42.9 & 7.7 & 8.1 & 2.9 \\
\hline $\begin{array}{l}\text { I do not have a problem if food } \\
\text { standards require producers to be } \\
\text { inspected every } 3 \text { years. }\end{array}$ & 3.57 & 1.28 & 7.7 & 17.4 & 7.7 & 41.3 & 25.2 \\
\hline $\begin{array}{l}\text { I prefer food standards that require at } \\
\text { least one announced audit of } \\
\text { producers per year. }\end{array}$ & 2.13 & 1.03 & 26.5 & 46.1 & 13.5 & 10.6 & 2.3 \\
\hline $\begin{array}{l}\text { I would still have confidence in food } \\
\text { standards that do not require } \\
\text { announced audits of producers. }\end{array}$ & 3.24 & 1.27 & 6.5 & 27.1 & 13.5 & 35.2 & 16.5 \\
\hline
\end{tabular}

On the other hand, another $65 \%$ of the sample were shown to have a problem when food standards required inspections of producers every 3 years. Furthermore, respondents also 
showed high preference for the implementation of audit requirements: more than $70 \%$ agreed to this statement and nearly $50 \%$ stated that they would not have confidence in food standards that do not require announced audits.

Concerning the answers referring to reliability of the audit information, the means varied from 1.55 to almost 4.00 , and the levels of standard deviations ranged from 0.75 up to nearly 1.20 demonstrating the existence of less consensus towards some statements than others (Table 9). Despite the fact that there is the indication that most respondents (around 70\%) believe the information provided by food standards, they considered it necessary that this information should always be precise and accurate. These positions are reflected when more than $65 \%$ disagree with the statement that it is not necessary to have precise information about the certified area; and also when almost $75 \%$ of the respondents agreed they do not rely on certification systems that cannot provide accurate information about the certified products.

Table 9: Results of the statements assessing the reliability of the audit information

\begin{tabular}{|c|c|c|c|c|c|c|c|}
\hline & $\begin{array}{c}\text { I } \\
\text { strongly } \\
\text { agree }\end{array}$ & I agree & $\begin{array}{c}\text { Neither / } \\
\text { nor }\end{array}$ & I disagree & $\begin{array}{l}\text { I strongly } \\
\text { disagree }\end{array}$ \\
\hline & & & 1 & 2 & 3 & 4 & 5 \\
\hline Statement & $\mu$ & $\sigma$ & \multicolumn{5}{|c|}{ Frequency (\%) } \\
\hline $\begin{array}{l}\text { I believe in the information provided } \\
\text { by food standards (e.g. current } \\
\text { certification status of products) }\end{array}$ & 2.20 & 1.17 & 13.5 & 59.4 & 19.0 & 6.5 & 1.0 \\
\hline $\begin{array}{l}\text { It is not necessary to have the precise } \\
\text { information about the area of a } \\
\text { certified farm }\end{array}$ & 3.65 & 1.18 & 4.2 & 17.1 & 11.0 & 42.3 & 24.8 \\
\hline $\begin{array}{l}\text { I do not rely on food certification } \\
\text { systems which cannot provide } \\
\text { accurate information about the } \\
\text { certified products }\end{array}$ & 2.08 & 0.99 & 25.8 & 49.0 & 11.3 & 11.0 & 1.3 \\
\hline $\begin{array}{l}\text { Food standards which cannot trace } \\
\text { products back into the supply chain } \\
\text { are not trustworthy }\end{array}$ & 1.87 & 0.97 & 39.0 & 42.9 & 8.4 & 6.8 & 1.9 \\
\hline $\begin{array}{l}\text { It should be always possible to } \\
\text { identify the origin of the certified } \\
\text { products }\end{array}$ & 1.55 & 0.74 & 53.2 & 39.0 & 3.5 & 2.9 & .3 \\
\hline $\begin{array}{l}\text { I have confidence that certified } \\
\text { products are not mixed with non } \\
\text { certified products }\end{array}$ & 2.91 & 1.13 & 9.4 & 31.3 & 24.5 & 27.1 & 7.4 \\
\hline $\begin{array}{l}\text { A credible food certification system } \\
\text { does not have to provide full } \\
\text { traceability }\end{array}$ & 3.99 & 1.08 & 3.9 & 8.1 & 4.8 & 48.4 & 34.2 \\
\hline
\end{tabular}

Source: Online survey 2010

Moreover, despite the fact that many respondents have confidence in the segregation between certified products and non certified products (around 40\%) there appears to be an lack of consensus since the same proportion of respondents did not have confidence in the segregation of products. The latter position could be corroborated when nearly $90 \%$ of the 
respondents agreed that it should always be possible to identify the origin of the certified product and another $90 \%$ considered that in order to be a credible food certification system this should provide full traceability.

With respect to the confidence in the degree of economic development, the means varied from 2.70 to almost 3.40 , with high standard deviation levels indicating variance of options towards the several statements (Table 10). In first place, there is a higher confidence in certification systems from developed countries than those from developing countries. This is also reflected in the greater confidence that respondents demonstrated for certified food coming from developed countries than those coming from developing countries. In this respect, around $40 \%$ of the sample disagree that certified food products coming from developing countries are more trustworthy than similar products available in developed countries; and almost 50\% recommended buying certified food products from developed countries rather than from developing countries.

Table 10: Results of the statements assessing the confidence in degree of economic development

\begin{tabular}{|c|c|c|c|c|c|c|c|}
\hline & $\begin{array}{c}\text { I } \\
\text { strongly } \\
\text { agree }\end{array}$ & I agree & $\begin{array}{c}\text { Neither / } \\
\text { nor }\end{array}$ & I disagree & $\begin{array}{l}\text { I strongly } \\
\text { disagree }\end{array}$ \\
\hline & & & 1 & 2 & 3 & 4 & 5 \\
\hline Statement & $\boldsymbol{\mu}$ & $\sigma$ & \multicolumn{5}{|c|}{ Frequency (\%) } \\
\hline $\begin{array}{l}\text { Food certification systems } \\
\text { established in developed countries } \\
\text { are always carefully designed by } \\
\text { trustworthy technical experts }\end{array}$ & 2.81 & 1.11 & 8.1 & 32.3 & 29.7 & 22.3 & 6.1 \\
\hline $\begin{array}{l}\text { Certified food products coming from } \\
\text { developing countries are more } \\
\text { trustworthy than similar products } \\
\text { available in developed countries }\end{array}$ & 3.30 & 1.02 & 3.9 & 15.8 & 31.6 & 39.4 & 8.4 \\
\hline $\begin{array}{l}\text { Whenever possible, I would } \\
\text { recommend buying certified food } \\
\text { products from developed countries }\end{array}$ & 2.70 & 1.23 & 14.5 & 32.9 & 22.9 & 19.4 & 8.7 \\
\hline $\begin{array}{l}\text { Auditors in developed countries are } \\
\text { more reliable than auditors in } \\
\text { developing countries }\end{array}$ & 3.11 & 1.26 & 9.4 & 22.9 & 21.6 & 31.3 & 13.2 \\
\hline $\begin{array}{l}\text { I have less confidence in certification } \\
\text { bodies in developing countries than } \\
\text { those in developed countries }\end{array}$ & 2.83 & 1.22 & 11.3 & 34.8 & 19.4 & 24.2 & 9.4 \\
\hline $\begin{array}{l}\text { I would not suggest buying food } \\
\text { products certified by a food standard } \\
\text { of a developing country }\end{array}$ & 3.39 & 1.13 & 3.9 & 12.3 & 26.5 & 42.9 & 11.9 \\
\hline
\end{tabular}

On the other hand, $46 \%$ of the respondents showed they have less confidence in certification bodies from developing countries than those from developed countries. However, another $45 \%$ disagree that auditors in developed countries are more reliable than auditors from 
developing countries. Except for the latter, the results confirms the cultural affinity of the sample towards developed countries than to developing countries (Berkley and Nes, 1982)

Regarding the reliability of standard requirements, survey results show that the means range from 2.07 to 3.65 , with high standard deviation levels indicating variance of options towards the several statements (Table 11). In first place, it seems that there is no significant consensus about the coverage of the food standards requirements along the supply chain since there are similar proportions of respondents $(29 \%)$ who agree and disagree that food standards that are focused on a single stage of the supply chain are trustworthy. But, on the other hand, there is clear disagreement when more than $50 \%$ of the sample consider those food standards covering a wide range of the supply chain unreliable. A similar situation occurs when we observe that respondents are equally divided when they asked about the specificity of the type of requirements in food standards. Again proportions between disagreement and agreement

Table 11: Results of the statements assessing the reliability of the standard requirements

\begin{tabular}{|c|c|c|c|c|c|c|c|}
\hline & $\begin{array}{c}\text { I } \\
\text { strongly } \\
\text { agree }\end{array}$ & I agree & $\begin{array}{c}\text { Neither / } \\
\text { nor }\end{array}$ & I disagree & $\begin{array}{l}\text { I strongly } \\
\text { disagree }\end{array}$ \\
\hline & & & 1 & 2 & 3 & 4 & 5 \\
\hline Statement & $\mu$ & $\sigma$ & \multicolumn{5}{|c|}{ Frequency (\%) } \\
\hline $\begin{array}{l}\text { Food standards that focus on one } \\
\text { single stage of the supply chain (e.g. } \\
\text { pre or post farm) are trustworthy }\end{array}$ & 2.82 & 1.14 & 8.7 & 29.7 & 26.1 & 28.7 & 4.2 \\
\hline $\begin{array}{l}\text { Food standards that cover a wide } \\
\text { range of the supply chain (e.g. pre } \\
\text { and post farm) are not reliable }\end{array}$ & 3.50 & 1.16 & 5.5 & 10.6 & 17.1 & 50.6 & 13.9 \\
\hline $\begin{array}{l}\text { Food standards are more reliable } \\
\text { when they are focused on only one } \\
\text { type of requirements (e.g. food } \\
\text { safety) }\end{array}$ & 2.86 & 1.24 & 12.9 & 26.1 & 20.6 & 31.6 & 6.5 \\
\hline $\begin{array}{l}\text { Credible food standards will not } \\
\text { integrate food safety, environment } \\
\text { and social requirements }\end{array}$ & 2.24 & 1.22 & 29.0 & 35.8 & 12.9 & 15.2 & 4.8 \\
\hline $\begin{array}{l}\text { Food standards which could have } \\
\text { several interpretations among } \\
\text { auditors are reliable }\end{array}$ & 3.65 & 1.19 & 2.6 & 14.5 & 12.6 & 44.2 & 23.9 \\
\hline $\begin{array}{l}\text { Food standards are more credible } \\
\text { when they can be adopted in } \\
\text { different local conditions }\end{array}$ & 2.07 & 1.00 & 23.5 & 51.9 & 9.0 & 11.6 & 1.3 \\
\hline
\end{tabular}

Source: Online survey 2010

appear the same about considering a food standard more reliable when it is focused on only one specific type of requirement. On the other hand, there are expectations among $60 \%$ of the respondents that credible food standards can integrate different types of requirements. However, more than $50 \%$ of the respondents considered that reliable food standards should not have several interpretations and should be able to be adopted in different local conditions. 
Furthermore, results about the confidence in the type of governance structure leading food standards show means ranging from about 2.20 to nearly 3.70 , with high standard deviation levels indicating high variance among responses towards the several statements (Table 12). Respondents have significant confidence in food standards that are developed by producer organizations, international organizations and certification bodies, and the majority of the respondents disagree that governments should be the only responsible agent in establishing food standards, and that NGOs are the right organizations to develop standards.

Table 12: Results of the statements assessing confidence in governance structure

\begin{tabular}{|c|c|c|c|c|c|c|c|}
\hline & $\begin{array}{l}\text { I } \\
\text { strongly } \\
\text { agree }\end{array}$ & I agree & $\begin{array}{c}\text { Neither / } \\
\text { nor }\end{array}$ & I disagree & $\begin{array}{l}\text { I strongly } \\
\text { disagree }\end{array}$ \\
\hline & & & 1 & 2 & 3 & 4 & 5 \\
\hline Statement & $\mu$ & $\sigma$ & \multicolumn{5}{|c|}{ Frequency (\%) } \\
\hline $\begin{array}{l}\text { Governments should be the only } \\
\text { responsible parties in establishing food } \\
\text { standards }\end{array}$ & 3.66 & 1.17 & 4.2 & 9.0 & 16.8 & 45.5 & 22.3 \\
\hline $\begin{array}{l}\text { I have confidence in food standards } \\
\text { developed by producer organizations }\end{array}$ & 2.73 & 1.06 & 7.1 & 34.5 & 31.9 & 20.3 & 3.9 \\
\hline $\begin{array}{l}\text { Food standards are more credible } \\
\text { when they are developed by } \\
\text { international organizations (e.g. ISO) }\end{array}$ & 2.23 & 1.11 & 23.9 & 41.0 & 18.4 & 11.0 & 3.5 \\
\hline $\begin{array}{l}\text { I have confidence in food standards } \\
\text { developed by certification bodies } \\
\text { (auditing companies) }\end{array}$ & 2.68 & 1.18 & 8.7 & 39.7 & 21.3 & 20.6 & 6.8 \\
\hline $\begin{array}{l}\text { Non Governmental Organizations } \\
\text { (NGOs) are the right organizations to } \\
\text { develop food standards }\end{array}$ & 3.15 & 1.24 & 6.1 & 23.5 & 25.5 & 27.7 & 14.8 \\
\hline
\end{tabular}

Source: Online survey 2010

Finally, results of the assessment about the influence of stakeholders experience show means ranging from about 1.90 to nearly 3.15, with standard deviations levels ranging between 1.00 and 1.10 indicating variance among responses towards the various statements (Table 13). In most statements, responses neither agreed or disagreed with suggesting buying certified products under very popular food standards or those that were very well advertised in the media. They strongly agreed that they will only recommend food standards which are based on $3^{\text {rd }}$ party certification, however, proving the relevance and importance of third party certification assuring extrinsic cues (Anders et al., 2010). 
Table 13: Results of the statements assessing the influence of stakeholder trust

\begin{tabular}{|c|c|c|c|c|c|c|c|}
\hline & $\begin{array}{l}\text { I } \\
\text { strongly } \\
\text { agree }\end{array}$ & I agree & $\begin{array}{c}\text { Neither / } \\
\text { nor }\end{array}$ & I disagree & $\begin{array}{l}\text { I strongly } \\
\text { disagree }\end{array}$ \\
\hline & & & 1 & 2 & 3 & 4 & 5 \\
\hline Statement & $\mu$ & $\sigma$ & \multicolumn{5}{|c|}{ Frequency (\%) } \\
\hline $\begin{array}{l}\text { I would suggest buying certified fresh } \\
\text { products under food standards that are } \\
\text { well advertised in the media }\end{array}$ & 3.13 & 1.08 & 2.6 & 18.4 & 37.1 & 31.6 & 7.1 \\
\hline $\begin{array}{l}\text { I would advise others to have } \\
\text { confidence in food standards that are } \\
\text { very popular }\end{array}$ & 3.01 & 1.10 & 3.9 & 25.8 & 32.3 & 28.7 & 6.8 \\
\hline $\begin{array}{l}\text { I would not propose that others rely on } \\
\text { food standards which I am not } \\
\text { interested in }\end{array}$ & 3.15 & 1.09 & 2.9 & 17.4 & 34.8 & 34.8 & 6.8 \\
\hline $\begin{array}{l}\text { I would only recommend food } \\
\text { standards which are based on 3rd } \\
\text { party certification }\end{array}$ & 1.90 & 1.03 & 34.5 & 43.2 & 8.4 & 9.0 & 1.6 \\
\hline
\end{tabular}

Source: Online survey 2010

\subsection{Determinants of Credibility}

The determinants of credibility were identified through an exploratory factor analysis. Construct loading was examined for both dependent and independent variables. For the endogenous variables, the countries selected were separated into two groups, developed and developing countries, to analyze the factor loadings related to the overall credibility of national food standards. In the case of exogenous variables, the loadings of statements selected for each construct were analyzed. The reliability of the individual items was checked in each construct, and only items with loading above 0.5 were taken into account. On the other hand, the consistencies of the constructs were indicated by Cronbach's alpha (CRA) values greater or equal to 0.6. Furthermore, the average variance shared between the items and the construct was controlled by cumulative values higher than 0.5 of the average variance extracted (AVE), thus meaning that at least 50 percent of measurement variance is captured by the constructs (Chin, 1998).

\subsection{National Food Standards Credibility}

The results of the factor analysis carried out for the dependent variable proves that the overall credibility of national food standards is composed of the credibility of the food standard, the reliability in the certification system and the confidence in the standard setting process. Loadings of the variables for each country can be seen in Annex 4. In the case of developing countries, the outcome of the factor analysis showed one construct that itself accounts for $66 \%$ of the total variance. This construct is composed of 12 variables referring to the 
credibility of the food standards, reliability on the certification system and confidence in the standard setting process for each one of the four developing countries (i.e. China, Ghana, India and Mexico). Also this construct showed a reliability consistency CRA of 0.95 . In the case of the developed countries, 2 constructs resulted from the factor analysis. The first of these factors has a reliability CRA of 0.91 ; accounting for $40.3 \%$ of the total variance and included 9 variables related to the credibility of the food standards, reliability of the certification system and the confidence about the standard setting process for each one of the following countries: Australia, the United Kingdom and the United States. The second factor has a reliability CRA of 0.85 ; accounting for $24.4 \%$ of the total variance and included 3 variables corresponding to the credibility of the food standards, the reliability on the certification system and the confidence about the standard setting process for just one country, in this case Italy. The curious issue is that we could not identify any scientific background that could explain this separation within the developed countries but it could be assumed that there is a cultural factor such as the locally spoken language and country's media reputation that could be influencing these results (Beckley and Nes, 1982). These 3 constructs were called "Less Developed Countries (LDC)National Food Standards Credibility", "Developed Countries (DC) National Food Standards Credibility" and "Italy's National Food Standards Credibility" (see Table 14). In the factor analysis for the dependent variables factor, loadings for all statements were greater than 0.50, the Kaiser-Meyer-Olkin value (KMO for developing countries was 0.883 and for the developed countries 0.842 .

\subsubsection{Indicators Associated with Food Standards Credibility}

For this study, a total of 40 statements were used to measure the perception of credibility. Out of these, only 22 statements were considered in the factor analysis with loadings above 0.50 , Moreover, a bivariate analysis showed no correlation between these factors, proving a complete degree of independency between the constructs. The KMO was 0.7, indicating suitable sampling for carrying out the factor analysis. 
Table 14: Results of the factor analysis for credibility of national food standards

\begin{tabular}{lccc} 
CONSTRUCT & $\mathbf{N}^{\circ}$ of Items & CRA & AVE (\%) \\
\hline $\begin{array}{l}\text { LDC National Food Sandards } \\
\text { Credibility }\end{array}$ & 12 & 0.953 & 66.1 \\
$\begin{array}{l}\text { DC National Food Standards } \\
\text { Credibility }\end{array}$ & 9 & 0.914 & 40.3 \\
$\begin{array}{l}\text { Italy's National Food Standards } \\
\text { Credibility }\end{array}$ & 3 & 0.855 & 24.4 \\
\hline
\end{tabular}

Source: Author's elaboration

Table 15 shows the eight factors which resulted from the analysis, each one having an acceptable level of reliability and altogether amounting to $66 \%$ of the cumulative total variance explained. A general name was given to describe the statements loaded in each factor. The following is a description of the meaning of each:

Factor 1 -Certification Preference: The meaning of this factor is related to the respective reliability, confidence and preference showed for auditors, certification bodies and certified food in regard to the country's degree of economic development. It reflects the respondents' preferences towards certifications carried out in developed countries compare to those in developing countries. This factor shows an acceptable reliability with a Cronbach alpha value of 0.74 and explains $9.49 \%$ of the cumulative variance.

Factor 2 - Stakeholder Trust. The meaning of this construct is associated to the preference and confidence stakeholders may have towards standards that are well promoted or which are of interest for the stakeholder himself. This factor shows an acceptable internal consistency with a Cronbach's alpha value of 0.70 and explains $9.41 \%$ of the cumulative variance.

Factor 3 - Standard Adoption: This factor refers to the preference of food standards adoption concerning the coverage of the standards within the supply chain (e.g. pre and/or post farm) and the credibility related to their adaptability in different regions and consistent interpretations. This factor has an acceptable reliability with a Cronbach alpha value of 0.64 and a varince that explains $8.83 \%$ of the cumulative variance. 
Factor 4 - Audit Frequency: This factor suggests that the reliability of food standards could also be subject to provide a higher frequency of audits. Higher audit frequencies (e.g. once yearly) are preferred over lower frequencies (e.g. every 3 years). This construct has a Cronbach's alpha value of 0.62 and explains $8.35 \%$ of the cumulative variance.

Factor 5 - System Effectiveness: This factor is composed of statements related to the reliability of the compliance of food standards to objectives such as minimizing food safety risks and credibility of the information they provided concerning the certification status of the products. This construct has a Cronbach's alpha value of 0.60 and represents $7.88 \%$ of the cummulative variance explained.

Factor 6 - Information Gap: The meaning of this factor is related to the traceability and identification of certified products credibility perceptions are based on the fact how successful are food standards communicating the information associated to cetified products. The Cronbach value of this factor is 0.56 and thevariance explained is of $7.68 \%$

Factor 7 - Audit Type: This factor is associated to the preference of individual or group certification options. This factor has a CRA reliability of 0.72 and explains $7.57 \%$ of the total variance. The results in table 8 suggest that group certification may not make food standards less reliable, but also that there is a trend showing that individual certification could be a signal of higher credibility.

Factor 8 -Standard Scope: This factor describes the coverage of the food standards regarding the content coverage or length of their requirements. It reflects the confidence towards specfic food standard requirements (e.g. to only cover food safety issues) over integrated food standard requirements (e.g. include food safety, environmental and social requirements). This construct has a Cronbach's alpha value of 0.5 and represents $6.756 \%$ of the cumulative variance explained 
Table 15: Results of the factor analysis for food standard credibility indicators

\begin{tabular}{|c|c|c|c|c|}
\hline Factors /Staments & Loadings & $\begin{array}{c}\text { Cronbach's } \\
\text { Alpha }\end{array}$ & Variance & $\mathrm{N}^{\circ}$ of Items \\
\hline \multicolumn{5}{|l|}{ Certification Preference } \\
\hline $\begin{array}{l}\text { Auditors in developed countries are } \\
\text { more reliable than auditors in } \\
\text { developing countries }\end{array}$ & \multirow[t]{3}{*}{0.835} & \multirow[t]{3}{*}{0.741} & \multirow[t]{3}{*}{9.487} & \multirow[t]{3}{*}{3} \\
\hline $\begin{array}{l}\text { Whenever possible, I would } \\
\text { recommend to buy certified food } \\
\text { products from developed countries }\end{array}$ & & & & \\
\hline $\begin{array}{l}\text { I have less confidence in certification } \\
\text { bodies in developing countries than } \\
\text { those in developed countries }\end{array}$ & & & & \\
\hline \multicolumn{5}{|l|}{ Stakeholder Trust } \\
\hline $\begin{array}{l}\text { I would suggest buying certified fresh } \\
\text { products under food standards that are } \\
\text { well advertised in the media }\end{array}$ & \multirow[t]{3}{*}{0.856} & \multirow[t]{3}{*}{0.7} & \multirow[t]{3}{*}{9.408} & \multirow[t]{3}{*}{3} \\
\hline $\begin{array}{l}\text { I would advise others to have } \\
\text { confidence in food standards that are } \\
\text { very popular }\end{array}$ & & & & \\
\hline $\begin{array}{l}\text { I would not propose others to rely on } \\
\text { food standards which I am not } \\
\text { interested in }\end{array}$ & & & & \\
\hline \multicolumn{5}{|l|}{ Standard Adoption } \\
\hline $\begin{array}{l}\text { Food standards that cover a wide range } \\
\text { of the supply chain (e.g. pre and post } \\
\text { farm) are not reliable }\end{array}$ & \multirow[t]{2}{*}{0.742} & \multirow[t]{4}{*}{0.642} & \multirow[t]{4}{*}{8.834} & \multirow[t]{4}{*}{4} \\
\hline $\begin{array}{l}\text { Food standards are more credible when } \\
\text { they can be adopted in different local } \\
\text { conditions }\end{array}$ & & & & \\
\hline $\begin{array}{l}\text { Food standards which could have } \\
\text { several interpretations among auditors } \\
\text { are reliable }\end{array}$ & \multirow[t]{2}{*}{0.557} & & & \\
\hline $\begin{array}{l}\text { Food standards that focus on one single } \\
\text { stage of the supply chain (e.g. pre or } \\
\text { post farm) are trustworthy }\end{array}$ & & & & \\
\hline \multicolumn{5}{|l|}{ Audit Frequency } \\
\hline $\begin{array}{l}\text { A food standard is more reliable when } \\
\text { it requires producers to be inspected } \\
\text { every year }\end{array}$ & \multirow[t]{2}{*}{0.802} & \multirow[t]{2}{*}{0.618} & \multirow[t]{2}{*}{8.348} & \multirow[t]{2}{*}{3} \\
\hline $\begin{array}{l}\text { I do have a problem if food standards } \\
\text { require producers to be inspected every } \\
3 \text { years }\end{array}$ & & & & \\
\hline
\end{tabular}




\begin{tabular}{|c|c|c|c|c|}
\hline $\begin{array}{l}\text { I prefer food standards that requires at } \\
\text { least one unannounced audit to } \\
\text { producers per year }\end{array}$ & 0.671 & & & \\
\hline \multicolumn{5}{|l|}{ System Effectiveness } \\
\hline $\begin{array}{l}\text { Food standards are reliable in } \\
\text { minimizing food safety risks }\end{array}$ & \multirow[t]{2}{*}{0.815} & \multirow[t]{2}{*}{0.604} & \multirow[t]{2}{*}{7.883} & \multirow[t]{2}{*}{2} \\
\hline $\begin{array}{l}\text { I believe in the information provided } \\
\text { by food standards (e.g. current } \\
\text { certification status of products) }\end{array}$ & & & & \\
\hline \multicolumn{5}{|l|}{ Information gap } \\
\hline $\begin{array}{l}\text { Food standards that cannot trace } \\
\text { products back into the supply chain are } \\
\text { not trustworthy }\end{array}$ & \multirow{3}{*}{$\begin{array}{l}0.766 \\
0.676\end{array}$} & \multirow[t]{3}{*}{0.556} & \multirow[t]{3}{*}{7.682} & \multirow[t]{3}{*}{3} \\
\hline $\begin{array}{l}\text { It should be always possible to identify } \\
\text { the origin of the certified products }\end{array}$ & & & & \\
\hline $\begin{array}{l}\text { I do not rely on food certification } \\
\text { systems which cannot provide an } \\
\text { accurate information about the certfied } \\
\text { products }\end{array}$ & & & & \\
\hline \multicolumn{5}{|l|}{ Audit Type } \\
\hline $\begin{array}{l}\text { Certification of producers groups } \\
\text { makes food standards less reliable }\end{array}$ & \multirow[t]{2}{*}{0.888} & \multirow[t]{2}{*}{0.736} & \multirow[t]{2}{*}{7.565} & \multirow[t]{2}{*}{2} \\
\hline $\begin{array}{l}\text { Food standards are more credible when } \\
\text { they require to audit each individual } \\
\text { producer }\end{array}$ & & & & \\
\hline \multicolumn{5}{|l|}{ Standard Scope } \\
\hline $\begin{array}{l}\text { Credible food standards should not } \\
\text { integrate food safety, environment and } \\
\text { social requirements }\end{array}$ & \multirow[b]{2}{*}{0.726} & \multirow[t]{2}{*}{0.5} & \multirow[t]{2}{*}{6.756} & \multirow[t]{2}{*}{2} \\
\hline $\begin{array}{l}\text { Food standards are more reliable when } \\
\text { they are focused on only one type of } \\
\text { requirements (e.g. food safety) }\end{array}$ & & & & \\
\hline
\end{tabular}

\subsubsection{Adoption of Benchmarking Signals by National Food Standards}

In addition, a factor analysis was carried out to determine the construct that could represent the implications of benchmarking signals on the credibility of food standards (see Table 16). The results of the analysis showed a KMO close to 0.9 and a cumulative variance explained 
of $88 \%$. Two constructs were extracted from the factor analysis. These represent the likelihood of improvement in credibility of the national food standards when they decide to go through a benchmarking system (either GFSI or GLOBALG.A.P.). The first factor includes single loadings over 0.5 from four developing country variables such as Ghana, China, India and Mexico. The reliability of this factor had a Cronbach's alpha of 0.94, implying its suitability for the analysis of this study.

Table 16: Results of the factor analysis for adoption of benchmarking signals by national food standards

\section{CONSTRUCT}

Adoption of Benchmarking Signals by Developing Countries (LDC)

Adoption of Benchmarking Signals by Developed Countries (DC)
$\mathbf{N}^{\circ}$ of Items Variables CRA

4 China,Ghana, India and Mexico

0.94

3
0.95
Australia, United

Kingdom, and

United States

Source: Author's elaboration

The second factor includes single loadings over 0.50 of country variables representing developed countries such as Australia, the United Kingdom and the United States. The Cronbach's alpha measurement of 0.95 corroborates the reliability of this factor. Both variables show a country of origin effect concerning cultural affinities associated to local language. Here we can observe that English-speaking countries are highly correlated and were gathered in one construct. These countries coincidently had higher credibility perception among stakeholders about their national food standards. The second construct represents non English-speaking countries that coincidently obtained a lower rate of stakeholders' credibility perception about their national food standards. It is important to note that the variable Italy was not considered in this analysis because cross loading appears under 0.50 in both constructs. These constructs will be considered as exogenous variables for our analysis.

\subsection{Resulting Model: Determinants of Credibility}

Using the results of the factor analysis we re-structured the empirical model as shown below in the Figure 9. Here the overall credibility of national food standards is a variable constructed by the three elements proposed in Hypothesis 2, i.e. Food Standards Credibility, Certification 
System Reliability and Standard Setting Confidence. This variable represents the dependent variable of the model.

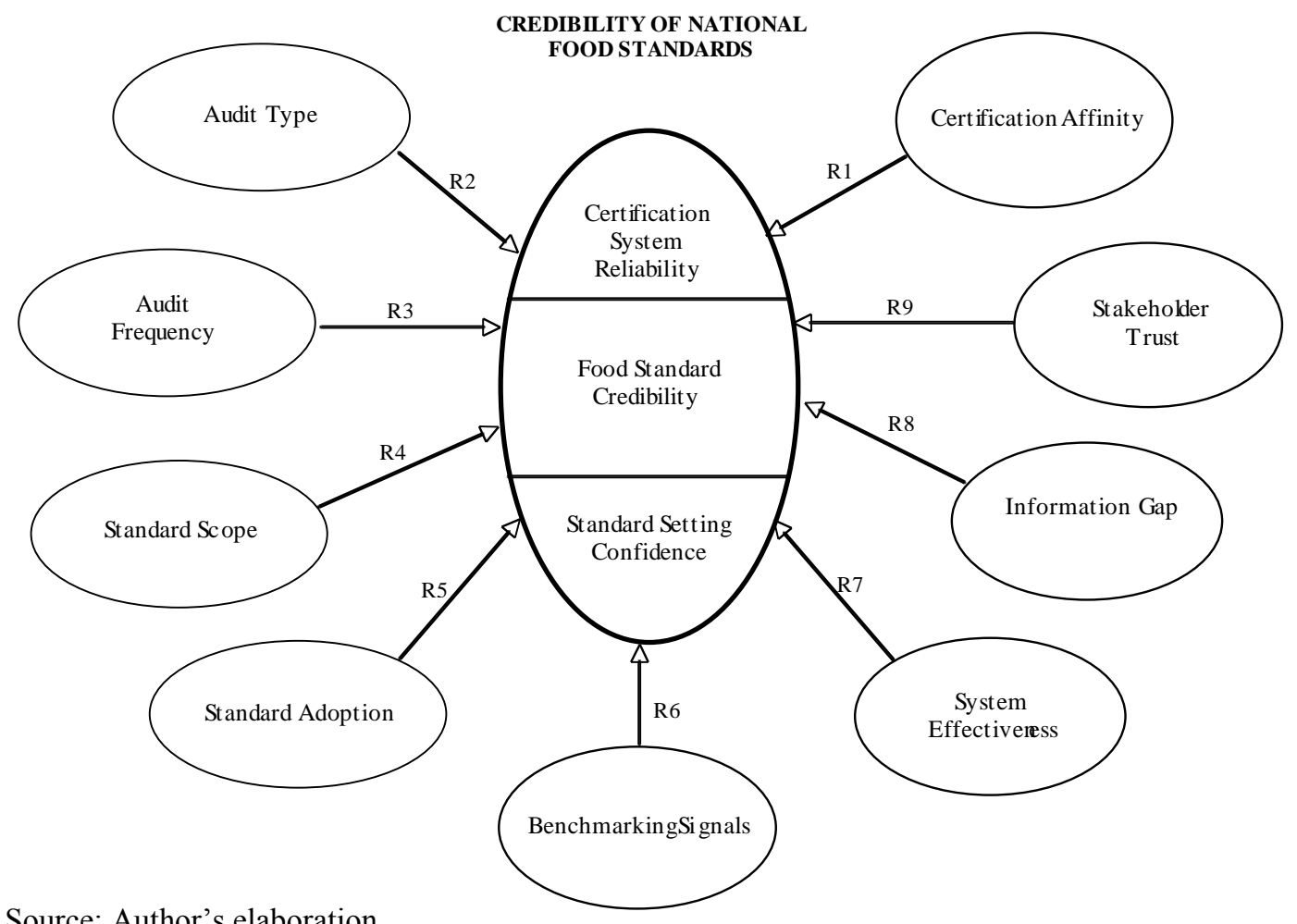

Source: Author's elaboration

Figure 9: Resulting empirical model

Furthermore, the constructs affecting credibility of food standards differs significantly from those hypothesized in the proposed model, while some constructs remain in the model (e.g. benchmarking signals, stakeholder trust), others were proved not to be part of the analysis (e.g. gorvenance structure, degree of economic developement). As a result eight constructs became considered as exogenous variables that will be tested to explain the following reformulated hypothesis (RH):

RH0: There is no significant relationship between an exogenous variable and the dependent variable (applies for all)

RH1: The higher the certification affinity, the higher the credibility of national food standards. 
RH2: The higher the confidence in the audit type, the higher the credibility of national food standards.

RH3: The higher audit frequency, the higher the credibility of national food standards.

RH4: The more specific the standard scope, the higher the credibility of national food standards.

RH5: The higher the reliability of the standard adoption, the higher the credibility of national food standards.

RH6: The adoption of benchmarking signals improves the credibility of national food standards.

RH7: The higher the reliability of the system effectiveness, the higher credibility of national food standards.

RH8: The smaller the information gap, the higher the credibility of national food standards.

RH9: The higher the reliability of food standards effectiveness, the higher the credibility of national schemes.

\subsection{Sources of Credibility Influencing National Food Standards}

Table 17 shows the relationship between the dependent variable "the credibility of national food standards of developing countries" and the independent variables (extracted factors and individual statements). These results were obtained by performing a linear regression analysis, using the Stepwise method. Here we observed a significantly positive influence of "Certification Affinity", "System Effectiveness" and "Benchmarking Signals LDC", but the $\mathrm{R}^{2}$ value of the regression was 0.26 , indicating that these factors could altogether explain only $26 \%$ of the credibility of the national food standard in countries such as Mexico, China, Ghana and India.

The beta values indicate the way these sources affect the credibility of national food standards. Table 17 shows that there is an inverse relationship between "certification affinity" 
and "LDC national food standards credibility" $(\beta=-0.135, \mathrm{p}=0.007)$. This reflects the higher confidence respondents have in the certification practices in developed countries, hence negatively affecting the credibility of LDC national food standards. In this case, RH1 is rejected. This once again confirms Barrets et al. (2009) assumption about the disadvantages of certification bodies in LDC, explained this time by the lack of auditor expertise and local certification capacity.

Table 17: Sources of credibility affecting food standards in developing countries (LDC)

\begin{tabular}{|l|c|c|c|}
\hline \multicolumn{1}{|c|}{ Independent Variables } & Beta value & $\begin{array}{c}\text { T } \\
\text { Value }\end{array}$ & p \\
\hline Certification Affinity $^{1} * *$ & -0.135 & -2.709 & 0.007 \\
\hline System Effectiveness $^{1} * *$ & 0.131 & 2.626 & 0.009 \\
\hline $\begin{array}{l}\text { Adoption of Benchmarking Signals } \\
\text { by Developing Countries }\end{array}{ }^{2 * * *}$ & 0.437 & 8.709 & 0.000 \\
\hline
\end{tabular}

${ }^{1}$ Scale from $1=$ Strongly Agree to $5=$ Strongly Disagree ${ }^{2}$ Scale from $1=$ extremely likely to $5=$ extremely unlikely, $\mathrm{R}^{2}=0.26 ; \mathrm{F}=11.73 * * . \quad * * *=\mathrm{p}<0.001 * *=\mathrm{p}<0.01 *=\mathrm{p}<0.05$

Dependent variable $=$ LDC National Food Standards Credibility

Independent variables: Certification Affinity, Stakeholder Trust, Standard Adoption, Audit Frequency, System Effectiveness, Information Gap, Standard Scope, Audit Type, Adoption of Benchmarking Signals by Developing Countries

On the other hand, the regression shows that there is a direct relationship between "System effectiveness" and the LDC national food standards credibility ( $\beta=0.131, \mathrm{p}=0.009)$. This confirms RH7, implying that the higher the reliability of the standard effectiveness in preventing food safety (or any other food hazard), the better the perception will be of the overall credibility of national food standards. Finally, the third variable that has the strongest influence is "the adoption of benchmarking signals" which has a positive relationship with the LDC national food standards credibility $(\beta=0.437, p=0.000)$. This result confirms RH6, implying that the adoption of benchmarking signals may improve the credibility of national food standards. For all other variables, RH0 applies.

Next, Table 18 shows the relationship between the dependent variable "DC National Food Standards credibility" and the independent variables (extracted factors and individual statements). These results were obtained by performing a linear regression analysis, using the Stepwise method. Here we observe that there is a significant influence of "Audit Frequency", 
strong influence on the perception about these food standards. Finally, although there is an influence of "the adoption of benchmarking signals" on the credibility of LDC national food standards $(B=0.437, p=0.000)$ this is not as strong as for developing countries. However, this result also confirms RH6, implying that the adoption of benchmarking signals may improve the credibility of national food standards. For all other variables RH0 applies. 


\section{Chapter 6}

This research demonstrates that industrial products such as national food standards are also affected by country-of-origin effects and at the same time, this can be significantly diminished by implementing benchmarking signals such as GFSI and /or GLOBALG.A.P. endorsements. This type of harmonization strategy is recommended mainly for national standard owners from developing countries as an initial step towards improving their credibility and to reduce negative cultural perceptions prompted by the disclosure of country-of-origin labels. However, $100 \%$ credibility is not automatically gained since the contribution of benchmarking signals seems to be significantly low. In that sense, further marketing strategies using other credibility sources need to be explored.

This research has also contributed to developing a model tool to explain (in an empirical way) which factors can be associated with improving the credibility of national food standards and what the effects these factors have on it. Although this model will require improvement, based on the results presented here standard owners should pay attention to their "system effectiveness" i.e. to enforce communication about achievements concerning the quality and safety aspects they intend to ensure. For example, in the case of food safety assurance programs the periodical progress in the reduction of the detection of food hazards should be published. In addition, developing countries should pay attention to improving their certification and metric infrastructure as well as building human capacity in order to increase the credibility of their national food standards assurance. In this case, efficiency can be obtained through encouraging the establishment of credible services such as certification, laboratory tests and local assurance know-how.

On the other hand, national food standards from developed countries like the UK, Australia and the US seem to have reached a higher level of confidence. However, we could not confirm from this research if this is due to their technical expertise or it is just the perception that on average high production costs are associated with higher quality delivery as suggested Barret et al. (2002) Haucap and Barmbold (1997) and Chiang and Mansson (1988). It is important to note that the existence of a significant influence of benchmarking signals on the credibility of national food standards from developed countries is an indication that they still 
have room for improving their credibility already achieved. This might not necessary imply forcing them into strict multi-stakeholder platform requirements, but might serve as a way to build up synergies for other standard owners to share and update their own know-how in assurance and standards developing management.

Notwithstanding the achievements of the multivariate analysis, I consider it important to highlight the trends that the factor and univariate analyses disclosed. On the one hand, the effects of the rest of the variables detected should not be neglected, especially those concerning the "information gap" and the "Standard Adoption". Although these variables do not appear to have an influence on the credibility of national food standards, I still believe that the practice of providing more information about what is behind a certificate could probably improve the understanding of the objectives of the food standards. Transparent access to data associated with certified products may help to analyze the real impact on food assurance as well as supporting food producers and manufactures to differentiate in the market and reduce the "lemons" effect. In this way, they could spark stronger motivation to take more responsibility in preventing negative impacts associated with food production. In other words, improving the credibility of national food standards implies also the improvement of the acceptability not only from the demand side but also from the implementation side.

Finally, it is important to recognize that the results of this research are not conclusive, and due to the characteristics of the sample, there might be bias on particular aggregated answers. Although here we attempt to demonstrate an overall impression within the global arena, further investigations should corroborate the stakeholders' perceptions about national food standards credibility in restricted geographical locations, in order to attain more practical responses that could help develop marketing strategies for specific cases. 


\section{REFERENCES}

Adams C. A. and Evans R. (2004). Accountability, completeness, credibility and the audit expectations gap. Journal of corporate citizenship, Vol.14, 97-115.

Akerlof G. (1970). The Market for "lemons": quality uncertainty and the market mechanism. The Quarterly Journal of Economics, 84 (3): 488-500.

Albersmeier F., Schulze H., Jahn G. and Spiller A. (2009a). The reliability of third-party certification in the food chain: From checklist to risk-oriented auditing. Food Control, 20 (10): 927-935.

Albersmeier F., Schulze H. and Spiller A. (2009b). Evaluation and reliability of the organic certification system: perceptions by farmers in Latin America. Sustainable Development, 17 (5): 311-324.

Amstel M.V., Driessen P. and Glasbergen P. (2007). Eco-labelling and information asymmetry: a comparison of five eco-labels in the Netherlands. Journal of Cleaner Production, 16 (3): 263-276.

Anders S. and Caswell J. (2007). Standards-as-Barriers versus Standards-as-Catalysts: Assessing the Impact of HACCP Implementation on U.S. Seafood Imports. Working Paper $\mathrm{N}^{\circ}$ 7. Department of Resource Economics, University of Massachusetts Amherst.

Anders S., Souza-Monteiro D. and Rouviere E. (2010). Competition and credibility of private third party certification in international food supply. Journal of International Food \& Agribusiness Marketing, 22: 328-341.

Andersen E.B. (1994). The evolution of credence goods: A transaction approach to product specification and quality control. MAPP working paper $\mathrm{N}^{\circ} 21$.

Antle J.M. (1999). Benefits and costs of food safety regulation. Food Policy, 24 (6): 605-623.

Antle J.M. (2001). Economic analysis of food safety. In: Handbook of Agricultural Economics. B. L. Gardner and G.C. Rausser (Eds.), Amstedarm: Elsevier Science B.V. (Vol 1B) pp.1083-1136.

Arrow K.A. (1985). The Economics of Agency. In: Principal and Agents: The Structure of Business. J.W. Pratt, R.J. Zeckhauser (Eds.), Boston MA: Harvard Business School Press, pp. 37-51.

Asfaw S., Mitho“ fer D. and Waibel H. (2009). EU food safety standards, pesticide use and farm-level productivity: The case of high-value crops in Kenya. Journal of Agricultural Economics, 60 (3): 645-667.

Barret H.R., Browne A.W., Harris P.J.C. and Cadoret K. (2002). Organic certification and the UK market: organic imports from developing countries. Food Policy , 27 (4): 301-318.

Bauwhede, H.V. and Willekens, M. (2004). Evidence on (the lack of) audit-quality differentiation in the private client segment of the Belgian audit market. European Accounting Review, 55: 293-320. 
Becker, G.S. (1968). Crime and punishment: An economic approach. Journal of Political Economy, 76: 169-217.

Berlo D. K., James B. L. and Mertz R. J. 1960/70. Dimensions for evaluating the acceptability of message sources. Public Opinion Quarterly, 33 (4): 563-76.

Bilkey W.J. and Nes E. 1982. Country of Origin Effects on Product Evaluations. Journal of International Business Studies, 13 (1): 89-99.

Boström M. (2006). Establishing Credibility: Practising standard-setting ideals in a Swedish seafood-labelling case. Journal of Environmental policy and planning, 8(2): 135-158.

Boxwell R.J. (1994). Benchmarking for Competitive Advantage. New York: McGraw-Hill. pp. 225.

Bruning E.R. (1997). Country of Origin, national loyalty and product choice: the case of international air travel. International Marketing Review, 14 (1): 59-74.

Byrne J. (2008). Melamine detection service offered to EU food and drink sector. In: http://www.foodproductiondaily.com. Access: October 2008.

Casella A. (1996). Free Trade and evolving standards. In: Fair Trade and Harmonization: prerquisites for free trade? J. Bhagwati and R.E. Hudec (Eds), Cambridge: MIT Press, (Vol. 1) pp. 119-156.

Caswell J. A., Bredahl M.E. and Hooker N.H. (1998). How quality management metasystems are affecting the food industry. Applied Economic Perspectives and Policy, 20 (2): 547-557.

Clemens R. (2003). Meat traceability and consumer assurance in Japan. Briefing Paper, Midwest Agribusiness Trade Research and Information Centre, Iowa State University. September 2003: pp. 24.

Dando N. and Swift T. (2003). Transparency and assurance: minding the credibility gap.

Journal of Business Ethics, 44 (2-3): 195-200.

David P. and Greenstein S. (1990). The economics of compatibility standards. Economics of Innovation and New Technology, 1 (1): 3-41.

DeAngelo L.E. (1981). Auditor independence, low-balling and disclosure regulation. Journal of Accounting and Economics, 3 (2): 113-127.

Doney P.M. and Cannon J.P. (1997). An examination of the nature of trust in buyer-seller relationships. Journal of Marketing ,61 (2): 35-51.

EUROPA, 2010. Food and Safety Farm to Fork: General Law. In: http://ec.europa.eu/food /food/foodlaw/index_en.htm. Access: June 2010.

Eisenhardt K.M., (1989). Agency Theory. An Assessment and Review. Academy of Management Review, 14 (1): 57-74. 
Fearne A., Ilnornibrook S. and Dedman S. (2001). The management of the perceived risk in the food supply chain: A comparative study of retailer-led quality assurance schemes in Germany and Italy. International Food and Agribusiness Management Review, 4 (1): 19-36.

Food and Agriculture Organization and World and Health Organization. (2010). Food Standards.: Codex Alimentarius In: http://www.codexalimentarius.net/web/index_en.jsp Access: June 2010.

Food and Drug Administration. (2009a). FDA History Part II - The 1938 Food, Drug, and Cosmetic Act.In: http://www.fda.gov/AboutFDA/WhatWeDo/History/Origin/ucm054826.htm Access: June 2010.

Food and Drug Administration. (2009b). FDA History - Part III-Drugs and Foods Under the 1938 Act and Its Amendments. In: http://www.fda.gov/AboutFDA/WhatWeDo/History/ Origin/ucm055118.htm Access: June 2010.

Food and Drug Administration. (2009c). Bioterrorism and Drug Preparedness. In: http://www.fda.gov/Drugs/EmergencyPreparedness/BioterrorismandDrugPreparedness/defaul t.htm Access: June 2010.

Foray, D. (1995). Coalitions and committees: How users get involved in information technology standardisation. In: Standards, Innovation and Competitiveness. R. Hawkins, R. Mansell, and J. Skea, (Eds.), Edward Elgar, Aldershot, UK, pp. 192-212.

Fox E. M. (1991/1992). Harmonization of law and procedures in a globalized world: Why, what and how? Antitrust Law Journal, 60 (1):593-598.

Friesen L. (2003). Targeting enforcement to improve compliance with environmental regulation. Journal of Environmental Management and Economics, 46 (1): 72-85

Fritz M. (2006). Trust and Risk in Business Networks: Towards a Due Diligence for Electronic Commerce. In $99^{\text {th }}$ EAAE Seminar, "Trust and Risk in Business Networks. Bonn 2006.

Fulponi L. (2006). Private voluntary standards in the food system. The perspective of major food retailers in OECD countries. Food Policy, 31(1): 1-13.

Garcia-Martinez M. and Poole N. (2004). The development of private fresh produce safety standards: Implications for developing mediterranean-exporting countries. Food Policy, 29 (3): 229-255.

Gardner B. (2003). U.S. food quality standards: Fix for market failure or costly anachronism? American Journal of Agricultural Economics, 85 (3): 725-730.

Gellynck X.; Verbeke W. and Viaene J. (2004). Quality management in the food supply chain: How does the food industry interact with consumers, retailers and public authorities? In: Quality Assurance, Risk Management and Environmental Control in Agriculture and Food Supply Networks. G.Schiefer and U, Rickert (Eds.), Universität Bonn:ILB. (Vol. B) pps. 443451. 
Getz C. and Shreck A. (2006). What organic and fair trade labels do not tell us: towards a place-based understanding of certification. International Journal of Consumer Studies, 30 (5): 490-501.

Giannakas K. (2002). Information asymmetries and consumption decision in organic food product markets. Canadian Journal of Agricultural Economics, 50 (1): 35-50.

Global food safety initiative. (2007). GFSI guidance document. $5^{\text {th }}$ edition, September 2007.

Globalgap. (2007). Benchmarking Process. In: Globalgap general regulations version 3.1 part IV.

Grant J., Wendelboe A.M., Wendel A., Jepson B., Torres P., Smelse C. and Rolfs R.T. (2008). Spinach-associated Escherichia coli O157:H7 Outbreak, Utah and New Mexico, 2006. Emerging Infectious Diseases, 14 (10): 1633-1636.

Grooves A.M. (2000). Authentic British food products: a review of consumer perceptions. International Journal of Consumer Studies, 25 (3): 25-31.

Haucap J., Wey C. and Barmbold J. F. (1997). Location choice as a signal for product quality: The economics of "Made in Germany". Journal of Institutional and Theoretical Economics, 153 (3): 510-531.

Hammoudi A., Hoffmann R. and Surry Y. (2009). Food safety standards and agri-food supply chains: an introductory overview. European Review of Agricultural Economics, 36 (4): 469478.

Harmon R. R. and Kenneth A. C. (1982). The persuasive effects of source credibility in buy and lease situations. Journal of Marketing Research, 19 (2): 255-60.

Hatanaka M., Bain, C. \& Busch L. (2008). Third-party certification in the global agrifood system. Food Policy, 30 (3): 354-369.

Havinga T. (2006). Private regulation of food safety by supermarkets. Law \& Policy, 28 (4): $515-533$.

Heffernan T. (2004). Trust formation in cross-cultural business-to-business relationships. Qualitative Market Research: An International Journal, 7 (2): 114-125.

Henson S.J. and Traill B. (1993). The demand for food safety: market imperfections and the role of government. Food Policy, 18 (2): 152-162.

Henson S.J. and Northen J.R. (1998). Economic determinants of food safety controls in the supply of retailer own-branded products in the UK. Agribusiness, 14 (2): 113-126.

Henson S.J. and Caswell J. (1999). Food safety regulation: an overview of contemporary issues. Food Policy, 24 (6): 589-603.

Henson S. J. and Hooker N. (2001). Private sector management of food safety: Public regulation and the role of private controls. International Food and Agribusiness Management Review, 4 (1): 7-17. 
Henson S.J. and Readon, T. (2005). Private agri-food standards: Implications for food policy and the agri-food system. Food Policy, 30 (3): 241-253.

Henson S.J. (2006). The Role of Public and Private Standards in Regulating International Food Markets. Paper prepared for the IATRC Summer symposium. "Food Regulation and Trade: Institutional Framework, Concepts of Analysis and Empirical Evidence" Bonn, Germany, May 28-30, 2006.

Holleran E., Bredahl M.E. and Zaibet L. (1999). Private incentives for adopting food safety and quality assurance. Food Policy, 24 (6): 669-683.

ISEAL. (2005). Code of good practice for setting social and environmental standards. Version 5.01 .

ISO/IEC. (1996). Guide 65: General requirements for bodies operating product certification systems. pp. 8.

Jeffe S. and Henson S. (2004). Standards and agro-food exports from developing countries: rebalancing the debate. World Bank Policy Research Working Paper 3348, June 2004.

Jahn G., Schramm M. and A. Spiller. (2004). Differentiation of certification standards: the trade-offs between generality and effectiveness in certification systems. IAMA's $14^{\text {th }}$ World Food and Agribusiness Forum, June 12-15 Montreux Switzerland. 2004.

Jahn G., Schramm M., Spiller A. (2005). The reliability of certification: quality labels as a consumer policy tool. Journal of Consumer Policy, 28 (1): 53-73.

Jahn G. and Spiller A. (2007). Dairy farmer's acceptance of a processor driven quality management system: a structural equation model. In: Quality and management in food chains L. Theuvsen, A. Spiller, M. Peupert and G. Jahn (Eds.), Wageningen: Wageningen Academic Publishers, pp. 385-396.

Jackson L.A. (2000). An economic model of agricultural labelling policy harmonization in international trading systems. In Transitions in Agrobiotech: Economics of Strategy and Policy, W.H. Lesser (Ed.), Proceedings of N.E. 165 Conference 1999, Washington, D.C.

Joint Research Centre (JRC). (2005). Food supply chain dynamics and quality certification. Final Report. DEI Agra-Universtiy of Bologna. November 2005.

Kleinwechter U. and Grethe H. (2006). The adoption of the Eurepgap standard by mango exporters in Piura, Peru. The $26^{\text {th }}$ IAAE Conference Brisbane, 2006.

Kotler P. (1998). Marketing management. analysis, planning, implementation and control. $9^{\text {th }}$ Edition. Prentice Hall.

Larsson S., Olsson E.K. and Ramberg B. (2005). Crisis management and the European Union In: Crisis Decision Making in the European Union. Larsson S., Olsson E.K. and Ramberg B. (Eds.) Crisis Management Europe Research Program, Chapter 1: pp. 9-18.

Lásztity R., Petró-Turza M. and Földesi T. (2009). Food quality and standards: History of the Food Quality Standards. Volume I. Encyclopedia of Life Support Systems. 
Lazo A., Jahn G. and Spiller A. (2007). Growers perceptions about Eurepgap in developing countries: results of a survey carried out in Peru. In: Quality and management in food chains L. Theuvsen, A. Spiller, M. Peupert and G. Jahn (Eds.), Wageningen: Wageningen Academic Publishers, pp. 369-383.

Leebron D. (1996). Lying down with Procrustes: An analysis of harmonization claims. In Fair Trade and Harmonization: prerequisites for free trade?, J. Bhagwati and R.E. Hudec (Eds.), Cambridge: MIT Press (Vol.1), pps.41-117.

Lennox, C. (2000). Do companies successfully engage in opinion-shopping? Evidence from the UK. Journal of Accounting and Economics, 29: 321-337.

Lingreen A. (2003). Trust as a valuable strategic variable in the food industry, different types of trust and their implementation. British Food Journal. 105 (6): 310-327.

Lobb E.A. and Mazzocchi M. (2006). The country-of-origin of Food: consumer perceptions of safety and the issue of trust. In $99^{\text {th }}$ EAAE Seminar " Trust and Risk in Business Networks. Bonn 2006.

Lohr L. and Krissoff B. (2002). Consumer effects of harmonizing international standards for trade in organic foods. In Global Food Trade and Consumer Demand for Quality, B. Krissoff, M. Bohmen and J.A. Caswell (Eds.), New York: Kluwer Academic Press, pps. 209-228.

Luning P.A., Marcelis W.J. and Jongen W.M.F. (2002). Food quality management a technomanagerial approach. Wageningen: Wageningen Press.

Marchant M.A. and Ballenger N. (1994). The trade environment debate: relevant for southern agriculture? Journal of Agricultural and Applied Economics, 26 (1): 108-128.

Martinez M.G. and Bañados F. (2004). Impact of EU organic product certification legislation on Chile organic exports. Food Policy, 29 (1): 1-14.

Mazé A. (2007). The organisation of private auditing systems and their limitations: a comparative analysis of the Eurep system. In: Quality and management in food chains L. Theuvsen, A. Spiller, M. Peupert and G. Jahn (Eds.), Wageningen: Wageningen Academic Publishers, pp. 315-329.

McCluskey J.J. (2007). Public and private food quality standards: recent trends and strategic incentives. In: Global Supply Chains, Standards and the Poor. J.F.M. Swinnen (Eds.), CAB Internationl, pp. 19-25.

McCluskey J. J. and Winfree J. A. (2009). Pre-empting public regulation with private food quality standards. European Review of Agricultural Economics, 36 (4): 525-539.

Moeller K. (2007). Economics of standard owners competition as barrier to global harmonisation of food assurance systems. In: Quality and management in food chains L. Theuvsen, A. Spiller, M. Paupert and G. Jahn (Eds.), Wageningen: Wageningen Academic Publishers, pp. 23-28. 
Morris C. and Young C. (2000). 'Seed to shelf', 'teat to table', 'barley to beer' and 'womb to tomb': discourses of food quality and quality assurance schemes in the UK. Journal of Rural Studies, 16 (1): 103-115.

Nelson, P. (1970). Information and consumer behaviour. The Journal of Political Economy. 78 (2): 311-329.

Nilsson,H., Tunçer B. and Thidell A. (2004). The use of eco-labeling like initiatives on food products to promote quality assurance - is there enough credibility? Journal of Cleaner Production. 12(5): 517-526.

Roobina O. (1990). Construction and validation of a scale to measure celebrity endorsers' perceived expertise, trustworthiness and attractiveness, Journal of Advertising, 19 (3): 39-52.

Pie Pierce, B. and Sweeney, B. (2004). Cost-quality conflict in audit firms: an empirical investigation. European Accounting Review, 13 (3): 415-441.

Roberts, D. (1999). Analyzing technical trade barriers in agricultural markets: challenges and priorities. Agribusiness, 15(3): 335-354.

Salop S.C. and Scheffman D.T. (1983). Raising rivals' costs. The American Economic Review, 73(2): 267-271.

Sawyer E., Kerr A. and J.E. Hobbs. (2008). Consumer preferences and the international harmonization of organic standards. Food Policy. 33 (6): 607-615.

Schulze H., Albersmeier F., Jahn G., \& Spiller A. (2006). Checklist governance: risk-oriented audits to improve the quality of certification standards in the food sector. In Proceedings of $16^{\text {th }}$ annual world food and agribusiness forum, symposium and case conference of the IAMA, Buenos Aires, Argentina, June 10-13, 2006.

Schulze B. and Spiller A. (2007). Trust as an effective governance instrument in food supply chains: an empirical study within the german meat sector. Paper presented at the 17th Annual World Forum and Symposium "Agribusiness Food Culture: Tradition, Innovation and Trust A Positive Force for Modern Agribusiness", IAMA Conference, June 23 - 24, 2007 in Parma, Italy.

Theuvesen L. (2003). Motivational limits to tracking and tracing: principal-agent problems in meat production and processing. In: Quality Assurance, Risk Management and Environmental Control in Agriculture and Food Supply Networks. Schiefer, G., Rickert, U. (Eds.), Bonn: ILB Press, (Vol. A) pp. 223-230.

Theuvesen, L. and Spiller, A. (2007). Perspectives of quality management in modern agribusiness. In: Quality Management in Food Chains, L. Theuvsen, A. Spiller, M. Paupert and G. Jahn (Eds.),Wageningen: Wageningen Academic Publishers, pp. 13-19.

Thompson, J.D. (1967), Organizations in action. Social Science Bases of Administrative Theory. New York et al., Mc Graw Hill. 
Tripp, C., Thomas D. J. and Carlso L. (1994). The effects of multiple product endorsements by celebrities on consumers' attitudes and intentions. Journal of Consumer Research, 20 (4): 535-47.

The Economist, 1998 The science of BSE: Bungled. Economist, 12 March. In: ttp://www.economist.com/node/370887/print.

Tuncer, B. 2001. From farm to fork? means of assuring food quality, an analysis of the European food quality initiative. Master Thesis in Environmental Management and Policy. The International Institute for Industrial Environmental Economics Lund, Sweden.

Turner C. R., Ortmann G. F. and Lyne M. C. (2000). Adoption of ISO 9000 quality assurance standards by South African agribusiness firms. Agribusiness, 16 (3): 295-307.

United Nations Conference on Trade and Development. (2007a). Food safety and environmental requirements in export markets: friend or foe for producers of fruit and vegetables in Asian developing countries. United Nations.

United Nations on Trade and Development. (2007b). The implications of private-sector standards for good agricultural practices. Exploring options to facilitate market access for developing country exporters of fruit and vegetables. Experience of Argentina, Brazil and Costa Rica. United Nations.

United Nations on Tade and Development. (2008a). Challenges and opportunities arinsing from private standards on food safety and environment for exporters of fresh fruit and vegetables in ASIA: Experiences of Malaysia and Viet Nam. United Nations.

United Nations on Tade and Development. (2008b). Private-sector standards and national schemes for good agricultural practices: implications for exports of fresh fruit and vegetables from Sub-Saharan Africa. Experiences of Ghana, Kenya, and Uganda. United Nations.

United States Government Accountability Office-GAO. (2005). "Food Safety Experiences of seven countries in consolidating their food safety Systems. Report to Congressional Requesters. Paper GAO-05-212.

Walenbach P. (2007). Façade and means of control: the use of ISO 9000 standards. In Quality Management in Food Chains. L. Theuvsen, A. Spiller, M. Paupert and G. Jahn (Eds.), Wageningen: Wageningen Academic Publishers, pp. 29-42.

Withehead, Jack L. (1968). "Factors of source credibility". Quarterly Journal of Speech, 54 (1): 59-63.

Windmöller, R. (2000). The auditor market and auditor independence. European Accounting Review, 9 (4): 639-642.

Williamson, O.E. (1985). The economic institutions of capitalism. New York - London, Free Press.

Williamson O. E. (1996). The mechanisms of governance. Oxford University Press. 
Wood J.D., Holder J.S. and Main D.C.J. (1998). Quality assurance schemes. Meat Science, 49 (1): 191-203.

World Trade Organization (WTO). (2005). World trade report, exploring the links between trade, standards and the WTO. Chapter II: 29-159. 
ANNEXES

Annex 1: Online Questionnaire

\section{WELCOME TO THE FOOD STANDARDS CREDIBILITY SURVEY}

The Department of Agricultural Economics of the University Göttingen in Germany is carrying out a survey about fresh food certification and quality standards (Food Standards). The study intends to extract perceptions about the establishment of quality assurance systems, in order to obtain some feedback useful for the improvement of such systems.

This is a good opportunity to share your experiences in this area, thus contributing to further improvement of food standards. Your cooperation for the study is very valuable. All collected data will be processed anonymously and neither you, nor your company will be identified with any response. The survey will take about 15 minutes.

If you have any questions or concerns about completing the questionnaire or participating in the survey, please do not hesitate to contact me; a.lazogaldos@stud.uni-goettingen.de

Thank you in advance for your cooperation!

Kind regards

M.Sc. Angelo Lazo

Department of Agriculture Economics and Rural Development

Goerge August University Göttingen

(Next)

First of all, we would like to learn about your experience with food standards

1. How many years have you been working in the food industry?

Please enter the number of years in the box below

years

2. So far, how much have you been involved with Food Standards?
Very Involved
Involved
Partially Involved
Little Involved
Not Involved at all

3. Does your company buy certified fresh food products?

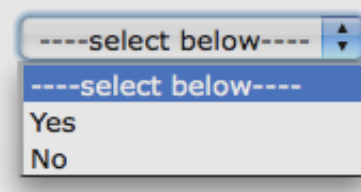

Back Next 
4. Why does your company request certified fresh food products to suppliers?

Using the mouse please drag each of the answers from the left below into the blue box on the right and place them in order of importance from the top ("the most important) to the bottom ("the least important").

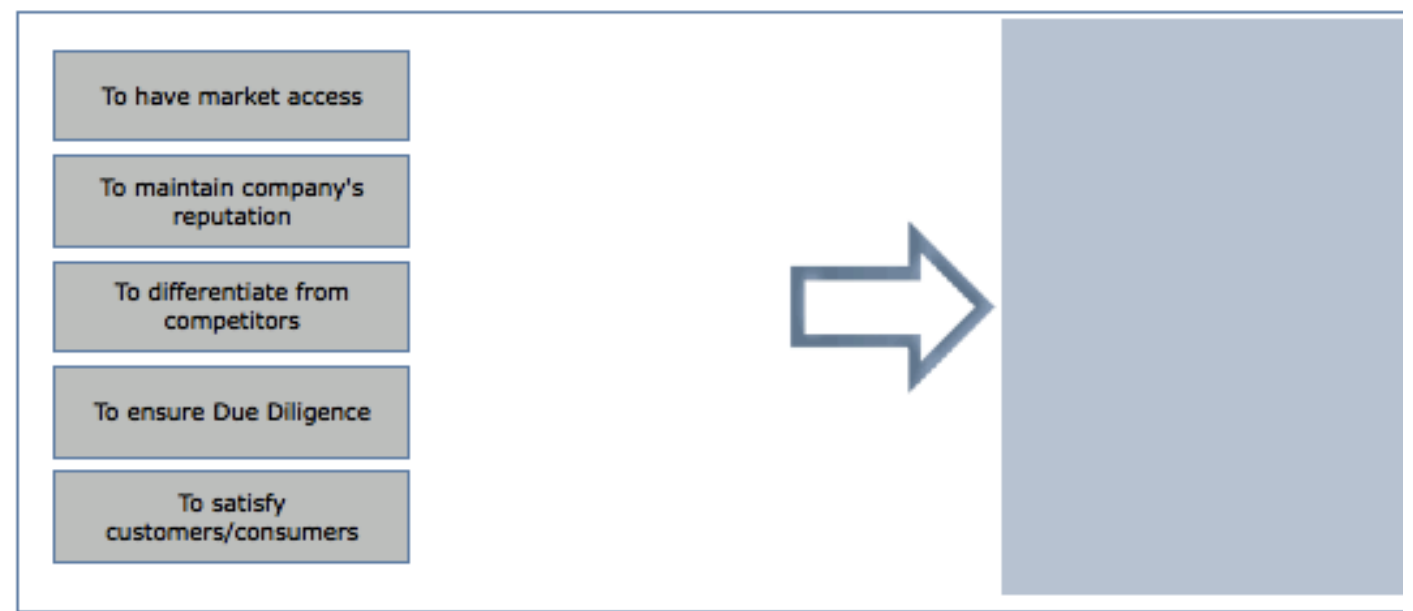

5. What type of certifications are mainly demanded by your company?

Please indicate the amount demanded (in percentage) for each standard that your company demands. Multiple answers are possible.

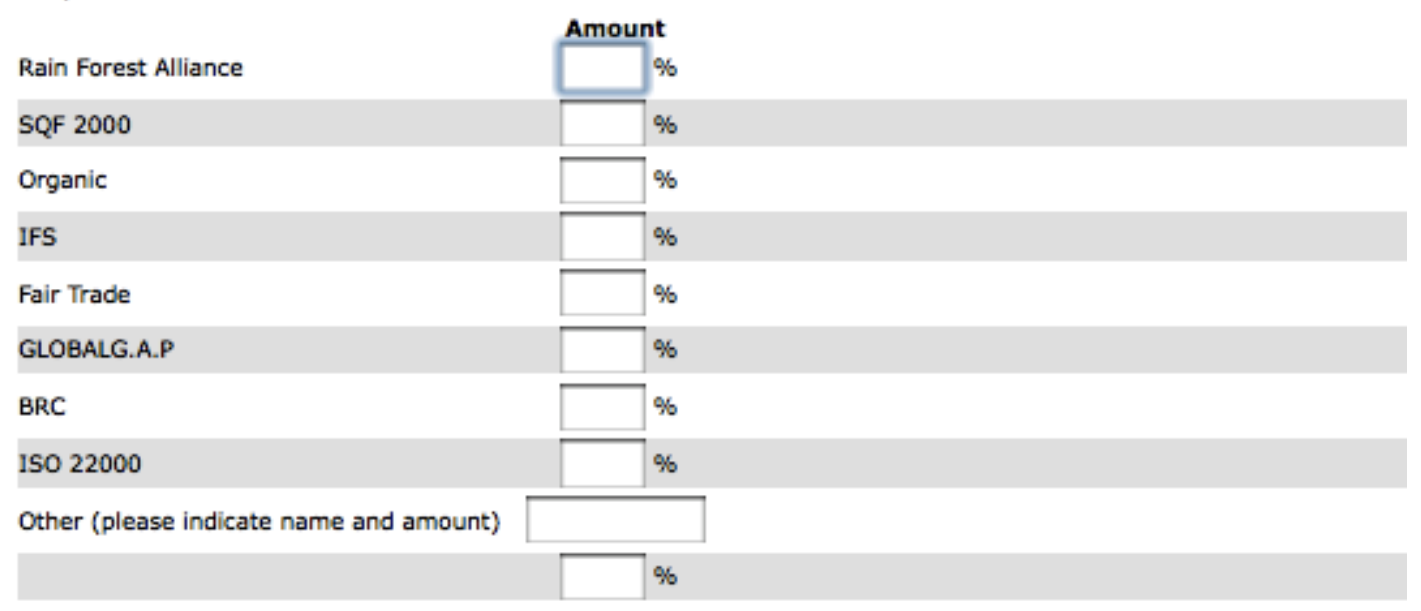


Food standards consist of a set of quality requirements (standards) and a set of audit rules that define how to obtain a certificate (certification system). In some cases, food standards that have been developed in different countries may differ in the standard content and/or in the audit demands. Taking this into consideration:

6. How credible do you think are the food standards developed in the following countries? Please indicate the degree of credibility for each one of the countries using the scale below.

$\begin{array}{lcccc}\text { Very credible } & \text { Credible } & \text { Neither / nor } & \begin{array}{c}\text { Slightly } \\ \text { credible }\end{array} \\ \text { Ghana } & 0 & 0 & 0 \\ \text { Italy } & 0 & 0 & 0 \\ \text { Australia } & 0 & 0 & 0 \\ \text { Mexico } & 0 & 0 & 0 \\ \text { China } & 0 & 0 & 0 \\ \text { United Kingdom } & 0 & 0 & 0 \\ \text { India } & 0 & 0\end{array}$

$$
\text { Back Next }
$$

Now we would like to know your opinion about the results provided by food standards. Please give your comments to each statement using the scale below

\section{What do you think about the effectiveness of food standards?}

$\begin{aligned} & \text { Food standards are reliable in minimizing } \\ & \text { food safety risks }\end{aligned}$
$\begin{aligned} & \text { I strongly } \\ & \text { agree } \\ & \text { environmental impacts }\end{aligned}$

8. What do you expect about the traceability of certified food?

A credible food certification system does I strongly agree I agree Neither / nor I disagre not have to provide full traceability It is not necessary to have the precise information about the area of a certified $\mathrm{O}$

$$
0
$$
farm

It should be always possible to identify the origin of the certified products

I have confidence that certified products are not mixed with non certified products

O

I do not rely on food certification systems which cannot provide an accurate information about the certfied products

0

$\mathrm{O}$

$\mathrm{O}$

O

0

O

O

0

$\mathrm{O}$

0 
Food certification systems (audit rules) include the requirements for obtaining the certificate of a specific food standard (e.g. audit frequency, auditor qualifications, standards compliance, etc.). These requirements may differ among food standards developed in different countries. Taking this into consideration:

9. How reliable do you think are the certification systems developed in each one of the following countries? Please indicate for each country the degree of reliability using the scale below.

$\begin{array}{lccccc}\text { Italy } & \text { Reliable } & \text { Slightly reliable } & \text { Neither / nor } & \begin{array}{c}\text { Slightly } \\ \text { unreliable }\end{array} & \text { Unreliable } \\ \text { Mexico } & 0 & 0 & 0 & 0 & 0 \\ \text { Ghana } & 0 & 0 & 0 & 0 & 0 \\ \text { Australia } & 0 & 0 & 0 & 0 & 0 \\ \text { United Kingdom } & 0 & 0 & 0 & 0 & 0 \\ \text { United States } & 0 & 0 & 0 & 0 & 0 \\ \text { China } & 0 & 0 & 0 & 0 & 0 \\ \text { India } & 0 & 0 & 0 & 0 & 0 \\ \end{array}$

\section{Back Next}

At this point we like to know your preferences towards food certification systems. Please give your opinion on each of the statements using the scale below

10. What is your opinion about the different auditing options?

$\begin{aligned} & \text { A food standard is more reliable when it } \\ & \text { requires producers to be inspected every } \\ & \text { year }\end{aligned}$
$\begin{aligned} & \text { I prefer food standards that requires at } \\ & \text { least one announced audit to producers } \\ & \text { per year }\end{aligned}$

\section{What is your opinion about the origin of food certification systems?}

I have less confidence in certification

I strongly

bodies in developing countries than those in developed countries

Auditors in developed countries are more reliable than auditors in developing countries

Whenever possible, I would recommend to buy certified food products from developed countries

Certified food coming from developing countries are more trustful than similar products available in developed countries

Food certification systems established in developed countries are always carefully designed by trustful technical experts

re

$(0$

O

o agree

$$
\text { agree }
$$$$
\text { I agree }
$$$$
\text { Neither / nor }
$$

I disagree

I strongly disagree

o

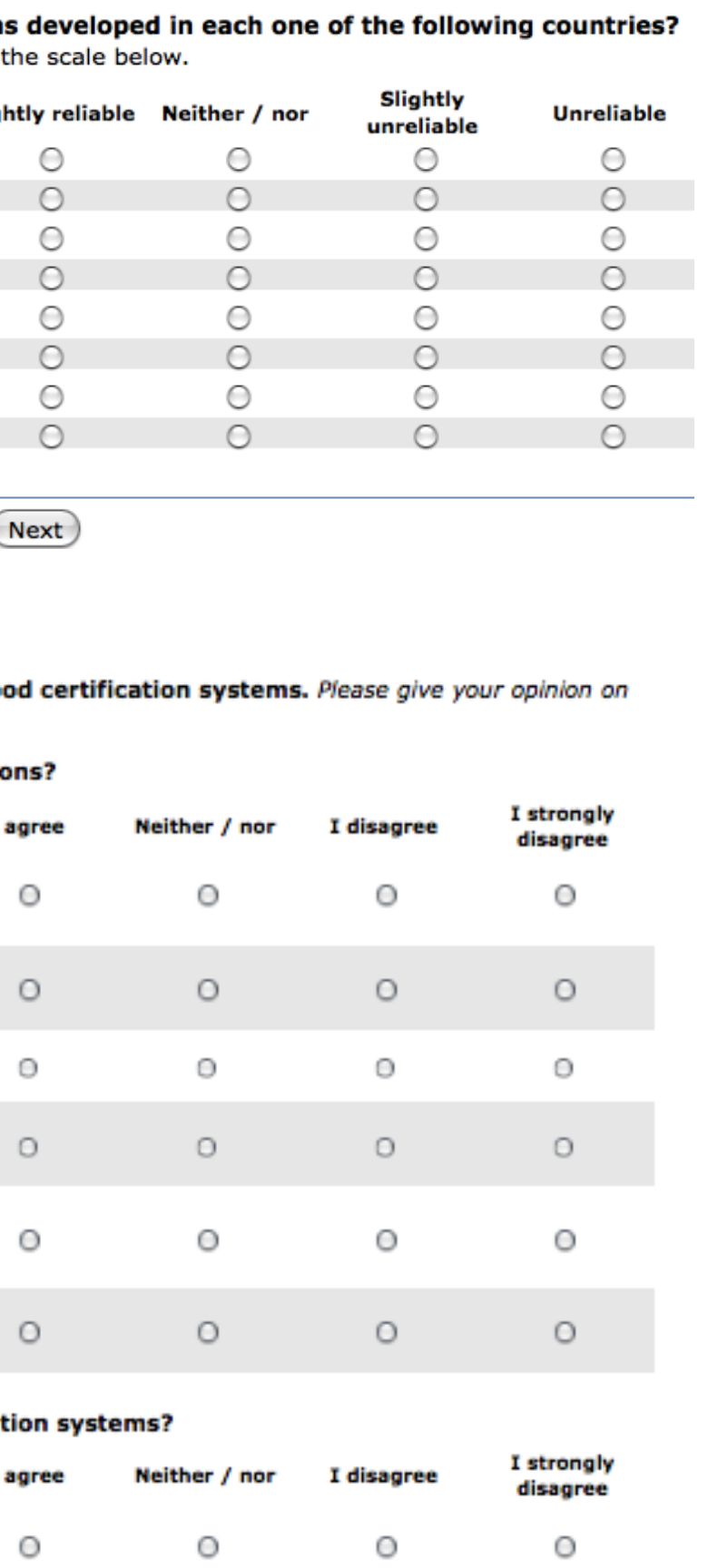

O 0

o

o

O

0

o


Food standard's requirements may include for example food safety, environmental and social aspects which have been established and chosen by a standard setting organization. The standard setting process to establish these requirements might differ among different organizations and countries. Taking this into consideration:.

12. In general, how much confidence would you have on the standard setting process held in each of the following countries?

Please indicate for each country the degree of confidence using the scale below.

\begin{tabular}{|c|c|c|c|c|c|}
\hline & $\begin{array}{c}\text { I have } \\
\text { confidence }\end{array}$ & $\begin{array}{l}\text { I have slight } \\
\text { confidence }\end{array}$ & Niether / nor & $\begin{array}{l}\text { I have slight no } \\
\text { confidence }\end{array}$ & $\begin{array}{l}\text { I have no } \\
\text { confidence }\end{array}$ \\
\hline United States & 0 & 0 & 0 & 0 & 0 \\
\hline United Kingdom & 0 & 0 & 0 & 0 & 0 \\
\hline Mexico & 0 & 0 & 0 & 0 & 0 \\
\hline India & 0 & 0 & 0 & 0 & 0 \\
\hline Australia & 0 & 0 & 0 & 0 & 0 \\
\hline China & 0 & 0 & 0 & 0 & 0 \\
\hline Ghana & 0 & 0 & 0 & 0 & 0 \\
\hline Italy & 0 & 0 & 0 & 0 & 0 \\
\hline
\end{tabular}

\section{Back Next}

Now we would like to know your opinion about food standards' requirements Please give your opinion on each of the statements using the scale below

13. What expectations do you have in respect to food standards' requirements?

\begin{tabular}{|c|c|c|c|c|c|}
\hline & $\begin{array}{l}\text { I strongly } \\
\text { agree }\end{array}$ & I agree & Neither / nor & I disagree & $\begin{array}{c}\text { I strongly } \\
\text { disagree }\end{array}$ \\
\hline $\begin{array}{l}\text { Food standards that focus on one single } \\
\text { stage of the supply chain (e.g. pre or post } \\
\text { farm) are trustworthy }\end{array}$ & 0 & 0 & 0 & 0 & 0 \\
\hline $\begin{array}{l}\text { Credible food standards shall integrate } \\
\text { food safety,environment and social } \\
\text { requirements }\end{array}$ & 0 & 0 & 0 & 0 & 0 \\
\hline $\begin{array}{l}\text { Food standards are more reliable when } \\
\text { they are focused on only one type of } \\
\text { requirements (e.g. food safety) }\end{array}$ & 0 & 0 & 0 & 0 & 0 \\
\hline $\begin{array}{l}\text { Food standards are more credible when } \\
\text { they can be adopted in different local } \\
\text { conditions }\end{array}$ & 0 & 0 & 0 & 0 & 0 \\
\hline $\begin{array}{l}\text { Food standards which could have several } \\
\text { interpretations among auditors are } \\
\text { reliable }\end{array}$ & 0 & 0 & 0 & 0 & 0 \\
\hline $\begin{array}{l}\text { Food standards that cover a wide range of } \\
\text { the supply chain (e.g. pre and post farm) } \\
\text { are not reliable }\end{array}$ & 0 & 0 & 0 & 0 & 0 \\
\hline
\end{tabular}

14. How much confidence do you have in the different standard setting organizations?

$\begin{aligned} & \text { I have confidence in food standards } \\ & \text { developed by certification bodies (auditing } \\ & \text { companies) }\end{aligned}$
$\begin{aligned} & \text { I have confidence in food standards } \\ & \text { developed by producer organizations }\end{aligned}$


15. What would you recommend when choosing a food standard? गease give your opinion on each of the statements using the scale below

I would only recommend food standards
$\begin{aligned} & \text { Nhich are based on 3rd party certification } \\ & \text { I would advice others to have confidence } \\ & \text { n food standards that are very popular }\end{aligned}$

itandards which I am not interested in

16. Local food standards have the option to become equivalent (Benchmark) against other international standards/guidelines and achieve the recognition of multi-stakeholder organizations such as GLOBALG.A.P and the Global Food Safety Initiative (GFSI). While most pre-farm gate Good Agricultural Practice standards have been benchmarked against GLOBALG.A.P, GFSI has benchmarked most post-farm gate food safety standards. Taking this into account:

How likely do you think it would improve the credibility of local food standards (pre and post farm) of the following countries if they become benchmarked against GLOBALG.A.P and/or GFSI? Please answer using the scale below.

\begin{tabular}{|c|c|c|c|c|c|}
\hline Jnited States & $\begin{array}{c}\text { Extremely } \\
\text { likely } \\
0\end{array}$ & $\begin{array}{c}\text { likely } \\
0\end{array}$ & $\begin{array}{c}\text { Neither / nor } \\
0\end{array}$ & $\begin{array}{c}\text { unlikely } \\
0\end{array}$ & $\begin{array}{c}\text { Extremely } \\
\text { unlikely } \\
0\end{array}$ \\
\hline Jnited Kingdom & 0 & 0 & 0 & 0 & 0 \\
\hline Italy & $\mathrm{O}$ & 0 & $\mathrm{O}$ & 0 & 0 \\
\hline China & 0 & 0 & 0 & 0 & 0 \\
\hline Shana & $\mathrm{O}$ & 0 & $\mathrm{O}$ & $\mathrm{O}$ & 0 \\
\hline India & 0 & 0 & 0 & 0 & 0 \\
\hline Australia & 0 & 0 & 0 & 0 & 0 \\
\hline Mexico & $\mathrm{O}$ & 0 & $\mathrm{O}$ & 0 & 0 \\
\hline
\end{tabular}

Back Next 
You are almost finishing this survey, but before doing so, we would like to ask you a few questions about your company

17. In which country is your company headquarters located?

Please type the country name

18. What type of business is your company mainly dedicated to?

Retail

Food Service / Restaurant

Manufacturing / Packing

Trading (Imports / Exports)

Supplier (e.g. Cooperative, Producer organization etc.)

Service Provider (Certification, Accreditation, laboratory, consultant,etc.)

Other (please indicate)

19. What is approximately the global annual turnover of your company?

Less than 1 Million $€$

1 Million $€$ to less than 50 Millions $€$

50 Millions $€$ to less than 100 Millions $€$

100 Millions $€$ to less than 500 Millions $€$

500 Millions $€$ to less than 1 billion $€$

More than 1 billion $€$

Back Next

20. What type of fresh food products are you mainly responsible for? Multiple answers are posible

$\square$ Fruit and Vegetables

Livestock (Cattle, poultry, pork, etc)

Aquaculture

$\square$ Flowers

$\square$ Coffee

Other (please indicate)

21. From which region(s) does your company mainly source these fresh food products? Multiple answers are posible

$\square$ North America

Latin America

Europe

Africa

$\square$ Asia

Australasia 
...and last but not least we would like ask a few questions about yourself

22. What is your current position in the company?

Sales Manager

Quality Manager

Buyer

Technical Expert

Auditor / Inspector

Other (please indicate)

23. In which country were you born?

24. Please indicate your year of birth.

19

25. Please indicate your gender.

Female Male

(Back Next

Thank you for your support in taking part in our survey! 
Annex 2: Distribution of Country of Birth by Region

LATIN AMERICA

\begin{tabular}{|c|c|c|}
\hline & Frequency & $\%$ \\
\hline Argentina & 6 & 1.9 \\
\hline Brazil & 8 & 2.6 \\
\hline Chile & 7 & 2.3 \\
\hline Colombia & 6 & 1.9 \\
\hline Costa Rica & 1 & 0.3 \\
\hline Ecuador & 6 & 1.9 \\
\hline Guatemala & 1 & 0.3 \\
\hline Mexico & 2 & 0.6 \\
\hline Paraguay & 1 & 0.3 \\
\hline Peru & 3 & 1 \\
\hline \multirow[t]{2}{*}{ Uruguay } & 5 & 1.6 \\
\hline & 46 & 14.7 \\
\hline \multicolumn{3}{|l|}{ EUROPE } \\
\hline & Frequency & $\%$ \\
\hline Austria & 5 & 1.6 \\
\hline Belgium & 2 & 0.6 \\
\hline Czech Republic & 1 & 0.3 \\
\hline Cyprus & 1 & 0.3 \\
\hline Denmark & 1 & 0.3 \\
\hline Faroe Islands & 1 & 0.3 \\
\hline Finland & 2 & 0.6 \\
\hline France & 9 & 2.9 \\
\hline Germany & 30 & 9.7 \\
\hline Greece & 1 & 0.3 \\
\hline Ireland & 2 & 0.6 \\
\hline Italy & 9 & 2.9 \\
\hline Luxembourg & 1 & 0.3 \\
\hline Malta & 1 & 0.3 \\
\hline Norway & 3 & 1 \\
\hline Poland & 1 & 0.3 \\
\hline Portugal & 4 & 1.3 \\
\hline Russia & 1 & 0.3 \\
\hline Serbia & 2 & 0.6 \\
\hline Slovakia & 1 & 0.3 \\
\hline Spain & 17 & 5.5 \\
\hline Suriname & 1 & 0.3 \\
\hline Sweden & 2 & 0.6 \\
\hline Switzerland & 5 & 1.6 \\
\hline Netherlands & 23 & 7.4 \\
\hline Turkey & 5 & 1.6 \\
\hline \multirow[t]{2}{*}{ United Kingdom } & 27 & 8.7 \\
\hline & 158 & 48.9 \\
\hline
\end{tabular}


AUSTRALASIA

\begin{tabular}{lcc}
\hline & Frequency & $\%$ \\
\hline Australia & 10 & 3.2 \\
New Zealand & 3 & 1 \\
\hline & $\mathbf{1 3}$ & $\mathbf{4 . 2}$
\end{tabular}

\section{NORTH AMERICA}

\begin{tabular}{lcc}
\hline & Frequency & $\%$ \\
\hline Canada & 5 & 1.6 \\
United States & 22 & 7.1 \\
\hline & $\mathbf{2 7}$ & $\mathbf{8 . 7}$
\end{tabular}

AFRICA

\begin{tabular}{lcc}
\hline & Frequency & $\%$ \\
\hline Algeria & 1 & 0.3 \\
Cameroon & 1 & 0.3 \\
Egypt & 11 & 3.5 \\
Ghana & 5 & 1.6 \\
Kenya & 5 & 1.6 \\
Libya & 1 & 0.3 \\
Morocco & 1 & 0.3 \\
South Africa & 6 & 1.9 \\
\hline & $\mathbf{3 1}$ & $\mathbf{9 . 8}$ \\
ASIAN & & \\
\hline & Frequency & $\%$ \\
\hline China & 4 & 1.3 \\
India & 6 & 1.9 \\
Indonesia & 1 & 0.3 \\
Palestine & 1 & 0.3 \\
Pakistan & 2 & 0.6 \\
Singapore & 1 & 0.3 \\
Syria & 1 & 0.3 \\
Taiwan & 2 & 0.6 \\
Thailand & 3 & 1 \\
Vietnam & 5 & 1.6 \\
\hline & $\mathbf{2 6}$ & $\mathbf{8 . 2}$ \\
& & \\
Missing & & \\
\hline TOTAL & $\mathbf{3 1 0}$ & $\mathbf{1 0 0}$ \\
& &
\end{tabular}


Annex 3: Distribution of Country of Birth by Economic Group

MAJOR ADVANCED ECONOMIES

\begin{tabular}{lcc}
\hline & Frequency & $\%$ \\
\hline Canada & 5 & 1.6 \\
France & 9 & 2.9 \\
Germany & 30 & 9.7 \\
Italy & 9 & 2.9 \\
United Kingdom & 27 & 8.7 \\
United States & 22 & 7.1 \\
\hline $\mathrm{n}=6$ countries & $\mathbf{1 0 2}$ & $\mathbf{3 2 . 9}$
\end{tabular}

ADVANCED ECONOMIES

\begin{tabular}{lcc}
\hline & Frequency & $\%$ \\
\hline Australia & 10 & 3.2 \\
Austria & 5 & 1.6 \\
Belgium & 2 & 0.6 \\
Cyprus & 1 & 0.3 \\
Czech Republic & 1 & 0.3 \\
Denmark & 1 & 0.3 \\
Faroe Islands & 1 & 0.3 \\
Finland & 2 & 0.6 \\
Greece & 1 & 0.3 \\
Ireland & 2 & 0.6 \\
Luxembourg & 1 & 0.3 \\
Malta & 1 & 0.3 \\
New Zealand & 3 & 1 \\
Norway & 3 & 1 \\
Portugal & 4 & 1.3 \\
Singapore & 1 & 0.3 \\
Slovakia & 1 & 0.3 \\
Spain & 17 & 5.5 \\
Sweden & 2 & 0.6 \\
Switzerland & 5 & 1.6 \\
Taiwan & 2 & 0.6 \\
Netherlands & 23 & 7.4 \\
\hline n=22 countries & $\mathbf{8 9}$ & $\mathbf{2 8 . 3}$
\end{tabular}

DEVELOPING COUNTRIES

\begin{tabular}{lcc}
\hline & Frequency & $\%$ \\
\hline Algeria & 1 & 0.3 \\
Argentina & 6 & 1.9 \\
Brazil & 8 & 2.6 \\
Cameroon & 1 & 0.3 \\
Chile & 7 & 2.3 \\
China & 4 & 1.3 \\
Colombia & 6 & 1.9 \\
Costa Rica & 1 & 0.3 \\
Ecuador & 6 & 1.9 \\
Egypt & 11 & 3.5 \\
Ghana & 5 & 1.6 \\
Guatemala & 1 & 0.3 \\
India & 6 & 1.9 \\
Indonesia & 1 & 0.3
\end{tabular}




\begin{tabular}{lcc} 
Kenya & 5 & 1.6 \\
Libya & 1 & 0.3 \\
Mexico & 2 & 0.6 \\
Morocco & 1 & 0.3 \\
Pakistan & 2 & 0.6 \\
Palestine & 1 & 0.3 \\
Paraguay & 1 & 0.3 \\
Peru & 3 & 1 \\
Poland & 1 & 0.3 \\
Russia & 1 & 0.3 \\
Serbia & 2 & 0.6 \\
South Africa & 6 & 1.9 \\
Suriname & 1 & 0.3 \\
Syria & 1 & 0.3 \\
Thailand & 3 & 1 \\
Turkey & 5 & 1.6 \\
Uruguay & 5 & 1.6 \\
Vietnam & 5 & 1.6 \\
\hline n=32 countries & $\mathbf{1 1 0}$ & $\mathbf{3 4 . 9}$ \\
Missing values & 9 & \\
\hline TOTAL & $\mathbf{3 1 0}$ & $\mathbf{1 0 0}$
\end{tabular}


Annex 4: Distribution of Country of Birth by Language Group

LATIN

\begin{tabular}{lcc}
\hline & Frequency & $\%$ \\
\hline Argentina & 6 & 1.9 \\
Belgium & 2 & 0.6 \\
Brazil & 8 & 2.6 \\
Chile & 7 & 2.3 \\
Colombia & 6 & 1.9 \\
Costa Rica & 1 & 0.3 \\
Ecuador & 6 & 1.9 \\
France & 9 & 2.9 \\
Guatemala & 1 & 0.3 \\
Italy & 9 & 2.9 \\
Mexico & 2 & 0.6 \\
Paraguay & 1 & 0.3 \\
Peru & 3 & 1 \\
Portugal & 4 & 1.3 \\
Spain & 17 & 5.5 \\
Uruguay & 5 & 1.6 \\
\hline & $\mathbf{8 7}$ & $\mathbf{2 7 . 9}$
\end{tabular}

ENGLISH

\begin{tabular}{lcc}
\hline & Frequency & $\%$ \\
\hline Australia & 10 & 3.2 \\
Cameroon & 1 & 0.3 \\
Canada & 5 & 1.6 \\
Ghana & 5 & 1.6 \\
India & 6 & 1.9 \\
Ireland & 2 & 0.6 \\
Kenya & 5 & 1.6 \\
Malta & 1 & 0.3 \\
New Zealand & 3 & 1 \\
Pakistan & 2 & 0.6 \\
South Africa & 6 & 1.9 \\
United Kingdom & 27 & 8.7 \\
United States & 22 & 7.1 \\
\hline & $\mathbf{9 5}$ & $\mathbf{3 0 . 4}$
\end{tabular}

GERMANIC

\begin{tabular}{lcc}
\hline & Frequency & $\%$ \\
\hline Austria & 5 & 1.6 \\
Denmark & 1 & 0.3 \\
Faroe Islands & 1 & 0.3 \\
Finland & 2 & 0.6 \\
Germany & 30 & 9.7 \\
Luxembourg & 1 & 0.3 \\
Norway & 3 & 1 \\
Netherlands & 23 & 7.4 \\
Suriname & 1 & 0.3 \\
Sweden & 2 & 0.6 \\
\hline & $\mathbf{6 9}$ & $\mathbf{2 2 . 1}$
\end{tabular}


ARABIC

\begin{tabular}{lcc}
\hline & Frequency & $\%$ \\
\hline Algeria & 1 & 0.3 \\
Egypt & 11 & 3.5 \\
Libya & 1 & 0.3 \\
Morocco & 1 & 0.3 \\
Palestine & 1 & 0.3 \\
Syria & 1 & 0.3 \\
\hline & $\mathbf{1 6}$ & $\mathbf{5}$
\end{tabular}

ASIAN

\begin{tabular}{lcc}
\hline & Frequency & $\%$ \\
\hline China & 4 & 1.3 \\
Indonesia & 1 & 0.3 \\
Singapore & 1 & 0.3 \\
Taiwan & 2 & 0.6 \\
Thailand & 3 & 1 \\
Turkey & 5 & 1.6 \\
Vietnam & 5 & 1.6 \\
\hline & $\mathbf{2 1}$ & $\mathbf{6 . 7}$
\end{tabular}

OTHERS

\begin{tabular}{lcc}
\hline & Frequency & $\%$ \\
\hline Cyprus & 1 & 0.3 \\
Czech Republic & 1 & 0.3 \\
Greece & 1 & 0.3 \\
Poland & 1 & 0.3 \\
Serbia & 2 & 0.6 \\
Slovakia & 1 & 0.3 \\
Russia & 1 & 0.3 \\
Turkey & 5 & 1.6 \\
\hline & $\mathbf{1 3}$ & $\mathbf{4}$ \\
Missing & & \\
\hline TOTAL & $\mathbf{3 1 0}$ & $\mathbf{1 0 0}$
\end{tabular}


Annex 5: Factor Analysis of Credibility of National Food Standards

\section{Credibility of National Food Sandards from Developing Countries}

\begin{tabular}{|l|c|c|}
\hline & $\begin{array}{c}\text { Component } \\
\text { LDC }\end{array}$ & \multirow{2}{*}{ KMO } \\
\hline CertGhana & 0.86 \\
\hline CertMexico & 0.859 \\
\hline CertChina & 0.835 \\
\hline CertIndia & 0.835 \\
\hline StandGhana & 0.83 \\
\hline StandChina & 0.824 \\
\hline StandMexico & 0.82 \\
\hline StandIndia & 0.818 \\
\hline CredMexico & 0.796 \\
\hline CredGhana & 0.762 \\
\hline CredIndia & 0.755 \\
\hline CredChina & 0.754 \\
\hline AVE $(\mathbf{\%})$ & $\mathbf{6 6 . 1}$ \\
\hline CRA & $\mathbf{0 . 9 5 3}$ \\
\hline $\mathbf{N}^{\circ}$ of Items & $\mathbf{1 2}$ \\
\hline
\end{tabular}

2. Credibility of National Food Standards from Developed Countries

\begin{tabular}{|c|c|c|c|}
\hline & \multicolumn{2}{|c|}{ Componenst } & \multirow[b]{2}{*}{$\mathrm{KMO}$} \\
\hline & English & Italian & \\
\hline CertUnited Kingdom & 0.811 & & \multirow[t]{12}{*}{0.842} \\
\hline StandUnited Kingdom & 0.8 & & \\
\hline StandAustralia & 0.765 & & \\
\hline CertAustralia & 0.757 & & \\
\hline StandUnited States & 0.692 & & \\
\hline CertUnited States & 0.684 & & \\
\hline CredAustralia & 0.664 & & \\
\hline CredUnited Kingdom & 0.635 & & \\
\hline CredUnited States & 0.587 & & \\
\hline CredItaly & & 0.841 & \\
\hline StandItaly & & 0.817 & \\
\hline CertItaly & & 0.812 & \\
\hline AVE (\%) & 40.3 & 24.4 & \\
\hline CRA & 0.914 & 0.855 & \\
\hline $\mathbf{N}^{\circ}$ of Items & 9 & 3 & \\
\hline
\end{tabular}


Annex 6: Factor Analysis for Adoption of Benchmarking Systems by National Food Standards

\begin{tabular}{|c|c|c|c|c|}
\hline Factors /Staments & Loadings & $\begin{array}{c}\text { Cronbach's } \\
\text { Alpha }\end{array}$ & $\mathrm{N}^{\circ}$ of Items & Variance \\
\hline \multicolumn{5}{|c|}{ Benchmarking Developing Countries } \\
\hline Ghana & 0.919 & \multirow[t]{4}{*}{0.941} & \multirow[t]{4}{*}{4} & \multirow[t]{4}{*}{47.955} \\
\hline China & 0.892 & & & \\
\hline India & 0.886 & & & \\
\hline Mexico & 0.852 & & & \\
\hline \multicolumn{5}{|c|}{ Benchmarking Developed Countries } \\
\hline United Kingdom & \multirow{3}{*}{$\begin{array}{c}0.94 \\
0.917 \\
0.9\end{array}$} & \multirow[t]{3}{*}{0.951} & \multirow[t]{3}{*}{3} & \multirow[t]{3}{*}{40.06} \\
\hline Australia & & & & \\
\hline United States & & & & \\
\hline
\end{tabular}


Annex 7: Frequencies results from online questionnaire.

Q1. Time in the Food Industry

\begin{tabular}{|c|c|c|c|c|}
\hline Years & Frequency & $\begin{array}{c}\text { Percent } \\
(\%)\end{array}$ & $\begin{array}{c}\text { Valid Percent } \\
(\%)\end{array}$ & $\begin{array}{c}\text { Cumulative } \\
\text { Percent } \\
(\%) \\
\end{array}$ \\
\hline 1 & 3 & 1.0 & 1.0 & 1.0 \\
\hline 2 & 5 & 1.6 & 1.6 & 2.6 \\
\hline 3 & 11 & 3.5 & 3.5 & 6.1 \\
\hline 4 & 4 & 1.3 & 1.3 & 7.4 \\
\hline 5 & 12 & 3.9 & 3.9 & 11.3 \\
\hline 6 & 16 & 5.2 & 5.2 & 16.5 \\
\hline 7 & 19 & 6.1 & 6.1 & 22.6 \\
\hline 8 & 10 & 3.2 & 3.2 & 25.8 \\
\hline 9 & 7 & 2.3 & 2.3 & 28.1 \\
\hline 10 & 43 & 13.9 & 13.9 & 41.9 \\
\hline 11 & 8 & 2.6 & 2.6 & 44.5 \\
\hline 12 & 17 & 5.5 & 5.5 & 50.0 \\
\hline 13 & 3 & 1.0 & 1.0 & 51.0 \\
\hline 14 & 10 & 3.2 & 3.2 & 54.2 \\
\hline 15 & 25 & 8.1 & 8.1 & 62.3 \\
\hline 16 & 2 & 0.6 & 0.6 & 62.9 \\
\hline 17 & 2 & 0.6 & 0.6 & 63.5 \\
\hline 18 & 8 & 2.6 & 2.6 & 66.1 \\
\hline 19 & 1 & 0.3 & 0.3 & 66.5 \\
\hline 20 & 20 & 6.5 & 6.5 & 72.9 \\
\hline 21 & 6 & 1.9 & 1.9 & 74.8 \\
\hline 22 & 6 & 1.9 & 1.9 & 76.8 \\
\hline 23 & 3 & 1.0 & 1.0 & 77.7 \\
\hline 24 & 1 & 0.3 & 0.3 & 78.1 \\
\hline 25 & 18 & 5.8 & 5.8 & 83.9 \\
\hline 26 & 5 & 1.6 & 1.6 & 85.5 \\
\hline 27 & 4 & 1.3 & 1.3 & 86.8 \\
\hline 28 & 3 & 1.0 & 1.0 & 87.7 \\
\hline 29 & 2 & 0.6 & 0.6 & 88.4 \\
\hline 30 & 10 & 3.2 & 3.2 & 91.6 \\
\hline 32 & 1 & 0.3 & 0.3 & 91.9 \\
\hline 33 & 2 & 0.6 & 0.6 & 92.6 \\
\hline 34 & 1 & 0.3 & 0.3 & 92.9 \\
\hline 35 & 7 & 2.3 & 2.3 & 95.2 \\
\hline 36 & 1 & 0.3 & 0.3 & 95.5 \\
\hline 37 & 2 & 0.6 & 0.6 & 96.1 \\
\hline 39 & 1 & 0.3 & 0.3 & 96.5 \\
\hline 40 & 5 & 1.6 & 1.6 & 98.1 \\
\hline 41 & 3 & 1.0 & 1.0 & 99.0 \\
\hline 42 & 1 & 0.3 & 0.3 & 99.4 \\
\hline 46 & 2 & 0.6 & 0.6 & 100.0 \\
\hline Total & 310 & 100 & 100 & \\
\hline
\end{tabular}


Q2. Involvement with Food Standards

\begin{tabular}{|l|c|c|c|c|}
\hline Degreee of involvement & $\begin{array}{c}\text { Frequency } \\
\left(\mathbf{N}^{\circ} \text { of }\right. \\
\text { Responses })\end{array}$ & $\begin{array}{c}\text { Percent } \\
(\%)\end{array}$ & $\begin{array}{c}\text { Valid } \\
\text { Percent } \\
(\%)\end{array}$ & $\begin{array}{c}\text { Cumulative } \\
\text { Percent } \\
(\%)\end{array}$ \\
\hline Very Involved & 175 & 56.5 & 56.5 & 56.5 \\
Involved & 86 & 27.7 & 27.7 & 84.2 \\
Partially Involved & 36 & 11.6 & 11.6 & 95.8 \\
Little Involved & 8 & 2.6 & 2.6 & 98.4 \\
Not Involved at all & 5 & 1.6 & 1.6 & 100 \\
\hline Total & 310 & 100 & 100 & \\
\hline
\end{tabular}

Q3.Certified Fresh Food Demand

\begin{tabular}{|c|c|c|c|c|}
\hline $\begin{array}{l}\text { Demand for certified fresh } \\
\text { food }\end{array}$ & $\begin{array}{l}\text { Frequency } \\
\left(\mathbf{N}^{\circ} \text { of }\right. \\
\text { Responses })\end{array}$ & $\begin{array}{c}\text { Percent } \\
(\%)\end{array}$ & $\begin{array}{c}\text { Valid Percent } \\
(\%)\end{array}$ & $\begin{array}{c}\text { Cumulative } \\
\text { Percent } \\
(\%)\end{array}$ \\
\hline Yes & 105 & 33.9 & 34.3 & 34.3 \\
\hline No & 201 & 64.8 & 65.7 & 100 \\
\hline n Total & 306 & 98.7 & 100 & \\
\hline Misssing values & 4 & 1.3 & & \\
\hline N Total & 310 & 100 & 100 & \\
\hline
\end{tabular}

Q4. Reasons to request certified fresh food to suppliers

\begin{tabular}{|l|c|c|c|c|}
\hline To maintain company's reputation & $\begin{array}{c}\text { Frequency } \\
\mathbf{N}^{\circ} \text { of } \\
\text { Responses) }\end{array}$ & $\begin{array}{c}\text { Percent } \\
(\boldsymbol{\%})\end{array}$ & $\begin{array}{c}\text { Valid } \\
\text { Percent } \\
(\boldsymbol{\%})\end{array}$ & $\begin{array}{c}\text { Cumulative } \\
\text { Percent } \\
(\boldsymbol{\%})\end{array}$ \\
\hline 0 & 23 & 7.4 & 20.9 & 20.9 \\
Rank 1 & 13 & 4.2 & 11.8 & 32.7 \\
Rank 2 & 15 & 4.8 & 13.6 & 46.4 \\
Rank 3 & 22 & 7.1 & 20 & 66.4 \\
Rank 4 & 24 & 7.7 & 21.8 & 88.2 \\
Rank 5 & 13 & 4.2 & 11.8 & 100 \\
\hline n Total & 110 & 35.5 & 100 & \\
Missing & 200 & 64.5 & & \\
N Total & 310 & 100 & & \\
\hline
\end{tabular}




\begin{tabular}{|c|c|c|c|c|}
\hline To ensure due dilligence & $\begin{array}{l}\text { Frequency } \\
\left(\mathbf{N}^{\circ} \text { of }\right. \\
\text { Responses })\end{array}$ & $\begin{array}{c}\text { Percent } \\
(\%)\end{array}$ & $\begin{array}{c}\text { Valid } \\
\text { Percent } \\
(\%)\end{array}$ & $\begin{array}{c}\text { Cumulative } \\
\text { Percent } \\
(\%)\end{array}$ \\
\hline Valid & 20 & 6.5 & 18.2 & 18.2 \\
\hline Rank 1 & 20 & 6.5 & 18.2 & 36.4 \\
\hline Rank 2 & 20 & 6.5 & 18.2 & 54.5 \\
\hline Rank 3 & 19 & 6.1 & 17.3 & 71.8 \\
\hline Rank 4 & 17 & 5.5 & 15.5 & 87.3 \\
\hline Rank 5 & 14 & 4.5 & 12.7 & 100 \\
\hline n Total & 110 & 35.5 & 100 & \\
\hline Missing & 200 & 64.5 & & \\
\hline N Total & 310 & 100 & & \\
\hline
\end{tabular}

\begin{tabular}{|l|c|c|c|c|}
\hline To satisfy customers/consumers & $\begin{array}{c}\text { Frequency } \\
\mathbf{N}^{\circ} \text { of } \\
\text { Responses) }\end{array}$ & $\begin{array}{c}\text { Percent } \\
(\boldsymbol{\%})\end{array}$ & $\begin{array}{c}\text { Valid } \\
\text { Percent } \\
(\boldsymbol{\%})\end{array}$ & $\begin{array}{c}\text { Cumulative } \\
\text { Percent } \\
(\boldsymbol{\%})\end{array}$ \\
\hline 0 & 17 & 5.5 & 15.5 & 15.5 \\
Rank 1 & 41 & 13.2 & 37.3 & 52.7 \\
Rank 2 & 32 & 10.3 & 29.1 & 81.8 \\
Rank 3 & 15 & 4.8 & 13.6 & 95.5 \\
Rank 4 & 4 & 1.3 & 3.6 & 99.1 \\
Rank 5 & 1 & 0.3 & 0.9 & 100 \\
\hline n Total & 110 & 35.5 & 100 & \\
Missing & 200 & 64.5 & & \\
N Total & 310 & 100 & & \\
\hline
\end{tabular}

\begin{tabular}{|l|c|c|c|c|}
\hline \multicolumn{1}{|c|}{ To have market access } & $\begin{array}{c}\text { Frequency } \\
\mathbf{N}^{\circ} \text { of } \\
\text { Responses) }\end{array}$ & $\begin{array}{c}\text { Percent } \\
(\mathbf{\%})\end{array}$ & $\begin{array}{c}\text { Valid } \\
\text { Percent } \\
(\mathbf{\%})\end{array}$ & $\begin{array}{c}\text { Cumulative } \\
\text { Percent } \\
(\mathbf{\%})\end{array}$ \\
\hline 0 & 22 & 7.1 & 20 & 20 \\
Rank 1 & 22 & 7.1 & 20 & 40 \\
Rank 2 & 19 & 6.1 & 17.3 & 57.3 \\
Rank 3 & 17 & 5.5 & 15.5 & 72.7 \\
Rank 4 & 12 & 3.9 & 10.9 & 83.6 \\
Rank 5 & 18 & 5.8 & 16.4 & 100 \\
\hline n Total & 110 & 35.5 & 100 & \\
Missing & 200 & 64.5 & & \\
N Total & 310 & 100 & & \\
\hline
\end{tabular}




\begin{tabular}{|l|c|c|c|c|}
\hline To differentiate from competitors & $\begin{array}{c}\text { Frequency } \\
\left(\mathbf{N}^{\circ} \text { of }\right. \\
\text { Responses })\end{array}$ & $\begin{array}{c}\text { Percent } \\
(\boldsymbol{\%})\end{array}$ & $\begin{array}{c}\text { Valid } \\
\text { Percent }(\%)\end{array}$ & $\begin{array}{c}\text { Cumulative } \\
\text { Percent } \\
(\%)\end{array}$ \\
\hline 0 & 28 & 9 & 25.5 & 25.5 \\
Rank 1 & 2 & 0.6 & 1.8 & 27.3 \\
Rank 2 & 8 & 2.6 & 7.3 & 34.5 \\
Rank 3 & 16 & 5.2 & 14.5 & 49.1 \\
Rank 4 & 25 & 8.1 & 22.7 & 71.8 \\
Rank 5 & 31 & 10 & 28.2 & 100 \\
\hline n Total & 110 & 35.5 & 100 & \\
Missing & 200 & 64.5 & & \\
N Total & 310 & 100 & & \\
\hline
\end{tabular}

Q5. Type of certifications mostly demanded

\begin{tabular}{|c|c|c|c|c|c|}
\hline $\begin{array}{l}\text { Rain Forest Alliance } \\
\text { in \%) }\end{array}$ & (Demand & $\begin{array}{c}\text { Frequency } \\
\left(\mathbf{N}^{\circ} \text { of }\right. \\
\text { Responses })\end{array}$ & $\begin{array}{c}\text { Percent } \\
(\%)\end{array}$ & $\begin{array}{c}\text { Valid } \\
\text { Percent } \\
(\%)\end{array}$ & $\begin{array}{c}\text { Cumulative } \\
\text { Percent } \\
(\%)\end{array}$ \\
\hline 1 & & 2 & 0.6 & 0.6 & 0.6 \\
\hline 5 & & 4 & 1.3 & 1.3 & 1.9 \\
\hline 10 & & 4 & 1.3 & 1.3 & 3.2 \\
\hline 15 & & 1 & 0.3 & 0.3 & 3.5 \\
\hline 50 & & 2 & 0.6 & 0.6 & 4.1 \\
\hline 60 & & 1 & 0.3 & 0.3 & 4.4 \\
\hline 80 & & 1 & 0.3 & 0.3 & 4.7 \\
\hline 98 & & 200 & 64.5 & 64.5 & 69.2 \\
\hline 99 & & 77 & 24.8 & 24.8 & 94 \\
\hline 100 & & 1 & 0.3 & 0.3 & 100 \\
\hline $\begin{array}{l}\text { Valid } \\
\text { N Total }\end{array}$ & & $\begin{array}{c}17 \\
310\end{array}$ & $\begin{array}{l}5.5 \\
100\end{array}$ & $\begin{array}{l}5.5 \\
100\end{array}$ & 5.5 \\
\hline
\end{tabular}




\begin{tabular}{|c|c|c|c|c|}
\hline $\begin{array}{c}\text { SQF 2000 } \\
\text { (Demand in \%) }\end{array}$ & $\begin{array}{c}\text { Frequency } \\
\mathbf{N}^{\circ} \text { of } \\
\text { Responses) }\end{array}$ & $\begin{array}{c}\text { Percent } \\
(\boldsymbol{\%})\end{array}$ & $\begin{array}{c}\text { Valid } \\
\text { Percent } \\
(\boldsymbol{\%})\end{array}$ & $\begin{array}{c}\text { Cumulative } \\
\text { Percent } \\
(\%)\end{array}$ \\
\hline 0 & 17 & 5.5 & 5.5 & 5.5 \\
4 & 1 & 0.3 & 0.3 & 5.8 \\
5 & 2 & 0.6 & 0.6 & 6.4 \\
10 & 3 & 1 & 1 & 7.4 \\
20 & 1 & 0.3 & 0.3 & 7.7 \\
25 & 1 & 0.3 & 0.3 & 8 \\
& 1 & 0.3 & 0.3 & 8.3 \\
45 & 1 & 0.3 & 0.3 & 8.6 \\
50 & 1 & 0.3 & 0.3 & 8.9 \\
& 1 & 0.3 & 0.3 & 9.2 \\
90 & 200 & 64.5 & 64.5 & 73.7 \\
& 10 & 25.8 & 25.8 & 99.5 \\
\hline N Total & 80 & 0.3 & 0.3 & 100 \\
\hline
\end{tabular}

\begin{tabular}{|c|c|c|c|c|}
\hline $\begin{array}{c}\text { Organic } \\
\text { (Demand in \%) }\end{array}$ & $\begin{array}{c}\text { Frequency } \\
\mathbf{N}^{\circ} \text { of } \\
\text { Responses) }\end{array}$ & $\begin{array}{c}\text { Percent } \\
(\boldsymbol{\%})\end{array}$ & $\begin{array}{c}\text { Valid } \\
\text { Percent } \\
(\boldsymbol{\%})\end{array}$ & $\begin{array}{c}\text { Cumulative } \\
\text { Percent } \\
(\boldsymbol{\%})\end{array}$ \\
\hline 0 & 8 & 2.6 & 2.6 & 2.6 \\
1 & 1 & 0.3 & 0.3 & 2.9 \\
3 & 1 & 0.3 & 0.3 & 3.2 \\
5 & 16 & 5.2 & 5.2 & 8.4 \\
8 & 1 & 0.3 & 0.3 & 8.7 \\
10 & 9 & 2.9 & 2.9 & 11.6 \\
15 & 3 & 1 & 1 & 12.6 \\
20 & 4 & 1.3 & 1.3 & 13.9 \\
30 & 4 & 1.3 & 1.3 & 15.2 \\
40 & 2 & 0.6 & 0.6 & 15.8 \\
50 & 2 & 0.6 & 0.6 & 16.4 \\
55 & 1 & 0.3 & 0.3 & 16.7 \\
60 & 2 & 0.6 & 0.6 & 17.3 \\
70 & 1 & 0.3 & 0.3 & 17.6 \\
75 & 1 & 0.3 & 0.3 & 17.9 \\
90 & 2 & 0.6 & 0.6 & 18.5 \\
95 & 1 & 0.3 & 0.3 & 18.8 \\
98 & 200 & 64.5 & 64.5 & 83.3 \\
99 & 47 & 15.2 & 15.2 & 98.5 \\
100 & 4 & 1.3 & 1.3 & 100 \\
\hline & & 100 & 100 & \\
\hline
\end{tabular}




\begin{tabular}{|c|c|c|c|c|}
\hline $\begin{array}{c}\text { IFS } \\
\text { (Demand in \%) }\end{array}$ & $\begin{array}{l}\text { Frequency } \\
\left(\mathbf{N}^{\circ} \text { of }\right. \\
\text { Responses })\end{array}$ & $\begin{array}{c}\text { Percent } \\
(\%)\end{array}$ & $\begin{array}{c}\text { Valid } \\
\text { Percent } \\
(\%)\end{array}$ & $\begin{array}{c}\text { Cumulative } \\
\text { Percent } \\
(\%)\end{array}$ \\
\hline 0 & 13 & 4.2 & 4.2 & 4.2 \\
\hline 1 & 2 & 0.6 & 0.6 & 4.8 \\
\hline 5 & 1 & 0.3 & 0.3 & 5.1 \\
\hline 10 & 2 & 0.6 & 0.6 & 5.7 \\
\hline 15 & 1 & 0.3 & 0.3 & 6 \\
\hline 20 & 6 & 1.9 & 1.9 & 7.9 \\
\hline 25 & 1 & 0.3 & 0.3 & 8.2 \\
\hline 50 & 6 & 1.9 & 1.9 & 10.1 \\
\hline 60 & 1 & 0.3 & 0.3 & 10.4 \\
\hline 75 & 1 & 0.3 & 0.3 & 10.7 \\
\hline 90 & 1 & 0.3 & 0.3 & 11 \\
\hline 98 & 200 & 64.5 & 64.5 & 75.5 \\
\hline 99 & 63 & 20.3 & 20.3 & 95.8 \\
\hline 100 & 12 & 3.9 & 3.9 & 100 \\
\hline N Total & 310 & 100 & 100 & \\
\hline
\end{tabular}

\begin{tabular}{|c|c|c|c|c|}
\hline $\begin{array}{c}\text { Fair Trade } \\
\text { (Demand in \%) }\end{array}$ & $\begin{array}{c}\text { Frequency } \\
\mathbf{N}^{\circ} \text { of } \\
\text { Responses) }\end{array}$ & $\begin{array}{c}\text { Percent } \\
(\boldsymbol{\%})\end{array}$ & $\begin{array}{c}\text { Valid } \\
\text { Percent }(\boldsymbol{\%})\end{array}$ & $\begin{array}{c}\text { Cumulative } \\
\text { Percent } \\
(\boldsymbol{\%})\end{array}$ \\
\hline 0 & 11 & 3.5 & 3.5 & 3.5 \\
1 & 2 & 0.6 & 0.6 & 4.1 \\
2 & 3 & 1 & 1 & 5.1 \\
4 & 1 & 0.3 & 0.3 & 5.4 \\
5 & 5 & 1.6 & 1.6 & 7 \\
10 & 2 & 0.6 & 0.6 & 7.6 \\
15 & 3 & 1 & 1 & 8.6 \\
20 & 4 & 1.3 & 1.3 & 9.9 \\
25 & 2 & 0.6 & 0.6 & 10.5 \\
30 & 1 & 0.3 & 0.3 & 10.8 \\
50 & 4 & 1.3 & 1.3 & 12.1 \\
70 & 1 & 0.3 & 0.3 & 12.4 \\
95 & 1 & 0.3 & 0.3 & 12.7 \\
98 & 200 & 64.5 & 64.5 & 77.2 \\
99 & 68 & 21.9 & 21.9 & 99.1 \\
& 2 & 0.6 & 0.6 & 100 \\
\hline N Total & 310 & 100 & 100 & \\
\hline
\end{tabular}




\begin{tabular}{|c|c|c|c|c|}
\hline $\begin{array}{c}\text { GLOBALG.A.P } \\
\text { (Demand in \%) }\end{array}$ & $\begin{array}{c}\text { Frequency } \\
\mathbf{N}^{\circ} \text { of } \\
\text { Responses) }\end{array}$ & $\begin{array}{c}\text { Percent } \\
(\boldsymbol{\%})\end{array}$ & $\begin{array}{c}\text { Valid } \\
\text { Percent }(\boldsymbol{\%})\end{array}$ & $\begin{array}{c}\text { Cumulative } \\
\text { Percent } \\
(\boldsymbol{\%})\end{array}$ \\
\hline 2 & 1 & 0.3 & 0.3 & 0.3 \\
10 & 4 & 1.3 & 1.3 & 1.6 \\
20 & 4 & 1.3 & 1.3 & 2.9 \\
25 & 1 & 0.3 & 0.3 & 2.2 \\
30 & 4 & 1.3 & 1.3 & 3.5 \\
35 & 2 & 0.6 & 0.6 & 4.1 \\
40 & 5 & 1.6 & 1.6 & 5.7 \\
50 & 5 & 1.6 & 1.6 & 7.3 \\
55 & 1 & 0.3 & 0.3 & 7.6 \\
60 & 2 & 0.6 & 0.6 & 8.2 \\
70 & 1 & 0.3 & 0.3 & 8.5 \\
75 & 1 & 0.3 & 0.3 & 8.8 \\
80 & 7 & 2.3 & 2.3 & 11.1 \\
90 & 3 & 1 & 1 & 12.1 \\
93 & 1 & 0.3 & 0.3 & 12.4 \\
95 & 5 & 1.6 & 1.6 & 14 \\
98 & 200 & 64.5 & 64.5 & 78.5 \\
99 & 25 & 8.1 & 8.1 & 86.6 \\
100 & 38 & 12.3 & 12.3 & 100 \\
\hline N Total & 310 & 100 & 100 & \\
\hline
\end{tabular}

\begin{tabular}{|c|c|c|c|c|}
\hline BRC (Demand in \%) & $\begin{array}{c}\text { Frequency } \\
\mathbf{N}^{\circ} \text { of } \\
\text { Responses) }\end{array}$ & $\begin{array}{c}\text { Percent } \\
(\boldsymbol{\%})\end{array}$ & $\begin{array}{c}\text { Valid } \\
\text { Percent }(\%)\end{array}$ & $\begin{array}{c}\text { Cumulative } \\
\text { Percent } \\
(\boldsymbol{\%})\end{array}$ \\
\hline 0 & 7 & 2.3 & 2.3 & 2.3 \\
5 & 6 & 1.9 & 1.9 & 4.2 \\
10 & 6 & 1.9 & 1.9 & 6.1 \\
20 & 3 & 1 & 1 & 7.1 \\
25 & 4 & 1.3 & 1.3 & 8.4 \\
30 & 1 & 0.3 & 0.3 & 8.7 \\
35 & 1 & 0.3 & 0.3 & 9 \\
50 & 6 & 1.9 & 1.9 & 10.9 \\
60 & 1 & 0.3 & 0.3 & 11.2 \\
70 & 2 & 0.6 & 0.6 & 11.8 \\
75 & 1 & 0.3 & 0.3 & 12.1 \\
90 & 1 & 0.3 & 0.3 & 12.4 \\
98 & 200 & 64.5 & 64.5 & 76.9 \\
99 & 59 & 19 & 19 & 95.9 \\
\hline N Total & 12 & 3.9 & 3.9 & 100 \\
\hline
\end{tabular}




\begin{tabular}{|c|c|c|c|c|}
\hline $\begin{array}{c}\text { ISO 22000 } \\
\text { (Demand in \%) }\end{array}$ & $\begin{array}{c}\text { Frequency } \\
\mathbf{N}^{\circ} \text { of } \\
\text { Responses) }\end{array}$ & $\begin{array}{c}\text { Percent } \\
(\boldsymbol{\%})\end{array}$ & $\begin{array}{c}\text { Valid } \\
\text { Percent }(\boldsymbol{\%})\end{array}$ & $\begin{array}{c}\text { Cumulative } \\
\text { Percent } \\
(\boldsymbol{\%})\end{array}$ \\
\hline 0 & 11 & 3.5 & 3.5 & 3.5 \\
1 & 2 & 0.6 & 0.6 & 4.1 \\
5 & 1 & 0.3 & 0.3 & 4.4 \\
6 & 1 & 0.3 & 0.3 & 4.7 \\
10 & 3 & 1 & 1 & 5.7 \\
15 & 1 & 0.3 & 0.3 & 6 \\
20 & 1 & 0.3 & 0.3 & 6.3 \\
30 & 3 & 1 & 1 & 7.3 \\
50 & 2 & 0.6 & 0.6 & 7.9 \\
70 & 2 & 0.6 & 0.6 & 10.5 \\
75 & 1 & 0.3 & 0.3 & 10.8 \\
& 4 & 1.3 & 1.3 & 12.1 \\
90 & 1 & 0.3 & 0.3 & 12.4 \\
98 & 200 & 64.5 & 64.5 & 76.9 \\
99 & 73 & 23.5 & 23.5 & 100 \\
& 4 & 1.3 & 1.3 & 100 \\
\hline N Total & 310 & 100 & 100 & \\
\hline
\end{tabular}

\begin{tabular}{|c|c|c|c|c|}
\hline $\begin{array}{c}\text { Other Standards* } \\
\text { (Demand in \%) }\end{array}$ & $\begin{array}{c}\text { Frequency } \\
\left(\mathbf{N}^{\circ} \text { of }\right. \\
\text { Responses })\end{array}$ & $\begin{array}{c}\text { Percent } \\
(\%)\end{array}$ & $\begin{array}{c}\text { Valid } \\
\text { Percent }(\%) \\
\end{array}$ & $\begin{array}{c}\text { Cumulative } \\
\text { Percent } \\
(\%)\end{array}$ \\
\hline 0 & 1 & 0.3 & 0.3 & 0.3 \\
\hline 5 & 2 & 0.6 & 0.6 & 0.9 \\
\hline 10 & 2 & 0.6 & 0.6 & 1.5 \\
\hline 20 & 8 & 2.6 & 2.6 & 4.1 \\
\hline 26 & 1 & 0.3 & 0.3 & 4.4 \\
\hline 30 & 3 & 1 & 1 & 5.4 \\
\hline 40 & 3 & 1 & 1 & 6.4 \\
\hline 50 & 2 & 0.6 & 0.6 & 7 \\
\hline 70 & 2 & 0.6 & 0.6 & 7.6 \\
\hline 75 & 1 & 0.3 & 0.3 & 7.9 \\
\hline 80 & 2 & 0.6 & 0.6 & 8.5 \\
\hline 98 & 200 & 64.5 & 64.5 & 73 \\
\hline 99 & 69 & 22.3 & 22.3 & 95.3 \\
\hline 100 & 14 & 4.5 & 4.5 & 100 \\
\hline N Total & 310 & 100 & 100 & \\
\hline
\end{tabular}




\begin{tabular}{|c|c|c|c|c|}
\hline *Other Standards & $\begin{array}{l}\text { Frequency } \\
\left(\mathbf{N}^{\circ} \text { of }\right. \\
\text { Responses })\end{array}$ & $\begin{array}{c}\text { Percent } \\
(\%)\end{array}$ & $\begin{array}{c}\text { Valid } \\
\text { Percent }(\%)\end{array}$ & $\begin{array}{c}\text { Cumulative } \\
\text { Percent } \\
(\%)\end{array}$ \\
\hline Agriconfiance & 2 & 0.6 & 0.6 & 0.6 \\
\hline BSCI & 1 & 0.3 & 0.3 & 0.9 \\
\hline CAFE practices & 1 & 0.3 & 0.3 & 1.2 \\
\hline Export license. BIS. PFA & 1 & 0.3 & 0.3 & 1.5 \\
\hline LEAF & 2 & 0.6 & 0.6 & 2.1 \\
\hline Field to Fork & 3 & 1 & 1 & 3.1 \\
\hline Freshcare & 2 & 0.6 & 0.6 & 3.7 \\
\hline GFSI Benchmarked & 2 & 0.6 & 0.6 & 4.3 \\
\hline GMP & 2 & 0.6 & 0.6 & 4.9 \\
\hline Green Food & 1 & 0.3 & 0.3 & 5.2 \\
\hline НАCCP & 5 & 1.6 & 1.6 & 6.8 \\
\hline IGP & 1 & 0.3 & 0.3 & 7.1 \\
\hline ISO 9001 & 2 & 0.6 & 0.6 & 7.7 \\
\hline ISO14000 & 1 & 0.3 & 0.3 & 8 \\
\hline Kosher \& Halal & 1 & 0.3 & 0.3 & 8.3 \\
\hline LGMA & 1 & 0.3 & 0.3 & 8.6 \\
\hline MSC & 2 & 0.6 & 0.6 & 9.2 \\
\hline PRIMUS & 2 & 0.6 & 0.6 & 9.8 \\
\hline Retailer & 1 & 0.3 & 0.3 & 10.1 \\
\hline TESCO NURTURE & 4 & 1.3 & 1.3 & 11.4 \\
\hline AH-protocol & 1 & 0.3 & 0.3 & 11.7 \\
\hline USDA GAP & 1 & 0.3 & 0.3 & 12 \\
\hline UTZ CERTIFIED & 1 & 0.3 & 0.3 & 12.3 \\
\hline N Total & 40 & 12.3 & 12.3 & \\
\hline
\end{tabular}

Q6. Food Standards Credibility per Country

\begin{tabular}{|l|c|c|c|c|}
\hline \multicolumn{1}{|c|}{ Credibility India } & $\begin{array}{c}\text { Frequency } \\
\mathbf{N}^{\circ} \text { of } \\
\text { Responses) }\end{array}$ & $\begin{array}{c}\text { Percent } \\
(\boldsymbol{\%})\end{array}$ & $\begin{array}{c}\text { Valid } \\
\text { Percent (\%) }\end{array}$ & $\begin{array}{c}\text { Cumulative } \\
\text { Percent } \\
(\%)\end{array}$ \\
\hline 0 & 38 & 12.3 & 12.3 & 12.3 \\
Very Credible & 7 & 2.3 & 2.3 & 14.5 \\
Credible & 38 & 12.3 & 12.3 & 26.8 \\
Neither/ nor & 102 & 32.9 & 32.9 & 59.7 \\
Slightly Credible & 82 & 26.5 & 26.5 & 86.1 \\
Not Credible & 43 & 13.9 & 13.9 & 100 \\
\hline N Total & 310 & 100 & 100 & \\
\hline
\end{tabular}




\begin{tabular}{|l|c|c|c|c|}
\hline \multicolumn{1}{|c|}{ Credibility Austria } & $\begin{array}{c}\text { Frequency } \\
\mathbf{N}^{\circ} \text { of } \\
\text { Responses) }\end{array}$ & $\begin{array}{c}\text { Percent } \\
(\mathbf{\%})\end{array}$ & $\begin{array}{c}\text { Valid } \\
\text { Percent } \\
(\%)\end{array}$ & $\begin{array}{c}\text { Cumulative } \\
\text { Percent } \\
(\%)\end{array}$ \\
\hline 0 & 29 & 9.4 & 9.4 & 9.4 \\
Very Credible & 74 & 23.9 & 23.9 & 33.2 \\
Credible & 158 & 51 & 51 & 84.2 \\
Neither/ nor & 39 & 12.6 & 12.6 & 96.8 \\
Slightly Credible & 9 & 2.9 & 2.9 & 99.7 \\
Not Credible & 1 & 0.3 & 0.3 & 100 \\
\hline N Total & 310 & 100 & 100 & \\
\hline
\end{tabular}

\begin{tabular}{|l|c|c|c|c|}
\hline \multicolumn{1}{|c|}{ Credibility United Kingdom } & $\begin{array}{c}\text { Frequency } \\
\mathbf{N}^{\circ} \text { of } \\
\text { Responses) }\end{array}$ & $\begin{array}{c}\text { Percent } \\
(\mathbf{\%})\end{array}$ & $\begin{array}{c}\text { Valid } \\
\text { Percent } \\
(\boldsymbol{\%})\end{array}$ & $\begin{array}{c}\text { Cumulative } \\
\text { Percent } \\
(\%)\end{array}$ \\
\hline 0 & 12 & 3.9 & 3.9 & 3.9 \\
Very Credible & 135 & 43.5 & 43.5 & 47.4 \\
Credible & 132 & 42.6 & 42.6 & 90 \\
Neither/ nor & 18 & 5.8 & 5.8 & 95.8 \\
Slightly Credible & 12 & 3.9 & 3.9 & 99.7 \\
Not Credible & 1 & 0.3 & 0.3 & 100 \\
\hline N Total & 310 & 100 & 100 & \\
\hline
\end{tabular}

\begin{tabular}{|l|c|c|c|c|}
\hline \multicolumn{1}{|c|}{ Credibility Ghana } & $\begin{array}{c}\text { Frequency } \\
\mathbf{N}^{\circ} \text { of } \\
\text { Responses })\end{array}$ & $\begin{array}{c}\text { Percent } \\
(\mathbf{\%})\end{array}$ & $\begin{array}{c}\text { Valid } \\
\text { Percent } \\
(\%)\end{array}$ & $\begin{array}{c}\text { Cumulative } \\
\text { Percent } \\
(\%)\end{array}$ \\
\hline 0 & 39 & 12.6 & 12.6 & 12.6 \\
Very Credible & 4 & 1.3 & 1.3 & 13.9 \\
Credible & 29 & 9.4 & 9.4 & 23.2 \\
Neither/ nor & 90 & 29 & 29 & 52.3 \\
Slightly Credible & 81 & 26.1 & 26.1 & 78.4 \\
Not Credible & 67 & 21.6 & 21.6 & 100 \\
\hline N Total & 310 & 100 & 100 & \\
\hline
\end{tabular}




\begin{tabular}{|l|c|c|c|c|}
\hline \multicolumn{1}{|c|}{ Credibility China } & $\begin{array}{c}\text { Frequency } \\
\mathbf{N}^{\circ} \text { of } \\
\text { Responses) }\end{array}$ & $\begin{array}{c}\text { Percent } \\
(\mathbf{\%})\end{array}$ & $\begin{array}{c}\text { Valid } \\
\text { Percent } \\
(\boldsymbol{\%})\end{array}$ & $\begin{array}{c}\text { Cumulative } \\
\text { Percent } \\
(\%)\end{array}$ \\
\hline 0 & 29 & 9.4 & 9.4 & 9.4 \\
Very Credible & 6 & 1.9 & 1.9 & 11.3 \\
Credible & 36 & 11.6 & 11.6 & 22.9 \\
Neither/ nor & 75 & 24.2 & 24.2 & 47.1 \\
Slightly Credible & 80 & 25.8 & 25.8 & 72.9 \\
Not Credible & 84 & 27.1 & 27.1 & 100 \\
\hline N Total & 310 & 100 & 100 & \\
\hline
\end{tabular}

\begin{tabular}{|l|c|c|c|c|}
\hline \multicolumn{1}{|c|}{ Credibility Mexico } & $\begin{array}{c}\text { Frequency } \\
\mathbf{N}^{\circ} \text { of } \\
\text { Responses) }\end{array}$ & $\begin{array}{c}\text { Percent } \\
(\mathbf{\%})\end{array}$ & $\begin{array}{c}\text { Valid } \\
\text { Percent } \\
(\boldsymbol{\%})\end{array}$ & $\begin{array}{c}\text { Cumulative } \\
\text { Percent } \\
(\%)\end{array}$ \\
\hline 0 & 37 & 11.9 & 11.9 & 11.9 \\
Very Credible & 9 & 2.9 & 2.9 & 14.8 \\
Credible & 62 & 20 & 20 & 34.8 \\
Neither/ nor & 116 & 37.4 & 37.4 & 72.3 \\
Slightly Credible & 65 & 21 & 21 & 93.2 \\
Not Credible & 21 & 6.8 & 6.8 & 100 \\
\hline N Total & 310 & 100 & 100 & \\
\hline
\end{tabular}

\begin{tabular}{|l|c|c|c|c|}
\hline \multicolumn{1}{|c|}{ Credibility Italy } & $\begin{array}{c}\text { Frequency } \\
\mathbf{N}^{\circ} \text { of } \\
\text { Responses) }\end{array}$ & $\begin{array}{c}\text { Percent } \\
(\mathbf{\%})\end{array}$ & $\begin{array}{c}\text { Valid } \\
\text { Percent } \\
(\%)\end{array}$ & $\begin{array}{c}\text { Cumulative } \\
\text { Percent } \\
(\%)\end{array}$ \\
\hline 0 & 26 & 8.4 & 8.4 & 8.4 \\
Very Credible & 28 & 9 & 9 & 17.4 \\
Credible & 123 & 39.7 & 39.7 & 57.1 \\
Neither/ nor & 86 & 27.7 & 27.7 & 84.8 \\
Slightly Credible & 37 & 11.9 & 11.9 & 96.8 \\
Not Credible & 10 & 3.2 & 3.2 & 100 \\
\hline N Total & 310 & 100 & 100 & \\
\hline
\end{tabular}




\begin{tabular}{|l|c|c|c|c|}
\hline \multicolumn{1}{|c|}{ Credibility United States } & $\begin{array}{c}\text { Frequency } \\
\mathbf{N}^{\circ} \text { of } \\
\text { Responses) }\end{array}$ & $\begin{array}{c}\text { Percent } \\
(\mathbf{\%})\end{array}$ & $\begin{array}{c}\text { Valid } \\
\text { Percent } \\
(\boldsymbol{\%})\end{array}$ & $\begin{array}{c}\text { Cumulative } \\
\text { Percent } \\
(\%)\end{array}$ \\
\hline 0 & 23 & 7.4 & 7.4 & 7.4 \\
Very Credible & 71 & 22.9 & 22.9 & 30.3 \\
Credible & 136 & 43.9 & 43.9 & 74.2 \\
Neither/ nor & 51 & 16.5 & 16.5 & 90.6 \\
Slightly Credible & 24 & 7.7 & 7.7 & 98.4 \\
Not Credible & 5 & 1.6 & 1.6 & 100 \\
\hline N Total & 310 & 100 & 100 & \\
\hline
\end{tabular}

Q7. Effectiveness of Food Standards

\begin{tabular}{|l|c|c|c|c|}
\hline $\begin{array}{c}\text { Food standards are reliable in } \\
\text { minimizing food safety risks }\end{array}$ & $\begin{array}{c}\text { Frequency } \\
\mathbf{N}^{\circ} \text { of } \\
\text { Responses) }\end{array}$ & $\begin{array}{c}\text { Percent } \\
(\boldsymbol{\%})\end{array}$ & $\begin{array}{c}\text { Valid } \\
\text { Percent } \\
(\boldsymbol{\%})\end{array}$ & $\begin{array}{c}\text { Cumulative } \\
\text { Percent } \\
(\%)\end{array}$ \\
\hline $0 \quad$ & 3 & 1 & 1 & 1 \\
I strongly agree & 68 & 21.9 & 21.9 & 22.9 \\
I agree & 184 & 59.4 & 59.4 & 82.3 \\
Neither/ nor & 34 & 11 & 11 & 93.2 \\
I disagree & 18 & 5.8 & 5.8 & 99 \\
I strongly disagree & 3 & 1 & 1 & 100 \\
\hline N Total & 310 & 100 & 100 & \\
\hline
\end{tabular}




\begin{tabular}{|c|c|c|c|c|}
\hline $\begin{array}{l}\text { Food standards which cannot trace } \\
\text { products back into the supply chain } \\
\text { are not trustworthy }\end{array}$ & $\begin{array}{l}\text { Frequency } \\
\left(\mathbf{N}^{\circ} \text { of }\right. \\
\text { Responses })\end{array}$ & $\begin{array}{c}\text { Percent } \\
(\%)\end{array}$ & $\begin{array}{c}\text { Valid } \\
\text { Percent } \\
(\%)\end{array}$ & $\begin{array}{l}\text { Cumulative } \\
\text { Percent } \\
(\%)\end{array}$ \\
\hline 0 & 3 & 1 & 1 & 1 \\
\hline I strongly agree & 121 & 39 & 39 & 40 \\
\hline I agree & 133 & 42.9 & 42.9 & 82.9 \\
\hline Neither/ nor & 26 & 8.4 & 8.4 & 91.3 \\
\hline I disagree & 21 & 6.8 & 6.8 & 98.1 \\
\hline I strongly disagree & 6 & 1.9 & 1.9 & 100 \\
\hline N Total & 310 & 100 & 100 & \\
\hline
\end{tabular}

\begin{tabular}{|l|c|c|c|c|}
\hline $\begin{array}{c}\text { I believe in the information } \\
\text { provided by food standards (e.g. } \\
\text { current certification status of } \\
\text { products) }\end{array}$ & $\begin{array}{c}\text { Frequency } \\
\mathbf{( \mathbf { N } ^ { \circ } \text { of }} \\
\text { Responses })\end{array}$ & $\begin{array}{c}\text { Percent } \\
(\boldsymbol{\%})\end{array}$ & $\begin{array}{c}\text { Valid } \\
\text { Percent } \\
(\boldsymbol{\%})\end{array}$ & $\begin{array}{c}\text { Cumulative } \\
\text { Percent } \\
(\%)\end{array}$ \\
\hline 0 & 2 & 0.6 & 0.6 & 0.6 \\
I strongly agree & 42 & 13.5 & 13.5 & 14.2 \\
I agree & 184 & 59.4 & 59.4 & 73.5 \\
Neither/ nor & 59 & 19 & 19 & 92.6 \\
I disagree & 20 & 6.5 & 6.5 & 99 \\
I strongly disagree & 3 & 1 & 1 & 100 \\
\hline N Total & 310 & 100 & 100 & \\
\hline
\end{tabular}




\begin{tabular}{|c|c|c|c|c|}
\hline $\begin{array}{l}\text { Food standards cannot help to } \\
\text { minimize environmental impacts }\end{array}$ & $\begin{array}{l}\text { Frequency } \\
\left(\mathbf{N}^{\circ} \text { of }\right. \\
\text { Responses })\end{array}$ & $\begin{array}{l}\text { Percent } \\
(\%)\end{array}$ & $\begin{array}{c}\text { Valid } \\
\text { Percent } \\
(\%)\end{array}$ & $\begin{array}{c}\text { Cumulative } \\
\text { Percent } \\
(\%)\end{array}$ \\
\hline 0 & 3 & 1 & 1 & 1 \\
\hline I strongly agree & 19 & 6.1 & 6.1 & 7.1 \\
\hline I agree & 53 & 17.1 & 17.1 & 24.2 \\
\hline Neither/ nor & 50 & 16.1 & 16.1 & 40.3 \\
\hline I disagree & 155 & 50 & 50 & 90.3 \\
\hline I strongly disagree & 30 & 9.7 & 9.7 & 100 \\
\hline N Total & 310 & 100 & 100 & \\
\hline
\end{tabular}

Q8. Traceability of Certified Food

\begin{tabular}{|l|c|c|c|c|}
\hline $\begin{array}{c}\text { It should be always possible to } \\
\text { identify the origin of the certified } \\
\text { products }\end{array}$ & $\begin{array}{c}\text { Frequency } \\
\mathbf{N}^{\circ} \text { of } \\
\text { Responses })\end{array}$ & $\begin{array}{c}\text { Percent } \\
(\%)\end{array}$ & $\begin{array}{c}\text { Valid } \\
\text { Percent } \\
(\%)\end{array}$ & $\begin{array}{c}\text { Cumulative } \\
\text { Percent } \\
(\%)\end{array}$ \\
\hline 0 & 3 & 1 & 1 & 1 \\
I strongly agree & 165 & 53.2 & 53.2 & 54.2 \\
I agree & 121 & 39 & 39 & 93.2 \\
Neither/ nor & 11 & 3.5 & 3.5 & 96.8 \\
I disagree & 9 & 2.9 & 2.9 & 99.7 \\
I strongly disagree & 1 & 0.3 & 0.3 & 100 \\
\hline N Total & 310 & 100 & 100 & \\
\hline
\end{tabular}




\begin{tabular}{|l|c|c|c|c|}
\hline $\begin{array}{c}\text { I have confidence that certified } \\
\text { products are not mixed with non } \\
\text { certified products }\end{array}$ & $\begin{array}{c}\text { Frequency } \\
\mathbf{N}^{\circ} \text { of } \\
\text { Responses) }\end{array}$ & $\begin{array}{c}\text { Percent } \\
(\boldsymbol{\%})\end{array}$ & $\begin{array}{c}\text { Valid } \\
\text { Percent } \\
(\%)\end{array}$ & $\begin{array}{c}\text { Cumulative } \\
\text { Percent } \\
(\%)\end{array}$ \\
\hline 0 & 1 & 0.3 & 0.3 & 0.3 \\
I strongly agree & 29 & 9.4 & 9.4 & 9.7 \\
I agree & 97 & 31.3 & 31.3 & 41 \\
Neither/ nor & 76 & 24.5 & 24.5 & 65.5 \\
I disagree & 84 & 27.1 & 27.1 & 92.6 \\
I strongly disagree & 23 & 7.4 & 7.4 & 100 \\
\hline N Total & 310 & 100 & 100 & \\
\hline
\end{tabular}

\begin{tabular}{|l|c|c|c|c|}
\hline $\begin{array}{c}\text { It is not necessary to have the } \\
\text { precise information about the area } \\
\text { of a certified farm }\end{array}$ & $\begin{array}{c}\text { Frequency } \\
\mathbf{N}^{\circ} \text { of } \\
\text { Responses) }\end{array}$ & $\begin{array}{c}\text { Percent } \\
(\boldsymbol{\%})\end{array}$ & $\begin{array}{c}\text { Valid } \\
\text { Percent } \\
(\boldsymbol{\%})\end{array}$ & $\begin{array}{c}\text { Cumulative } \\
\text { Percent } \\
(\%)\end{array}$ \\
\hline 0 & 2 & 0.6 & 0.6 & 0.6 \\
I strongly agree & 13 & 4.2 & 4.2 & 4.8 \\
I agree & 53 & 17.1 & 17.1 & 21.9 \\
Neither/ nor & 34 & 11 & 11 & 32.9 \\
I disagree & 131 & 42.3 & 42.3 & 75.2 \\
I strongly disagree & 77 & 24.8 & 24.8 & 100 \\
\hline N Total & 310 & 100 & 100 & \\
\hline
\end{tabular}




\begin{tabular}{|l|c|c|c|c|}
\hline $\begin{array}{c}\text { I do not rely on food certification } \\
\text { systems which cannot provide } \\
\text { accurate information about the } \\
\text { certified products }\end{array}$ & $\begin{array}{c}\text { Frequency } \\
\text { (No of } \\
\text { Responses) }\end{array}$ & $\begin{array}{c}\text { Percent } \\
\mathbf{( \% )}\end{array}$ & $\begin{array}{c}\text { Percent } \\
\mathbf{( \% )}\end{array}$ & $\begin{array}{c}\text { Cumulative } \\
\text { Percent } \\
(\boldsymbol{\%})\end{array}$ \\
\hline 0 & 5 & 1.6 & 1.6 & 1.6 \\
I strongly agree & 80 & 25.8 & 25.8 & 27.4 \\
I agree & 152 & 49 & 49 & 76.5 \\
Neither/ nor & 35 & 11.3 & 11.3 & 87.7 \\
I disagree & 34 & 11 & 11 & 98.7 \\
I strongly disagree & 4 & 1.3 & 1.3 & 100 \\
\hline N Total & 310 & 100 & 100 & \\
\hline
\end{tabular}

\begin{tabular}{|l|c|c|c|c|}
\hline $\begin{array}{c}\text { A credible food certification system } \\
\text { does not have to provide full } \\
\text { traceability }\end{array}$ & $\begin{array}{c}\text { Frequency } \\
\mathbf{N}^{\circ} \text { of } \\
\text { Responses) }\end{array}$ & $\begin{array}{c}\text { Percent } \\
(\boldsymbol{\%})\end{array}$ & $\begin{array}{c}\text { Valid } \\
\text { Percent } \\
(\boldsymbol{\%})\end{array}$ & $\begin{array}{c}\text { Cumulative } \\
\text { Percent } \\
(\%)\end{array}$ \\
\hline 0 & 2 & 0.6 & 0.6 & 0.6 \\
I strongly agree & 12 & 3.9 & 3.9 & 4.5 \\
I agree & 25 & 8.1 & 8.1 & 12.6 \\
Neither/ nor & 15 & 4.8 & 4.8 & 17.4 \\
I disagree & 150 & 48.4 & 48.4 & 65.8 \\
I strongly disagree & 106 & 34.2 & 34.2 & 100 \\
\hline N Total & 310 & 100 & 100 & \\
\hline
\end{tabular}


Q9. Certification Systems Reliability per Country

\begin{tabular}{|l|c|c|c|c|}
\hline \multicolumn{1}{|c|}{ Reliability United Kingdom } & $\begin{array}{c}\text { Frequency } \\
\mathbf{N}^{\circ} \text { of } \\
\text { Responses })\end{array}$ & $\begin{array}{c}\text { Percent } \\
(\mathbf{\%})\end{array}$ & $\begin{array}{c}\text { Valid } \\
\text { Percent } \\
(\boldsymbol{\%})\end{array}$ & $\begin{array}{c}\text { Cumulative } \\
\text { Percent } \\
(\%)\end{array}$ \\
\hline 0 & 25 & 8.1 & 8.1 & 8.1 \\
Reliable & 197 & 63.5 & 63.5 & 71.6 \\
Slightly Reliable & 62 & 20 & 20 & 91.6 \\
Neither/ nor & 20 & 6.5 & 6.5 & 98.1 \\
Slightly Unreliable & 5 & 1.6 & 1.6 & 99.7 \\
Unreliable & 1 & 0.3 & 0.3 & 100 \\
\hline N Total & 310 & 100 & 100 & \\
\hline
\end{tabular}

\begin{tabular}{|c|c|c|c|c|}
\hline Reliability Mexico & $\begin{array}{c}\text { Frequency } \\
\left(\mathbf{N}^{\circ} \text { of }\right. \\
\text { Responses }) \\
\end{array}$ & $\begin{array}{c}\text { Percent } \\
(\%)\end{array}$ & $\begin{array}{c}\text { Valid } \\
\text { Percent } \\
(\%) \\
\end{array}$ & $\begin{array}{c}\text { Cumulative } \\
\text { Percent } \\
(\%)\end{array}$ \\
\hline 0 & 48 & 15.5 & 15.5 & 15.5 \\
\hline Reliable & 19 & 6.1 & 6.1 & 21.6 \\
\hline Slightly Reliable & 64 & 20.6 & 20.6 & 42.3 \\
\hline Neither/ nor & 102 & 32.9 & 32.9 & 75.2 \\
\hline Slightly Unreliable & 55 & 17.7 & 17.7 & 92.9 \\
\hline Unreliable & 22 & 7.1 & 7.1 & 100 \\
\hline N Total & 310 & 100 & 100 & \\
\hline
\end{tabular}




\begin{tabular}{|l|c|c|c|c|}
\hline \multicolumn{1}{|c|}{ Reliability United States } & $\begin{array}{c}\text { Frequency } \\
\mathbf{N}^{\circ} \text { of } \\
\text { Responses) }\end{array}$ & $\begin{array}{c}\text { Percent } \\
\mathbf{( \% )}\end{array}$ & $\begin{array}{c}\text { Valid } \\
\text { Percent } \\
(\%)\end{array}$ & $\begin{array}{c}\text { Cumulative } \\
\text { Percent } \\
(\%)\end{array}$ \\
\hline 0 & 35 & 11.3 & 11.3 & 11.3 \\
Reliable & 135 & 43.5 & 43.5 & 54.8 \\
Slightly Reliable & 76 & 24.5 & 24.5 & 79.4 \\
Neither/ nor & 44 & 14.2 & 14.2 & 93.5 \\
Slightly Unreliable & 13 & 4.2 & 4.2 & 97.7 \\
Unreliable & 7 & 2.3 & 2.3 & 100 \\
\hline N Total & 310 & 100 & 100 & \\
\hline
\end{tabular}

\begin{tabular}{|c|c|c|c|c|}
\hline Reliability Italy & $\begin{array}{l}\text { Frequency } \\
\left(\mathbf{N}^{\circ} \text { of }\right. \\
\text { Responses })\end{array}$ & $\begin{array}{c}\text { Percent } \\
(\%)\end{array}$ & $\begin{array}{c}\text { Valid } \\
\text { Percent } \\
(\%)\end{array}$ & $\begin{array}{c}\text { Cumulative } \\
\text { Percent } \\
(\%)\end{array}$ \\
\hline 0 & 37 & 11.9 & 11.9 & 11.9 \\
\hline Reliable & 70 & 22.6 & 22.6 & 34.5 \\
\hline Slightly Reliable & 96 & 31 & 31 & 65.5 \\
\hline Neither/ nor & 75 & 24.2 & 24.2 & 89.7 \\
\hline Slightly Unreliable & 21 & 6.8 & 6.8 & 96.5 \\
\hline Unreliable & 11 & 3.5 & 3.5 & 100 \\
\hline N Total & 310 & 100 & 100 & \\
\hline
\end{tabular}

\begin{tabular}{|l|c|c|c|c|}
\hline \multicolumn{1}{|c|}{ Reliability China } & $\begin{array}{c}\text { Frequency } \\
\mathbf{N}^{\circ} \text { of } \\
\text { Responses) }\end{array}$ & $\begin{array}{c}\text { Percent } \\
(\boldsymbol{\%})\end{array}$ & $\begin{array}{c}\text { Valid } \\
\text { Percent } \\
(\%)\end{array}$ & $\begin{array}{c}\text { Cumulative } \\
\text { Percent } \\
(\%)\end{array}$ \\
\hline 0 & 41 & 13.2 & 13.2 & 13.2 \\
Reliable & 12 & 3.9 & 3.9 & 17.1 \\
Slightly Reliable & 41 & 13.2 & 13.2 & 30.3 \\
Neither/ nor & 71 & 22.9 & 22.9 & 53.2 \\
Slightly Unreliable & 69 & 22.3 & 22.3 & 75.5 \\
Unreliable & 76 & 24.5 & 24.5 & 100 \\
\hline N Total & 310 & 100 & 100 & \\
\hline
\end{tabular}




\begin{tabular}{|l|c|c|c|c|}
\hline \multicolumn{1}{|c|}{ Reliability Ghana } & $\begin{array}{c}\text { Frequency } \\
\mathbf{N}^{\circ} \text { of } \\
\text { Responses })\end{array}$ & $\begin{array}{c}\text { Percent } \\
(\mathbf{\%})\end{array}$ & $\begin{array}{c}\text { Valid } \\
\text { Percent } \\
(\%)\end{array}$ & $\begin{array}{c}\text { Cumulative } \\
\text { Percent } \\
(\%)\end{array}$ \\
\hline 0 & 41 & 13.2 & 13.2 & 13.2 \\
Reliable & 11 & 3.5 & 3.5 & 16.8 \\
Slightly Reliable & 34 & 11 & 11 & 27.7 \\
Neither/ nor & 100 & 32.3 & 32.3 & 60 \\
Slightly Unreliable & 70 & 22.6 & 22.6 & 82.6 \\
Unreliable & 54 & 17.4 & 17.4 & 100 \\
\hline N Total & 310 & 100 & 100 & \\
\hline
\end{tabular}

\begin{tabular}{|l|c|c|c|c|}
\hline \multicolumn{1}{|c|}{ Reliability Australia } & $\begin{array}{c}\text { Frequency } \\
\mathbf{N}^{\circ} \text { of } \\
\text { Responses) }\end{array}$ & $\begin{array}{c}\text { Percent } \\
(\mathbf{\%})\end{array}$ & $\begin{array}{c}\text { Valid } \\
\text { Percent } \\
(\%)\end{array}$ & $\begin{array}{c}\text { Cumulative } \\
\text { Percent } \\
(\%)\end{array}$ \\
\hline 0 & 35 & 11.3 & 11.3 & 11.3 \\
Reliable & 154 & 49.7 & 49.7 & 61 \\
Slightly Reliable & 79 & 25.5 & 25.5 & 86.5 \\
Neither/ nor & 36 & 11.6 & 11.6 & 98.1 \\
Slightly Unreliable & 4 & 1.3 & 1.3 & 99.4 \\
Unreliable & 2 & 0.6 & 0.6 & 100 \\
\hline N Total & 310 & 100 & 100 & \\
\hline
\end{tabular}




\begin{tabular}{|l|c|c|c|c|}
\hline $\begin{array}{c}\text { Food standards are more credible } \\
\text { when they require an audit of each } \\
\text { individual producer }\end{array}$ & $\begin{array}{c}\text { Frequency } \\
\mathbf{N}^{\circ} \text { of } \\
\text { Responses })\end{array}$ & $\begin{array}{c}\text { Percent } \\
(\mathbf{\%})\end{array}$ & $\begin{array}{c}\text { Valid } \\
\text { Percent } \\
(\%)\end{array}$ & $\begin{array}{c}\text { Cumulative } \\
\text { Percent } \\
(\%)\end{array}$ \\
\hline 0 & 2 & 0.6 & 0.6 & 0.6 \\
I strongly agree & 95 & 30.6 & 30.6 & 31.3 \\
I agree & 129 & 41.6 & 41.6 & 72.9 \\
Neither/ nor & 26 & 8.4 & 8.4 & 81.3 \\
I disagree & 50 & 16.1 & 16.1 & 97.4 \\
I strongly disagree & 8 & 2.6 & 2.6 & 100 \\
\hline N Total & 310 & 100 & 100 & \\
\hline
\end{tabular}

\begin{tabular}{|l|c|c|c|c|}
\hline $\begin{array}{c}\text { Certification of producer groups } \\
\text { makes food standards less reliable }\end{array}$ & $\begin{array}{c}\text { Frequency } \\
\mathbf{N}^{\circ} \text { of } \\
\text { Responses })\end{array}$ & $\begin{array}{c}\text { Percent } \\
(\boldsymbol{\%})\end{array}$ & $\begin{array}{c}\text { Valid } \\
\text { Percent } \\
(\boldsymbol{\%})\end{array}$ & $\begin{array}{c}\text { Cumulative } \\
\text { Percent } \\
(\%)\end{array}$ \\
\hline 0 & 1 & 0.3 & 0.3 & 0.3 \\
I strongly agree & 31 & 10 & 10 & 10.3 \\
I agree & 90 & 29 & 29 & 39.4 \\
Neither/ nor & 56 & 18.1 & 18.1 & 57.4 \\
I disagree & 101 & 32.6 & 32.6 & 90 \\
I strongly disagree & 31 & 10 & 10 & 100 \\
\hline N Total & 310 & 100 & 100 & \\
\hline
\end{tabular}




\begin{tabular}{|c|c|c|c|c|}
\hline $\begin{array}{l}\text { I would still have confidence in food } \\
\text { standards that do not require } \\
\text { announced audits to producers }\end{array}$ & $\begin{array}{l}\text { Frequency } \\
\quad\left(\mathbf{N}^{\circ} \text { of }\right. \\
\text { Responses })\end{array}$ & $\begin{array}{c}\text { Percent } \\
(\%)\end{array}$ & $\begin{array}{l}\text { Valid } \\
\text { Percent } \\
(\%)\end{array}$ & $\begin{array}{l}\text { Cumulative } \\
\text { Percent } \\
(\%)\end{array}$ \\
\hline 0 & 4 & 1.3 & 1.3 & 1.3 \\
\hline I strongly agree & 20 & 6.5 & 6.5 & 7.7 \\
\hline I agree & 84 & 27.1 & 27.1 & 34.8 \\
\hline Neither/ nor & 42 & 13.5 & 13.5 & 48.4 \\
\hline I disagree & 109 & 35.2 & 35.2 & 83.5 \\
\hline I strongly disagree & 51 & 16.5 & 16.5 & 100 \\
\hline $\mathrm{N}$ Total & 310 & 100 & 100 & \\
\hline
\end{tabular}

Q11. Origin of food certification systems

\begin{tabular}{|l|c|c|c|c|}
\hline $\begin{array}{c}\text { Food certification systems } \\
\text { established in developed countries } \\
\text { are always carefully designed by } \\
\text { trustworthy technical expert }\end{array}$ & $\begin{array}{c}\text { Frequency } \\
\mathbf{N}^{\circ} \text { of } \\
\text { Responses })\end{array}$ & $\begin{array}{c}\text { Percent } \\
(\boldsymbol{\%})\end{array}$ & $\begin{array}{c}\text { Valid } \\
\text { Percent } \\
(\boldsymbol{\%})\end{array}$ & $\begin{array}{c}\text { Cumulative } \\
\text { Percent } \\
(\%)\end{array}$ \\
\hline 0 & 5 & 1.6 & 1.6 & 1.6 \\
I strongly agree & 25 & 8.1 & 8.1 & 9.7 \\
I agree & 100 & 32.3 & 32.3 & 41.9 \\
Neither/ nor & 92 & 29.7 & 29.7 & 71.6 \\
I disagree & 69 & 22.3 & 22.3 & 93.9 \\
I strongly disagree & 19 & 6.1 & 6.1 & 100 \\
\hline N Total & 310 & 100 & 100 & \\
\hline
\end{tabular}




\begin{tabular}{|l|c|c|c|c|}
\hline $\begin{array}{c}\text { Certified food coming from } \\
\text { developing countries are more } \\
\text { trustworthy than similar products } \\
\text { available in developed countries }\end{array}$ & $\begin{array}{c}\text { Frequency } \\
\mathbf{N}^{\circ} \text { of } \\
\text { Responses })\end{array}$ & $\begin{array}{c}\text { Percent } \\
(\mathbf{\%})\end{array}$ & $\begin{array}{c}\text { Valid } \\
\text { Percent } \\
(\mathbf{\%})\end{array}$ & $\begin{array}{c}\text { Cumulative } \\
\text { Percent } \\
(\%)\end{array}$ \\
\hline 0 I strongly agree & 12 & 1 & 1 & 1 \\
I agree & 49 & 15.8 & 3.9 & 4.8 \\
Neither/ nor & 98 & 31.6 & 31.6 & 20.6 \\
I disagree & 122 & 39.4 & 39.4 & 91.6 \\
I strongly disagree & 26 & 8.4 & 8.4 & 100 \\
\hline N Total & 310 & 100 & 100 & \\
\hline
\end{tabular}

\begin{tabular}{|l|c|c|c|c|}
\hline $\begin{array}{c}\text { Whenever possible. I would } \\
\text { recommend to buy certified food } \\
\text { products from developed countries }\end{array}$ & $\begin{array}{c}\text { Frequency } \\
\mathbf{N}^{\circ} \text { of } \\
\text { Responses })\end{array}$ & $\begin{array}{c}\text { Percent } \\
(\boldsymbol{\%})\end{array}$ & $\begin{array}{c}\text { Valid } \\
\text { Percent } \\
(\boldsymbol{\%})\end{array}$ & $\begin{array}{c}\text { Cumulative } \\
\text { Percent } \\
(\%)\end{array}$ \\
\hline 0 & 5 & 1.6 & 1.6 & 1.6 \\
I strongly agree & 45 & 14.5 & 14.5 & 16.1 \\
I agree & 102 & 32.9 & 32.9 & 49 \\
Neither/ nor & 71 & 22.9 & 22.9 & 71.9 \\
I disagree & 60 & 19.4 & 19.4 & 91.3 \\
I strongly disagree & 27 & 8.7 & 8.7 & 100 \\
\hline N Total & 310 & 100 & 100 & \\
\hline
\end{tabular}




\begin{tabular}{|l|c|c|c|c|}
\hline $\begin{array}{c}\text { Auditors in developed countries are } \\
\text { more reliable than auditors in } \\
\text { developing countries }\end{array}$ & $\begin{array}{c}\text { Frequency } \\
\mathbf{( \mathbf { N } ^ { \circ } \text { of }} \\
\text { Responses })\end{array}$ & $\begin{array}{c}\text { Percent } \\
(\mathbf{\%})\end{array}$ & $\begin{array}{c}\text { Valid } \\
\text { Percent } \\
(\%)\end{array}$ & $\begin{array}{c}\text { Cumulative } \\
\text { Percent } \\
(\%)\end{array}$ \\
\hline 0 & 5 & 1.6 & 1.6 & 1.6 \\
I strongly agree & 29 & 9.4 & 9.4 & 11 \\
I agree & 71 & 22.9 & 22.9 & 33.9 \\
Neither/ nor & 67 & 21.6 & 21.6 & 55.5 \\
I disagree & 97 & 31.3 & 31.3 & 86.8 \\
I strongly disagree & 41 & 13.2 & 13.2 & 100 \\
\hline N Total & 310 & 100 & 100 & \\
\hline
\end{tabular}

\begin{tabular}{|l|c|c|c|c|}
\hline $\begin{array}{c}\text { I have less confidence in } \\
\text { certification bodies in developing } \\
\text { countries than those in developed } \\
\text { countries }\end{array}$ & $\begin{array}{c}\text { Frequency } \\
\mathbf{N}^{\circ} \text { of } \\
\text { Responses })\end{array}$ & $\begin{array}{c}\text { Percent } \\
(\boldsymbol{\%})\end{array}$ & $\begin{array}{c}\text { Valid } \\
\text { Percent } \\
(\boldsymbol{\%})\end{array}$ & $\begin{array}{c}\text { Cumulative } \\
\text { Percent } \\
(\boldsymbol{\%})\end{array}$ \\
\hline 0 & 3 & 1 & 1 & 1 \\
I strongly agree & 35 & 11.3 & 11.3 & 12.3 \\
I agree & 108 & 34.8 & 34.8 & 47.1 \\
Neither/ nor & 60 & 19.4 & 19.4 & 66.5 \\
I disagree & 75 & 24.2 & 24.2 & 90.6 \\
I strongly disagree & 29 & 9.4 & 9.4 & 100 \\
\hline N Total & 310 & 100 & 100 & \\
\hline
\end{tabular}




\begin{tabular}{|l|c|c|c|c|}
\hline \multicolumn{1}{|c|}{ Confidence China } & $\begin{array}{c}\text { Frequency } \\
\mathbf{N}^{\circ} \text { of } \\
\text { Responses })\end{array}$ & $\begin{array}{c}\text { Percent } \\
(\mathbf{\%})\end{array}$ & $\begin{array}{c}\text { Valid } \\
\text { Percent } \\
(\%)\end{array}$ & $\begin{array}{c}\text { Cumulative } \\
\text { Percent } \\
(\%)\end{array}$ \\
\hline 0 & 35 & 11.3 & 11.3 & 11.3 \\
I have confidence & 14 & 4.5 & 4.5 & 15.8 \\
I have slight confidence & 60 & 19.4 & 19.4 & 35.2 \\
Neither / nor & 61 & 19.7 & 19.7 & 54.8 \\
I have slight no confidence & 74 & 23.9 & 23.9 & 78.7 \\
I have no confidence & 66 & 21.3 & 21.3 & 100 \\
\hline N Total & 310 & 100 & 100 & \\
\hline
\end{tabular}

\begin{tabular}{|l|c|c|c|c|}
\hline \multicolumn{1}{|c|}{ Confidence Ghana } & $\begin{array}{c}\text { Frequency } \\
\mathbf{N}^{\circ} \text { of } \\
\text { Responses })\end{array}$ & $\begin{array}{c}\text { Percent } \\
(\mathbf{\%})\end{array}$ & $\begin{array}{c}\text { Valid } \\
\text { Percent } \\
(\%)\end{array}$ & $\begin{array}{c}\text { Cumulative } \\
\text { Percent } \\
(\%)\end{array}$ \\
\hline 0 & 35 & 11.3 & 11.3 & 11.3 \\
I have confidence & 17 & 5.5 & 5.5 & 16.8 \\
I have slight confidence & 50 & 16.1 & 16.1 & 32.9 \\
Neither / nor & 94 & 30.3 & 30.3 & 63.2 \\
I have slight no confidence & 62 & 20 & 20 & 83.2 \\
I have no confidence & 52 & 16.8 & 16.8 & 100 \\
\hline N Total & 310 & 100 & 100 & \\
\hline
\end{tabular}




\begin{tabular}{|l|c|c|c|c|}
\hline \multicolumn{1}{|c|}{ Confidence Italy } & $\begin{array}{c}\text { Frequency } \\
\mathbf{N}^{\circ} \text { of } \\
\text { Responses })\end{array}$ & $\begin{array}{c}\text { Percent } \\
(\mathbf{\%})\end{array}$ & $\begin{array}{c}\text { Valid } \\
\text { Percent } \\
(\boldsymbol{\%})\end{array}$ & $\begin{array}{c}\text { Cumulative } \\
\text { Percent } \\
(\%)\end{array}$ \\
\hline 0 & 31 & 10 & 10 & 10 \\
I have confidence & 68 & 21.9 & 21.9 & 31.9 \\
I have slight confidence & 107 & 34.5 & 34.5 & 66.5 \\
Neither / nor & 72 & 23.2 & 23.2 & 89.7 \\
I have slight no confidence & 25 & 8.1 & 8.1 & 97.7 \\
I have no confidence & 7 & 2.3 & 2.3 & 100 \\
\hline N Total & 310 & 100 & 100 & \\
\hline
\end{tabular}

\begin{tabular}{|l|c|c|c|c|}
\hline \multicolumn{1}{|c|}{ Confidence Australia } & $\begin{array}{c}\text { Frequency } \\
\left(\mathbf{N}^{\circ} \text { of }\right. \\
\text { Responses })\end{array}$ & $\begin{array}{c}\text { Percent } \\
(\boldsymbol{\%})\end{array}$ & $\begin{array}{c}\text { Valid } \\
\text { Percent } \\
(\%)\end{array}$ & $\begin{array}{c}\text { Cumulative } \\
\text { Percent } \\
(\%)\end{array}$ \\
\hline 0 & 32 & 10.3 & 10.3 & 10.3 \\
I have confidence & 156 & 50.3 & 50.3 & 60.6 \\
I have slight confidence & 70 & 22.6 & 22.6 & 83.2 \\
Neither / nor & 45 & 14.5 & 14.5 & 97.7 \\
I have slight no confidence & 6 & 1.9 & 1.9 & 99.7 \\
I have no confidence & 1 & 0.3 & 0.3 & 100 \\
\hline N Total & 310 & 100 & 100 & \\
\hline
\end{tabular}




\begin{tabular}{|l|c|c|c|c|}
\hline \multicolumn{1}{|c|}{ Confidence United States } & $\begin{array}{c}\text { Frequency } \\
\left(\mathbf{N}^{\circ} \text { of }\right. \\
\text { Responses })\end{array}$ & $\begin{array}{c}\text { Percent } \\
(\mathbf{\%})\end{array}$ & $\begin{array}{c}\text { Valid } \\
\text { Percent } \\
(\boldsymbol{\%})\end{array}$ & $\begin{array}{c}\text { Cumulative } \\
\text { Percent } \\
(\%)\end{array}$ \\
\hline 0 & 29 & 9.4 & 9.4 & 9.4 \\
I have confidence & 126 & 40.6 & 40.6 & 50 \\
I have slight confidence & 93 & 30 & 30 & 80 \\
Neither / nor & 40 & 12.9 & 12.9 & 92.9 \\
I have slight no confidence & 18 & 5.8 & 5.8 & 98.7 \\
I have no confidence & 4 & 1.3 & 1.3 & 100 \\
\hline N Total & 310 & 100 & 100 & \\
\hline
\end{tabular}

\begin{tabular}{|l|c|c|c|c|}
\hline \multicolumn{1}{|c|}{ Confidence India } & $\begin{array}{c}\text { Frequency } \\
\mathbf{N}^{\circ} \text { of } \\
\text { Responses) }\end{array}$ & $\begin{array}{c}\text { Percent } \\
(\boldsymbol{\%})\end{array}$ & $\begin{array}{c}\text { Valid } \\
\text { Percent } \\
(\%)\end{array}$ & $\begin{array}{c}\text { Cumulative } \\
\text { Percent } \\
(\%)\end{array}$ \\
\hline 0 & 33 & 10.6 & 10.6 & 10.6 \\
I have confidence & 17 & 5.5 & 5.5 & 16.1 \\
I have slight confidence & 73 & 23.5 & 23.5 & 39.7 \\
Neither / nor & 92 & 29.7 & 29.7 & 69.4 \\
I have slight no confidence & 62 & 20 & 20 & 89.4 \\
I have no confidence & 33 & 10.6 & 10.6 & 100 \\
\hline N Total & 310 & 100 & 100 & \\
\hline
\end{tabular}




\begin{tabular}{|l|c|c|c|c|}
\hline \multicolumn{1}{|c|}{ Confidence United Kingdom } & $\begin{array}{c}\text { Frequency } \\
\mathbf{N}^{\circ} \text { of } \\
\text { Responses) }\end{array}$ & $\begin{array}{c}\text { Percent } \\
(\mathbf{\%})\end{array}$ & $\begin{array}{c}\text { Valid } \\
\text { Percent } \\
(\%)\end{array}$ & $\begin{array}{c}\text { Cumulative } \\
\text { Percent } \\
(\%)\end{array}$ \\
\hline 0 & 24 & 7.7 & 7.7 & 7.7 \\
I have confidence & 188 & 60.6 & 60.6 & 68.4 \\
I have slight confidence & 64 & 20.6 & 20.6 & 89 \\
Neither / nor & 26 & 8.4 & 8.4 & 97.4 \\
I have slight no confidence & 7 & 2.3 & 2.3 & 99.7 \\
I have no confidence & 1 & 0.3 & 0.3 & 100 \\
\hline N Total & 310 & 100 & 100 & \\
\hline
\end{tabular}

\begin{tabular}{|l|c|c|c|c|}
\hline \multicolumn{1}{|c|}{ Confidence Mexico } & $\begin{array}{c}\text { Frequency } \\
\mathbf{N}^{\circ} \text { of } \\
\text { Responses) }\end{array}$ & $\begin{array}{c}\text { Percent } \\
(\boldsymbol{\%})\end{array}$ & $\begin{array}{c}\text { Valid } \\
\text { Percent } \\
(\boldsymbol{\%})\end{array}$ & $\begin{array}{c}\text { Cumulative } \\
\text { Percent } \\
(\%)\end{array}$ \\
\hline 0 & 39 & 12.6 & 12.6 & 12.6 \\
I have confidence & 26 & 8.4 & 8.4 & 21 \\
I have slight confidence & 79 & 25.5 & 25.5 & 46.5 \\
Neither / nor & 92 & 29.7 & 29.7 & 76.1 \\
I have slight no confidence & 58 & 18.7 & 18.7 & 94.8 \\
I have no confidence & 16 & 5.2 & 5.2 & 100 \\
\hline N Total & 310 & 100 & 100 & \\
\hline
\end{tabular}


Q13. Requirements of food standards

\begin{tabular}{|l|c|c|c|c|}
\hline $\begin{array}{c}\text { Food standards that focus on one } \\
\text { single stage of the supply chain }(\mathbf{e . g} . \\
\text { pre or post farm) are trustworthy }\end{array}$ & $\begin{array}{c}\text { Frequency } \\
\left(\mathbf{N}^{\circ} \text { of }\right. \\
\text { Responses })\end{array}$ & $\begin{array}{c}\text { Percent } \\
(\mathbf{\%})\end{array}$ & $\begin{array}{c}\text { Valid } \\
\text { Percent } \\
(\boldsymbol{\%})\end{array}$ & $\begin{array}{c}\text { Cumulative } \\
\text { Percent } \\
(\%)\end{array}$ \\
\hline 0 & 8 & 2.6 & 2.6 & 2.6 \\
I strongly agree & 27 & 8.7 & 8.7 & 11.3 \\
I agree & 92 & 29.7 & 29.7 & 41 \\
Neither/ nor & 81 & 26.1 & 26.1 & 67.1 \\
I disagree & 89 & 28.7 & 28.7 & 95.8 \\
I strongly disagree & 13 & 4.2 & 4.2 & 100 \\
\hline N Total & 310 & 100 & 100 & \\
\hline
\end{tabular}

\begin{tabular}{|c|c|c|c|c|}
\hline $\begin{array}{c}\text { Food standards are more reliable } \\
\text { when they are focused on only one } \\
\text { type of requirements (e.g. food } \\
\text { safety) }\end{array}$ & $\begin{array}{l}\text { Frequency } \\
\left(\mathbf{N}^{\circ} \text { of }\right. \\
\text { Responses })\end{array}$ & $\begin{array}{c}\text { Percent } \\
(\%)\end{array}$ & $\begin{array}{c}\text { Valid } \\
\text { Percent } \\
(\%)\end{array}$ & $\begin{array}{l}\text { Cumulative } \\
\text { Percent } \\
(\%)\end{array}$ \\
\hline 0 & 7 & 2.3 & 2.3 & 2.3 \\
\hline I strongly agree & 40 & 12.9 & 12.9 & 15.2 \\
\hline I agree & 81 & 26.1 & 26.1 & 41.3 \\
\hline Neither/ nor & 64 & 20.6 & 20.6 & 61.9 \\
\hline I disagree & 98 & 31.6 & 31.6 & 93.5 \\
\hline I strongly disagree & 20 & 6.5 & 6.5 & 100 \\
\hline \begin{tabular}{|l|} 
N Total \\
\end{tabular} & 310 & 100 & 100 & \\
\hline
\end{tabular}




\begin{tabular}{|l|c|c|c|c|}
\hline $\begin{array}{c}\text { Credible food standards should } \\
\text { integrate food safety, environmental } \\
\text { and social requirements }\end{array}$ & $\begin{array}{c}\text { Frequency } \\
\mathbf{N}^{\circ} \text { of } \\
\text { Responses) }\end{array}$ & $\begin{array}{c}\text { Percent } \\
(\boldsymbol{\%})\end{array}$ & $\begin{array}{c}\text { Valid } \\
\text { Percent } \\
(\%)\end{array}$ & $\begin{array}{c}\text { Cumulative } \\
\text { Percent } \\
(\%)\end{array}$ \\
\hline 0 & 7 & 2.3 & 2.3 & 2.3 \\
I strongly agree & 90 & 29 & 29 & 31.3 \\
I agree & 111 & 35.8 & 35.8 & 67.1 \\
Neither/ nor & 40 & 12.9 & 12.9 & 80 \\
I disagree & 47 & 15.2 & 15.2 & 95.2 \\
I strongly disagree & 15 & 4.8 & 4.8 & 100 \\
\hline N Total & 310 & 100 & 100 & \\
\hline
\end{tabular}

\begin{tabular}{|l|c|c|c|c|}
\hline $\begin{array}{c}\text { Food standards that cover a wide } \\
\text { range of the supply chain (e.g. pre } \\
\text { and post farm) are not reliable }\end{array}$ & $\begin{array}{c}\text { Frequency } \\
\mathbf{N}^{\circ} \text { of } \\
\text { Responses) }\end{array}$ & $\begin{array}{c}\text { Percent } \\
(\mathbf{\%})\end{array}$ & $\begin{array}{c}\text { Valid } \\
\text { Percent } \\
(\%)\end{array}$ & $\begin{array}{c}\text { Cumulative } \\
\text { Percent } \\
(\%)\end{array}$ \\
\hline 0 & 7 & 2.3 & 2.3 & 2.3 \\
I strongly agree & 17 & 5.5 & 5.5 & 7.7 \\
I agree & 33 & 10.6 & 10.6 & 18.4 \\
Neither/ nor & 53 & 17.1 & 17.1 & 35.5 \\
I disagree & 157 & 50.6 & 50.6 & 86.1 \\
I strongly disagree & 43 & 13.9 & 13.9 & 100 \\
\hline N Total & 310 & 100 & 100 & \\
\hline
\end{tabular}




\begin{tabular}{|l|c|c|c|c|}
\hline $\begin{array}{c}\text { Food standards are more credible } \\
\text { when they can be adopted in } \\
\text { different local conditions }\end{array}$ & $\begin{array}{c}\text { Frequency } \\
\mathbf{N}^{\circ} \text { of } \\
\text { Responses })\end{array}$ & $\begin{array}{c}\text { Percent } \\
(\boldsymbol{\%})\end{array}$ & $\begin{array}{c}\text { Valid } \\
\text { Percent } \\
(\boldsymbol{\%})\end{array}$ & $\begin{array}{c}\text { Cumulative } \\
\text { Percent } \\
(\%)\end{array}$ \\
\hline 0 & 8 & 2.6 & 2.6 & 2.6 \\
I strongly agree & 73 & 23.5 & 23.5 & 26.1 \\
I agree & 161 & 51.9 & 51.9 & 78.1 \\
Neither/ nor & 28 & 9 & 9 & 87.1 \\
I disagree & 36 & 11.6 & 11.6 & 98.7 \\
I strongly disagree & 4 & 1.3 & 1.3 & 100 \\
\hline N Total & 310 & 100 & 100 & \\
\hline
\end{tabular}

Q14. Confidence in standard setting organizations

\begin{tabular}{|l|c|c|c|c|}
\hline $\begin{array}{c}\text { Governments should be the only } \\
\text { responsible parties in establishing } \\
\text { food standards }\end{array}$ & $\begin{array}{c}\text { Frequency } \\
\mathbf{N}^{\circ} \text { of } \\
\text { Responses) }\end{array}$ & $\begin{array}{c}\text { Percent } \\
(\mathbf{\%})\end{array}$ & $\begin{array}{c}\text { Valid } \\
\text { Percent } \\
(\%)\end{array}$ & $\begin{array}{c}\text { Cumulative } \\
\text { Percent } \\
(\%)\end{array}$ \\
\hline 0 & 7 & 2.3 & 2.3 & 2.3 \\
I strongly agree & 13 & 4.2 & 4.2 & 6.5 \\
I agree & 28 & 9 & 9 & 15.5 \\
Neither/ nor & 52 & 16.8 & 16.8 & 32.3 \\
I disagree & 141 & 45.5 & 45.5 & 77.7 \\
I strongly disagree & 69 & 22.3 & 22.3 & 100 \\
\hline N Total & 310 & 100 & 100 & \\
\hline
\end{tabular}




\begin{tabular}{|c|c|c|c|c|}
\hline $\begin{array}{c}\text { I have confidence in food standards } \\
\text { developed by producer } \\
\text { organizations }\end{array}$ & $\begin{array}{l}\text { Frequency } \\
\quad\left(\mathbf{N}^{\circ} \text { of }\right. \\
\text { Responses })\end{array}$ & $\begin{array}{c}\text { Percent } \\
(\%)\end{array}$ & $\begin{array}{l}\text { Valid } \\
\text { Percent } \\
(\%)\end{array}$ & $\begin{array}{l}\text { Cumulative } \\
\text { Percent } \\
(\%)\end{array}$ \\
\hline 8 & 7 & 2.3 & 2.3 & 2.3 \\
\hline I strongly agree & 22 & 7.1 & 7.1 & 9.4 \\
\hline I agree & 107 & 34.5 & 34.5 & 43.9 \\
\hline Neither/ nor & 99 & 31.9 & 31.9 & 75.8 \\
\hline I disagree & 63 & 20.3 & 20.3 & 96.1 \\
\hline I strongly disagree & 12 & 3.9 & 3.9 & 100 \\
\hline $\mathrm{N}$ Total & 310 & 100 & 100 & \\
\hline
\end{tabular}

\begin{tabular}{|l|c|c|c|c|}
\hline $\begin{array}{c}\text { Food standards are more credible } \\
\text { when they are developed by } \\
\text { international organizations (e.g. } \\
\text { ISO) }\end{array}$ & $\begin{array}{c}\text { Frequency } \\
\mathbf{( \mathbf { N } ^ { \circ } \text { of }} \\
\text { Responses })\end{array}$ & $\begin{array}{c}\text { Percent } \\
(\mathbf{\%})\end{array}$ & $\begin{array}{c}\text { Percent } \\
(\boldsymbol{\%})\end{array}$ & $\begin{array}{c}\text { Cumulative } \\
\text { Percent } \\
(\%)\end{array}$ \\
\hline 0 & 7 & 2.3 & 2.3 & 2.3 \\
I strongly agree & 74 & 23.9 & 23.9 & 26.1 \\
I agree & 127 & 41 & 41 & 67.1 \\
Neither/ nor & 57 & 18.4 & 18.4 & 85.5 \\
I disagree & 34 & 11 & 11 & 96.5 \\
I strongly disagree & 11 & 3.5 & 3.5 & 100 \\
\hline N Total & 310 & 100 & 100 & \\
\hline
\end{tabular}




\begin{tabular}{|l|c|c|c|c|}
\hline $\begin{array}{c}\text { I have confidence in food standards } \\
\text { developed by certification bodies } \\
\text { (auditing companies) }\end{array}$ & $\begin{array}{c}\text { Frequency } \\
\mathbf{( N}^{\circ} \text { of } \\
\text { Responses) }\end{array}$ & $\begin{array}{c}\text { Percent } \\
(\boldsymbol{\%})\end{array}$ & $\begin{array}{c}\text { Valid } \\
\text { Percent } \\
(\boldsymbol{\%})\end{array}$ & $\begin{array}{c}\text { Cumulative } \\
\text { Percent } \\
(\%)\end{array}$ \\
\hline 0 & 9 & 2.9 & 2.9 & 2.9 \\
I strongly agree & 27 & 8.7 & 8.7 & 11.6 \\
I agree & 123 & 39.7 & 39.7 & 51.3 \\
Neither/ nor & 66 & 21.3 & 21.3 & 72.6 \\
I disagree & 64 & 20.6 & 20.6 & 93.2 \\
I strongly disagree & 21 & 6.8 & 6.8 & 100 \\
\hline N Total & 310 & 100 & 100 & \\
\hline
\end{tabular}

\begin{tabular}{|l|c|c|c|c|}
\hline $\begin{array}{c}\text { Non Governmental Organizations } \\
\text { (NGOs) are the right organizations } \\
\text { to develop food standards }\end{array}$ & $\begin{array}{c}\text { Frequency } \\
\mathbf{N}^{\circ} \text { of } \\
\text { Responses) }\end{array}$ & $\begin{array}{c}\text { Percent } \\
(\boldsymbol{\%})\end{array}$ & $\begin{array}{c}\text { Valid } \\
\text { Percent } \\
(\boldsymbol{\%})\end{array}$ & $\begin{array}{c}\text { Cumulative } \\
\text { Percent } \\
(\%)\end{array}$ \\
\hline 0 & 7 & 2.3 & 2.3 & 2.3 \\
I strongly agree & 19 & 6.1 & 6.1 & 8.4 \\
I agree & 73 & 23.5 & 23.5 & 31.9 \\
Neither/ nor & 79 & 25.5 & 25.5 & 57.4 \\
I disagree & 86 & 27.7 & 27.7 & 85.2 \\
I strongly disagree & 46 & 14.8 & 14.8 & 100 \\
\hline N Total & 310 & 100 & 100 & \\
\hline
\end{tabular}


Q15. Recommendations about Food Standards

\begin{tabular}{|l|c|c|c|c|}
\hline $\begin{array}{c}\text { I would suggest buying certified } \\
\text { fresh products under food standards } \\
\text { that are well advertised in the media }\end{array}$ & $\begin{array}{c}\text { Frequency } \\
\left(\mathbf{N}^{\circ} \text { of }\right. \\
\text { Responses })\end{array}$ & $\begin{array}{c}\text { Percent } \\
(\boldsymbol{\%})\end{array}$ & $\begin{array}{c}\text { Valid } \\
\text { Percent } \\
(\boldsymbol{\%})\end{array}$ & $\begin{array}{c}\text { Cumulative } \\
\text { Percent } \\
(\%)\end{array}$ \\
\hline 0 & 10 & 3.2 & 3.2 & 3.2 \\
I strongly agree & 8 & 2.6 & 2.6 & 5.8 \\
I agree & 57 & 18.4 & 18.4 & 24.2 \\
Neither/ nor & 115 & 37.1 & 37.1 & 61.3 \\
I disagree & 98 & 31.6 & 31.6 & 92.9 \\
I strongly disagree & 22 & 7.1 & 7.1 & 100 \\
\hline N Total & 310 & 100 & 100 & \\
\hline
\end{tabular}

\begin{tabular}{|c|c|c|c|c|}
\hline $\begin{array}{l}\text { I would advise others to have } \\
\text { confidence in food standards that } \\
\text { are very popular }\end{array}$ & $\begin{array}{l}\text { Frequency } \\
\quad\left(\mathbf{N}^{\circ} \text { of }\right. \\
\text { Responses })\end{array}$ & $\begin{array}{c}\text { Percent } \\
(\%)\end{array}$ & $\begin{array}{c}\text { Valid } \\
\text { Percent } \\
(\%)\end{array}$ & $\begin{array}{l}\text { Cumulative } \\
\text { Percent } \\
(\%)\end{array}$ \\
\hline 0 & 8 & 2.6 & 2.6 & 2.6 \\
\hline I strongly agree & 12 & 3.9 & 3.9 & 6.5 \\
\hline I agree & 80 & 25.8 & 25.8 & 32.3 \\
\hline Neither/ nor & 100 & 32.3 & 32.3 & 64.5 \\
\hline I disagree & 89 & 28.7 & 28.7 & 93.2 \\
\hline I strongly disagree & 21 & 6.8 & 6.8 & 100 \\
\hline N Total & 310 & 100 & 100 & \\
\hline
\end{tabular}




\begin{tabular}{|c|c|c|c|c|}
\hline $\begin{array}{l}\text { I would not propose others to rely } \\
\text { on food standards which I am not } \\
\text { interested in }\end{array}$ & $\begin{array}{l}\text { Frequency } \\
\quad\left(\mathbf{N}^{\circ} \text { of }\right. \\
\text { Responses })\end{array}$ & $\begin{array}{c}\text { Percent } \\
(\%)\end{array}$ & $\begin{array}{l}\text { Valid } \\
\text { Percent } \\
\quad(\%)\end{array}$ & $\begin{array}{l}\text { Cumulative } \\
\text { Percent } \\
(\%)\end{array}$ \\
\hline 0 & 10 & 3.2 & 3.2 & 3.2 \\
\hline I strongly agree & 9 & 2.9 & 2.9 & 6.1 \\
\hline I agree & 54 & 17.4 & 17.4 & 23.5 \\
\hline Neither/ nor & 108 & 34.8 & 34.8 & 58.4 \\
\hline I disagree & 108 & 34.8 & 34.8 & 93.2 \\
\hline I strongly disagree & 21 & 6.8 & 6.8 & 100 \\
\hline $\mathrm{N}$ Total & 310 & 100 & 100 & \\
\hline
\end{tabular}

\begin{tabular}{|l|c|c|c|c|}
\hline $\begin{array}{c}\text { I would only recommend food } \\
\text { standards which are based on 3rd } \\
\text { party certification }\end{array}$ & $\begin{array}{c}\text { Frequency } \\
\mathbf{N}^{\circ} \text { of } \\
\text { Responses })\end{array}$ & $\begin{array}{c}\text { Percent } \\
(\mathbf{\%})\end{array}$ & $\begin{array}{c}\text { Valid } \\
\text { Percent } \\
(\boldsymbol{\%})\end{array}$ & $\begin{array}{c}\text { Cumulative } \\
\text { Percent } \\
(\%)\end{array}$ \\
\hline 0 & 10 & 3.2 & 3.2 & 3.2 \\
I strongly agree & 107 & 34.5 & 34.5 & 37.7 \\
I agree & 134 & 43.2 & 43.2 & 81 \\
Neither/ nor & 26 & 8.4 & 8.4 & 89.4 \\
I disagree & 28 & 9 & 9 & 98.4 \\
I strongly disagree & 5 & 1.6 & 1.6 & 100 \\
\hline N Total & 310 & 100 & 100 & \\
\hline
\end{tabular}




\begin{tabular}{|l|c|c|c|c|}
\hline $\begin{array}{c}\text { I would not suggest buying food } \\
\text { products certified by a food } \\
\text { standard of a developing country }\end{array}$ & $\begin{array}{c}\text { Frequency } \\
\mathbf{N}^{\circ} \text { of } \\
\text { Responses) }\end{array}$ & $\begin{array}{c}\text { Percent } \\
(\boldsymbol{\%})\end{array}$ & $\begin{array}{c}\text { Valid } \\
\text { Percent } \\
(\boldsymbol{\%})\end{array}$ & $\begin{array}{c}\text { Cumulative } \\
\text { Percent } \\
(\%)\end{array}$ \\
\hline 0 & 8 & 2.6 & 2.6 & 2.6 \\
I strongly agree & 12 & 3.9 & 3.9 & 6.5 \\
I agree & 38 & 12.3 & 12.3 & 18.7 \\
Neither/ nor & 82 & 26.5 & 26.5 & 45.2 \\
I disagree & 133 & 42.9 & 42.9 & 88.1 \\
I strongly disagree & 37 & 11.9 & 11.9 & 100 \\
\hline N Total & 310 & 100 & 100 & \\
\hline
\end{tabular}

Q16. Likelihood benchmarking could improve credibility of standards

\begin{tabular}{|l|c|c|c|c|}
\hline \multicolumn{1}{|c|}{ Likelihood Ghana } & $\begin{array}{c}\text { Frequency } \\
\mathbf{N}^{\circ} \text { of } \\
\text { Responses })\end{array}$ & $\begin{array}{c}\text { Percent } \\
(\mathbf{\%})\end{array}$ & $\begin{array}{c}\text { Valid } \\
\text { Percent } \\
(\%)\end{array}$ & $\begin{array}{c}\text { Cumulative } \\
\text { Percent } \\
(\%)\end{array}$ \\
\hline 0 & 38 & 12.3 & 12.3 & 12.3 \\
Extremely likely & 76 & 24.5 & 24.5 & 36.8 \\
Likely & 95 & 30.6 & 30.6 & 67.4 \\
Neither / nor & 49 & 15.8 & 15.8 & 83.2 \\
Unlikely & 42 & 13.5 & 13.5 & 96.8 \\
Extremely unlikely & 10 & 3.2 & 3.2 & 100 \\
\hline N Total & 310 & 100 & 100 & \\
\hline
\end{tabular}




\begin{tabular}{|l|c|c|c|c|}
\hline \multicolumn{1}{|c|}{ Likelihood United Kingdom } & $\begin{array}{c}\text { Frequency } \\
\left(\mathbf{N}^{\circ} \text { of }\right. \\
\text { Responses })\end{array}$ & $\begin{array}{c}\text { Percent } \\
(\boldsymbol{\%})\end{array}$ & $\begin{array}{c}\text { Valid } \\
\text { Percent } \\
(\boldsymbol{\%})\end{array}$ & $\begin{array}{c}\text { Cumulative } \\
\text { Percent } \\
(\%)\end{array}$ \\
\hline 0 & 32 & 10.3 & 10.3 & 10.3 \\
Extremely likely & 82 & 26.5 & 26.5 & 36.8 \\
Likely & 102 & 32.9 & 32.9 & 69.7 \\
Neither / nor & 54 & 17.4 & 17.4 & 87.1 \\
Unlikely & 33 & 10.6 & 10.6 & 97.7 \\
Extremely unlikely & 7 & 2.3 & 2.3 & 100 \\
\hline N Total & 310 & 100 & 100 & \\
\hline
\end{tabular}

\begin{tabular}{|l|c|c|c|c|}
\hline \multicolumn{1}{|c|}{ Likelihood India } & $\begin{array}{c}\text { Frequency } \\
\left(\mathbf{N}^{\circ} \text { of }\right. \\
\text { Responses) }\end{array}$ & $\begin{array}{c}\text { Percent } \\
(\boldsymbol{\%})\end{array}$ & $\begin{array}{c}\text { Valid } \\
\text { Percent } \\
(\boldsymbol{\%})\end{array}$ & $\begin{array}{c}\text { Cumulative } \\
\text { Percent } \\
(\boldsymbol{\%})\end{array}$ \\
\hline 0 & 33 & 10.6 & 10.6 & 10.6 \\
Extremely likely & 70 & 22.6 & 22.6 & 33.2 \\
Likely & 110 & 35.5 & 35.5 & 68.7 \\
Neither / nor & 48 & 15.5 & 15.5 & 84.2 \\
Unlikely & 38 & 12.3 & 12.3 & 96.5 \\
Extremely unlikely & 11 & 3.5 & 3.5 & 100 \\
\hline N Total & 310 & 100 & 100 & \\
\hline
\end{tabular}




\begin{tabular}{|l|c|c|c|c|}
\hline \multicolumn{1}{|c|}{ Likelihood United States } & $\begin{array}{c}\text { Frequency } \\
\mathbf{N}^{\circ} \text { of } \\
\text { Responses) }\end{array}$ & $\begin{array}{c}\text { Percent } \\
(\mathbf{\%})\end{array}$ & $\begin{array}{c}\text { Valid } \\
\text { Percent } \\
(\%)\end{array}$ & $\begin{array}{c}\text { Cumulative } \\
\text { Percent } \\
(\%)\end{array}$ \\
\hline 0 & 33 & 10.6 & 10.6 & 10.6 \\
Extremely likely & 72 & 23.2 & 23.2 & 33.9 \\
likely & 114 & 36.8 & 36.8 & 70.6 \\
Neither / nor & 56 & 18.1 & 18.1 & 88.7 \\
Unlikely & 29 & 9.4 & 9.4 & 98.1 \\
Extremely unlikely & 6 & 1.9 & 1.9 & 100 \\
\hline N Total & 310 & 100 & 100 & \\
\hline
\end{tabular}

\begin{tabular}{|l|c|c|c|c|}
\hline \multicolumn{1}{|c|}{ Likelihood Mexico } & $\begin{array}{c}\text { Frequency } \\
\mathbf{( N}^{\circ} \text { of } \\
\text { Responses })\end{array}$ & $\begin{array}{c}\text { Percent } \\
(\boldsymbol{\%})\end{array}$ & $\begin{array}{c}\text { Valid } \\
\text { Percent } \\
(\boldsymbol{\%})\end{array}$ & $\begin{array}{c}\text { Cumulative } \\
\text { Percent } \\
(\%)\end{array}$ \\
\hline 0 & 37 & 11.9 & 11.9 & 11.9 \\
Extremely likely & 74 & 23.9 & 23.9 & 35.8 \\
Likely & 106 & 34.2 & 34.2 & 70 \\
Neither / nor & 58 & 18.7 & 18.7 & 88.7 \\
Unlikely & 26 & 8.4 & 8.4 & 97.1 \\
Extremely unlikely & 9 & 2.9 & 2.9 & 100 \\
\hline N Total & 310 & 100 & 100 & \\
\hline
\end{tabular}




\begin{tabular}{|l|c|c|c|c|}
\hline \multicolumn{1}{|c|}{ Likelihood Australia } & $\begin{array}{c}\text { Frequency } \\
\left(\mathbf{N}^{\circ} \text { of }\right. \\
\text { Responses })\end{array}$ & $\begin{array}{c}\text { Percent } \\
(\boldsymbol{\%})\end{array}$ & $\begin{array}{c}\text { Valid } \\
\text { Percent } \\
(\%)\end{array}$ & $\begin{array}{c}\text { Cumulative } \\
\text { Percent } \\
(\%)\end{array}$ \\
\hline 0 & 36 & 11.6 & 11.6 & 11.6 \\
Extremely likely & 73 & 23.5 & 23.5 & 35.2 \\
Likely & 108 & 34.8 & 34.8 & 70 \\
Neither / nor & 57 & 18.4 & 18.4 & 88.4 \\
Unlikely & 29 & 9.4 & 9.4 & 97.7 \\
Extremely unlikely & 7 & 2.3 & 2.3 & 100 \\
\hline N Total & 310 & 100 & 100 & \\
\hline
\end{tabular}

\begin{tabular}{|l|c|c|c|c|}
\hline \multicolumn{1}{|c|}{ Likelihood China } & $\begin{array}{c}\text { Frequency } \\
\mathbf{( \mathbf { N } ^ { \circ } \text { of }} \\
\text { Responses })\end{array}$ & $\begin{array}{c}\text { Percent } \\
(\boldsymbol{\%})\end{array}$ & $\begin{array}{c}\text { Valid } \\
\text { Percent } \\
(\boldsymbol{\%})\end{array}$ & $\begin{array}{c}\text { Cumulative } \\
\text { Percent } \\
(\%)\end{array}$ \\
\hline 0 & 36 & 11.6 & 11.6 & 11.6 \\
Extremely likely & 73 & 23.5 & 23.5 & 35.2 \\
Likely & 90 & 29 & 29 & 64.2 \\
Neither / nor & 48 & 15.5 & 15.5 & 79.7 \\
Unlikely & 46 & 14.8 & 14.8 & 94.5 \\
Extremely unlikely & 17 & 5.5 & 5.5 & 100 \\
\hline N Total & 310 & 100 & 100 & \\
\hline
\end{tabular}




\begin{tabular}{|l|c|c|c|c|}
\hline \multicolumn{1}{|c|}{ Likelihood Italy } & $\begin{array}{c}\text { Frequency } \\
\mathbf{( N}^{\circ} \text { of } \\
\text { Responses })\end{array}$ & $\begin{array}{c}\text { Percent } \\
(\boldsymbol{\%})\end{array}$ & $\begin{array}{c}\text { Valid } \\
\text { Percent } \\
(\boldsymbol{\%})\end{array}$ & $\begin{array}{c}\text { Cumulative } \\
\text { Percent } \\
(\%)\end{array}$ \\
\hline 0 & 36 & 11.6 & 11.6 & 11.6 \\
Extremely likely & 65 & 21 & 21 & 32.6 \\
Likely & 140 & 45.2 & 45.2 & 77.7 \\
Neither / nor & 38 & 12.3 & 12.3 & 90 \\
Unlikely & 24 & 7.7 & 7.7 & 97.7 \\
Extremely unlikely & 7 & 2.3 & 2.3 & 100 \\
\hline N Total & 310 & 100 & 100 & \\
\hline
\end{tabular}

Q17. Location of Headquarters

\begin{tabular}{|c|c|c|c|c|}
\hline Country Location & $\begin{array}{c}\text { Frequency } \\
\left(\mathbf{N}^{\circ} \text { of }\right. \\
\text { Responses })\end{array}$ & $\begin{array}{c}\text { Percent } \\
(\%)\end{array}$ & $\begin{array}{c}\text { Valid } \\
\text { Percent }(\%)\end{array}$ & $\begin{array}{c}\text { Cumulative } \\
\text { Percent } \\
(\%)\end{array}$ \\
\hline 99 & 8 & 2.6 & 2.6 & 2.6 \\
\hline Argentina & 7 & 2.3 & 2.3 & 4.8 \\
\hline Australia & 17 & 5.5 & 5.5 & 10.3 \\
\hline Austria & 6 & 1.9 & 1.9 & 12.3 \\
\hline Belgium & 5 & 1.6 & 1.6 & 13.9 \\
\hline Brazil & 9 & 2.9 & 2.9 & 16.8 \\
\hline Canada & 4 & 1.3 & 1.3 & 18.1 \\
\hline Chile & 4 & 1.3 & 1.3 & 19.4 \\
\hline China & 3 & 1 & 1 & 20.3 \\
\hline Colombia & 6 & 1.9 & 1.9 & 22.3 \\
\hline Costa Rica & 1 & 0.3 & 0.3 & 22.6 \\
\hline Czech Republic & 1 & 0.3 & 0.3 & 22.9 \\
\hline Denmark & 1 & 0.3 & 0.3 & 23.2 \\
\hline Ecuador & 4 & 1.3 & 1.3 & 24.5 \\
\hline Egypt & 7 & 2.3 & 2.3 & 26.8 \\
\hline Faroe Islands & 1 & 0.3 & 0.3 & 27.1 \\
\hline Finland & 1 & 0.3 & 0.3 & 27.4 \\
\hline France & 17 & 5.5 & 5.5 & 32.9 \\
\hline Germany & 25 & 8.1 & 8.1 & 41 \\
\hline Ghana & 4 & 1.3 & 1.3 & 42.3 \\
\hline Greece & 1 & 0.3 & 0.3 & 42.6 \\
\hline Guatemala & 1 & 0.3 & 0.3 & 42.9 \\
\hline India & 6 & 1.9 & 1.9 & 44.8 \\
\hline
\end{tabular}




\begin{tabular}{|c|c|c|c|c|}
\hline Indonesia & 1 & 0.3 & 0.3 & 45.2 \\
\hline Ireland & 4 & 1.3 & 1.3 & 46.5 \\
\hline Italy & 10 & 3.2 & 3.2 & 49.7 \\
\hline Kenya & 5 & 1.6 & 1.6 & 51.3 \\
\hline Luxembourg & 1 & 0.3 & 0.3 & 51.6 \\
\hline Malta & 1 & 0.3 & 0.3 & 51.9 \\
\hline Mexico & 2 & 0.6 & 0.6 & 52.6 \\
\hline New Zealand & 4 & 1.3 & 1.3 & 53.9 \\
\hline Norway & 6 & 1.9 & 1.9 & 55.8 \\
\hline Pakistan & 2 & 0.6 & 0.6 & 56.5 \\
\hline Palestine & 1 & 0.3 & 0.3 & 56.8 \\
\hline Peru & 1 & 0.3 & 0.3 & 57.1 \\
\hline Poland & 1 & 0.3 & 0.3 & 57.4 \\
\hline Portugal & 3 & 1 & 1 & 58.4 \\
\hline Republican Dominican & 1 & 0.3 & 0.3 & 58.7 \\
\hline Russia & 1 & 0.3 & 0.3 & 59 \\
\hline Saudi Arabia & 2 & 0.6 & 0.6 & 59.7 \\
\hline Serbia & 1 & 0.3 & 0.3 & 60 \\
\hline Slovakia & 1 & 0.3 & 0.3 & 60.3 \\
\hline South Africa & 4 & 1.3 & 1.3 & 61.6 \\
\hline Spain & 13 & 4.2 & 4.2 & 65.8 \\
\hline Suriname & 2 & 0.6 & 0.6 & 66.5 \\
\hline Sweden & 2 & 0.6 & 0.6 & 67.1 \\
\hline Switzerland & 13 & 4.2 & 4.2 & 71.3 \\
\hline Syria & 1 & 0.3 & 0.3 & 71.6 \\
\hline Taiwan & 2 & 0.6 & 0.6 & 72.3 \\
\hline Thailand & 3 & 1 & 1 & 73.2 \\
\hline The Netherlands & 18 & 5.8 & 5.8 & 79 \\
\hline Turkey & 4 & 1.3 & 1.3 & 80.3 \\
\hline United Arab Emirates & 2 & 0.6 & 0.6 & 81 \\
\hline United Kingdom & 24 & 7.7 & 7.7 & 88.7 \\
\hline United States & 28 & 9 & 9 & 97.7 \\
\hline Uruguay & 2 & 0.6 & 0.6 & 98.4 \\
\hline Vietnam & 4 & 1.3 & 1.3 & 99.7 \\
\hline Yemen & 1 & 0.3 & 0.3 & 100 \\
\hline Total & 310 & 100 & 100 & \\
\hline
\end{tabular}


Q18. Business Type

\begin{tabular}{|l|c|c|c|c|}
\hline \multicolumn{1}{|c|}{ Business Type } & $\begin{array}{c}\text { Frequency } \\
\mathbf{N}^{\circ} \text { of } \\
\text { Responses) }\end{array}$ & $\begin{array}{c}\text { Percent } \\
(\%)\end{array}$ & $\begin{array}{c}\text { Valid } \\
\text { Percent } \\
(\%)\end{array}$ & $\begin{array}{c}\text { Cumulative } \\
\text { Percent } \\
(\%)\end{array}$ \\
\hline 0 & 4 & 1.3 & 1.3 & 1.3 \\
Retail & 23 & 7.4 & 7.4 & 8.7 \\
Food Service / Restaurant & 4 & 1.3 & 1.3 & 10 \\
Manufacturing / Packing & 28 & 9 & 9 & 19 \\
Trading (Imports / Exports) & 28 & 9 & 9 & 28.1 \\
Supplier & 28 & 9 & 9 & 37.1 \\
Service Provider & 131 & 42.3 & 42.3 & 79.4 \\
Other (please indicate) & 64 & 20.6 & 20.6 & 100 \\
\hline Total & 310 & 100 & 100 & \\
\hline
\end{tabular}

Q19. Turnover

\begin{tabular}{|l|c|c|c|c|}
\hline \multicolumn{1}{|c|}{$\begin{array}{c}\text { Turnover } \\
\text { (EUR) }\end{array}$} & $\begin{array}{c}\text { Frequency } \\
\mathbf{N}^{\circ} \text { of } \\
\text { Responses) }\end{array}$ & $\begin{array}{c}\text { Percent } \\
(\boldsymbol{\%})\end{array}$ & $\begin{array}{c}\text { Valid } \\
\text { Percent } \\
(\%)\end{array}$ & $\begin{array}{c}\text { Cumulative } \\
\text { Percent } \\
(\%)\end{array}$ \\
\hline 0 & 27 & 8.7 & 8.7 & 8.7 \\
Less than 1 million & 75 & 24.2 & 24.2 & 32.9 \\
1 million EUR to less than 50 million & 99 & 31.9 & 31.9 & 64.8 \\
50 million EUR to less than 100 million & 39 & 12.6 & 12.6 & 77.4 \\
100 million EUR to less than 500 million & 19 & 6.1 & 6.1 & 83.5 \\
500 million EUR to less than 1 billion & 14 & 4.5 & 4.5 & 88.1 \\
More than 1 billion & 37 & 11.9 & 11.9 & 100 \\
\hline Total & 310 & 100 & 100 & \\
\hline
\end{tabular}


Q20. Type of food products

\begin{tabular}{|l|c|c|c|c|}
\hline \multicolumn{1}{|c|}{ Fruit and Vegetables } & $\begin{array}{c}\text { Frequency } \\
\mathbf{N}^{\circ} \text { of } \\
\text { Responses })\end{array}$ & $\begin{array}{c}\text { Percent } \\
(\mathbf{\%})\end{array}$ & $\begin{array}{c}\text { Valid } \\
\text { Percent } \\
(\%)\end{array}$ & $\begin{array}{c}\text { Cumulative } \\
\text { Percent } \\
(\%)\end{array}$ \\
\hline not quoted & 14 & 4.5 & 12.8 & 12.8 \\
Quoted & 95 & 30.6 & 87.2 & 100 \\
Total & 109 & 35.2 & 100 & \\
Missing & 201 & 64.8 & & \\
\hline Total & 310 & 100 & & \\
\hline
\end{tabular}

\begin{tabular}{|c|c|c|c|c|}
\hline Livestock & $\begin{array}{l}\text { Frequency } \\
\left(\mathbf{N}^{\circ} \text { of }\right. \\
\text { Responses })\end{array}$ & $\begin{array}{c}\text { Percent } \\
(\%)\end{array}$ & $\begin{array}{c}\text { Valid } \\
\text { Percent } \\
(\%)\end{array}$ & $\begin{array}{c}\text { Cumulative } \\
\text { Percent } \\
(\%)\end{array}$ \\
\hline not quoted & 90 & 29 & 82.6 & 82.6 \\
\hline Quoted & 19 & 6.1 & 17.4 & 100 \\
\hline Total & 109 & 35.2 & 100 & \\
\hline Missing & 201 & 64.8 & & \\
\hline Total & 310 & 100 & & \\
\hline
\end{tabular}

\begin{tabular}{|l|c|c|c|c|}
\hline & $\begin{array}{c}\text { Frequency } \\
\mathbf{N}^{\circ} \text { of } \\
\text { Responses) }\end{array}$ & $\begin{array}{c}\text { Percent } \\
(\boldsymbol{\%})\end{array}$ & $\begin{array}{c}\text { Valid } \\
\text { Percent } \\
(\%)\end{array}$ & $\begin{array}{c}\text { Cumulative } \\
\text { Percent } \\
(\%)\end{array}$ \\
\hline not quoted & 92 & 29.7 & 84.4 & 84.4 \\
Quoted & 17 & 5.5 & 15.6 & 100 \\
Total & 109 & 35.2 & 100 & \\
Missing & 201 & 64.8 & & \\
\hline Total & 310 & 100 & & \\
\hline
\end{tabular}




\begin{tabular}{|c|c|c|c|c|}
\hline Flowers & $\begin{array}{c}\text { Frequency } \\
\left(\mathbf{N}^{\circ} \text { of }\right. \\
\text { Responses })\end{array}$ & $\begin{array}{c}\text { Percent } \\
(\%)\end{array}$ & $\begin{array}{c}\text { Valid } \\
\text { Percent } \\
(\%) \\
\end{array}$ & $\begin{array}{c}\text { Cumulative } \\
\text { Percent } \\
(\%)\end{array}$ \\
\hline not quoted & 97 & 31.3 & 89 & 89 \\
\hline Quoted & 12 & 3.9 & 11 & 100 \\
\hline Total & 109 & 35.2 & 100 & \\
\hline Missing & 201 & 64.8 & & \\
\hline Total & 310 & 100 & & \\
\hline
\end{tabular}

\begin{tabular}{|l|c|c|c|c|}
\hline & $\begin{array}{c}\text { Frequency } \\
\mathbf{N}^{\circ} \text { of } \\
\text { Responses) }\end{array}$ & $\begin{array}{c}\text { Percent } \\
(\boldsymbol{\%})\end{array}$ & $\begin{array}{c}\text { Valid } \\
\text { Percent } \\
(\boldsymbol{\%})\end{array}$ & $\begin{array}{c}\text { Cumulative } \\
\text { Percent } \\
(\%)\end{array}$ \\
\hline not quoted & 98 & 31.6 & 89.9 & 89.9 \\
Quoted & 11 & 3.5 & 10.1 & 100 \\
Total & 109 & 35.2 & 100 & \\
\hline Total & 201 & 64.8 & & \\
\hline
\end{tabular}




\begin{tabular}{|c|c|c|c|c|}
\hline others & $\begin{array}{l}\text { Frequency } \\
\left(\mathbf{N}^{\circ} \text { of }\right. \\
\text { Responses })\end{array}$ & $\begin{array}{c}\text { Percent } \\
(\%)\end{array}$ & $\begin{array}{c}\text { Valid } \\
\text { Percent } \\
(\%)\end{array}$ & $\begin{array}{c}\text { Cumulative } \\
\text { Percent } \\
(\%)\end{array}$ \\
\hline & 201 & 64.8 & 64.8 & 64.8 \\
\hline & 100 & 32.3 & 32.3 & 97.1 \\
\hline and various others & 1 & 0.3 & 0.3 & 97.4 \\
\hline Cereals & 1 & 0.3 & 0.3 & 97.7 \\
\hline Cocoa & 1 & 0.3 & 0.3 & 98.1 \\
\hline Dairy Products & 1 & 0.3 & 0.3 & 98.4 \\
\hline Dairy Products. Infant Formulas & 1 & 0.3 & 0.3 & 98.7 \\
\hline General Grocery+Non Foods & 1 & 0.3 & 0.3 & 99 \\
\hline Native Products & 1 & 0.3 & 0.3 & 99.4 \\
\hline Nuts & 1 & 0.3 & 0.3 & 99.7 \\
\hline Processed Food & 1 & 0.3 & 0.3 & 100 \\
\hline Total & 310 & 100 & 100 & \\
\hline
\end{tabular}

Q21. Sourcing Region

\begin{tabular}{|c|c|c|c|c|}
\hline North America & $\begin{array}{l}\text { Frequency } \\
\left(\mathbf{N}^{\circ} \text { of }\right. \\
\text { Responses })\end{array}$ & $\begin{array}{c}\text { Percent } \\
(\%)\end{array}$ & $\begin{array}{c}\text { Valid } \\
\text { Percent } \\
(\%)\end{array}$ & $\begin{array}{c}\text { Cumulative } \\
\text { Percent } \\
(\%)\end{array}$ \\
\hline not quoted & 92 & 29.7 & 84.4 & 84.4 \\
\hline Quoted & 17 & 5.5 & 15.6 & 100 \\
\hline Total & 109 & 35.2 & 100 & \\
\hline Missing & 201 & 64.8 & & \\
\hline Total & 310 & 100 & & \\
\hline
\end{tabular}




\begin{tabular}{|c|c|c|c|c|}
\hline Latin America & $\begin{array}{c}\text { Frequency } \\
\left(\mathbf{N}^{\circ} \text { of }\right. \\
\text { Responses })\end{array}$ & $\begin{array}{c}\text { Percent } \\
(\%)\end{array}$ & $\begin{array}{c}\text { Valid } \\
\text { Percent } \\
(\%)\end{array}$ & $\begin{array}{c}\text { Cumulative } \\
\text { Percent } \\
(\%)\end{array}$ \\
\hline not quoted & 53 & 17.1 & 48.6 & 48.6 \\
\hline Quoted & 56 & 18.1 & 51.4 & 100 \\
\hline Total & 109 & 35.2 & 100 & \\
\hline Missing & 201 & 64.8 & & \\
\hline Total & 310 & 100 & & \\
\hline
\end{tabular}

\begin{tabular}{|c|c|c|c|c|}
\hline Europe & $\begin{array}{l}\text { Frequency } \\
\left(\mathbf{N}^{\circ} \text { of }\right. \\
\text { Responses })\end{array}$ & $\begin{array}{c}\text { Percent } \\
(\%)\end{array}$ & $\begin{array}{c}\text { Valid } \\
\text { Percent } \\
(\%)\end{array}$ & $\begin{array}{c}\text { Cumulative } \\
\text { Percent } \\
(\%)\end{array}$ \\
\hline not quoted & 60 & 19.4 & 55 & 55 \\
\hline Quoted & 49 & 15.8 & 45 & 100 \\
\hline Total & 109 & 35.2 & 100 & \\
\hline Missing & 201 & 64.8 & & \\
\hline Total & 310 & 100 & & \\
\hline
\end{tabular}

\begin{tabular}{|lc|c|c|c|c|}
\hline & Africa & $\begin{array}{c}\text { Frequency } \\
\mathbf{N}^{\circ} \text { of } \\
\text { Responses) }\end{array}$ & $\begin{array}{c}\text { Percent } \\
(\boldsymbol{\%})\end{array}$ & $\begin{array}{c}\text { Valid } \\
\text { Percent } \\
(\%)\end{array}$ & $\begin{array}{c}\text { Cumulative } \\
\text { Percent } \\
(\%)\end{array}$ \\
\hline not quoted & 70 & 22.6 & 64.2 & 64.2 \\
Quoted & 39 & 12.6 & 35.8 & 100 \\
Total & 97 & 201 & 64.8 & 100 & \\
\hline Total & 109 & 35.2 & & \\
\hline
\end{tabular}




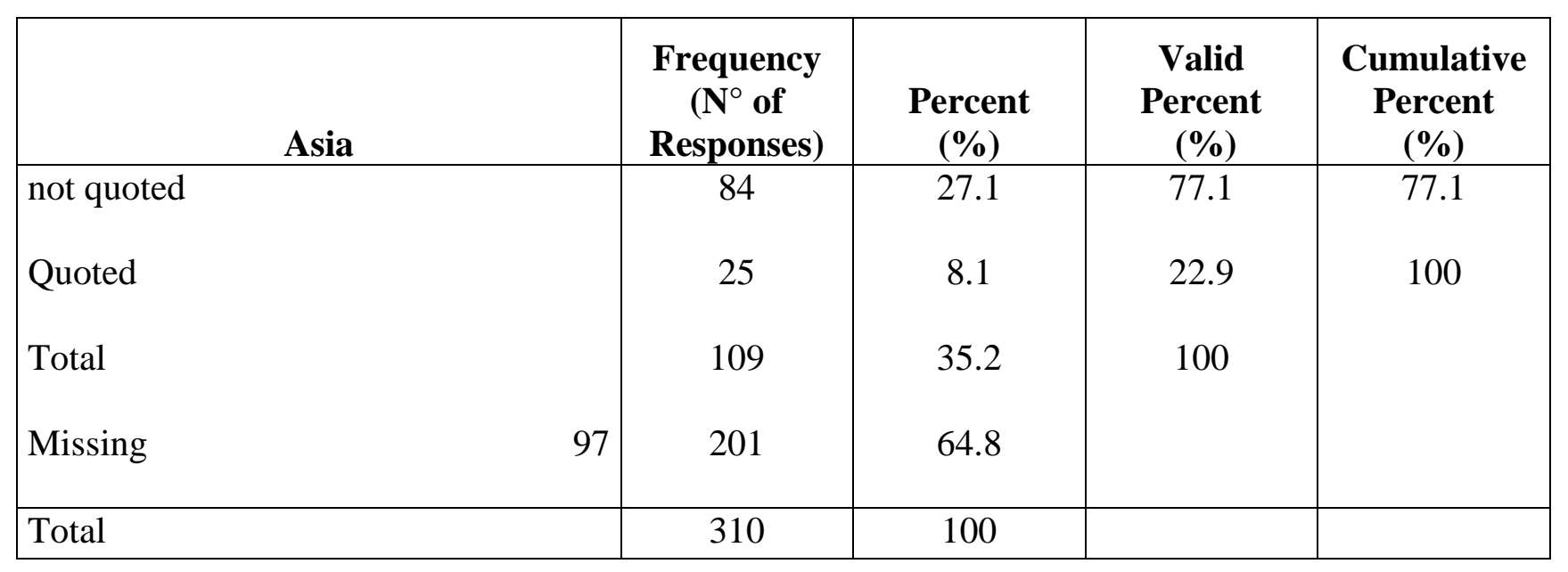

\begin{tabular}{|c|c|c|c|c|}
\hline Australasia & $\begin{array}{l}\text { Frequency } \\
\left(\mathbf{N}^{\circ} \text { of }\right. \\
\text { Responses })\end{array}$ & $\begin{array}{c}\text { Percent } \\
(\%)\end{array}$ & $\begin{array}{c}\text { Valid } \\
\text { Percent } \\
(\%)\end{array}$ & $\begin{array}{c}\text { Cumulative } \\
\text { Percent } \\
(\%)\end{array}$ \\
\hline not quoted & 100 & 32.3 & 91.7 & 91.7 \\
\hline Quoted & 9 & 2.9 & 8.3 & 100 \\
\hline Total & 109 & 35.2 & 100 & \\
\hline Missing & 201 & 64.8 & & \\
\hline Total & 310 & 100 & & \\
\hline
\end{tabular}




\begin{tabular}{|l|c|c|c|c|}
\hline \multicolumn{1}{|c|}{ Position } & $\begin{array}{c}\text { Frequency } \\
\left(\mathbf{N}^{\circ} \text { of }\right. \\
\text { Responses) }\end{array}$ & $\begin{array}{c}\text { Percent } \\
(\boldsymbol{\%})\end{array}$ & $\begin{array}{c}\text { Valid } \\
\text { Percent (\%) }\end{array}$ & $\begin{array}{c}\text { Cumulative } \\
\text { Percent } \\
(\%)\end{array}$ \\
\hline 0 & 5 & 1.6 & 1.6 & 1.6 \\
Sales Manager & 13 & 4.2 & 4.2 & 5.8 \\
Quality Manager & 53 & 17.1 & 17.1 & 22.9 \\
Buyer & 1 & 0.3 & 0.3 & 23.2 \\
Technical Expert & 72 & 23.2 & 23.2 & 46.5 \\
Auditor / Inspector & 51 & 16.5 & 16.5 & 62.9 \\
Other (please indicate) & 115 & 37.1 & 37.1 & 100 \\
Total & 310 & 100 & 100 & \\
\hline
\end{tabular}

\begin{tabular}{|c|c|c|c|c|}
\hline Other position & $\begin{array}{l}\text { Frequency } \\
\left(\mathbf{N}^{\circ} \text { of }\right. \\
\text { Responses })\end{array}$ & $\begin{array}{c}\text { Percent } \\
(\%)\end{array}$ & $\begin{array}{c}\text { Valid } \\
\text { Percent } \\
(\%)\end{array}$ & $\begin{array}{c}\text { Cumulative } \\
\text { Percent } \\
(\%)\end{array}$ \\
\hline 99 & 201 & 64.8 & 64.8 & 64.8 \\
\hline Accreditation Manager & 1 & 0.3 & 0.3 & 65.2 \\
\hline Advisor & 1 & 0.3 & 0.3 & 65.5 \\
\hline Advisor of the board & 1 & 0.3 & 0.3 & 65.8 \\
\hline Ag Global Leader & 1 & 0.3 & 0.3 & 66.1 \\
\hline all of the above & 1 & 0.3 & 0.3 & 66.5 \\
\hline Auditor & 1 & 0.3 & 0.3 & 66.8 \\
\hline Business Development Manager & 1 & 0.3 & 0.3 & 67.1 \\
\hline C.E.O. & 10 & 3.2 & 3.2 & 70.3 \\
\hline Certification Officer & 1 & 0.3 & 0.3 & 70.6 \\
\hline Company Owner & 1 & 0.3 & 0.3 & 71 \\
\hline Company Owner & 8 & 2.6 & 2.6 & 73.5 \\
\hline Consultant & 2 & 0.6 & 0.6 & 74.2 \\
\hline Country General Manager & 1 & 0.3 & 0.3 & 74.5 \\
\hline Country Manager & 1 & 0.3 & 0.3 & 74.8 \\
\hline
\end{tabular}




\begin{tabular}{|c|}
\hline CEO \\
\hline Deputy Managing Director \\
\hline Director of Compliance \\
\hline Director of Sourcing \\
\hline Economics Professor \\
\hline Editor \\
\hline Executive \\
\hline Executive/owner \\
\hline$F \& B$ \\
\hline Food Certification Manager \\
\hline Food Chain Manager \\
\hline General Director \\
\hline General Manager \\
\hline Global Food Market Analyst \\
\hline Grower Services/Food Safety \\
\hline Head of Section \\
\hline HSEQ Manager \\
\hline Import Food Safety Manager \\
\hline Inspection Director \\
\hline Inspector \\
\hline International Coordinator \\
\hline Journalist \\
\hline Managing Director \\
\hline Marketing Manager \\
\hline MD \\
\hline Operations Manager \\
\hline Operations/ Coordinator \\
\hline Policy Adviser \\
\hline President \\
\hline President of Company \\
\hline
\end{tabular}

\begin{tabular}{|c|c|c|c|}
\hline 1 & 0.3 & 0.3 & 75.2 \\
\hline 1 & 0.3 & 0.3 & 75.5 \\
\hline 1 & 0.3 & 0.3 & 75.8 \\
\hline 1 & 0.3 & 0.3 & 76.1 \\
\hline 1 & 0.3 & 0.3 & 76.5 \\
\hline 1 & 0.3 & 0.3 & 76.8 \\
\hline 1 & 0.3 & 0.3 & 77.1 \\
\hline 1 & 0.3 & 0.3 & 77.4 \\
\hline 1 & 0.3 & 0.3 & 77.7 \\
\hline 1 & 0.3 & 0.3 & 78.1 \\
\hline 3 & 1 & 1 & 79 \\
\hline 11 & 3.5 & 3.5 & 82.6 \\
\hline 9 & 2.9 & 2.9 & 85.5 \\
\hline 1 & 0.3 & 0.3 & 85.8 \\
\hline 1 & 0.3 & 0.3 & 86.1 \\
\hline 1 & 0.3 & 0.3 & 86.5 \\
\hline 1 & 0.3 & 0.3 & 86.8 \\
\hline 1 & 0.3 & 0.3 & 87.1 \\
\hline 1 & 0.3 & 0.3 & 87.4 \\
\hline 1 & 0.3 & 0.3 & 87.7 \\
\hline 1 & 0.3 & 0.3 & 88.1 \\
\hline 1 & 0.3 & 0.3 & 88.4 \\
\hline 4 & 1.3 & 1.3 & 89.7 \\
\hline 2 & 0.6 & 0.6 & 90.3 \\
\hline 3 & 1 & 1 & 91.3 \\
\hline 1 & 0.3 & 0.3 & 91.6 \\
\hline 1 & 0.3 & 0.3 & 91.9 \\
\hline 1 & 0.3 & 0.3 & 92.3 \\
\hline 1 & 0.3 & 0.3 & 92.6 \\
\hline 1 & 0.3 & 0.3 & 92.9 \\
\hline
\end{tabular}




\begin{tabular}{|c|c|c|c|c|}
\hline $\begin{array}{l}\text { Procurement and Quality Manager } \\
\text { South America }\end{array}$ & 1 & 0.3 & 0.3 & 93.2 \\
\hline Product Manager & 1 & 0.3 & 0.3 & 93.5 \\
\hline Professional (agronomist) & 1 & 0.3 & 0.3 & 93.9 \\
\hline Project Manager & 2 & 0.6 & 0.6 & 94.5 \\
\hline Raw Product Food Safety Manager & 1 & 0.3 & 0.3 & 95.2 \\
\hline Research Associate & 1 & 0.3 & 0.3 & 95.5 \\
\hline Scheme Manager & 1 & 0.3 & 0.3 & 95.8 \\
\hline Senior Program Director Accreditation & 1 & 0.3 & 0.3 & 96.1 \\
\hline Teacher & 1 & 0.3 & 0.3 & 96.5 \\
\hline Team Leader & 1 & 0.3 & 0.3 & 96.8 \\
\hline Technical and Sales Support & 1 & 0.3 & 0.3 & 97.1 \\
\hline Technical Director & 3 & 1 & 1 & 98.1 \\
\hline $\begin{array}{l}\text { Technical Food Safety Manager and } \\
\text { Internal Auditor }\end{array}$ & 1 & 0.3 & 0.3 & 98.4 \\
\hline Technical Manager & 3 & 1 & 1 & 99.4 \\
\hline $\begin{array}{l}\text { Trainer for auditors. coordination of } \\
\text { controls }\end{array}$ & 1 & 0.3 & 0.3 & 99.7 \\
\hline VP of Operations & 1 & 0.3 & 0.3 & 100 \\
\hline Total & 310 & 100 & 100 & \\
\hline
\end{tabular}




\begin{tabular}{|c|c|c|c|c|}
\hline Country of Birth & $\begin{array}{c}\text { Frequency } \\
\left(\mathbf{N}^{\circ} \text { of }\right. \\
\text { Responses) }\end{array}$ & $\begin{array}{c}\text { Percent } \\
(\%)\end{array}$ & $\begin{array}{c}\text { Valid } \\
\text { Percent } \\
(\%)\end{array}$ & $\begin{array}{c}\text { Cumulative } \\
\text { Percent } \\
(\%)\end{array}$ \\
\hline 99 & 9 & 2.9 & 2.9 & 2.9 \\
\hline Algeria & 1 & 0.3 & 0.3 & 3.2 \\
\hline Argentina & 6 & 1.9 & 1.9 & 5.2 \\
\hline Australia & 10 & 3.2 & 3.2 & 8.4 \\
\hline Austria & 5 & 1.6 & 1.6 & 10 \\
\hline Belgium & 2 & 0.6 & 0.6 & 10.6 \\
\hline Brazil & 8 & 2.6 & 2.6 & 13.2 \\
\hline Cameroon & 1 & 0.3 & 0.3 & 13.5 \\
\hline Canada & 5 & 1.6 & 1.6 & 15.2 \\
\hline Chile & 7 & 2.3 & 2.3 & 17.4 \\
\hline China & 4 & 1.3 & 1.3 & 18.7 \\
\hline Colombia & 6 & 1.9 & 1.9 & 20.6 \\
\hline Costa Rica & 1 & 0.3 & 0.3 & 21 \\
\hline Cyprus & 1 & 0.3 & 0.3 & 21.3 \\
\hline Czech Republic & 1 & 0.3 & 0.3 & 21.6 \\
\hline Denmark & 1 & 0.3 & 0.3 & 21.9 \\
\hline Ecuador & 6 & 1.9 & 1.9 & 23.9 \\
\hline Egypt & 11 & 3.5 & 3.5 & 27.4 \\
\hline Faroe Islands & 1 & 0.3 & 0.3 & 27.7 \\
\hline Finland & 1 & 0.3 & 0.3 & 28.1 \\
\hline Finland & 1 & 0.3 & 0.3 & 28.4 \\
\hline France & 9 & 2.9 & 2.9 & 31.3 \\
\hline Germany & 30 & 9.7 & 9.7 & 41 \\
\hline Ghana & 5 & 1.6 & 1.6 & 42.6 \\
\hline Greece & 1 & 0.3 & 0.3 & 42.9 \\
\hline Guatemala & 1 & 0.3 & 0.3 & 43.2 \\
\hline India & 6 & 1.9 & 1.9 & 45.2 \\
\hline Indonesia & 1 & 0.3 & 0.3 & 45.5 \\
\hline Ireland & 2 & 0.6 & 0.6 & 46.1 \\
\hline Italy & 9 & 2.9 & 2.9 & 49 \\
\hline Kenya & 5 & 1.6 & 1.6 & 50.6 \\
\hline Libya & 1 & 0.3 & 0.3 & 51 \\
\hline Luxembourg & 1 & 0.3 & 0.3 & 51.3 \\
\hline Malta & 1 & 0.3 & 0.3 & 51.6 \\
\hline Mexico & 2 & 0.6 & 0.6 & 52.3 \\
\hline Morocco & 1 & 0.3 & 0.3 & 52.6 \\
\hline
\end{tabular}




\begin{tabular}{|c|c|c|c|c|}
\hline New Zealand & 3 & 1 & 1 & 53.5 \\
\hline Norway & 3 & 1 & 1 & 54.5 \\
\hline Pakistan & 2 & 0.6 & 0.6 & 55.2 \\
\hline Palestine & 1 & 0.3 & 0.3 & 55.5 \\
\hline Paraguay & 1 & 0.3 & 0.3 & 55.8 \\
\hline Peru & 3 & 1 & 1 & 56.8 \\
\hline Poland & 1 & 0.3 & 0.3 & 57.1 \\
\hline Portugal & 4 & 1.3 & 1.3 & 58.4 \\
\hline Russia & 1 & 0.3 & 0.3 & 58.7 \\
\hline Serbia & 2 & 0.6 & 0.6 & 59.4 \\
\hline Singapore & 1 & 0.3 & 0.3 & 59.7 \\
\hline Slovakia & 1 & 0.3 & 0.3 & 60 \\
\hline South Africa & 6 & 1.9 & 1.9 & 61.9 \\
\hline Spain & 17 & 5.5 & 5.5 & 67.4 \\
\hline Suriname & 1 & 0.3 & 0.3 & 67.7 \\
\hline Sweden & 2 & 0.6 & 0.6 & 68.4 \\
\hline Switzerland & 5 & 1.6 & 1.6 & 70 \\
\hline Syria & 1 & 0.3 & 0.3 & 70.3 \\
\hline Taiwan & 2 & 0.6 & 0.6 & 71 \\
\hline Thailand & 3 & 1 & 1 & 71.9 \\
\hline The Netherlands & 23 & 7.4 & 7.4 & 79.4 \\
\hline Turkey & 5 & 1.6 & 1.6 & 81 \\
\hline UK & 27 & 8.7 & 8.7 & 89.7 \\
\hline Uruguay & 5 & 1.6 & 1.6 & 91.3 \\
\hline USA & 22 & 7.1 & 7.1 & 98.4 \\
\hline Vietnam & 5 & 1.6 & 1.6 & 100 \\
\hline Total & 310 & 100 & 100 & \\
\hline
\end{tabular}




\begin{tabular}{|c|c|c|c|c|}
\hline $\begin{array}{c}\text { Year of Birth } \\
(19 \ldots) \\
\end{array}$ & $\begin{array}{c}\text { Frequency } \\
\left(\mathbf{N}^{\circ} \text { of }\right. \\
\text { Responses) }\end{array}$ & $\begin{array}{c}\text { Percent } \\
(\%)\end{array}$ & $\begin{array}{c}\text { Valid } \\
\text { Percent } \\
(\%) \\
\end{array}$ & $\begin{array}{c}\text { Cumulative } \\
\text { Percent } \\
(\%)\end{array}$ \\
\hline 19 & 5 & 1.6 & 1.6 & 1.6 \\
\hline 36 & 1 & 0.3 & 0.3 & 1.9 \\
\hline 38 & 1 & 0.3 & 0.3 & 2.3 \\
\hline 41 & 1 & 0.3 & 0.3 & 2.6 \\
\hline 42 & 1 & 0.3 & 0.3 & 2.9 \\
\hline 43 & 2 & 0.6 & 0.6 & 3.5 \\
\hline 44 & 1 & 0.3 & 0.3 & 3.9 \\
\hline 45 & 1 & 0.3 & 0.3 & 4.2 \\
\hline 46 & 4 & 1.3 & 1.3 & 5.5 \\
\hline 47 & 3 & 1 & 1 & 6.5 \\
\hline 48 & 3 & 1 & 1 & 7.4 \\
\hline 49 & 2 & 0.6 & 0.6 & 8.1 \\
\hline 50 & 8 & 2.6 & 2.6 & 10.6 \\
\hline 51 & 6 & 1.9 & 1.9 & 12.6 \\
\hline 52 & 5 & 1.6 & 1.6 & 14.2 \\
\hline 53 & 6 & 1.9 & 1.9 & 16.1 \\
\hline 54 & 9 & 2.9 & 2.9 & 19 \\
\hline 55 & 6 & 1.9 & 1.9 & 21 \\
\hline 56 & 9 & 2.9 & 2.9 & 23.9 \\
\hline 57 & 11 & 3.5 & 3.5 & 27.4 \\
\hline 58 & 5 & 1.6 & 1.6 & 29 \\
\hline 59 & 10 & 3.2 & 3.2 & 32.3 \\
\hline 60 & 9 & 2.9 & 2.9 & 35.2 \\
\hline 61 & 12 & 3.9 & 3.9 & 39 \\
\hline 62 & 7 & 2.3 & 2.3 & 41.3 \\
\hline 63 & 13 & 4.2 & 4.2 & 45.5 \\
\hline 64 & 7 & 2.3 & 2.3 & 47.7 \\
\hline 65 & 2 & 0.6 & 0.6 & 48.4 \\
\hline 66 & 12 & 3.9 & 3.9 & 52.3 \\
\hline 67 & 9 & 2.9 & 2.9 & 55.2 \\
\hline 68 & 7 & 2.3 & 2.3 & 57.4 \\
\hline 69 & 6 & 1.9 & 1.9 & 59.4 \\
\hline 70 & 11 & 3.5 & 3.5 & 62.9 \\
\hline 71 & 8 & 2.6 & 2.6 & 65.5 \\
\hline 72 & 15 & 4.8 & 4.8 & 70.3 \\
\hline 73 & 6 & 1.9 & 1.9 & 72.3 \\
\hline 74 & 13 & 4.2 & 4.2 & 76.5 \\
\hline 75 & 9 & 2.9 & 2.9 & 79.4 \\
\hline 76 & 10 & 3.2 & 3.2 & 82.6 \\
\hline 77 & 8 & 2.6 & 2.6 & 85.2 \\
\hline 78 & 12 & 3.9 & 3.9 & 89 \\
\hline 79 & 5 & 1.6 & 1.6 & 90.6 \\
\hline
\end{tabular}




\begin{tabular}{|c|c|c|c|c|}
80 & 4 & 1.3 & 1.3 & 91.9 \\
81 & 2 & 0.6 & 0.6 & 92.6 \\
82 & 7 & 2.3 & 2.3 & 94.8 \\
83 & 1 & 0.3 & 0.3 & 95.2 \\
85 & 3 & 1 & 1 & 96.1 \\
99 & 12 & 3.9 & 3.9 & 100 \\
\hline Total & 310 & 100 & 100 & \\
\hline
\end{tabular}

Q25. Gender

\begin{tabular}{|l|c|c|c|c|}
\hline \multicolumn{1}{|c|}{ Gender } & $\begin{array}{c}\text { Frequency } \\
\mathbf{N}^{\circ} \text { of } \\
\text { Responses })\end{array}$ & $\begin{array}{c}\text { Percent } \\
(\boldsymbol{\%})\end{array}$ & $\begin{array}{c}\text { Valid } \\
\text { Percent } \\
(\boldsymbol{\%})\end{array}$ & $\begin{array}{c}\text { Cumulative } \\
\text { Percent } \\
(\%)\end{array}$ \\
\hline 0 & 5 & 1.6 & 1.6 & 1.6 \\
Female & 76 & 24.5 & 24.5 & 26.1 \\
Male & 229 & 73.9 & 73.9 & 100 \\
\hline Total & 310 & 100 & 100 & \\
\hline
\end{tabular}

